\title{
ANÁLISE EXPERIMENTAL DE PILARES DE CONCRETO DE ALTO DESEMPENHO SUBMETIDOS À COMPRESSÃO SIMPLES
}

Marcos Vinícios Mendonça de Queiroga

Dissertação apresentada à Escola de Engenharia de São Carlos, da Universidade de São Paulo, como parte dos requisitos para a obtenção do título de Mestre em Engenharia de Estruturas.

ORIENTADOR: José Samuel Giongo

São Carlos 
Clase. TESE-EESC

Gutt.

4624

Fombo

0087199

Ficha catalográfica preparada pela Seção de Tratamento

da Informação do Serviço de Biblioteca - EESC/USP

Queiroga, Marcos Vinícios Mendonça de
Q3a Análise experimental de pilares de desempenho submetidos à compressão simples / Marcos Vinícios Mendonça de Queiroga. -- São Carlos, 1999.

Dissertação (Mestrado) -- Escola de Engenharia de São Carlos-Universidade de São Paulo, 1999.

Área: Engenharia de Estruturas.

Orientador: Prof. Dr. José Samuel Giongo.

1. Concreto de alto desempenho. 2. Pilares.

3. Experimentação. I. Título. 
Candidato: Engenheiro MARCOS VINICIOS MENDONÇA DE QUEIROGA

Dissertação defendida e aprovada em 29-03-1999

pela Comissão Julgadora:

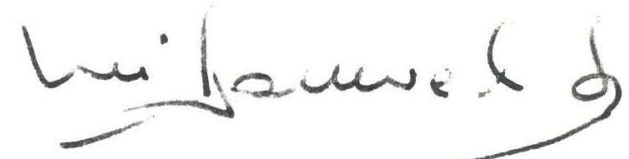

Prof. Doutor JOSÉ SAMUEL GIONGO (Orientador)

(Escola de Engenharia de São Carlos - Universidade de São Paulo)

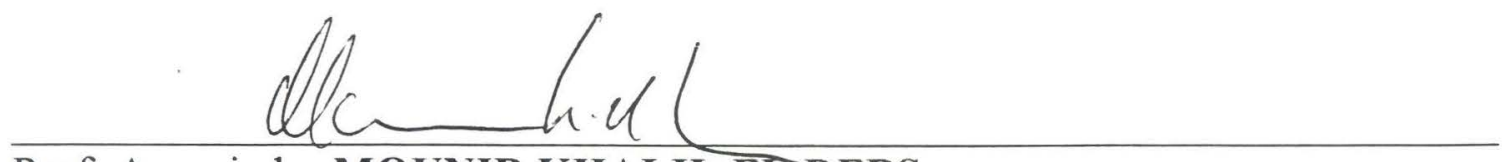

Prof. Associado MOUNIR KHALIL EL DEBS

(Escola de Engenharia de São Carlos - Universidade de São Paulo)

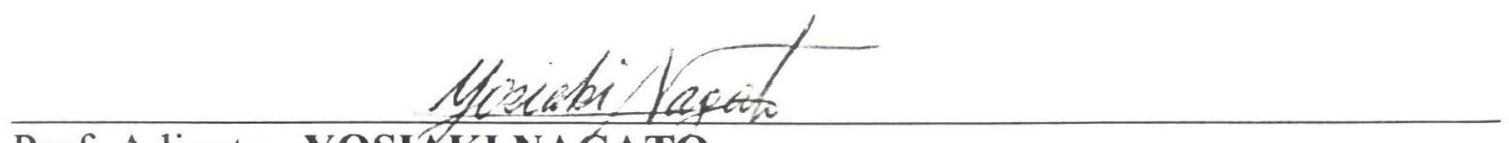

Prof. Adjunto YOSIÁKI NAGATO

(Universidade de Brasília)

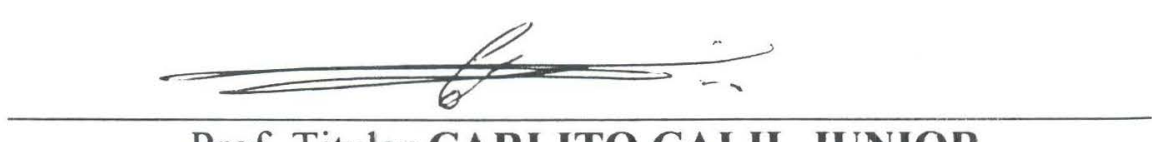

Prof. Titular CARLITO CALIL JUNIOR

Coordenador da Área de Engenharia de Estruturas

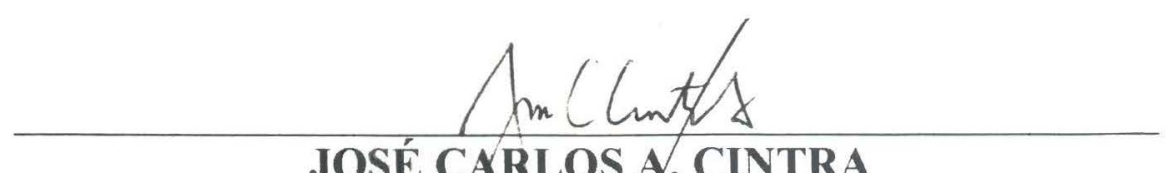

Presidente da Comissão de Pós-Graduação da EESC 
A meus pais 


\section{AGRADECIMENTOS}

A Deus por ter me capacitado, até aqui, a vencer todas as etapas desta jornada da vida.

Ao meu Orientador, José Samuel Giongo, pela paciência, amizade e valiosa orientação.

Aos amados Galdino e Rose pela grande amizade e apoio sem os quais não teria sucesso.

Aos professores Márcio Corrêa, Toshiaki Takeya e Mounir Khalil el Debs pelas valiosas contribuições ao trabalho.

Ao professor Luís Alberto de Melo Carvalho, pela amizade e encaminhamento ao Mestrado.

A Ana Elisabete Paganelli Guimarâes pelas sugestões importantes ao trabalho.

Ao meu amigo Romel Dias Vanderlei pelo companheirismo durante a pesquisa.

Aos funcionários do Departamento de Engenharia de Estruturas de Escola de Engenharia de São Carlos - USP, especialmente a Maria Nadir Minatel e Rosi Aparecida Jordão Rodrigues.

Aos funcionários do Laboratório de Estruturas, Amauri Ignácio da Silva, Jorge L. R. Brabo, Mário Botelho, Mauri Dias Guillen, Valdir C. de Lucca e o dr. Luiz Vicente Vareda.

Aos funcionários dos Laboratórios de Construção Civil e de Madeira e Estruturas de Madeira, pelo apoio nos ensaios complementares.

À CAPES e à FAPESP, pelo apoio financeiro recebido através de Bolsa de Mestrado. 


\section{CRÉDITOS}

O desenvolvimento desta pesquisa só foi possível devido ao apoio de instituições e empresas. Assim são dignos de crédito:

Universidade de São Paulo

- Escola de Engenharia de São Carlos

- Departamento de Engenharia de Estruturas.

CAPES - Fundação de Aperfeiçoamento de Pessoal de Nível Superior, pela concessão de bolsa de Estudos.

FAPESP - Fundação de Amparo à Pesquisa do Estado de São Paulo, pela bolsa de estudos correspondente ao processo número 97/13378-7.

CAMARGO CORRÊA CIMENTOS S.A.,

através do Engenheiro Christovam S. C. Cunha e do Tecnólogo Railton Ap.

De Carvalho e Engenheiro João Paulo F. Guimarães.

REAX INDÚSTRIA E COMÉRCIO LTDA, através do Engenheiro Mauro M. Movikawa. 


\section{Sumário}

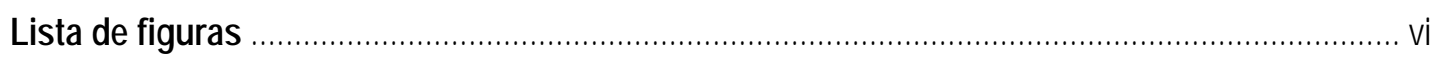

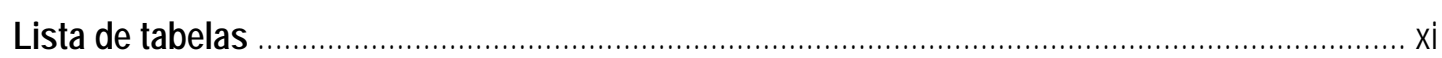

Lista de abreviaturas e siglas ...................................................................................... xiv

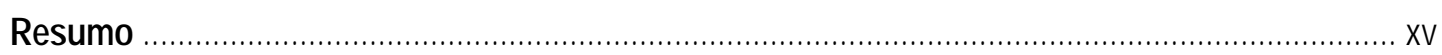

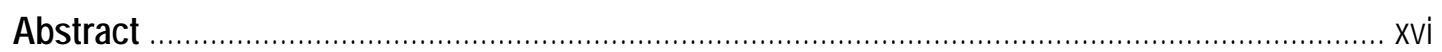

1 Introdução

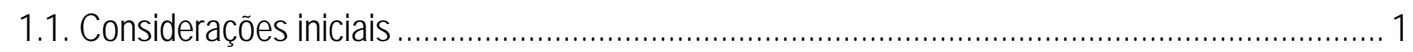

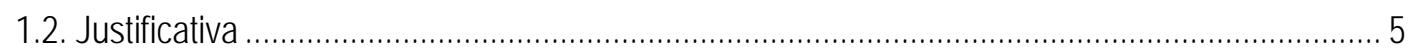

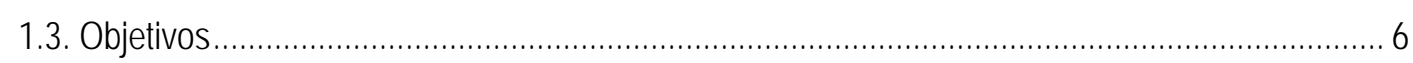

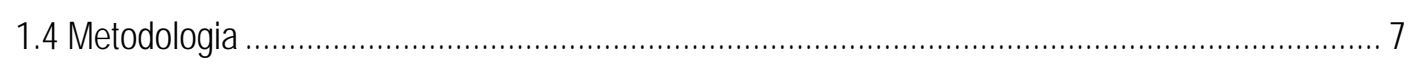

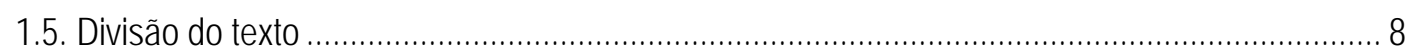

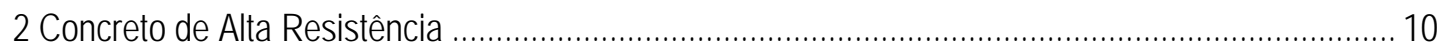

2.5.1. O Concreto de Alta Resistência no Brasil ...................................................................... 14

2.6. Vantagens e desvantagens do Concreto de Alta Resistência .............................................. 15

2.7. Aplicabilidade do Concreto de Alta Resistência ................................................................ 17

2.8. Materiais utilizados na produção do Concreto de Alta Resistência ........................................... 20

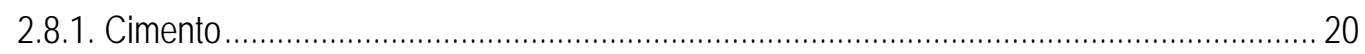

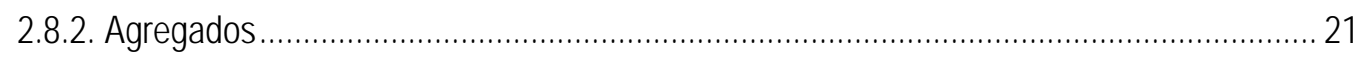

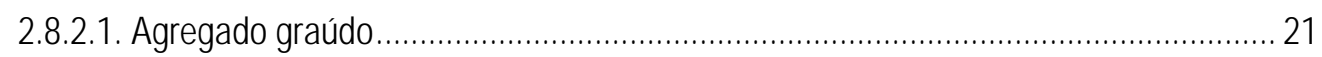

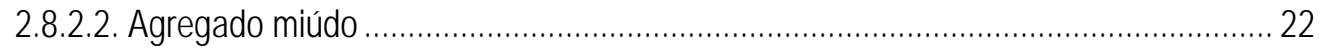

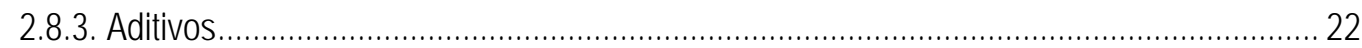

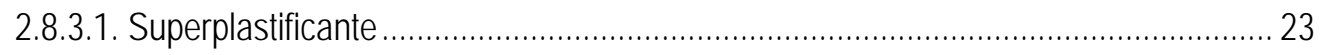




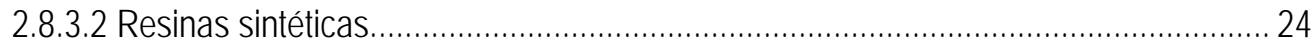

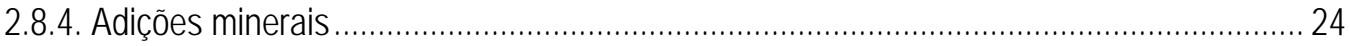

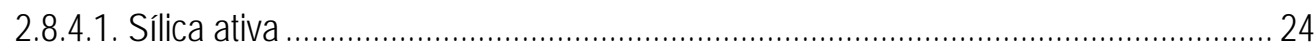

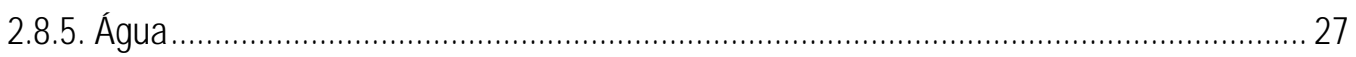

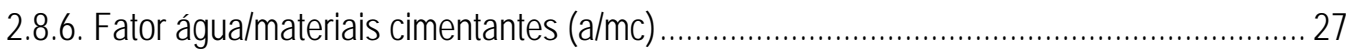

2.9. HPC: High Performace Cement (Cimento de Alto Desempenho).............................................. 27

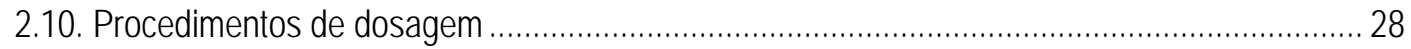

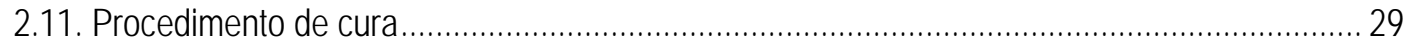

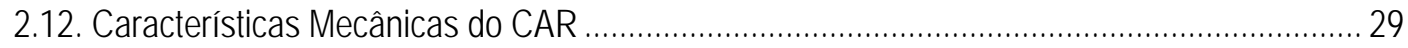

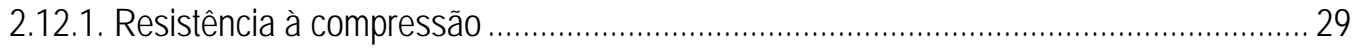

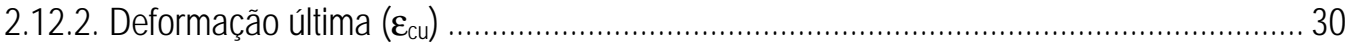

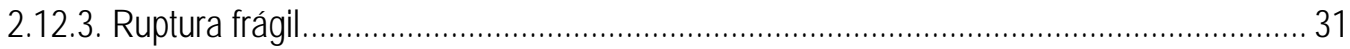

2.12.4. Maior resistência a carregamentos de longa duração.................................................... 33

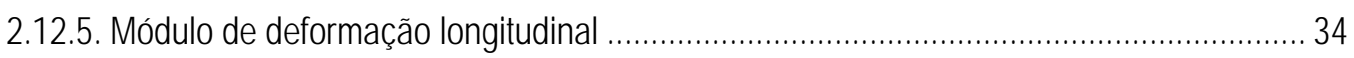

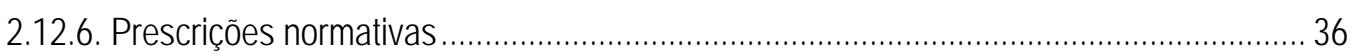

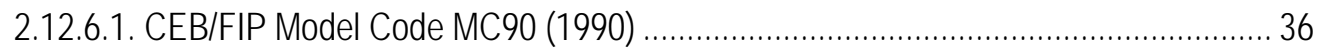

2.12.6.2. Código Norueguês - NS 34731989 (1989) ………………………………....... 36

2.12.6.3. Código Finlandês - Rak MK B4 1983/84 (1984) ...................................................... 37

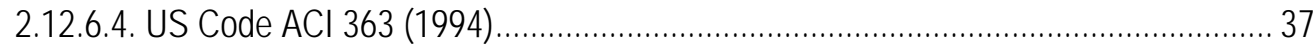

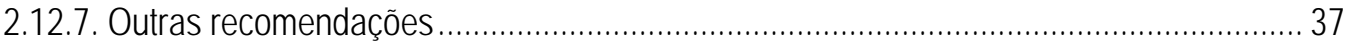

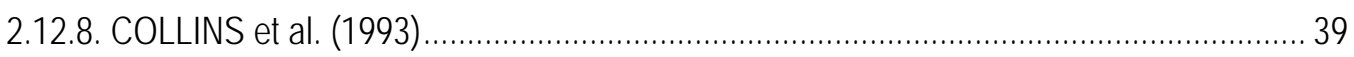

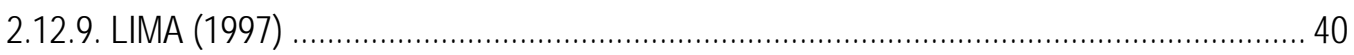

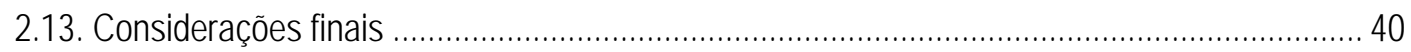

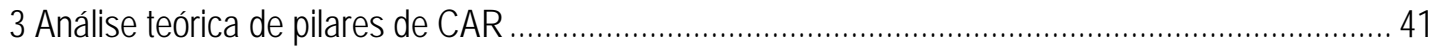

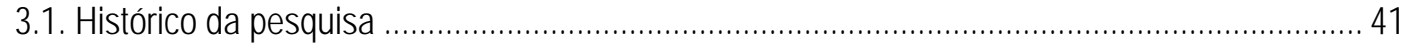

3.2. Modelos Teóricos para confinamento e diagrama tensão x deformação …………………...... 52

3.2.1. Modelos para confinamento ................................................................................... 53

3.2.1.1. Concreto de baixa resistência ......................................................................... 53

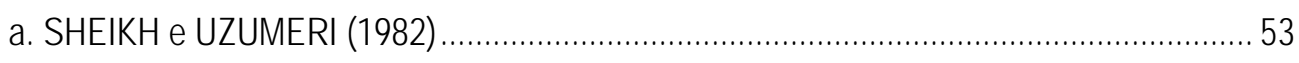

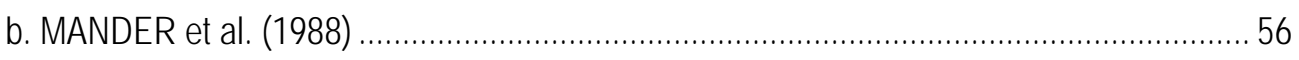

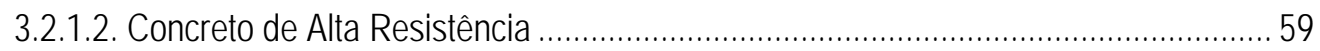

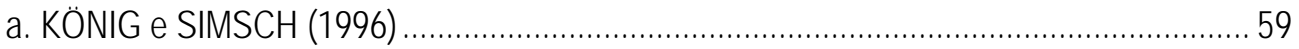

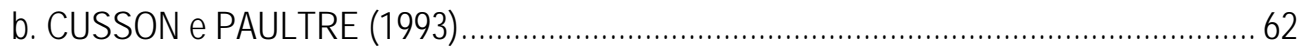

3.2.1.3. Comentário sobre os modelos apresentados .......................................................... 67

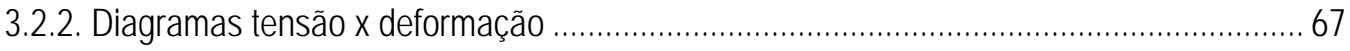

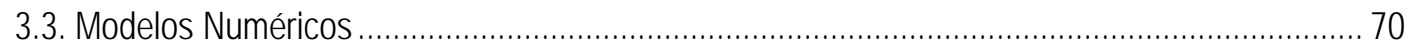




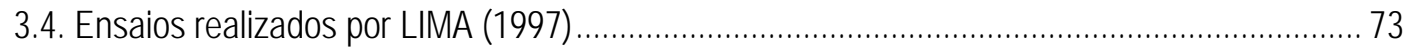

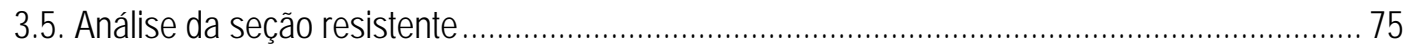

3.6. Seção resistente segundo COLLINS et al. (1993) ............................................................ 76

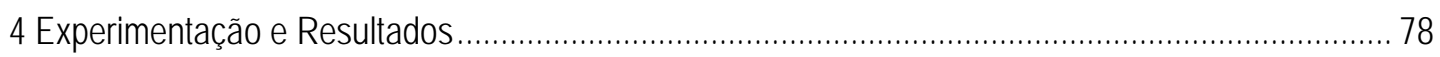

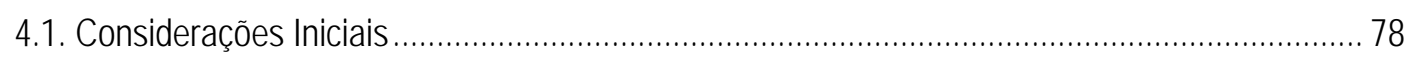

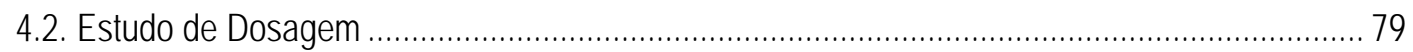

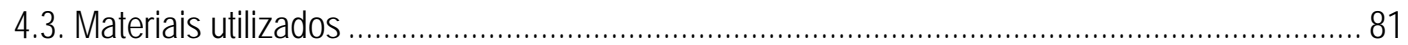

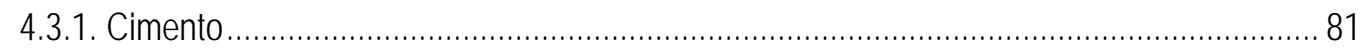

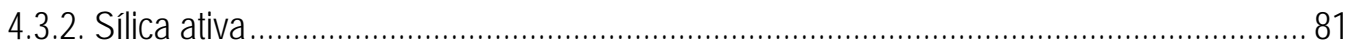

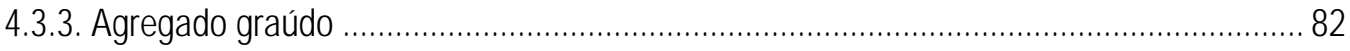

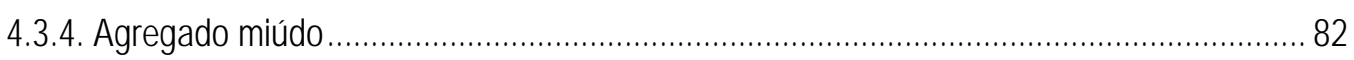

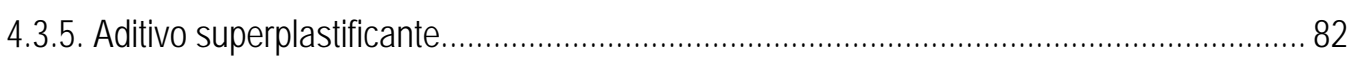

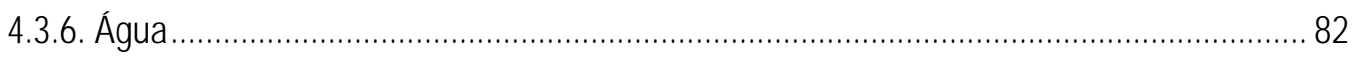

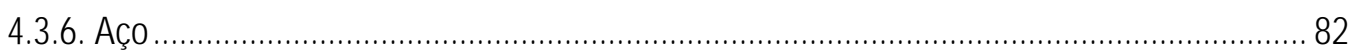

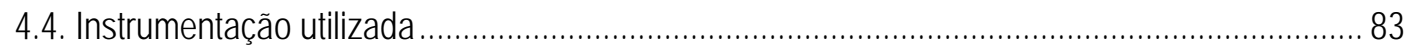

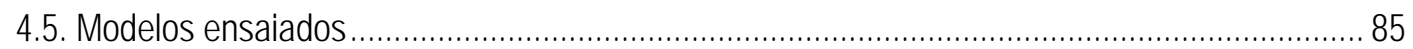

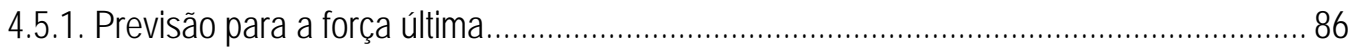

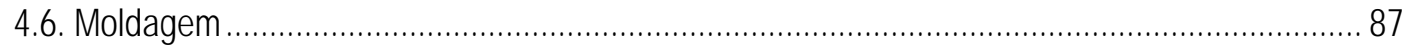

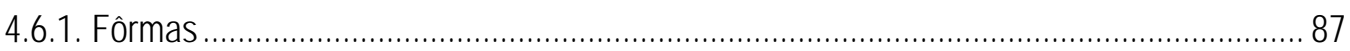

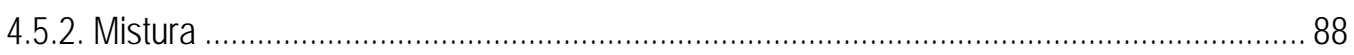

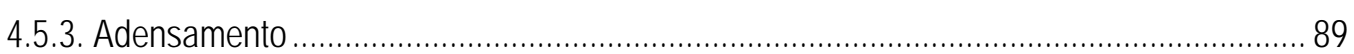

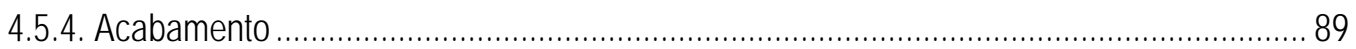

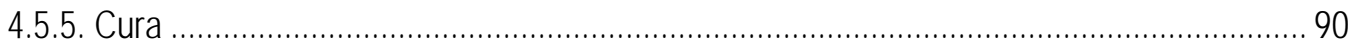

4.5.6. Determinação das deformaç̧ões ............................................................................. 91

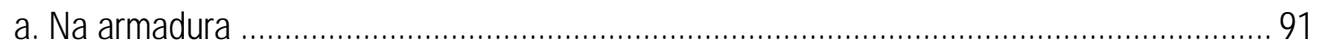

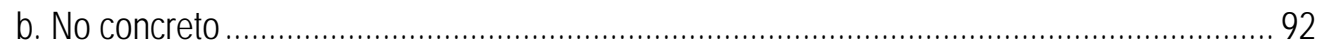

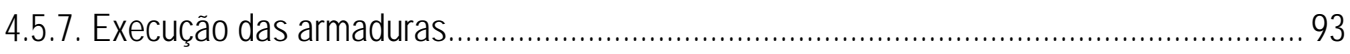

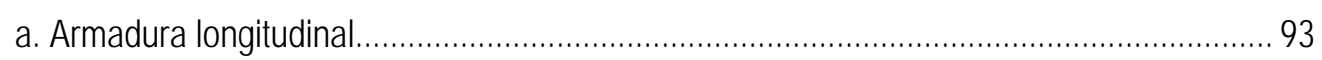

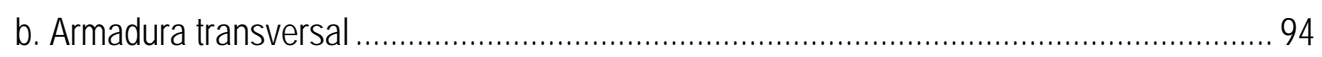

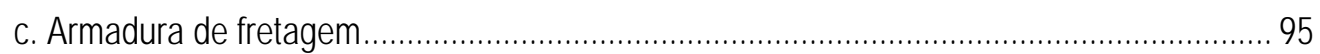

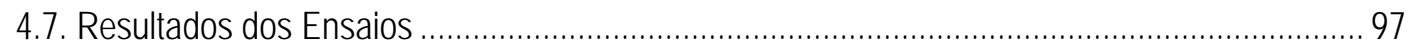

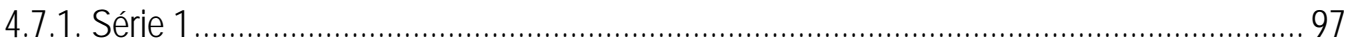

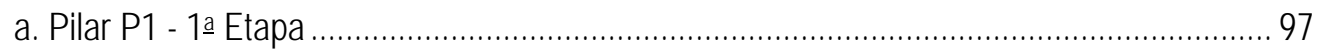

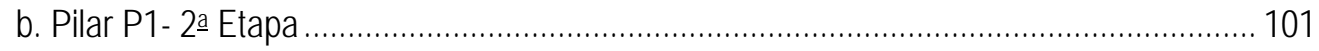

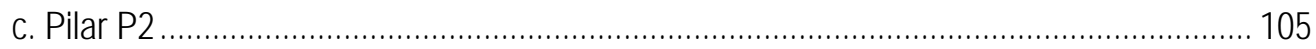

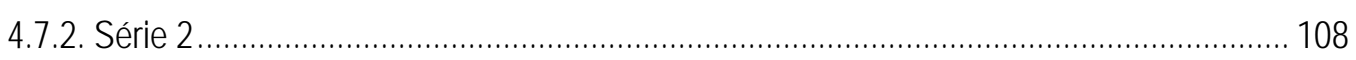

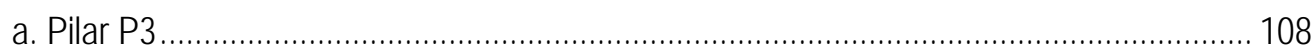




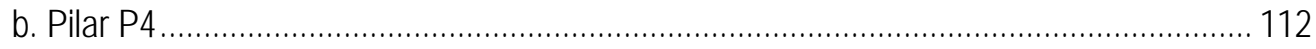

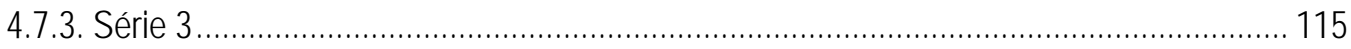

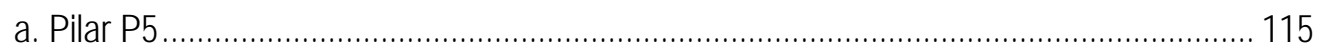

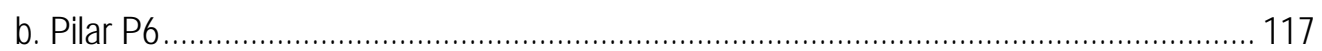

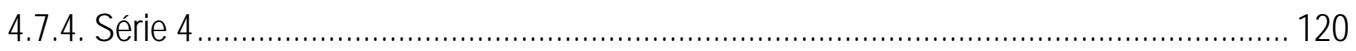

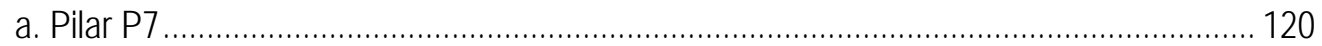

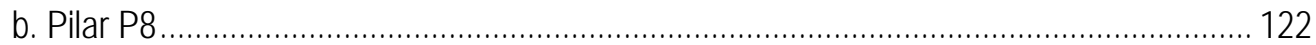

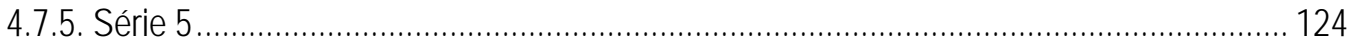

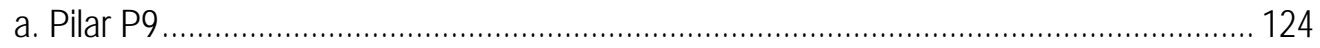

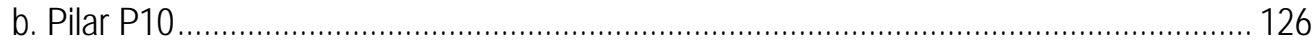

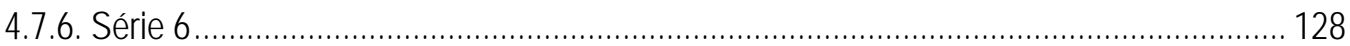

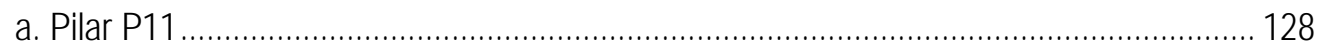

b. Pilar P12 .

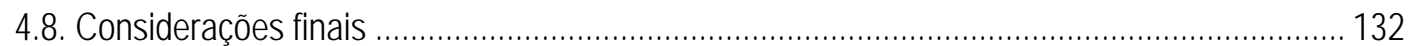

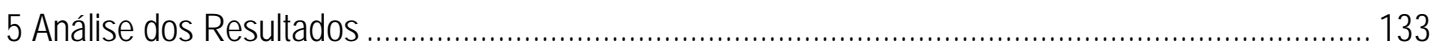

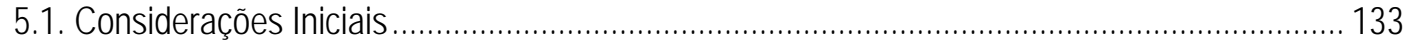

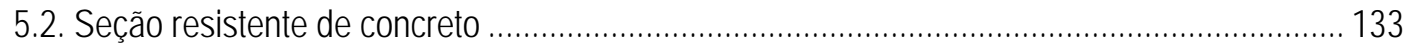

5.3. Capacidade resistente segundo COLLINS et al. (1993) ................................................... 135

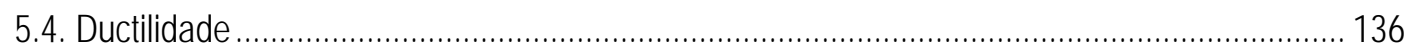

5.4.1. Índice de Eficiência do Confinamento ……............................................................. 136

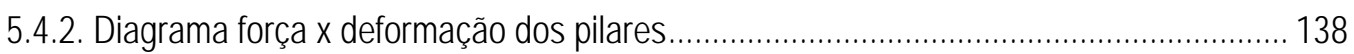

5.4.3. Deformação na armadura transversal .................................................................. 141

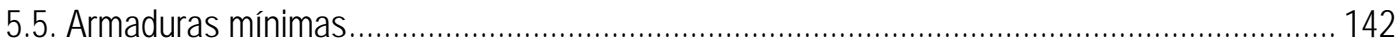

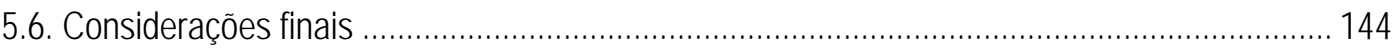

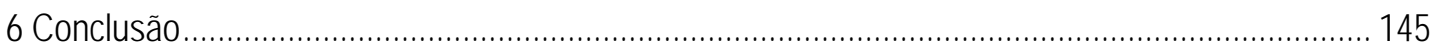

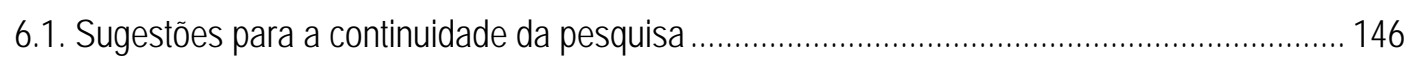

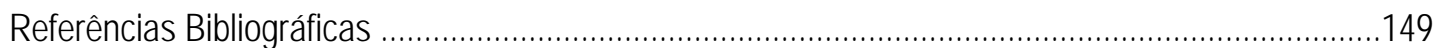

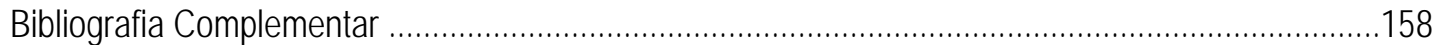




\section{Lista de figuras}

\section{Capítulo 1}

Figura 1.1. Utilização de aço e CAR nos 100 edifícios mais altos do mundo ao longo dos anos, BEEDLE (1992) 3

Figura 1.2. Torre Petronas (Malásia), a mais alta do mundo, concreto de $60 \mathrm{MPa}$ e $80 \mathrm{MPa}$ utilizado nos pilares ${ }^{2}$ 3

Figura 1.3. Detalhes do núcleo de concreto definido pela configuração das armaduras longitudinais e transversais.. 4

\section{Capítulo 2}

Figura 2.1. Ensaios sobre o comportamento de pilares de CAR submetidos à flexo-compressão, XIAO e ANDERSON ${ }^{1}$ 13

Figura 2.2. Ligações viga-pilar, XIAO e ANDERSON²............................................................. 13

Figura 2.3. Comportamento de vigas de CAR submetidas à flexão com cisalhamento, XIAO e MA3 .. 14

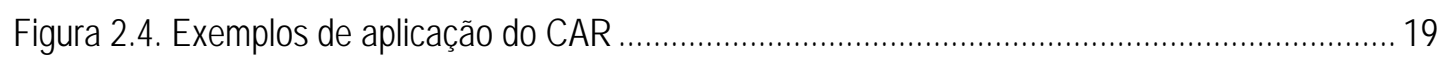

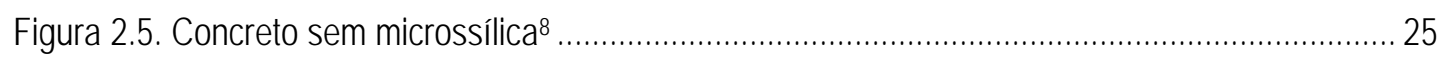

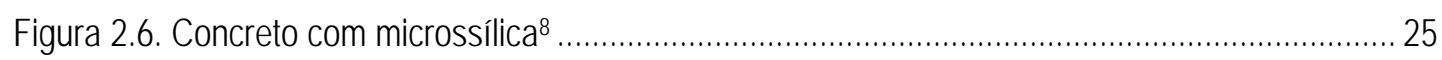

Figura 2.7. Desenvolvimento da resistência do cimento, SOBOLEV (1998) .................................... 28

Figura 2.8. Diagramas tensão $x$ deformação, COLLINS et al. (1993) ................................................ 30

Figura 2.9. Diagrama tensão $x$ deformação para compressão axial (concreto de 60MPa), XIE et al. (1995). 32

Figura 2.10. Diagrama tensão $x$ deformação para compressão axial (concreto de 90MPa), XIE et al. (1995). 
Figura 2.11. Diagrama tensão x deformação para compressão axial (concreto de 120MPa), XIE et al. (1995) 32

Figura 2.12. Acréscimo da resistência com a idade, PINTO JÚNIOR (1992) 34

Figura 2.13. Detalhe da instrumentação dos corpos-de-prova usados para a determinação do módulo de elasticidade do concreto 34

Figura 2.14. Máquina de ensaio dos corpos-de-prova 35

Figura 2.15. Diagrama força $x$ deformação e tensão $x$ deformação obtido dos ensaios dos corpos-deprova. 35

Figura 2.16. Diagrama tensão $x$ deformação segundo o CEB/FIP M90 ……..................................... 36

Figura 2.17. Diagrama tensão $x$ deformação segundo o NS3473 ....................................................... 36

Figura 2.18. Diagrama tensão $x$ deformação segundo o Rak MK B4 ……………………................ 37

Figura 2.19. Diagrama tensão $x$ deformação segundo o ACl - 363 (1994) ………............................ 37

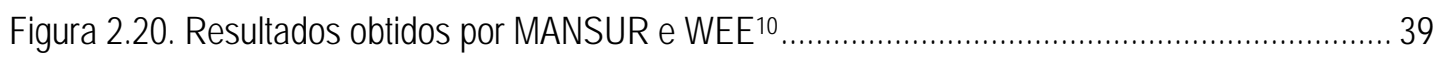

Figura 2.21. Aproximação para o diagrama tensão x deformação experimental, LIMA (1997) ............ 40

\section{Capítulo 3}

Figura 3.1. Forma aproximada do núcleo resistente de concreto ..................................................... 42

Figura 3.2. Diagrama força $x$ deformação para pilares de CAR ………............................................. 43

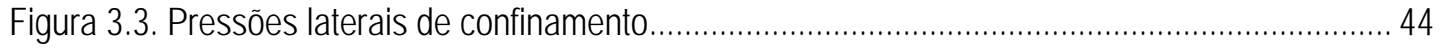

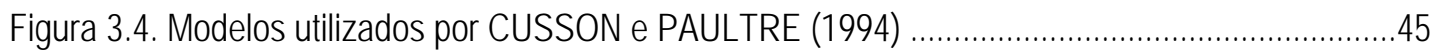

Figura 3.5. Efeito da configuração e espaçamento da armadura transversal sobre 0 confinamento do núcleo: (a) Configuração de estribos com grande espaçamento; (b) Configuração de estribos mais eficiente, com pequeno espaçamento, CUSSON e PAULTRE (1994) ....... 45

Figura 3.6. Efeito do espaçamento entre estribos para a definição da área de concreto efetivamente confinada, seção crítica, Aec, SHEIKH e UZUMERI (1982). 46

Figura 3.7. Causas da ruptura do cobrimento, CUSSON e PAULTRE (1993) ...................................... 47

Figura 3.8. Separação do cobrimento, PAULTRE et al. (1996)....................................................... 48

Figura 3.9. Diagrama força $x$ deslocamento para CAR e CRN, CLAESON et al. (1996) ...................... 48

Figura 3.10. Flambagem das barras da armadura longitudinal, RANGAN e LLOYD (1994) ................ 50

Figura 3.11. Esquema de proteção da extremidades dos modelos, RANGAN e LLOYD (1994) .......... 51

Figura 3.12. Detalhe da armadura de fretagem, QUEIROGA e GIONGO (1998) ............................... 51

Figura 3.13. Esquema de proteção da extremidades dos modelos através do alargamento da seção, SHEIKH e UZUMERI (1980) ........................................................................... 51

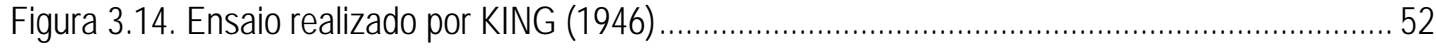

Figura 3.15. Detalhe da flambagem das barras da armadura longitudinal em ensaio realizado por BRESLER e GILBERT (1961). 
Figura 3.16. Estimativa da área não confinada de concreto, SHEIKH e UZUMERI (1982). 54

Figura 3.17. Região não confinada entre níveis da armadura transversal, SHEIKH e UZUMERI (1982)

Figura 3.18. Coeficiente * em função do espaçamento entre estribos e da dimensão do núcleo para várias configurações de estribos em pilares de seção quadrada, SHEIKH e UZUMERI (1982). 56

Figura 3.19. Núcleo efetivamente confinado de concreto para armadura transversal composta por estribos, MANDER et al. (1988).

Figura 3.20. Determinação da resistência de confinamento para tensões laterais de confinamento em pilares de seção retangular, MANDER et al. (1988) 58

Figura 3.21. Área efetiva de confinamento em pilares de seção retangular, KÖNIG e SIMSCH (1996)

Figura 3.22. Tensão lateral provocada pela armadura de confinamento, KÖNIG e SIMSCH (1996)... 61

Figura 3.23. Variáveis geométricas para o modelo sugerido por CUSSON e PAULTRE (1993) ......... 63

Figura 3.24. Configurações de estribos utilizadas por CUSSON e PAULTRE (1993).......................... 65

Figura 3.25. Aplicação do modelo de CUSSON e PAULTRE (1993) ao Pilar P3................................. 66

Figura 3.26. Pilar de CAR discretizado em elementos finitos, CLAESON1….................................. 70

Figura 3.27. Curvas tensão $x$ deformação para concretos comprimidos de acordo com o Eurocode 2 e o BBK 94, CLAESON et al. (1996)........................................................................ 70

Figura 3.28. Curva de colapso no diagrama momento - força axial. Os pontos marcam os resultados experimentais, CLAESON et al. (1996) ................................................................... 71

Figura 3.29. Diagrama tensão longitudinal versus deformação longitudinal para ensaios de compressão triaxial com concreto de 60MPa, XIE et al. (1995) ....................................... 72

Figura 3.30. Diagrama tensão longitudinal versus deformação longitudinal para ensaios de compressão triaxial com concreto de 90MPa, XIE et al. (1995) .................................... 72

Figura 3.31. Diagrama tensão longitudinal versus deformação longitudinal para ensaios de compressão triaxial com concreto de 120MPa, XIE et al. (1995) .................................... 72

Figura 3.32. Esquema dos ensaios realizados por LIMA (1997): 1. Pilar instrumentado; 2. Confinamento metálico das extremidades do pilar; 3. Pórtico de reação; 4. Célula de carga (capacidade nominal de 5000kN) ................................................................... 74

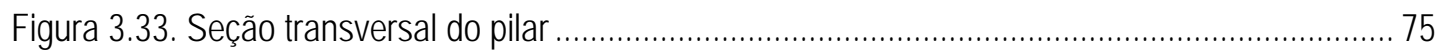

\section{Capítulo 4}

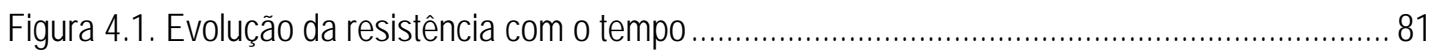

Figura 4.2. Visão parcial da máquina INSTRON com pilares de seção quadrada e retangular posicionados para os ensaios. 
Figura 4.3. Detalhe da aparelhagem utilizada nos ensaios 84

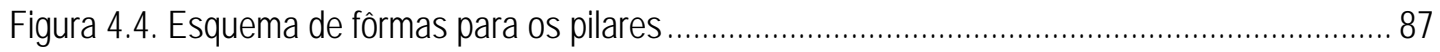

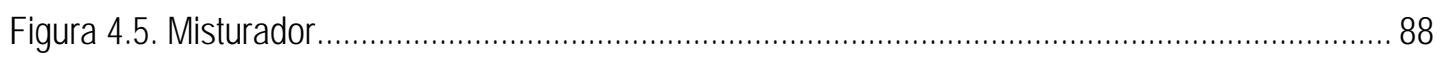

Figura 4.6. Detalhe dos corpos-de-prova moldados para cada série de pilares................................. 89

Figura 4.7. Detalhe da mesa vibratória com a fôrma já posicionada para concretagem ...................... 89

Figura 4.8. Modelos com superfície acabada ............................................................................... 90

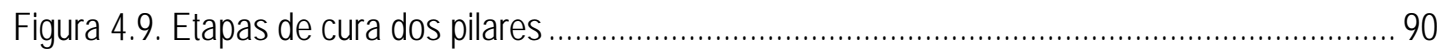

Figura 4.10. Detalhe da seção instrumentada .......................................................................... 91

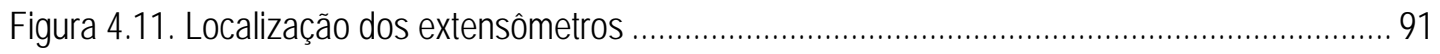

Figura 4.12. Detalhe do posicionamento dos extensômetros em uma face do pilar ........................... 92

Figura 4.13. Esquema de instrumentação do pilar .......................................................................... 93

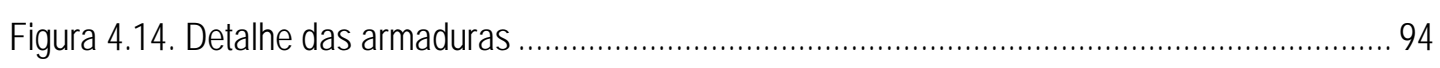

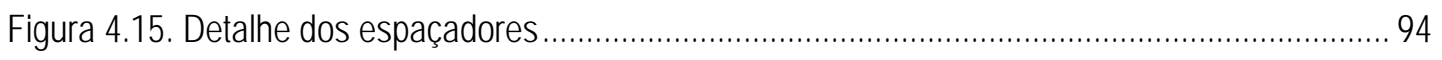

Figura 4.16. Configurações para os estribos dos modelos de seção transversal quadrada e retangular 95

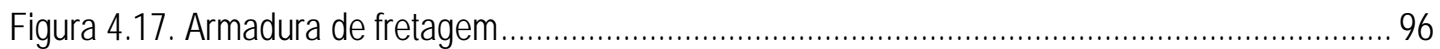

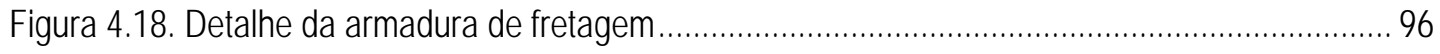

Figura 4.19. Diagramas força $x$ deformação para o pilar P1 - 1a Etapa ............................................... 98

Figura 4.20. Diagramas força $x$ deformação para o pilar P1 - 2a Etapa ..........................................102

Figura 4.21. Esquema de solicitação dos estribos através da flambagem das barras da armadura

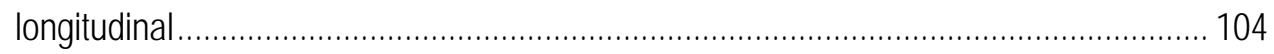

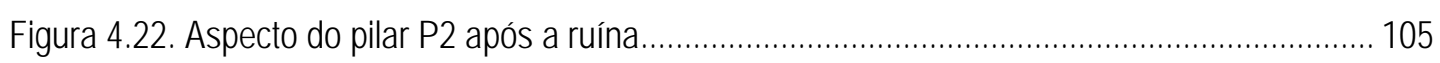

Figura 4.23. Diagramas força $x$ deformação para o pilar P2 …...................................................... 106

Figura 4.24. Diagramas força $x$ deformação para o pilar P3 ........................................................... 109

Figura 4.25. Comparação entre os diagramas força $x$ deformação para a armadura longitudinal, pilares P2 e P3 110

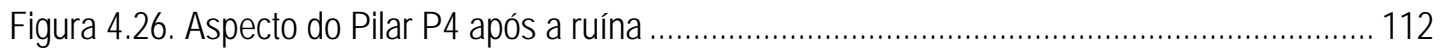

Figura 4.27. Diagramas força $x$ deformação para o pilar P4 …....................................................... 113

Figura 4.28. Diagramas força $x$ deformação para o pilar P5 ………............................................... 116

Figura 4.29. Diagramas força $x$ deformação para o pilar P6 …........................................................ 118

Figura 4.30. Aspecto do Pilar P6 após a ruína. A figura mostra a nítida separação da camada de cobrimento 119

Figura 4.31. Diagramas força $x$ deformação para o pilar P7 ............................................................ 121

Figura 4.32. Diagramas força $x$ deformação para o pilar P8 …......................................................... 123

Figura 4.23. Diagramas força $x$ deformação para o pilar P9 .......................................................... 125

Figura 4.34. Comparação entre os diagramas força x deformação para o pilar ................................. 126

Figura 4.35. Diagramas força $x$ deformação para o pilar P10 ........................................................ 127 
Figura 4.36. Diagramas força $x$ deformação para o pilar P11 …................................................... 129

Figura 4.37. Diagramas força $x$ deformação para o pilar P12 …....................................................... 131

\section{Capítulo 5}

Figura 5.1. Esquema para cálculo da pressão lateral de confinamento $\left(\mathrm{f}_{\mathrm{I}}\right)$...................................... 137

Figura 5.2. Diagramas força $x$ deformação para os pilares P2, P4 e P6 (valores médios)................ 139

Figura 5.3. Diagramas força $x$ deformação para os pilares P7, P9 e P12 ....................................... 141

Figura 5.4. Configuração "simples" para a armadura transversal................................................... 143

\section{Capítulo 6}

Figura 6.1. Configurações mais eficientes para os estribos 146 


\section{Lista de tabelas}

\section{Capítulo 2}

Tabela 2.1. Classificação dos concretos, AMARAL FILHO (1993).................................................... 12

Tabela 2.2. Classificação dos CAR segundo SANCHEZ (1997) ........................................................ 12

Tabela 2.3. Composição química do HPC e do cimento Portland comum (NCP), SOBOLEV (1998) ${ }^{9} .28$

Tabela 2.4. Valores para a deformação última do concreto segundo DINIZ apud LIMA (1997)........... 31

\section{Capítulo 3}

Tabela 3.1. Classificação segundo a eficiência do confinamento, CUSSON e PAULTRE (1993) ....... 64

Tabela 3.2. Características dos modelos ensaiados por LIMA (1997). ............................................. 73

Tabela 3.3. Modelos ensaiados à compressão centrada: resultados, LIMA (1997)........................... 74

\section{Capítulo 4}

Tabela 4.1. Consumo unitário de Materiais (Dosagem 1) 80

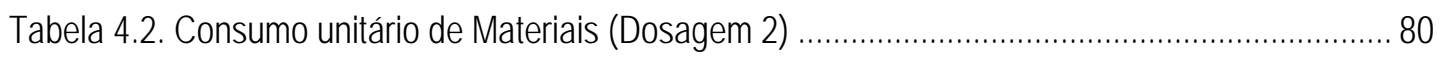

Tabela 4.3. Resistência à compressão do concreto aos 15 dias (Dosagem 1 e 2).............................. 80

Tabela 4.4. Características do aço empregado - resultados do ensaio à tração.................................. 83

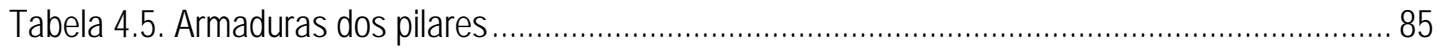

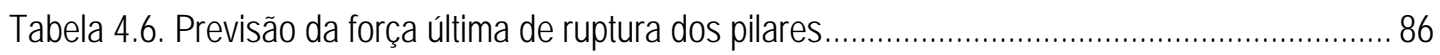

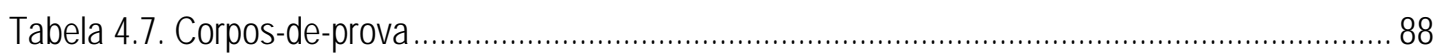

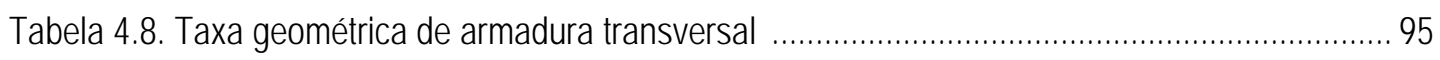

Tabela 4.9. Valores das deformações para o pilar P1 - 1․ Etapa (\%o) ................................................ 100

Tabela 4.10. Valores das deformações para o pilar P1 - 1a Etapa (\%o) ............................................... 101 
Tabela 4.11. Valores das deformações para o pilar P1 - 2a Etapa (\%) ............................................. 104

Tabela 4.12. Valores das deformações para o pilar P1 - 2ª Etapa (\%o) ............................................... 105

Tabela 4.13. Valores das deformações para o pilar P2 (\%) ............................................................. 107

Tabela 4.14. Valores das deformações para o pilar P2 (\%o) ............................................................ 108

Tabela 4.15. Valores das deformações para o pilar P3 (\%o) ........................................................ 111

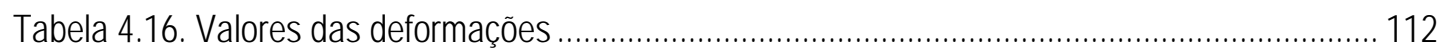

Tabela 4.17. Valores das deformações para o pilar P4 (\%) .......................................................... 114

Tabela 4.18. Valores das deformações para o pilar P4 (\%) ......................................................... 115

Tabela 4.19. Valores das deformações para o pilar P5 (\%) ......................................................... 117

Tabela 4.20. Valores das deformações para o pilar P5 (\%) ......................................................... 117

Tabela 4.21. Valores das deformações para o pilar P6 (\%o) .......................................................... 119

Tabela 4.22. Valores das deformações para o pilar P6 (\%o) ......................................................... 119

\section{Capítulo 5}

Tabela 5.1. Resumo dos resultados dos ensaios e verificação da seção resistente de concreto ....... 134

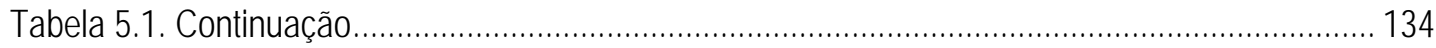

Tabela 5.2. Comparação dos resultados com os valores obtidos através da equação proposta por

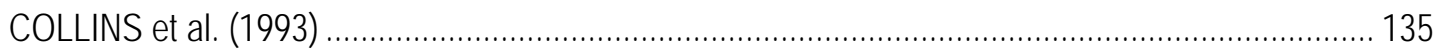

Tabela 5.3. Índice de Eficiência do Confinamento para os modelos ................................................. 138

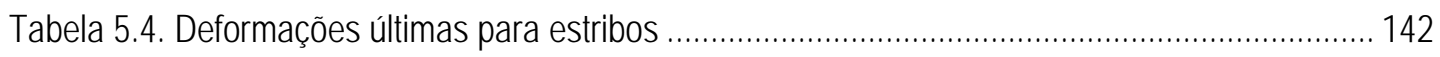

Tabela 5.5. Determinação de $\lambda^{*}$, SHEIKH e UZUMERI (1982)....................................................... 143 


\section{Lista de abreviaturas e siglas}

$\begin{array}{lll}\text { ABNT } & - & \text { Associação Brasileira de Normas Técnicas } \\ \text { ABCP } & - & \text { Associação Brasileira de Cimento Portland } \\ \text { ACI } & \text { - } & \text { American Concrete Institute } \\ \text { ARI } & \text { - } & \text { Alta Resistência Inicial } \\ \text { ASCE } & \text { - } & \text { American Society of Civil Engineering } \\ \text { ASTM } & \text { - } & \text { American Society for Testing and Materials } \\ \text { BBK } & - & \text { Boverket, Byggavdelningen, Kerlskrona (norma sueca para } \\ & & \text { Projeto de estruturas de concreto) } \\ \text { CAD } & - & \text { Concreto de Alto Desempenho } \\ \text { CAR } & - & \text { Concreto de Alta Resistência } \\ \text { CEB } & - & \text { Comitee Euro-International du Beton } \\ \text { EESC } & - & \text { Escola de Engenharia de São Carlos } \\ \text { FIP } & - & \text { Féderation Internationale de la Précontrainte } \\ \text { IBRACON } & - & \text { Instituto Brasileiro do Concreto } \\ \text { MC } & - & \text { Model Code } \\ \text { NBR } & - & \text { Norma Brasileira Registrada } \\ \text { NS } & - & \text { Norwergian Standard } \\ \text { USP } & - & \text { Universidade de São Paulo } \\ & & \end{array}$




\section{RESUMO}

QUEIROGA, Marcos Vinícios Mendonça. Análise experimental de pilares de concreto de alto desempenho submetidos à compressão simples São Carlos, 1999. Dissertação de Mestrado - Escola de Engenharia de São Carlos, Universidade de São Paulo.

O objetivo da pesquisa foi obter subsídios para o projeto de pilares de concreto de alta resistência, submetidos à compressão simples, com concreto de resistência média de $60 \mathrm{MPa}$. Este projeto faz parte de um plano mais amplo onde já se têm resultados experimentais que traduzem o comportamento de pilares moldados com concreto de resistência média à compressão de 80MPa. Nestes constatou-se a participação isolada do núcleo de concreto definido pelo eixo da armadura transversal como seção resistente dos pilares.

$\mathrm{Na}$ etapa experimental foram ensaiados pilares com seções transversais quadradas de $200 \mathrm{~mm} \times 200 \mathrm{~mm}$ e retangulares de $150 \mathrm{~mm} \times 300 \mathrm{~mm}$. As alturas dos pilares correspondem a seis vezes a menor dimensão da seção transversal, portanto, $1200 \mathrm{~mm}$ e $900 \mathrm{~mm}$, respectivamente.

Nos modelos de seção quadrada, o valor médio das relações entre as forças últimas experimentais e as forças últimas teóricas, considerando a seção total de concreto, resultou igual a 0,82 , indicando que a seção resistente não é a seção total. Por outro lado, a média das relações entre as forças últimas experimentais e as forças últimas teóricas, considerando apenas a área do núcleo limitada pelo eixo dos estribos, resultou igual a 1,21, o que mostra que a seção resistente pode ser considerada, no Estado Limite Último, como a seção do núcleo.

Palavras-chave: Concreto de alto desempenho; Pilares; Experimentação 


\begin{abstract}
QUEIROGA, Marcos Vinícios Mendonça. Experimental analysis of high strength concrete columns (60MPa) under axial compression, São Carlos, 1999. Dissertação de Mestrado - Escola de Engenharia de São Carlos, Universidade de São Paulo.

This research's aim is to obtain information for design of high strength concrete columns under concentrically loads with medium cylinder compressive strength of $60 \mathrm{MPa}$. This project belongs to a more extensive plan which already has experimental results that represent the behavior of columns performed with concrete with medium cylinder compressive strength of $80 \mathrm{MPa}$. In these models has been verified the independent participation of concrete core defined by the transversal reinforcement axis as resistant section near the ultimate load.

In the experimental stage it was tested twelve columns with square $(200 \mathrm{~mm} \times$ $200 \mathrm{~mm})$ and rectangular $(150 \mathrm{~mm} \times 300 \mathrm{~mm})$ cross sections. The height of the columns corresponds to six times the smallest dimension of the cross section, $1,200 \mathrm{~mm}$ and $900 \mathrm{~mm}$, respectively.

The medium value of the ratios between the ultimate experimental force and the ultimate theoretical force, regarding the full concrete section, was 0.82 , indicating that the resistant section is not the full section. On the other hand, the medium of ratios between the ultimate experimental force and the ultimate theoretical force, considering only the core area limited by the axis of the lateral reinforcement bars, was 1.21 , what shows that the resistant section can be considered as the core section in the Ultimate Limit State.
\end{abstract}

Keywords: High-strength concrete; Columns; Tests 


\subsection{Considerações iniciais}

O surgimento do Concreto de Alta Resistência (CAR), embora recente, abriu novos horizontes para a utilização do concreto em estruturas. Resistências à compressão do concreto da ordem de 100MPa passaram a ser realidade em diversas construções. Além das vantagens proporcionadas pelas altas resistências, somam-se os aspectos positivos ligados àdurabilidade: um concreto menos poroso, com microestrutura mais densa, proporcionando expressivo aumento da vida útil das edificações. Ao salientar-se este aspecto, surge uma nova designação para o material: CAD - Concreto de Alto Desempenho.

É conveniente também mencionar a importância do avanço da tecnologia dos materiais na produção de novos componentes que, misturados ao concreto, melhoram suas características. Dentre estes estão as adições, como a sílica ativa e a cinza volante, e os aditivos, como o superplastificante, indispensável para a obtenção de concreto de alta resistência com trabalhabilidade.

A elevada tendência de utilização do CAR, somada às particularidades deste material quando comparado ao concreto de baixa resistência, têm contribuído de modo decisivo para 0 grande número de pesquisas atualmente em desenvolvimento em vários países do mundo. O estudo do comportamento do material sob diversas solicitações e dos elementos estruturais dele constituídos, têm se tornado prioridade em vista das vantagens econômicas e funcionais de sua 
aplicação. Neste aspecto, o estudo de pilares de CAR tem despertado atenção especial no meio científico devido a fatores como:

- A importância estrutural dos pilares como elementos de sustentação da estrutura;

- As diferenças relevantes de comportamento entre pilares moldados em CAR e em concretos de baixa resistência. Estas diferenças serão enumeradas no capítulo 3;

- A substancial economia resultante da aplicação de CAR em elementos comprimidos. Em estudo de caso apresentado por DAL MOLIN ${ }^{1}$ verificou-se a viabilidade econômica da aplicação do CAR em edifícios. Na mesma estrutura, calculada para resistências características à compressão do concreto $\left(f_{c k}\right)$ de $21 \mathrm{MPa}$ e $60 \mathrm{MPa}$, verificou-se que, para todos os elementos estruturais moldados em CAR, a economia proporcionada pelo emprego de concreto de resistência superior era de $12 \%$ em relação ao custo total da estrutura calculada com concreto de $\mathrm{f}_{\mathrm{ck}}=21 \mathrm{MPa}$. Na aplicação do CAD apenas nos pilares, verificou-se uma economia total de $11,5 \%$ também em relação ao custo final da estrutura de concreto calculada com $\mathrm{f}_{\mathrm{ck}}=21 \mathrm{MPa}$. Justifica-se deste fato a tendência preferencial de utilização do CAR em pilares, excetuando-se os casos em que o aspecto durabilidade é preponderante. Dentre as principais vantagens de utilização do CAR em pilares de edifícios está a redução da seção dos elementos (com a conseqüente economia de fôrmas) e a redução do número de pilares na estrutura, proporcionando melhor aproveitamento das vagas na garagem.

Devido às evidentes vantagens de aplicação do CAR, seu emprego em pilares de edifícios altos se intensificou nos últimos anos, conforme mostra BEEDLE (1992), figura 1.1. A torre PETRONAS, o mais alto edifício do mundo na atualidade, emprega concreto de 60MPa e 80MPa nos pilares, figura 1.2. O Boletim $\mathrm{n}^{\circ} 197$ do CEB/FIP (1990) traz a relação de 27 edifícios cujos pilares foram moldados com IBRACON. 
concreto de alta resistência. Nos casos mencionados as resistências variam de 45MPa (Pacific Park Plaza) a 115MPa (Two Union Square e Pacific First Center). No Brasil alguns edifícios já foram construídos com o emprego de concreto de resistência àcompressão da ordem de 60MPa nos pilares.

\section{口aço $\square$ concreto}

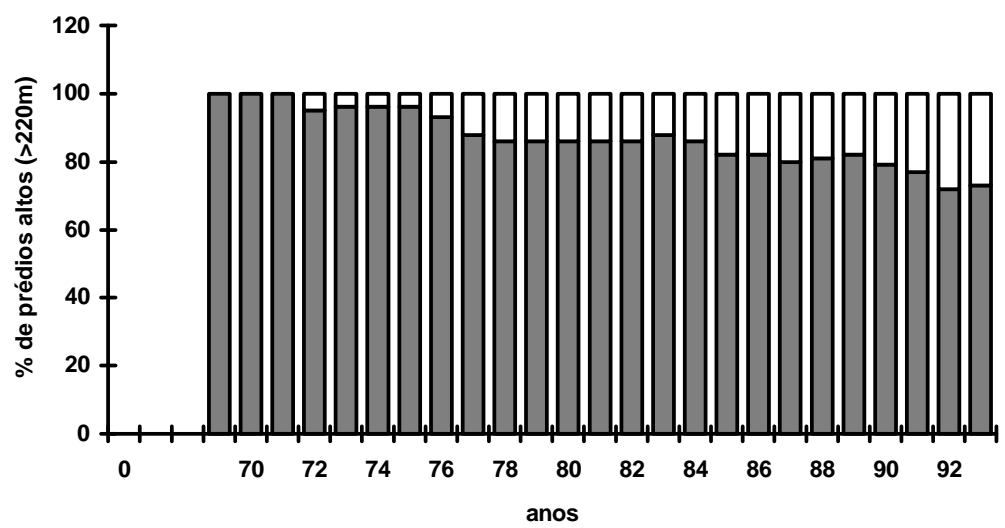

Figura 1.1. Utilização de aço e CAR nos 100 edifícios mais altos do mundo ao longo dos anos, BEEDLE (1992)

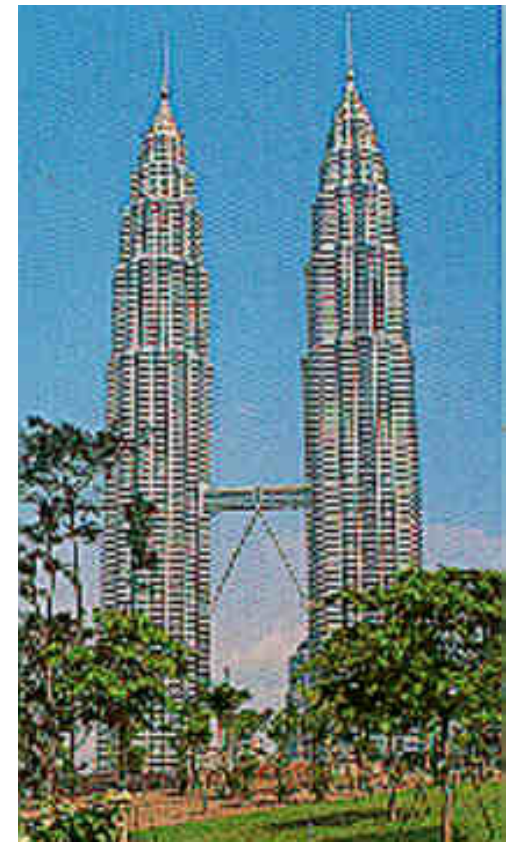

Figura 1.2. Torre Petronas (Malásia), a mais alta do mundo, concreto de $60 \mathrm{MPa}$ e $80 \mathrm{MPa}$ utilizado nos pilares ${ }^{2}$

${ }^{2}$ http://www.jaring.my/petronas/compro/twintwrs/twintwrs.html

apresentam características particulares quando comparados à pilares moldados 
com concreto de baixa resistência. Diversos pesquisadores observaram comportamento frágil para pilares de CAR quando utilizadas taxas de armaduras previstas nos atuais códigos de projeto, sendo, portanto, necessários acréscimos à quantidade de armadura transversal para se obter ductilidade do pilar. Tornou-se claro, portanto, que, para o projeto de pilares de CAR, as atuais taxas mínimas de armadura transversal sugeridas pelas normas devem ser modificadas.

Além disto observou-se também a não participação do cobrimento como área efetiva na contribuição para a resistência axial do pilar. Nos ensaios apresentados pela literatura, verificou-se que a camada de cobrimento apresentava ruptura prematura, destacando-se do núcleo (definido pelas armaduras longitudinais e transversais) e isolando-o como seção resistente do pilar, figura 1.3.

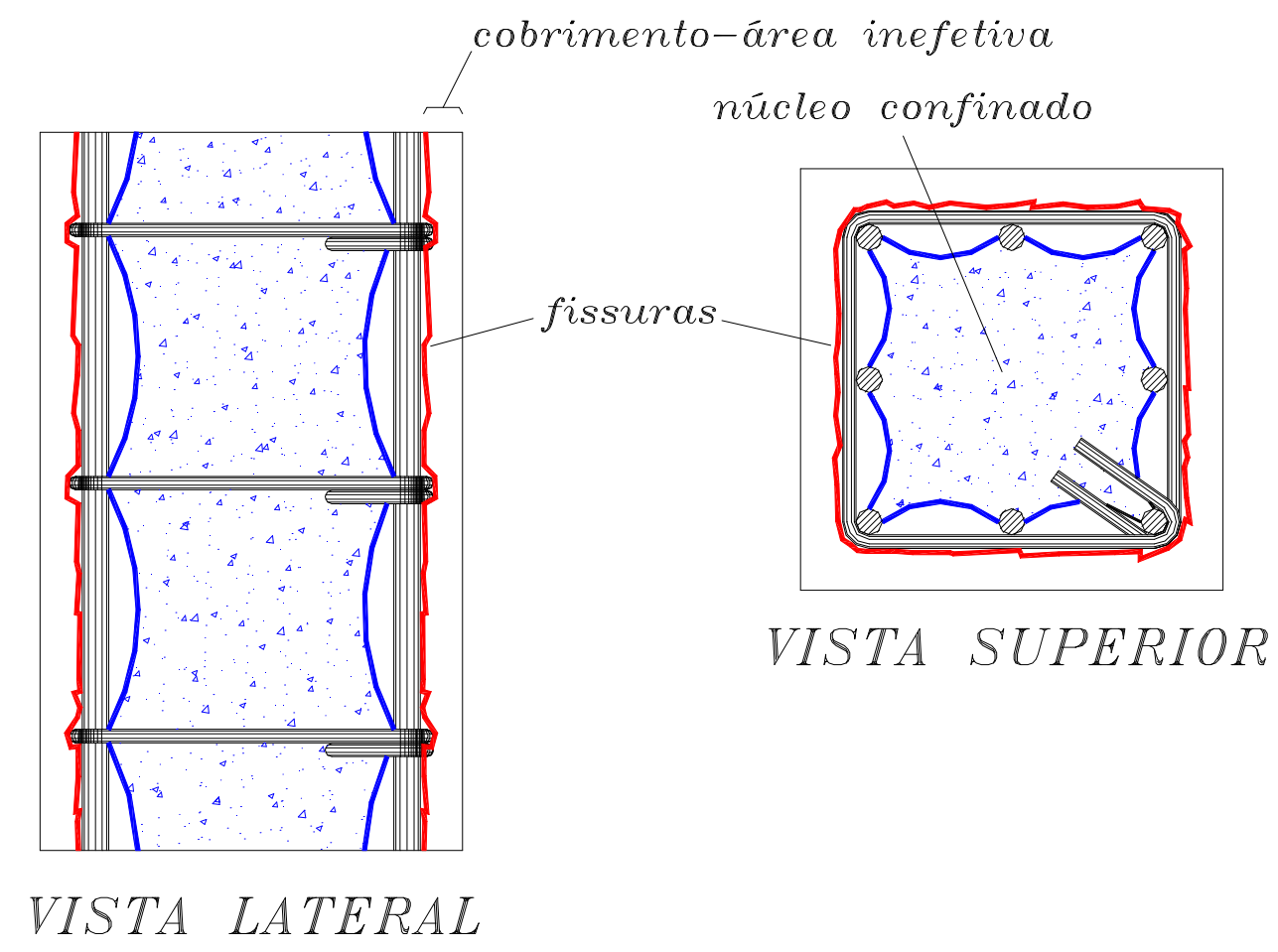

Figura 1.3. Detalhes do núcleo de concreto definido pela configuração das armaduras longitudinais e transversais

Estas e outras particularidades dos pilares de CAR têm revelado a carência de maior número de pesquisas sobre seu comportamento. Para a análise mais detalhada deste elemento estrutural moldado com CAR, torna-se necessário verificar o efeito de variáveis como: taxa e configuração da armadura longitudinal, 
configuração, quantidade e tensão de escoamento da armadura transversal e diâmetro $\left(\phi_{t}\right)$ da mesma.

O presente trabalho foi, portanto, motivado pelas conclusões de diversos pesquisadores sobre a formação do núcleo resistente de concreto, delimitado pelas armaduras longitudinais e transversais, presente em pilares de CAD quando a resistência à compressão do concreto está em torno de $80 \mathrm{MPa}$. A ruptura frágil observada nestes pilares foi proporcionada pelo ineficiente confinamento do núcleo pela armadura transversal.

$\mathrm{Na}$ etapa experimental da presente pesquisa, foi avaliado o efeito do espaçamento entre estribos no comportamento de pilares de CAR moldados em concreto com resistência média àcompressão de 60MPa.

\subsection{Justificativa}

Apresentam-se a seguir algumas razões que justificam a necessidade da pesquisa:

a. Tendo em vista a tendência crescente de utilização de pilares de CAR em edifícios, especialmente em edifícios altos, torna-se imprescindível o domínio de seu comportamento estrutural, especialmente àcompressão;

b. O estudo do Concreto de Alta Resistência (CAR) tem-se voltado essencialmente às resistências à compressão iguais ou superiores a 80MPa. Este fato comprova-se pela relativa escassez de pesquisas, de âmbito nacional, com CAR de resistência média à compressão variando no intervalo entre $40 \mathrm{MPa}$ a $70 \mathrm{MPa}$. A deficiência de resultados experimentais para este intervalo de resistências mostra a importância da pesquisa para o conhecimento do comportamento do CAR quando aplicado a pilares submetidos à compressão simples;

c. Além disso, a comprovação por AGOSTINI (1992), PAIVA (1994) e LIMA (1997) da formação do núcleo resistente de concreto, definido pelas armaduras longitudinais e transversais, para CAR com 
resistência média à compressão de $80 \mathrm{MPa}$, exige a verificação experimental deste fato para concretos situados na faixa de resistência em estudo;

d. Também como conseqüência das conclusões de LIMA (1997), pelas quais torna-se imprescindível a determinação de áreas mínimas de armadura que garantam o confinamento do concreto e a conseqüente ductilização do pilar, está a necessidade de verificar se as taxas de armadura transversal previstas pela NBR-6118 (1978) são suficientes para o confinamento do concreto, caso se verifique a existência do núcleo para concretos de resistência média de $60 \mathrm{MPa}$. Se as taxas previstas por essa norma forem insuficientes, novos valores serão sugeridos pela pesquisa;

e. A utilização crescente do CAR também exige do meio científico o fornecimento de critérios de projeto que orientem 0 dimensionamento e detalhamento de elementos estruturais moldados com Concreto de Alta Resistência. A não existência de normalização nacional para CAR agrava o problema, visto que a NBR 6118 (1978) foi elaborada com base nos conhecimentos adquiridos para concretos de baixa resistência.

\subsection{Objetivos}

Com os resultados obtidos nesta pesquisa são fornecidos subsídios para o projeto de pilares de concreto de alta resistência, submetidos à compressão simples, com resistência média de 60MPa. Este projeto faz parte de um plano mais amplo onde já se dispõem de resultados experimentais que orientam 0 comportamento de pilares moldados com concreto de resistência média à compressão de 80MPa.

São objetivos da pesquisa: 
a. Obter informações sobre o comportamento de pilares submetidos à compressão centrada executados com concretos de alta resistência com resistência média àcompressão de 60MPa aos 15 dias;

b. Determinar, através da análise experimental, a formação do núcleo resistente. Tal análise foi feita através da comparação dos resultados experimentais com os valores teóricos obtidos para a força última nos seguintes casos: 1. toda a seção transversal participa como seção resistente e, 2. apenas o núcleo coopera na resistência axial do pilar;

c. Verificar, caso seja comprovado o confinamento do núcleo, as taxas mínimas de armaduras longitudinais e transversais que garantam ruptura dúctil dos pilares;

d. Fornecer subsídios para possível normalização para concreto de alta resistência, baseado não apenas nos resultados experimentais, mas também na revisão bibliográfica detalhada sobre o assunto;

e. Verificar aspectos gerais da obtenção de concretos de alta resistência, tais como: dosagem para se obter a resistência desejada, atuação do superplastificante e da sílica ativa, influência do fator água/materiais cimentantes.

\subsection{Metodologia}

O programa experimental incluiu inicialmente a determinação da dosagem que forneceu resistência média àcompressão de 60MPa aos 15 dias. Para este fim, partiu-se de dosagem inicial, proposta por DAL MOLIN (1995), chegando-se, após várias tentativas, àresistência desejada.

Foi realizado estudo teórico das características mecânicas do CAD, dando ênfase ao seu comportamento àcompressão simples. Na etapa experimental foram ensaiados doze pilares distribuídos em seis séries: as três séries iniciais eram compostas por modelos com seção transversal quadrada $(20 \mathrm{~cm} \times 20 \mathrm{~cm})$, as séries seguintes foram constituídas por modelos de seção retangular $(15 \mathrm{~cm} \times 30 \mathrm{~cm})$. A 
altura dos pilares correspondeu a seis vezes a menor dimensão da seção transversal, portanto, $120 \mathrm{~cm}$ e $90 \mathrm{~cm}$, para pilares de seção transversal quadrada e retangular, respectivamente.

Os resultados dos ensaios, além de comprovar a formação da região de concreto confinada pela armadura lateral, para pilares moldados com concreto de resistência média à compressão de $60 \mathrm{MPa}$, serviram também para verificar a influência da taxa de armadura transversal $\left(\rho_{w}\right)$ e da configuração de estribos para a eficiência do confinamento do núcleo. Para a avaliação da eficiência do confinamento proporcionado pela armadura transversal, utilizaram-se os seguintes estimadores:

- Índice de Eficiência do Confinamento (I.E.C), proposto por CUSSON e PAULTRE (1993);

- comportamento do diagrama força x deformação;

- tensão nas barras da armadura transversal.

\subsection{Divisão do texto}

O texto da dissertação apresenta-se dividido em seis capítulos, descritos como segue:

Capítulo 2: Concreto de Alta Resistência. Além da parte conceitual, este capítulo mostra as vantagens e desvantagens do material, exemplos de sua aplicação e seus materiais constituintes. Também descreve sucintamente as características mecânicas do CAR de interesse à pesquisa e as principais recomendações normativas que versam sobre seu comportamento.

Capítulo 3: Análise teórica de pilares de CAR. Descreve as principais características de pilares de CAR submetidos àcompressão simples, apontando as diferenças em relação a pilares de concreto de baixa resistência. São também apresentados modelos para confinamento e diagramas tensão $\mathrm{x}$ deformação sugeridos por diversos pesquisadores.

Capítulo 4: Experimentação e Resultados. É fornecida neste capítulo a metodologia experimental empregada na presente pesquisa. São descritos os 
materiais utilizados na execução dos modelos, a instrumentação e os equipamentos de ensaio. No final do capítulo são apresentados os resultados dos ensaios àcompressão simples dos doze modelos.

Capítulo 5. Análise dos resultados. São aqui discutidos os resultados experimentais obtidos, através das recomendações contidas na literatura. Os resultados são comparados aos modelos teóricos sugeridos pela bibliografia.

Capítulo 6. Conclusões. Neste capítulo são apresentadas algumas diretrizes para o detalhamento de pilares de CAR. São também apresentadas sugestões para trabalhos futuros.

Por fim, apresentam-se as Referências Bibliográficas e a Bibliografia Complementar. 


\section{Concreto de Alta Resistência}

\subsection{Considerações Iniciais}

O Concreto de Alta Resistência (CAR) representa um dos últimos avanços no campo da tecnologia do concreto, e o interesse do meio técnico por este "novo" material de construção vem se intensificando àmedida que as pesquisas põem em relevo os aspectos positivos de sua utilização. Em diversos países são inúmeras as obras d'arte que utilizam o CAR com grandes vantages econômicas e estruturais. A exemplo disto tem-se o Canadá, que já utiliza concreto com resistência à compressão da ordem de 200MPa.

No Brasil também já se percebe a tendência de substituição do concreto de resistência usual $\left(\mathrm{f}_{\mathrm{ck}}<30 \mathrm{MPa}\right)$ por concreto de resistência superior. Não é raro, hoje, no canteiro de obras, obter-se concreto com resistência superior a $30 \mathrm{MPa}$, em virtude do avanço da tecnologia dos materiais e do rigor no controle de qualidade do concreto.

Fica claro então o porquê da necessidade de pesquisas, em nosso País, sobre o comportamento deste material (características mecânicas e reológicas) e dos elementos estruturais dele compostos, principalmente quando o concreto é constituído por materiais de origem nacional, como o cimento e os agregados. 


\subsection{Conceito}

O Concreto de Alta Resistência (CAR), segundo DJANIKIAN (1995), é o concreto com resistência característica à compressão $\left(\mathrm{f}_{\mathrm{ck}}\right)$ superior a $40 \mathrm{MPa}$. No Brasil, o concreto comumente utilizado nas construções têm resistência à compressão em torno de 20MPa a 25MPa.

DAL MOLIN (1995) define concreto de alta resistência como aquele que apresenta média de resistência à compressão acima das usuais em um determinado local ou época. Por exemplo - em obras de edificações convencionais no Brasil, nas quais as resistências características $\left(f_{c k}\right)$ normalmente não ultrapassam 25MPa, concretos com resistências de $30 \mathrm{MPa}$ já podem ser considerados de alta resistência. Nos EUA, onde já existe certa tradição na produção de concretos com $\mathrm{f}_{\mathrm{ck}}$ mais elevado, consideram-se normalmente concretos de alta resistência os que possuem $\mathrm{f}_{\mathrm{ck}}$ acima de $50 \mathrm{MPa}$, já tendo sido produzidos concretos com resistência à compressão de até 150MPa. Esta definição concorda com DINIZ e FRANGOPOL (1997).

A escolha do limite de $40 \mathrm{MPa}$, sugerido anteriormente, deve-se ao fato de as normas de projeto e as regras de detalhamento de armaduras, incluindo-se aqui a NBR 6118 (1978), estarem baseadas na análise experimental de concretos com resistência não superior a 40MPa. Concretos com resistências características desta ordem aos 28 dias podem ser obtidos com materiais de uso corrente e técnicas tradicionais, sem necessidade de adições, técnicas especiais ou controle rigoroso de execução.

Desta forma, o posicionamento da maioria dos especialistas diante da questão é o de considerar como concreto de alta resistência, com agregados normais, aquele com resistência àcompressão superior a 40MPa.

\subsection{Alta Resistência x Alto Desempenho}

Segundo NEVILLE e AÏ TCIN (1993) nas aplicações práticas deste tipo de concreto, a ênfase, em muitos casos, tem mudado gradualmente de resistência à compressão para outras propriedades do material, como: elevado módulo de elasticidade, alta densidade, baixa permeabilidade e elevada resistência a algumas formas de ataque. Por esta razão, é viável designar este concreto através do termo mais abrangente: Concreto de Alto Desempenho (CAD). 
Vê-se, entretanto que, na obtenção de concreto de alto desempenho, mesmo quando a característica de maior interesse não é a resistência àcompressão, esta acaba sendo obtida por estar atrelada ao reduzido fator água/ cimento utilizado nestes concretos. Portanto Concreto de Alta Resistência e Concreto de Alto Desempenho se confundem neste aspecto.

\subsection{Classificação dos Concretos de Alta Resistência}

Segundo AMARAL FILHO (1993) os concretos podem ser classificados do seguinte modo (tabela 2.1):

Tabela 2.1. Classificação dos concretos, AMARAL FILHO (1993)

\begin{tabular}{|c|c|}
\hline Resistência & Classificação \\
\hline $\mathrm{f}_{\mathrm{ck}}<25 \mathrm{MPa}$ & Baixa \\
\hline $25 \mathrm{MPa} \leq \mathrm{f}_{\mathrm{ck}} \leq 50 \mathrm{MPa}$ & Média \\
\hline $50 \mathrm{MPa} \leq \mathrm{f}_{\mathrm{ck}} \leq 90 \mathrm{MPa}$ & Alta \\
\hline $\mathrm{f}_{\mathrm{ck}}>90 \mathrm{MPa}$ & Ultra alta \\
\hline
\end{tabular}

SANCHEZ (1997) também sugere um sistema de classificação do concreto, através de sua resistência àcompressão $f_{c}$ (tabela 2.2).

Tabela 2.2. Classificação dos CAR segundo SANCHEZ (1997)

\begin{tabular}{|c|c|c|c|c|}
\hline Parâmetro & $\begin{array}{l}\text { Concreto } \\
\text { convencional }\end{array}$ & CAR & $\begin{array}{l}\text { Concreto com } \\
\text { altíssima } \\
\text { resistência }\end{array}$ & $\begin{array}{l}\text { Concreto com } \\
\text { ultra-alta } \\
\text { resistência }\end{array}$ \\
\hline $\mathrm{f}_{\mathrm{c}}(\mathrm{MPa})$ & $\leq 50$ & $50-100$ & $100-150$ & $>150$ \\
\hline Fator $\mathrm{a} / \mathrm{c}$ & $>0,45$ & $0,45-0,30$ & $0,30-0,25$ & $<0,25$ \\
\hline Aditivos químicos & $\begin{array}{c}\text { Não é } \\
\text { necessário }\end{array}$ & $\begin{array}{c}\text { redutor de água } \\
\text { ou } \\
\text { superplastificante }\end{array}$ & superplastificante & $\begin{array}{c}\text { alto redutor de } \\
\text { água }\end{array}$ \\
\hline Adições minerais & $\begin{array}{c}\text { Não é } \\
\text { necessário }\end{array}$ & cinza volante & sílica ativa & sílica ativa \\
\hline $\begin{array}{l}\text { Coeficiente de } \\
\text { permeabilidade }\end{array}$ & $>10^{-10}$ & $>10^{-11}$ & $>10^{-12}$ & $>10^{-13}$ \\
\hline
\end{tabular}




\subsection{Histórico}

Pesquisas sobre o comportamento dos concretos de alta resistência, com ou sem adição de sílica ativa, estão em desenvolvimento na Noruega e Dinamarca desde 1976, e mais recentemente em outros países como Estados Unidos, Canadá e Japão.

Pesquisas voltadas à análise estrutural de diversos elementos moldados em CAR estão sendo realizadas desde anos recentes. O comportamento de pilares, vigas e elementos especiais tem sido exaustivamente estudado em laboratório. Alguns exemplos são mostrados nas figuras a seguir.

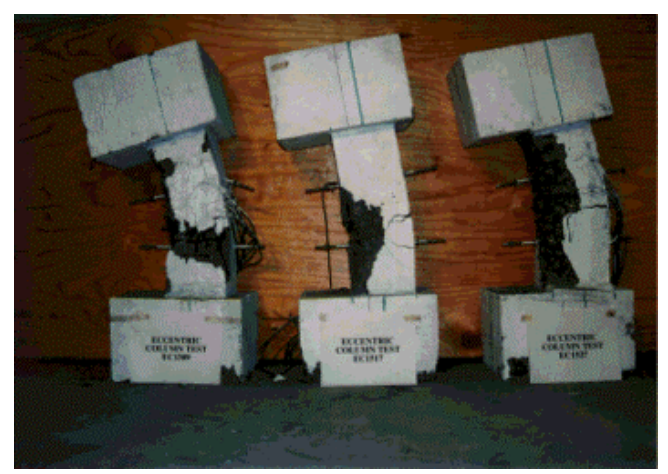

Figura 2.1. Ensaios sobre o comportamento de pilares de CAR submetidos à flexocompressão, XIAO e ANDERSON ${ }^{1}$

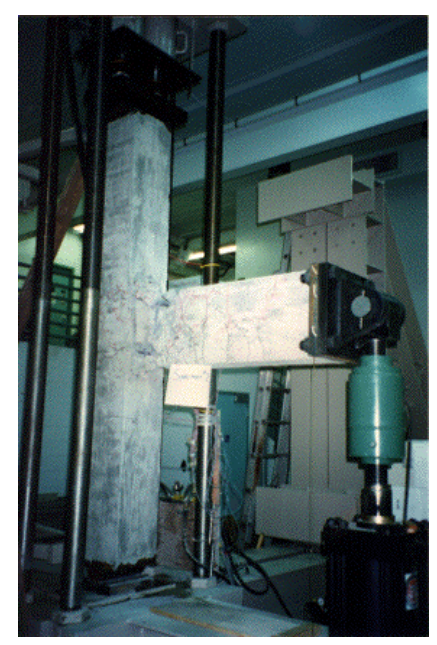

Figura 2.2. Ligações viga-pilar, XIAO e ANDERSON²

${ }^{1}$ http://www.usc.edu/dept/civil_eng/structural_lab/projects/c4col.html

${ }^{2}$ http://www.usc.edu/dept/civil_eng/structural_lab/projects/c4joint.html 


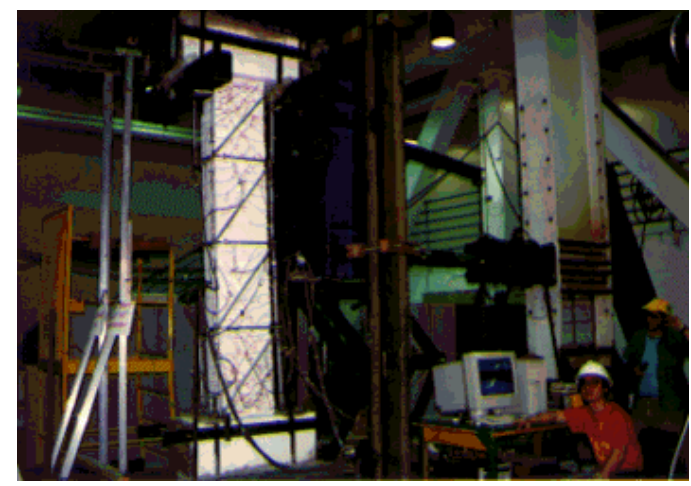

Figura 2.3. Comportamento de vigas de CAR submetidas à flexão com cisalhamento, XIAO e $M A^{3}$

\subsubsection{O Concreto de Alta Resistência no Brasil}

No Brasil o concreto de alta resistência já se encontra em obras de grande vulto, como o Museu de Arte Contemporânea no Rio de Janeiro, o Superior Tribunal de Justiça em Brasília e em vários edifícios construídos em Salvador, Bahia. As pesquisas sobre este material também se desenvolvem em várias Universidades, como a USP (Escola de Engenharia de São Carlos e Escola Politécnica), UNICAMP, UnB, UFRGS, UFRJ e UFF. Inúmeros trabalhos foram publicados sobre este assunto nos últimos anos, em especial nos congressos promovidos pelo IBRACON e nas JORNADAS SUL-AMERICANS DE ENGENHARIA ESTRUTURAL.

Um estudo inicial sobre pilares de CAR foi desenvolvido por AGOSTINI (1992). PAIVA (1994) deu continuidade a este trabalho. Além disso, PINTO JÚNIOR (1992) e FERNANDES (1992) estudaram o comportamento de vigas de concreto de alta resistência sujeitas, respectivamente, a momento fletor e a força cortante. DUCATTI (1993) estudou a aderência da armadura com o CAR.

No âmbito da Escola de Engenharia de São Carlos - USP, trabalhos sobre o CAR foram desenvolvidos e outros estão em andamento. Dentre os trabalhos experimentais já concluídos, citam-se o estudo de pilares de CAR submetidos à flexo-compressão e àcompressão simples realizado por LIMA (1997), o estudo das ligações laje-pilar em lajes sem viga realizado por VARGAS (1997), e a aplicação de fibras metálicas em CAR para utilização em pilares, realizado por GIONGO, GUIMARÃES e TAKEYA (1997). Também estudos teóricos foram realizados por SILVA (1997), analisando características gerais do CAR e sua aplicação a vigas e

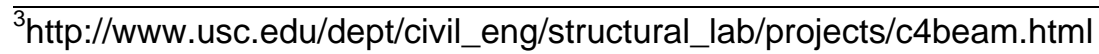


pilares, e BACCIN (1998), que estudou o dimensionamento de pilares de CAR. Atualmente diversas pesquisas estão em andamento, enfocando a aplicação do CAR a diferentes elementos estruturais.

\subsection{Vantagens e desvantagens do Concreto de Alta Resistência}

Dentre as causas principais do acentuado interesse despertado pelo concreto de alta resistência, podem ser relacionadas as seguintes:

a. Aumento da capacidade resistente dos elementos estruturais para uma dada seção transversal, principalmente em elementos comprimidos, como pilares). Quanto æ̀s características mecânicas, o CAR é superior ao concreto de baixa resistência nos seguintes aspectos: resistência àcompressão e àtração, módulo de elasticidade, entre outros.

b. Redução da área da seção transversal dos elementos de suporte para uma dada força, como conseqüência da elevada resistência do concreto;

c. Redução do peso próprio permitindo aumento dos vãos e da altura dos edifícios;

d. Redução da força na fundação;

e. Possibilidade de redução de custos, fator ligado especialmente à redução de fôrmas e do volume de concreto;

f. Boa trabalhabilidade, apesar do baixo fator água/ cimento, em decorrência da adição do superplastificante;

g. Reduzida segregação;

h. Pequena exsudação;

i. Menor fluência que os concretos de baixa resistência; 
j. Baixa porosidade. Enquanto nos concretos comuns a porosidade fica em torno de 25 a $30 \%$ do volume do concreto, no CAR a porosidade é de aproximadamente 5\%;

\section{Baixa permeabilidade;}

m. Alta resistência mecânica com pouca idade;

n. Maior durabilidade: resistência à abrasão, ciclos de congelamento e descongelamento, ataque de cloretos e sulfatos, etc.

Entretanto algumas desvantagens também são apontadas para a utilização do CAR:

a. Comprometimento da trabalhabilidade em razão do emprego de relação água-cimento reduzida. Esta desvantagem é contornada com o uso de superplastificantes;

b. Rigoroso controle de qualidade em todas as etapas de produção do concreto. Este fator praticamente obriga que concretos desse tipo sejam executados por concreteiras, desencorajando a produção no canteiro de obras;

c. Desconhecimento, pela maioria dos projetistas, das características, propriedades e metodologia de cálculo do concreto de alta resistência. Isto se agrava por não existir, até o momento, normalização nacional sobre o assunto;

d. Ruptura frágil do material (sem aviso). O comportamento dúctil do CAR pode ser obtido através do emprego de armadura transversal adequada que garanta o confinamento do concreto (no caso de elementos comprimidos) ou da adição de fibras ao concreto.

e. Perda de consistência. Isto se deve ao fato de que a consistência adquirida pelo concreto com superplastificante se manter por um período de 30 minutos a 60 
minutos, voltando gradativamente à consistência inicial. Este problema também está sendo contornado através da produção de aditivos com tempo de eficiência superior ao dos superplastificantes atualmente em uso.

\subsection{Aplicabilidade do Concreto de Alta Resistência}

Por todas as qualidades já mencionadas, o concreto de alta resistência tem encontrado lugar em vários campos de aplicação, dentre os quais se destacam:

a. Pilares de edifícios, especialmente edifícios altos;

b. Pontes;

c. Estruturas marítimas;

d. Pré-moldados;

e. Reparos em obras de concreto;

f. Pisos de alta resistência;

g. Pavimentos de rodovias e aeroportos.

São mostrados a seguir alguns exemplos de aplicação do CAR no Brasil e exterior:

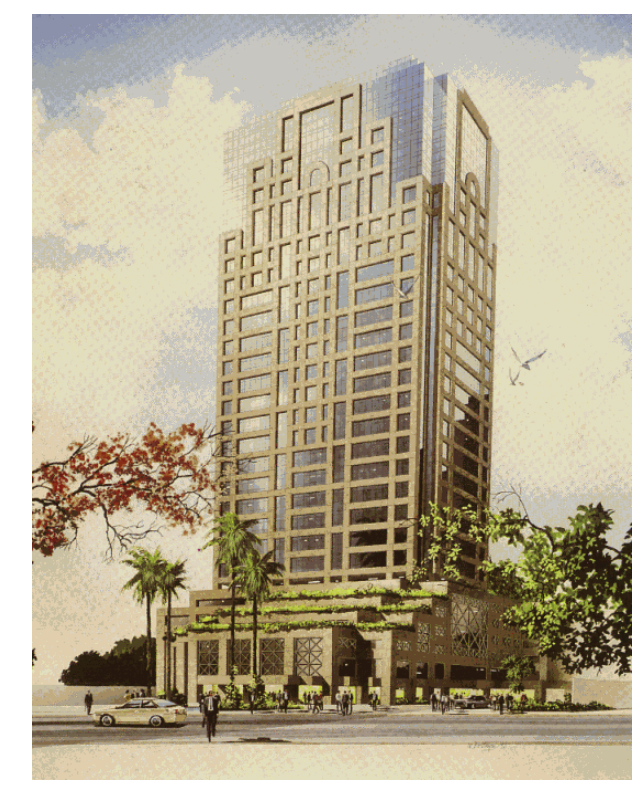

Figura 2.4.1. Edifício Comercial Suarez, Salvador - BA. Concreto de 60MPa utilizado no núcleo estrutural, LEITE \& MIRANDA ${ }^{4}$

${ }^{4}$ LEITE \& MIRANDA, http://www.stc.com.br/leiteemiranda/HighStrengthConcrete.html 


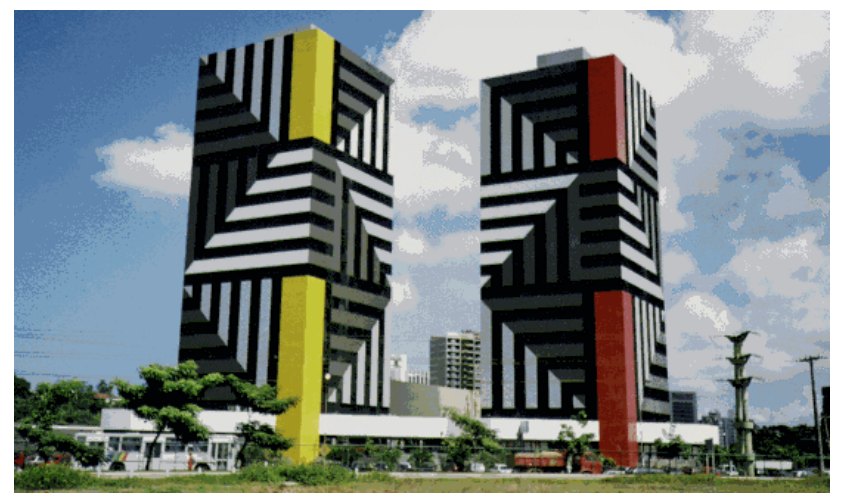

Figura 2.4.2. Edifício Previnor, Salvador - BA. 18 pavimentos, concreto de 60MPa nos pilares, LEITE \& MIRANDA

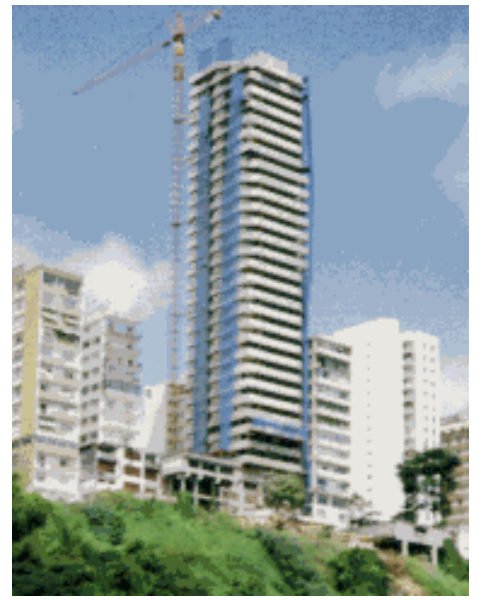

Figura 2.4.3. Edifício Arthur Moreira Lima, Salvador - BA. 33 pavimentos, $400 \mathrm{~m}^{3}$ de concreto de 60MPa nas paredes estruturais, LEITE \& MIRANDA

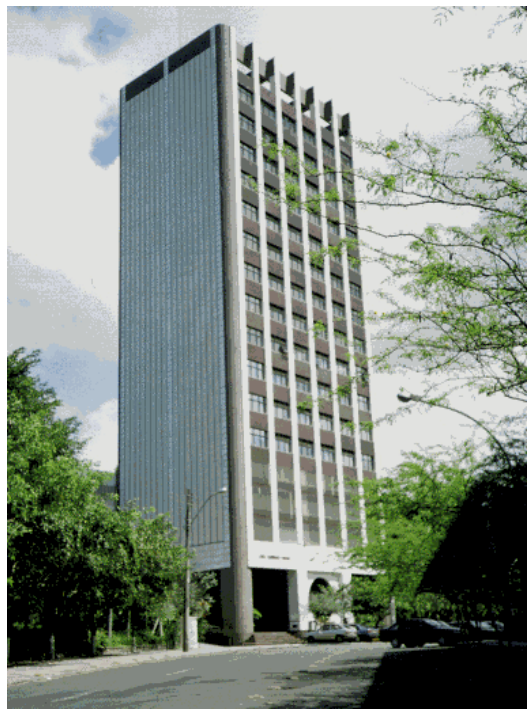

Figura 2.4.4. Edifício do Banco de Tókio, Salvador - BA. Concreto de 60MPa nos pilares centrais, LEITE \& MIRANDA 


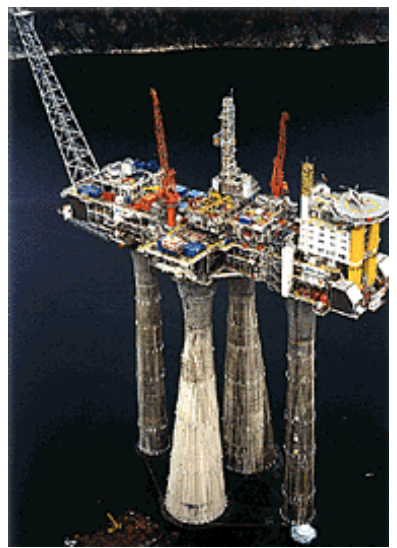

Figura 2.4.5. Estrutura offshore: plataforma Gullfaks $C, 240.000 \mathrm{~m}^{3}$ de concreto de resistência característica variando de $65 \mathrm{MPa}$ a $70 \mathrm{MPa}$ utilizado na estrutura de gravidade da base $^{5}$

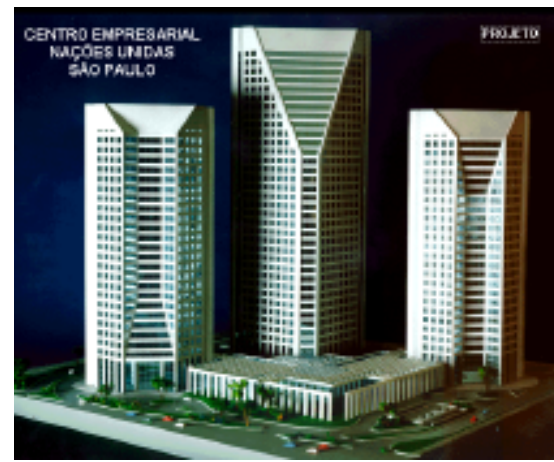

Figura 2.4.6. Centro empresarial Nações Unidas - SP, concreto de 50MPa nos pilares ${ }^{6}$

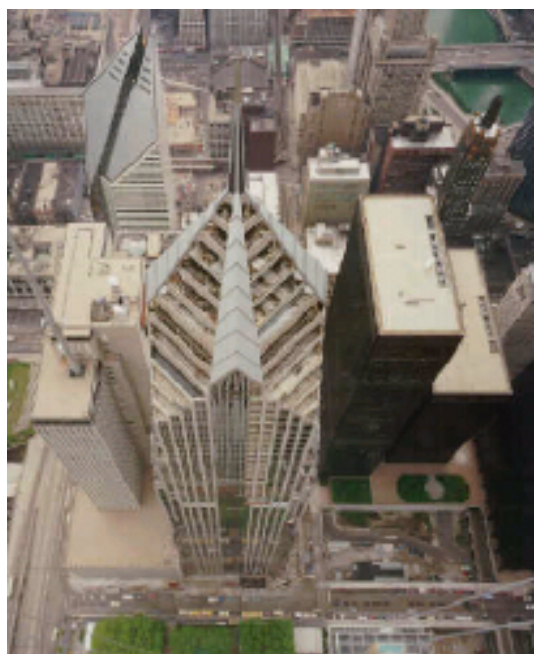

Figura 2.4.7. Two Prudential Plaza, Chicago, Illinois, concreto de 84 MPa utilizado no núcleo estrutural $^{7}$

Figura 2.4. Exemplos de aplicação do CAR

\footnotetext{
5 http://www.statoil.com

${ }^{6}$ Artigo contido do CD "Concreto de Alto Desempenho", versão 1.0, produzido pelo IBRACON

${ }^{7}$ http://www.mdcsystems.com/projects.htm
} 


\subsection{Materiais utilizados na produção do Concreto de Alta Resistência}

\subsubsection{Cimento}

Segundo o Boletim no 197 do CEB/FIP (1990), o desenvolvimento da resistência e a resistência potencial do CAR dependem da escolha do cimento. A composição do clinker e a finura são fatores que influenciam na resistência inicial e final do concreto. Os componentes do cimento: $\mathrm{C}_{3} \mathrm{~S}, \mathrm{C}_{2} \mathrm{~S}$ e $\mathrm{C}_{3} \mathrm{~A}$ têm grande influência sobre o desenvolvimento da resistência da pasta de cimento. $\mathrm{O}_{3} \mathrm{~S}$ contribui para o rápido aumento da resistência nas primeiras idades e para a alta resistência final. $\mathrm{O} \quad \mathrm{C}_{2} \mathrm{~S}$ hidrata um pouco lentamente, mas pode contribuir significativamente para a resistência final. $\mathrm{O}_{3} \mathrm{C}_{3} \mathrm{~A}$ tem influência particular na resistência inicial.

DAL MOLIN (1995) afirma que, para aumentar a resistência da pasta de cimento é desejável:

a. Aumentar as proporções de silicatos de cálcio na composição do cimento, propriamente $\circ \mathrm{C}_{2} \mathrm{~S}$;

b. Eliminar ao máximo os cristais de $\mathrm{Ca}(\mathrm{OH})_{2}$, produzidos paralelamente com O $\mathrm{CSH}$;

c. Reduzir ou eliminar as proporções de $\mathrm{C}_{3} \mathrm{~A}$ e $\mathrm{C}_{4} \mathrm{AF}$.

Cabe salientar que, para o concreto de alta resistência, mais do que no concreto de resistência usual, detalhes relativos à composição, finura e qualidade do cimento, podem influir sensivelmente no desempenho do produto final. Como salienta AÏ TCIN (1987), a experiência mostra que em cada região sempre existe um cimento mais adequado que outros para alcançar o objetivo desejado, ou seja, aquele que permite obter, ao mesmo tempo, alta resistência e boa trabalhabilidade em companhia de outros materiais.

O ACI 363 (1992) prescreve que os teores de cimento comuns nos concretos de alta resistência variam de $400 \mathrm{~kg} / \mathrm{m}^{3}$ a $600 \mathrm{~kg} / \mathrm{m}^{3}$. Segundo SILVA (1995) quantidades maiores de cimento adicionadas acima de um teor "ótimo", podem causar perda de resistência do concreto, perda de viscosidade, trabalhabilidade, e aumento do calor de hidratação.

Nos modelos estudados por LIMA (1997) na Escola de Engenharia de São Carlos - USP o consumo de cimento, para concreto de resistência média à 
compressão em torno de $80 \mathrm{MPa}$ (com adição de $10 \%$ de sílica ativa em relação ao consumo de cimento), foi de $480 \mathrm{~kg} / \mathrm{m}^{3}$. Na presente pesquisa, com concreto de resistência média àcompressão de $60 \mathrm{MPa}$, o consumo de cimento foi de $430 \mathrm{~kg} / \mathrm{m}^{3}$ (também com adição de $10 \%$ de sílica ativa em relação ao consumo de cimento). Estas quantidades estão, portanto, dentro do intervalo proposto pelo $\mathrm{ACl} 363$ (1992).

\subsubsection{Agregados}

\subsubsection{Agregado graúdo}

Sabe-se que, para concretos usuais, a resistência dos agregados não é o fator limitante da resistência do concreto, sendo a resistência da pasta de cimento o determinante da resistência final. Para os concretos usuais, a resistência da interface pasta-agregado constitui-se como o elo fraco no concreto, sendo a responsável pela microfissuração precoce e posterior ruína do material. Nos concretos de alta resistência, a interface pasta-agregado é altamente homogênea, deixando de se constituir como um plano preferencial de microfissuração.

O agregado graúdo deve ser de grande resistência à compressão e módulo de elasticidade que se aproxime daquele da argamassa, de modo a minimizar as deformações diferenciais na interface pasta-agregado, e apresentar uma textura superficial que favoreça a aderência da argamassa sem diminuir a trabalhabilidade.

O ACI 363 (1992) mostrou que, para se obter resistência àcompressão ótima, com alto teor de cimento e baixo fator água/cimento, a máxima dimensão do agregado graúdo deve se manter entre $9,5 \mathrm{~mm}$ e $12,5 \mathrm{~mm}$. A experiência tem mostrado que, para concretos de alta resistência, a dimensão máxima do agregado convêm situar-se entre 9,5mm a 12,5m, como indicado em AGOSTINI (1992) e PINTO JÚNIOR (1992), o que concorda com a recomendação do ACI 363 (1992). 


\subsubsection{Agregado miúdo}

Quanto ao agregado miúdo, as características mais importantes a serem consideradas são:

- forma ou angularidade das partículas;

- granulometria ou módulo de finura;

A grande proporção de partículas finas resultante da elevada quantidade de material cimentício requer um agregado miúdo com partículas angulosas, graduação grossa e módulo de finura acima de 2,8 (preferivelmente em torno de 3). Estes agregados proporcionam melhor trabalhabilidade e maiores resistências.

É ainda preferível que contenham o mínimo possível de partículas lisas graúdas (maiores que 4,8mm) que possam produzir falhas na aderência. As areias finas, com módulo de finura inferior a 2, além de diminuírem a trabalhabilidade não oferecem condições de maior ganho na resistência, AGOSTINI (1992), PINTO JúNIOR (1992) e Aï TCIN (1987).

\subsubsection{Aditivos}

Aditivos são substâncias introduzidas em pequena quantidade no concreto, durante a mistura, com alguma(s) das seguintes finalidades:

- aumento da plasticidade do concreto sem aumento da quantidade de água;

- redução da exsudação e da segregação;

- aumento ou redução do tempo de pega;

- rápido crescimento da resistência nas primeiras idades;

- trabalhabilidade, resistência e durabilidade.

Consideram-se aditivos aquelas substâncias incorporadas ao concreto em teor inferior a $5 \%$ da massa de cimento e denominam-se adições aquelas substâncias acrescentadas em quantidades superiores a este teor. 


\subsubsection{Superplastificante}

Os superplastificantes são redutores de água com alto poder de redução. Com estes aditivos pode-se conseguir redução de $20 \%$ a $30 \%$ de água, dependendo da dosagem e do tipo de superplastificante empregado. Podem também ser usados com a finalidade de produzir concretos com quantidade inferior de cimento, enquanto se mantém a relação água/cimento.

Na presente pesquisa, devido ao reduzido fator água/ materiais cimentantes empregado $(a /(c+s a)=0,35)$ utilizou-se aditivo superplastificante para a obtenção da trabalhabilidade necessária à concretagem dos pilares. Pensou-se, em especial, na concretagem das extremidades dos modelos em virtude do pequeno espaçamento entre estribos naquela região (2,5cm - armadura de fretagem).

A obtenção de concretos de alta resistência consiste na redução do fator água/cimento (a/c) ou, dependendo da utilização de adições, do fator água/materiais cimentantes $(\mathrm{a} / \mathrm{mc})$. Para significativa redução deste fator sem a perda de trabalhabilidade, torna-se imprescindível a utilização de superplastificantes. NEVILLE e AÏ TCIN (1993) afirmam que a combinação de um limite superior de conteúdo de cimento com um limite inferior de quantidade de água, significa que, sem superplastificante, a relação água/cimento não pode ser reduzida abaixo do valor aproximado de 0,4. É o efeito do superplastificante que permite uma relação água/materiais cimentantes para o concreto de alta resistência em torno de 0,30, sem a perda de trabalhabilidade.

Os superplastificantes podem ser empregados em teores de até 1,5\% em massa (sólidos/cimento) com pouca incorporação de ar e pouca influência no tempo de pega.

A presença do superplastificante no concreto melhora sensivelmente a consistência, principalmente para um tempo de mistura mais prolongado. Entretanto sua ação não é suficientemente lenta, sendo que, depois de 30 a 60 minutos, a consistência volta ao normal, DAL MOLIN (1995).

Como o teor de sólidos contidos nos superplastificantes gira em torno de $30 \%$ sendo o restante da massa constituído por água, faz-se a correção da quantidade de água na dosagem do concreto, LIMA (1997). 


\subsubsection{Resinas sintéticas}

Vale aqui mencionar esta nova alternativa para se obter concretos trabalháveis, apesar do reduzido fator água/cimento. Este produto preenche os vazios da massa de concreto com resina sintética de alta aderência, garantindo uma microestrutura perfeitamente densa. Permite uma sensível redução do fator a/c e otimiza o processo de hidratação. Possui os seguintes campos de aplicação:

- Concreto pré-fabricado;

- Concreto usinado;

- Argamassas.

\subsubsection{Adições minerais}

Alguns compostos formados por partículas muito finas podem ser incorporados ao concreto como adição (teor superior a 5\% da massa de cimento), suplementando o cimento, ou substituindo parcialmente o mesmo. Dentre estes produtos podem-se mencionar a Escória de Alto Forno, a Cinza Volante e a Sílica Ativa (tradução de Sílica Fume). Como na presente pesquisa utilizou-se apenas sílica ativa em substituição de parte do cimento, estudou-se apenas esta adição.

\subsubsection{Sílica ativa}

O ACI 363 (1992) define sílica ativa como o subproduto resultante da redução de quartzo de alta pureza com carvão, em fornos aquecidos eletricamente com circulação de ar, na produção de silício e ligas de ferro-silício. A fumaça coletada dos gases expelidos pelos fornos, tem alto teor de dióxido de silício amorfo, constituído por partículas esféricas muito finas.

A sílica ativa apresenta dois efeitos sobre os concretos de cimento Portland: o efeito pozolânico (como material aglomerante) e o efeito de microfiler (material inerte muito fino). No primeiro, a sílica ativa, por ser praticamente só sílica amorfa, reage com grande rapidez com o $\mathrm{Ca}(\mathrm{OH})_{2}$ formado na hidratação do cimento. $\mathrm{E}$, no segundo, por ser extremamente fina, a quantidade de grãos de sílica ativa por grão de cimento (na proporção de 10\% de sílica ativa em relação àmassa de cimento) é 
da ordem de 50.000 e esses grãos se alojam nos interstícios da pasta, subdividindo os poros capilares das partículas de cimento em poros de gel.

A adição de sílica ativa ao concreto ajuda, portanto, a preencher os vazios existentes entre a pasta e os agregados, tornando a microestrutura mais densa e homogênea (figuras 2.5 e 2.6). Desta característica, resultam alguns aspectos positivos da adição de sílica ativa ao concreto:

- acréscimos significativos na resistência àcompressão;

- redução da permeabilidade;

- melhora a resistência àcorrosão;

- melhora a coesão e a resistência àsegregação;

- melhora a aderência da armadura ao concreto;

- melhora a resistência à abrasão, e a ataques de agentes químicos agressivos.

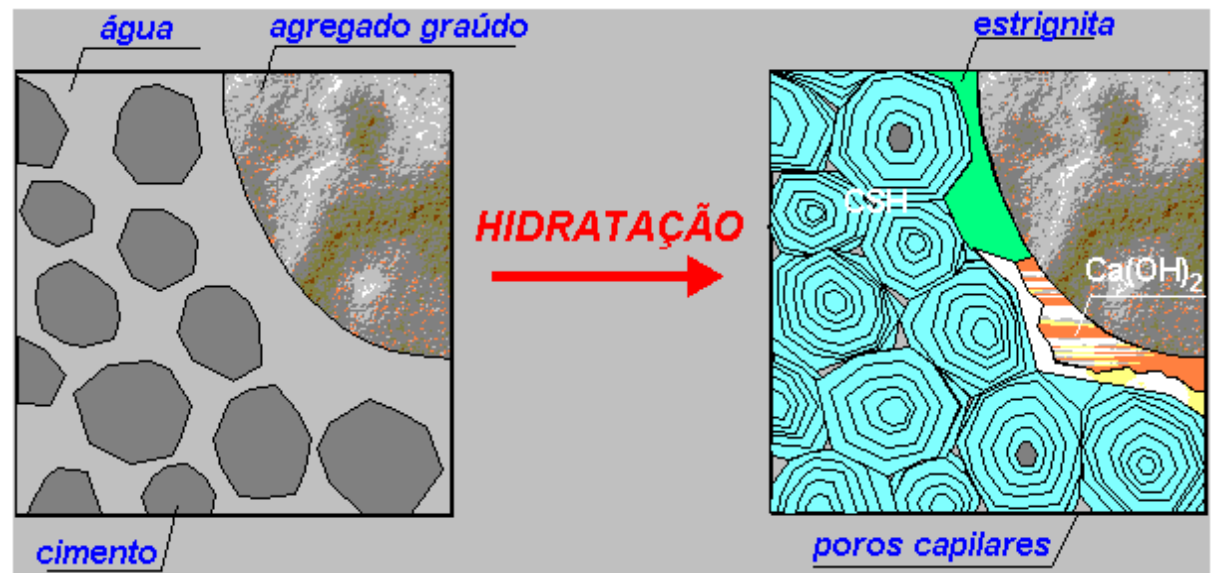

Figura 2.5. Concreto sem microssílica ${ }^{8}$

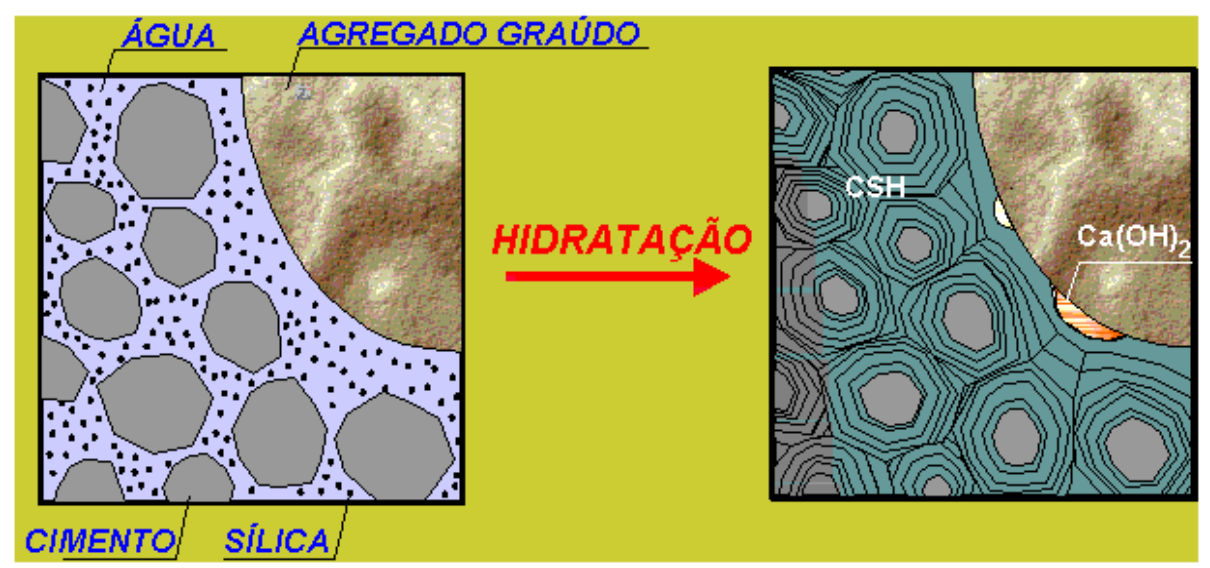

Figura 2.6. Concreto com microssílica ${ }^{8}$

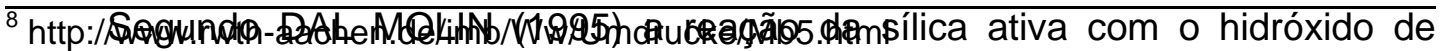


cálcio - $\mathrm{Ca}(\mathrm{OH})_{2}$ - forma o silicato de cálcio hidratado - $\mathrm{CSH}$ - adicional, que é o principal responsável pela resistência da pasta de cimento. Sua atividade pozolânica é bastante vigorosa e, quando aplicada com o cimento na produção de concretos de alta resistência, sua ação tem-se mostrado mais efetiva do que a da cinza volante e da escória de alto forno.

Como a sílica ativa interfere no consumo de água, para concretos de alta resistência, com adição de sílica ativa, não se fala em relação água/cimento $(\mathrm{a} / \mathrm{c})$, mas na relação água/materiais cimentantes $(\mathrm{a} / \mathrm{mc})$, onde os materiais cimentantes incluem o cimento e a sílica ativa.

NEVILLE e AÏ TCIN (1993) afirmam que a sílica ativa não é um ingrediente essencial para todas as misturas de CAR. Em alguns projetos citados pelos autores, resistências de $60 \mathrm{MPa}$ a $80 \mathrm{MPa}$ foram obtidas sem o uso de sílica ativa. $\mathrm{Na}$ opinião dos mesmos não há vantagem em se evitar o uso de sílica ativa se ela está disponível a baixo custo. Para resistências mais elevadas, o uso da sílica ativa é essencial. Os autores citam um caso onde um incremento de resistência à compressão de 90MPa para $100 \mathrm{MPa}$ requereu uma adição de sílica ativa em quantidade que representava $10 \%$ do consumo do cimento utilizado $\left(500 \mathrm{~kg} / \mathrm{m}^{3}\right)$.

Para SANCHEZ (1997), o uso da sílica ativa leva a incrementos de resistência àcompressão aos 3 dias e aos 7 dias inferiores aos obtidos aos 28 dias, ou seja, atua com melhor performace para idades maiores, em diversos aspectos, não só na resistência àcompressão.

A sílica ativa pode ser encontrada em três formas, SANCHEZ (1997):

- Densificada: material submetido a beneficiamento por aglomeração de partículas. Massa específica: $600 \mathrm{~kg} / \mathrm{m}^{3}$;

- Não densificada: material proveniente diretamente de filtro coletor. Massa específica: $250 \mathrm{~kg} / \mathrm{m}^{3}$;

- Na forma de suspensão aquosa com teor de sólidos de 50\% em massa. Massa específica de $1400 \mathrm{~kg} / \mathrm{m}^{3}$.

$\mathrm{Na}$ presente pesquisa, a sílica ativa foi empregada em teor de $10 \%$ relativo ao consumo de cimento, substituindo parcialmente o mesmo. Logo, para o cálculo do consumo dos outros materiais foi utilizado como referência o consumo total de material aglomerante, cimento + sílica ativa.

\subsection{5. Água}


As especificações para a qualidade de água de amassamento para concreto de alta resistência não são mais exigentes do que para concreto de baixa resistência. Geralmente, a água para concreto deve ser de qualidade potável, isenta de matérias orgânicas e de substâncias estranhas e nocivas.

\subsubsection{Fator água/materiais cimentantes $(\mathrm{a} / \mathrm{mc})$}

A relação água/materiais cimentantes é o fator principal para a obtenção de concretos de alta resistência. Ela define a trabalhabilidade da massa e interfere na resistência do concreto.

A redução do fator água/materiais cimentantes implica em ganho de resistência pelo concreto, uma vez que a porosidade do concreto fica reduzida. Enquanto nos concretos de resistência usual o fator água/cimento fica entre 0,45 e 0,60, nos concretos de alta resistência, devido a adição de superplastificante, gira em torno de 0,30. Segundo o $\mathrm{ACl} 363$ (1992) o fator água/materiais cimentantes (a/mc) para concretos de alta resistência, varia de 0,27 a 0,50 .

\subsection{HPC: High Performace Cement (Cimento de Alto Desempenho)}

SOBOLEV (1998) descreve o cimento de alto desempenho como o resultado do avanço na composição do cimento através da mistura mais rigorosa dos componentes do clinker. Sua tecnologia é baseada nos seguintes fatores:

- modificação do cimento Portland através de mistura mais complexa;

- introdução de escória de alto forno granulada na composição do cimento;

- otimização do esquema de mistura.

A composição do HPC, comparada ao cimento Portland comum é apresentada na tabela 2.3. 
Tabela 2.3. Composição química do HPC e do cimento Portland comum (NCP), SOBOLEV (1998) ${ }^{9}$

\begin{tabular}{||l|c|c|c|c|c|c|c|c|c||}
\cline { 2 - 10 } \multicolumn{1}{c|}{} & $\mathrm{SiO}_{2}$ & $\mathrm{Al}_{2} \mathrm{O}_{3}$ & $\mathrm{Fe}_{2} \mathrm{O}_{3}$ & $\mathrm{CaO}$ & $\mathrm{MgO}$ & $\mathrm{K}_{2} \mathrm{O}$ & $\mathrm{Na}_{2} \mathrm{O}$ & $\mathrm{SO}_{3}$ & L.O.I. \\
\hline \hline $\mathrm{NCP}$ & 19,4 & 4,8 & 3,6 & 63,7 & 1,9 & 0,8 & 0,2 & 2,7 & 2,4 \\
\hline $\mathrm{HPC}$ & 34,3 & 7,8 & 2,5 & 43,4 & 5,7 & 1,0 & 0,2 & 2,4 & 1,5 \\
\hline \hline
\end{tabular}

O desenvolvimento da resistência à compressão da pasta de HPC é comparado ao da pasta de cimento Portland comum (figura 2.7), revelando grande acréscimo de resistência principalmente em idades mais avançadas.

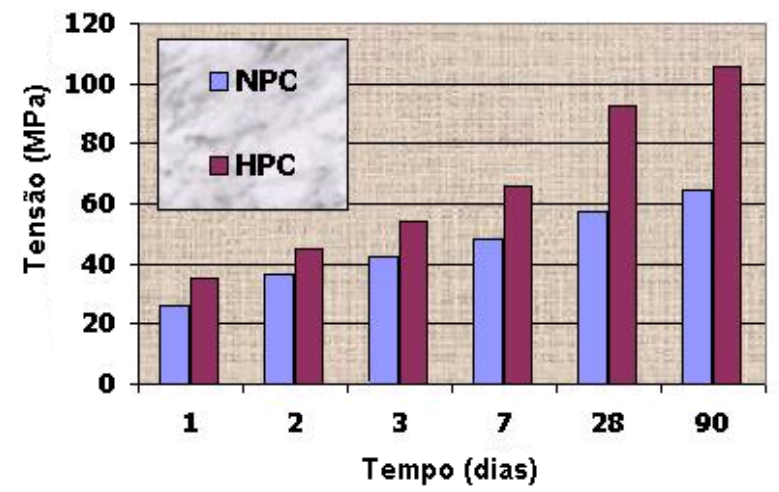

Figura 2.7. Desenvolvimento da resistência do cimento, SOBOLEV (1998)

As principais propriedades do concreto produzido com HPC são:

- elevada fluidez e trabalhabilidade;

- elevada resistência nas primeiras idades - acima de 34MPa com 24h;

- elevada resistência última àcompressão - acima de 145MPa;

- alta resistência àabrasão, alta densidade e rigidez;

- alta resistência a ataques químicos (cloretos, nitratos, ácidos e sulfatos).

\subsection{Procedimentos de dosagem}

Ensaios demonstraram que os aditivos superplastificantes são mais eficientes quando adicionados no final do ciclo de mistura, após todos os ingredientes terem sido introduzidos e completamente misturados.

Para VASCONCELOS e RIBAS SILVA (1997), devido ao elevado número de fatores envolvidos na dosagem dos concretos de alta resistência, como: uso de aditivos superplastificantes, uso de adições minerais, influência da porosidade e da ${ }^{9}$ SOBOLEV (1998), http://homepage.usr.com/s/sobolev/HPCEMENT/127972.shtml 
resistência do agregado graúdo, reduzido fator $\mathrm{a} /(\mathrm{mc})$, entre outros, torna-se inviável a "dosagem manual" para o CAR, tendo, então, desenvolvido software específico, o PROCAD 1.0. Software com a mesma finalidade também foi desenvolvido por DEHUAl et al. (1997).

\subsection{Procedimento de cura}

Segundo o ACI 363 (1992) para concretos com fator água/cimento igual a 0,29 , a resistência obtida aos 28 dias em corpos-de-prova moldados com agregados saturados e curados imersos em água, chega a ser de 5,9MPa a 6,9MPa superior àde amostras feitas com agregados secos e curados em câmara úmida.

PEGLICH e DUCATTI (1997), após ensaios de corpos-de-prova curados de diferentes modos, concluíram que a resistência à compressão evoluiu com a mesma taxa tanto na cura úmida como na cura seca, tendendo a estabilizar-se nas últimas idades.

\subsection{Características Mecânicas do CAR}

Os concretos de alta resistência apresentam particularidades em relação aos concretos de baixa resistência submetidos æ̀s mesmas ações. Isto se deve a fatores como a influência da rigidez do agregado graúdo, menor porosidade e maior resistência da interface pasta-agregado. São apresentadas neste ítem algumas características mecânicas do CAR de interesse à pesquisa, como resistência à compressão e módulo de deformação longitudinal.

\subsubsection{Resistência à compressão}

A resistência à compressão axial é o parâmetro mais comum utilizado na caracterização do concreto. Nos concretos de baixa resistência, para tensões da ordem de $30 \%$ da resistência última, a microfissuração na interface pasta-agregado se mantêm estável, e o diagrama tensão $x$ deformação é aproximadamente linear. Acima deste valor a microfissuração se intensifica, o que se traduz na perda da linearidade do diagrama (trecho curvo). 
Nos concretos de alta resistência a microfissuração é inibida até valores de tensão da ordem de $80 \%$ da tensão de ruptura, devido a maior resistência da interface pasta-agregado. Até este valor, o diagrama tensão $x$ deformação é praticamente linear. Acima deste o diagrama torna-se curvo em conseqüência do progresso da microfissuração. A figura 2.8 traz $o$ aspecto das curvas $\sigma \times \varepsilon$ para concretos de baixa, média e alta resistência.

Para a determinação da resistência à compressão do CAR, são comumente utilizados corpos-de-prova cilíndricos de $100 \mathrm{~mm}$ (diâmetro) x $200 \mathrm{~mm}$ (altura), ao invés dos cilindros de $150 \mathrm{~mm} \times 300 \mathrm{~mm}$. Isto se deve às limitações das máquinas de ensaio. A partir daí são estabelecidas correlações entre as resistências obtidas através destes dois corpos-de-prova.

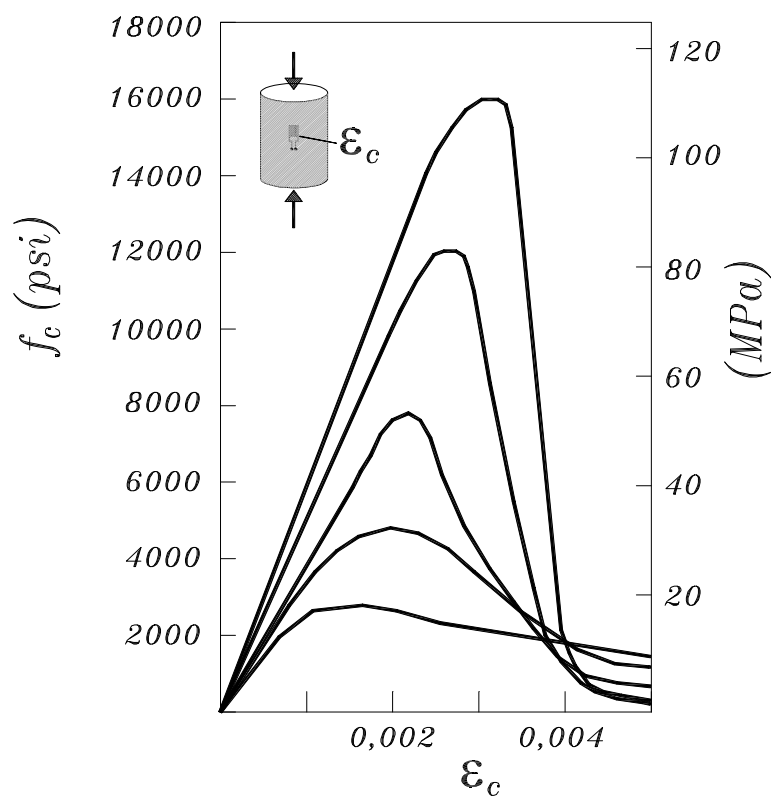

Figura 2.8. Diagramas tensão x deformação, COLLINS et al. (1993)

\subsubsection{Deformação última $\left(\varepsilon_{c u}\right)$}

Verificou-se que as deformações dos concretos de alta resistência, na ruptura por compressão simples diminuem com o acréscimo de resistência do concreto. DINIZ apud LIMA (1997), sugere alguns valores para a deformação última do concreto (tabela 2.4). 
Tabela 2.4. Valores para a deformação última do concreto $\left(\varepsilon_{\text {сu }}\right)$ segundo DINIZ apud LIMA (1997)

\begin{tabular}{||c|c|}
\hline Classe & $\varepsilon_{\text {cu }}(\% \circ)$ \\
\hline C10 a C50 & 3,5 \\
\hline C55 & 2,9 \\
\hline C60 & 2,8 \\
\hline C70 & 2,6 \\
\hline C80 & 2,4 \\
\hline
\end{tabular}

$\mathrm{Na}$ etapa experimental desta pesquisa, na determinação das deformações dos corpos-de-prova cilíndricos, encontrou-se o valor médio de 2,5\% para a deformação última do concreto.

\subsubsection{Ruptura frágil}

Nos concretos de baixa resistência, superfícies de fratura (interface pastaagregado) contornam os agregados. Com a reduzida resistência desta região, a ruptura ocorre aí, sem o comprometimento dos agregados. Nos concretos de alta resistência, as superfícies de fratura cortam as partículas dos agregados, em virtude da elevada resistência da pasta, levando à ruptura do agregado. $O$ fator limitante para a resistência do CAR deixa de ser a resistência da pasta e passa a ser a resistência do agregado graúdo.

Nos concretos de alta resistência a diferença de rigidez entre pasta e agregado graúdo é bem reduzida, o que provoca uma distribuição de tensões interna mais homogênea, resultando em um material com menor ductilidade, isto é, com menor capacidade de redistribuição de tensões.

Em conseqüência da ruptura frágil, o diagrama tensão $x$ deformação completo, incluindo sua parte descendente, só pode ser determinado com o emprego de máquinas de ensaio com velocidade de deformação controlada.

XIE et al. (1995) ensaiaram concretos com resistências médias àcompressão de 60MPa, 90MPa e 120MPa (séries A, B e C, respectivamente). Nos ensaios à compressão axial, 3 modelos para cada resistência foram ensaiados (cilindros de $100 \mathrm{~mm} \times 200 \mathrm{~mm}$ ), mostrando que, com o acréscimo de resistência, o trecho descendente do diagrama tensão $x$ deformação torna-se mais íngreme, sugerindo a perda de ductilidade para concretos de resistência superior (figuras 2.9 a 2.11). 


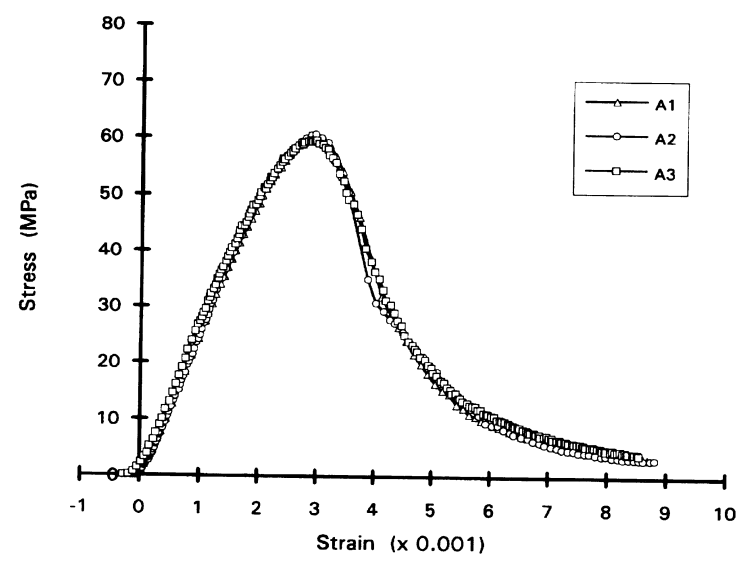

Figura 2.9. Diagrama tensão $x$ deformação para compressão axial (concreto de $60 \mathrm{MPa})$, XIE et al. (1995)

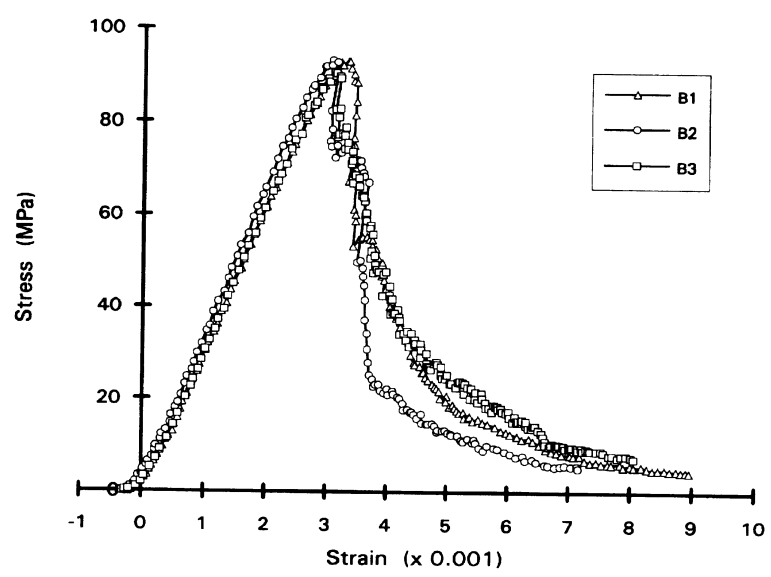

Figura 2.10. Diagrama tensão $x$ deformação para compressão axial (concreto de 90MPa), XIE et al. (1995)

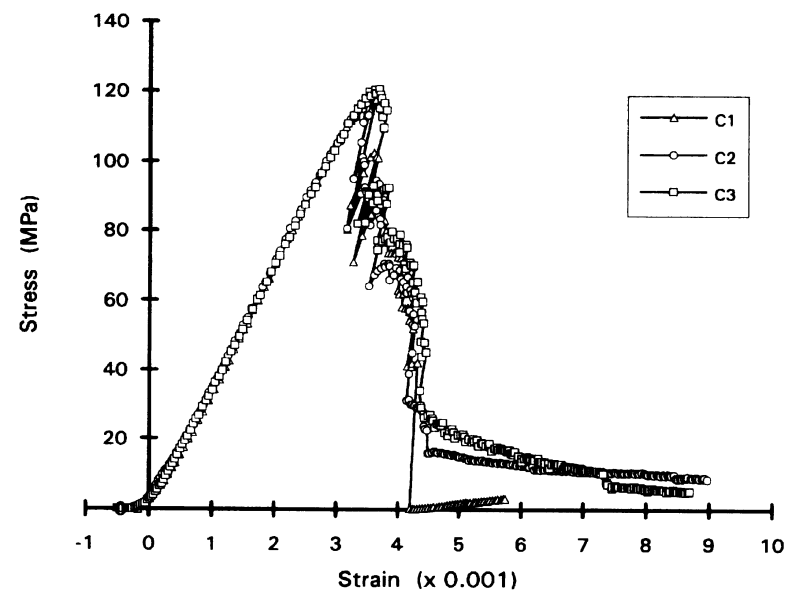

Figura 2.11. Diagrama tensão $x$ deformação para compressão axial (concreto de 120MPa), XIE et al. (1995) 
Em todos os corpos-de-prova rompidos durante a presente pesquisa (concreto com resistência média à compressão de 60MPa), a ruptura do concreto foi frágil, com a formação do "cone de ruptura" característico. Todos os corpos-deprova utilizados na determinação da resistência à compressão do concreto foram cilíndricos, de diâmetro 100mm e altura 200mm.

\subsubsection{Maior resistência a carregamentos de longa duração}

Para concretos de baixa resistência, a perda de resistência devido a carregamento de longa duração é de $25 \%$ do valor obtido em ensaio de carregamento rápido. Para efeito de projeto, este valor está inserido no coeficiente de modificação $\mathrm{k}_{\bmod }=0,85$ do seguinte modo:

$$
\mathrm{k}_{\bmod }=\mathrm{k}_{\bmod , 1} \cdot \mathrm{k}_{\bmod , 2} \cdot \mathrm{k}_{\bmod , \quad 3}=1,2 \cdot 0,95 \cdot 0,75=0,85
$$

O coeficiente $k_{\bmod , 1}=1,2$ leva em conta 0 acréscimo de resistência do concreto após os 28 dias de idade. $O$ coeficiente $k_{m o d, 2}=0,95$ considera 0 erro cometido com o uso de corpos-de-prova cilíndricos de $150 \mathrm{~mm} \times 300 \mathrm{~mm}$, devido ao atrito entre o corpo-de-prova e os pratos da prensa durante o ensaio. O coeficiente $\mathrm{k}_{\text {mod,3 }}=0,75$ traduz a perda de resistência do concreto pela ação de forças de longa duração.

Nos concretos de alta resistência, a redução da resistência devido a carregamento mantido é da ordem de $20 \%$, adotando-se portanto $k_{\text {mod, } 3}=0,80$.

Nos ensaios com concreto de alta resistência existe a tendência de utilização de corpos-de-prova cilíndricos de $100 \mathrm{~mm}$ x $200 \mathrm{~mm}$ em lugar do corpo-de-prova padrão (cilindro de $150 \mathrm{~mm} \times 300 \mathrm{~mm}$ ) devido às limitações das máquinas. A relação entre as resistências obtidas nos cilindros de $100 \mathrm{~mm} \times 200 \mathrm{~mm}$ e aquelas obtidas com corpo-de-prova padrão é 0,9, afirmam CARRASQUILLO et al. (1981). Desta forma $\mathrm{k}_{\mathrm{mod}, 2}=0,95 \times 0,9=0,855$.

Quanto ao ganho de resistência com o tempo sabe-se que, para os concretos de alta resistência, este crescimento é menor quando comparado ao acréscimo de resistência em concretos de baixa resistência (figura 2.12). Isto se deve, provavelmente, a menor quantidade de água livre que permitiria o prosseguimento da hidratação, combinada com a limitação da capacidade do agregado. Com isso o valor de $\mathbf{k}_{\mathrm{mod}, 1}$ é reduzido de 1,2 para 1. 


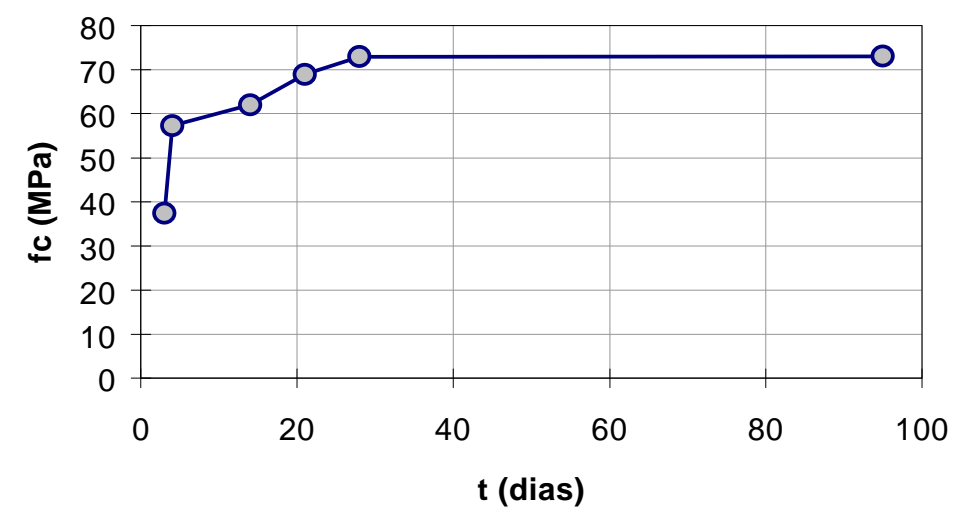

Figura 2.12. Acréscimo da resistência com a idade, PINTO JÚNIOR (1992)

Com as considerações anteriores obtêm-se um novo valor para $\mathbf{k}_{\bmod }$ :

$$
\mathrm{k}=\mathrm{k}_{\bmod , 1} \cdot \mathrm{k}_{\bmod , 2} \cdot \mathrm{k}_{\bmod , 3} 3=0,80 \cdot 0,855 \cdot 1=0,684 \cong 0,7
$$

\subsubsection{Módulo de deformação longitudinal}

O módulo de deformação longitudinal do CAR é maior que o apresentado pelos concretos de baixa resistência; isto se deve àmaior resistência à compressão e maior rigidez da pasta e da interface pasta-agregado graúdo e, ainda, ao retardamento da microfissuração interna apresentado pelos concretos de alta resistência.

Para a obtenção do Módulo de Deformação Longitudinal foram rompidos três corpos-de-prova, instrumentados com extensômetros elétricos, a fim de se obter a curva tensão $x$ deformação em seu trecho ascendente. A figura 2.13 mostra um dos corpos-de-prova ensaiados. O resultado dos ensaios é mostrado no gráfico da figura 2.15.

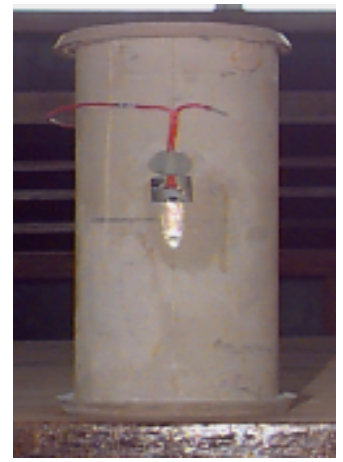

Figura 2.13. Detalhe da instrumentação dos corpos-de-prova usados para a determinação do módulo de elasticidade do concreto 
Os ensaios dos corpos-de-prova foram realizados no Laboratório de Estruturas da EESC-USP, na máquina hidráulica para ensaios, com capacidade nominal de $2000 \mathrm{kN}$, marca ELE (figura 2.14).

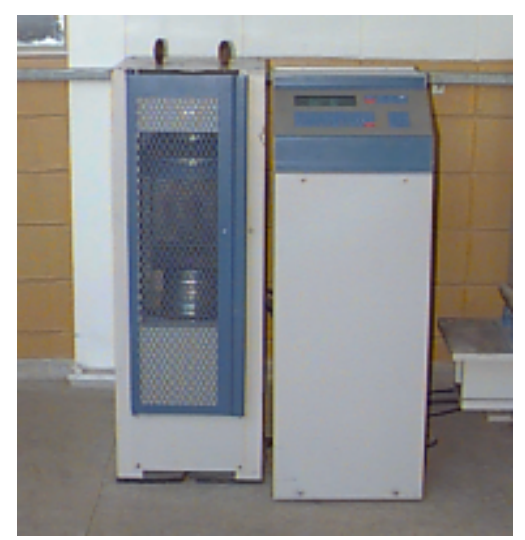

Figura 2.14. Máquina de ensaio dos corpos-de-prova
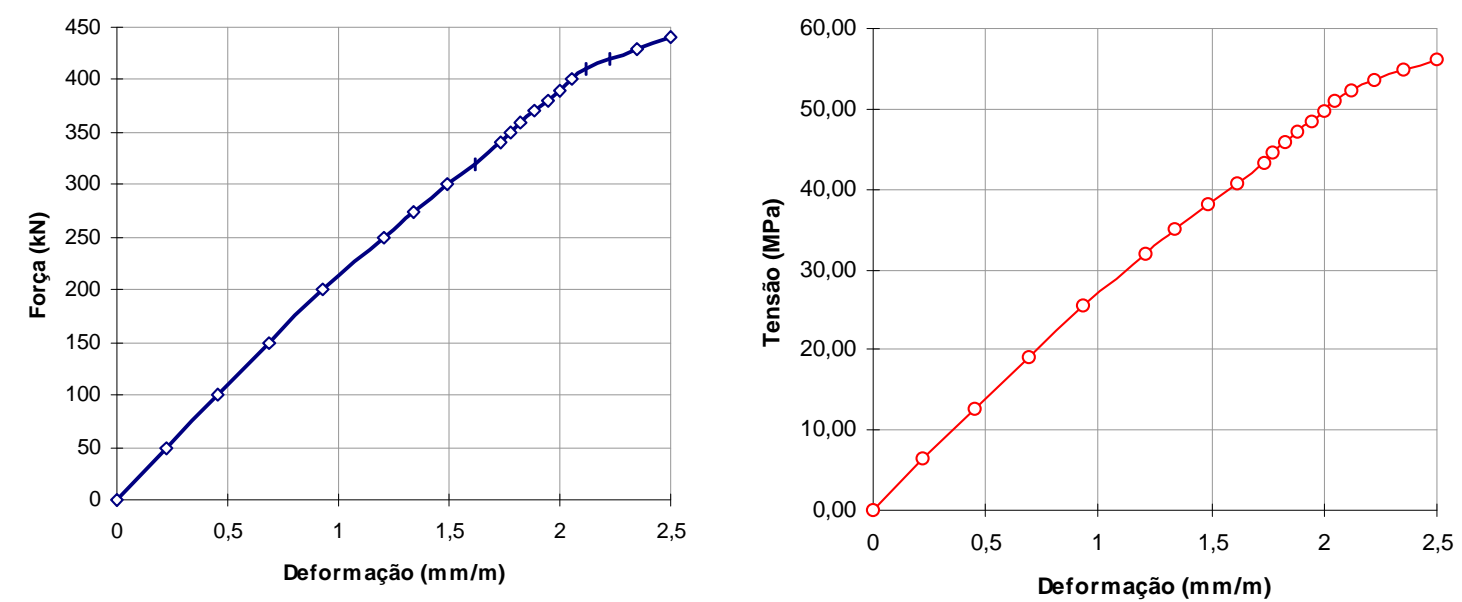

Figura 2.15. Diagrama força $x$ deformação e tensão $x$ deformação obtido dos ensaios dos corpos-de-prova

O valor do módulo de deformação longitudinal (secante) segundo a NBR 6118 (1978) é dado como o correspondente à inclinação da reta definida pela origem da curva tensão $x$ deformação e o ponto correspondente a $0,4 \mathrm{f}_{\mathrm{cu}}$, onde $\mathrm{f}_{\mathrm{cu}}$ é a resistência máxima do concreto.

Do gráfico obtemos: $\mathrm{f}_{\mathrm{cu}}=56 \mathrm{MPa} ; 0,4 \mathrm{f}_{\mathrm{cu}}=22,4 \mathrm{MPa}$. Como o gráfico é praticamente linear até $0,8 \%$ da tensão última, tem-se $\mathrm{E}_{\mathrm{c}} \approx 27300 \mathrm{MPa}$. 


\subsubsection{Prescrições normativas}

2.12.6.1. CEB/FIP Model Code MC90 (1990)

O módulo de elasticidade $\left(E_{c}\right)$ é calculado por:

$E_{c}=10^{4} \cdot\left[f_{c m}\right]^{1 / 3}=10^{4} \cdot\left[f_{c k}+8\right]^{1 / 3}$, onde:

$\mathrm{E}_{\mathrm{c}}$ - módulo de elasticidade do concreto aos 28 dias;

$\mathrm{f}_{\mathrm{ck}}$ - resistência característica do concreto àcompressão aos 28 dias;

$\mathrm{f}_{\mathrm{cm}}$ - resistência média àcompressão aos 28 dias.

Diagrama tensão $x$ deformação:

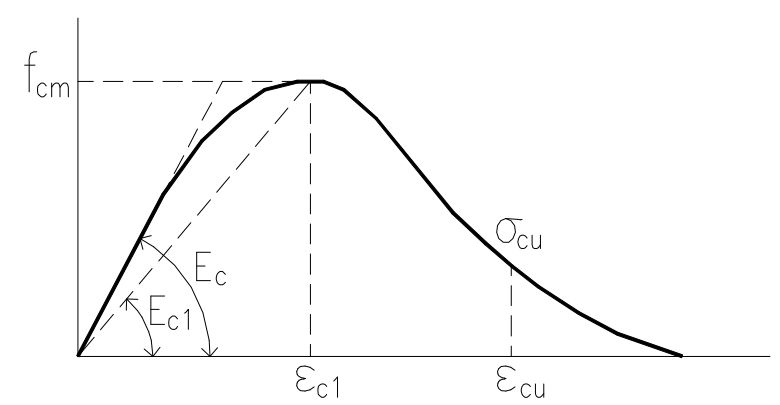

Figura 2.16. Diagrama tensão $x$ deformação segundo o CEB/FIP M90

2.12.6.2. Código Norueguês - NS 34731989 (1989)

O Módulo de Elasticidade é calculado pela fórmula:

$E_{c}=9500 \cdot f_{c k}^{0,3}$

O diagrama tensão $x$ deformação é mostrado na figura 2.17 .

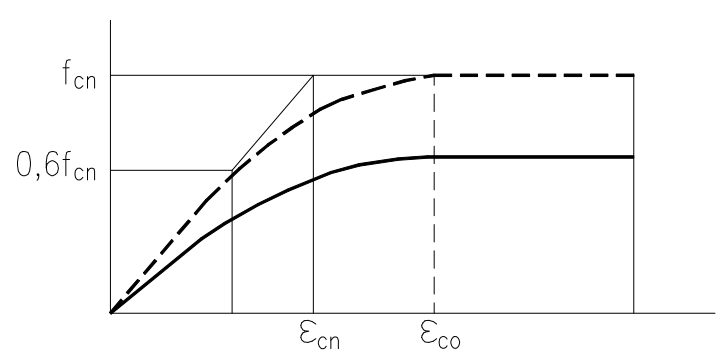

Figura 2.17. Diagrama tensão x deformação segundo o NS3473 
2.12.6.3. Código Finlandês - Rak MK B4 1983/84 (1984)

O módulo de elasticidade para classes de concreto com $\mathrm{f}_{\mathrm{ck}}>60 \mathrm{MPa}$ é considerado constante e igual a $\mathrm{E}_{\mathrm{c}}=38700 \mathrm{MPa}$.

O diagrama tensão $x$ deformação é mostrado na figura 2.18 .

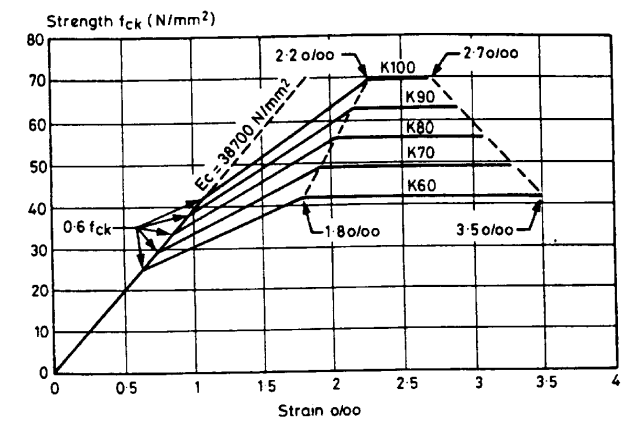

Figura 2.18. Diagrama tensão $x$ deformação segundo o Rak MK B4

2.12.6.4. US Code ACI 363 (1994)

O módulo de elasticidade é calculado pela fórmula:

$$
\mathrm{E}_{\mathrm{c}}=3320 \cdot \sqrt{\mathrm{f}_{\mathrm{ck}}}+6900 \quad(\mathrm{MPa})
$$

Diagrama tensão $x$ deformação (figura 2.19):

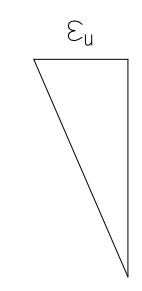

Deformações

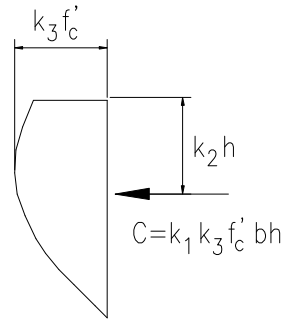

Diagrama de Tensões e Parâmetros

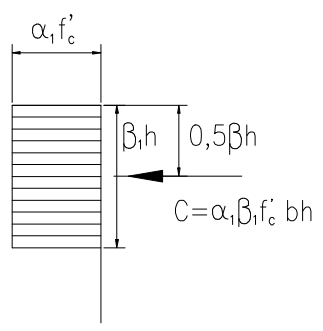

Diagrama Retangular do $\mathrm{ACl}$

Figura 2.19. Diagrama tensão x deformação segundo o ACI - 363 (1994)

\subsubsection{Outras recomendações}

IBRAHIM e MAcGREGOR (1997) sugerem que o diagrama retangular proposto pelo $\mathrm{ACl}$ pode ser usado para projeto em CAD, adotando o valor limite de $3 \%$ para a deformação e modificando os parâmetros $\alpha_{1}$ e $\beta_{1}$ como segue:

$$
\alpha_{1}=0,85-\frac{f_{c}}{800} \geq 0,725 \quad f_{c} \text { em MPa }
$$




$$
\beta_{1}=0,95-\frac{f_{c}}{400} \geq 0,70 \quad \quad f_{c} \text { em } \mathrm{MPa}
$$

CHIN et al. (1997), através de diversos ensaios com concreto de alta resistência não confinado, confinado com estribos laterais e concreto com fibras, sugerem expressões para os trechos ascendentes e descendentes da curva tensão $x$ deformação:

Trecho ascendente:

$$
\sigma_{\mathrm{c}}=\sigma_{\mathrm{co}} \cdot\left\{\frac{\beta \cdot\left(\frac{\varepsilon_{\mathrm{c}}}{\varepsilon_{\mathrm{co}}}\right)}{\beta-1+\left(\frac{\varepsilon_{\mathrm{c}}}{\varepsilon_{\mathrm{co}}}\right)}\right\}
$$

Trecho descendente:

$$
\sigma_{c}=\sigma_{c o} \cdot\left\{\frac{k_{1} \cdot \beta \cdot\left(\frac{\varepsilon_{c}}{\varepsilon_{c o}}\right)}{k_{1} \cdot \beta-1+\left(\frac{\varepsilon_{c}}{\varepsilon_{c o}}\right)^{k_{2} \cdot \beta}}\right\}
$$

onde:

$$
\beta=\frac{1}{1-\frac{\sigma_{\mathrm{co}}}{\varepsilon_{\mathrm{co}} \cdot \mathrm{E}_{\mathrm{ct}}}}
$$

$\sigma_{\mathrm{c}}$ e $\varepsilon_{\mathrm{c}}$ - tensão e deformação do concreto;

$\sigma_{\mathrm{co}}$ e $\varepsilon_{\mathrm{co}}$ - tensão e deformação no ponto de tensão máxima;

$\mathrm{E}_{\mathrm{ct}}$ - módulo de elasticidade tangente na origem;

$k_{1}$ e $k_{2}$ - fatores de correção, obtidos experimentalmente para diferentes tipos de concreto confinado e não confinado.

As equações mostraram boa adequação com os resultados experimentais (figura 2.20). 


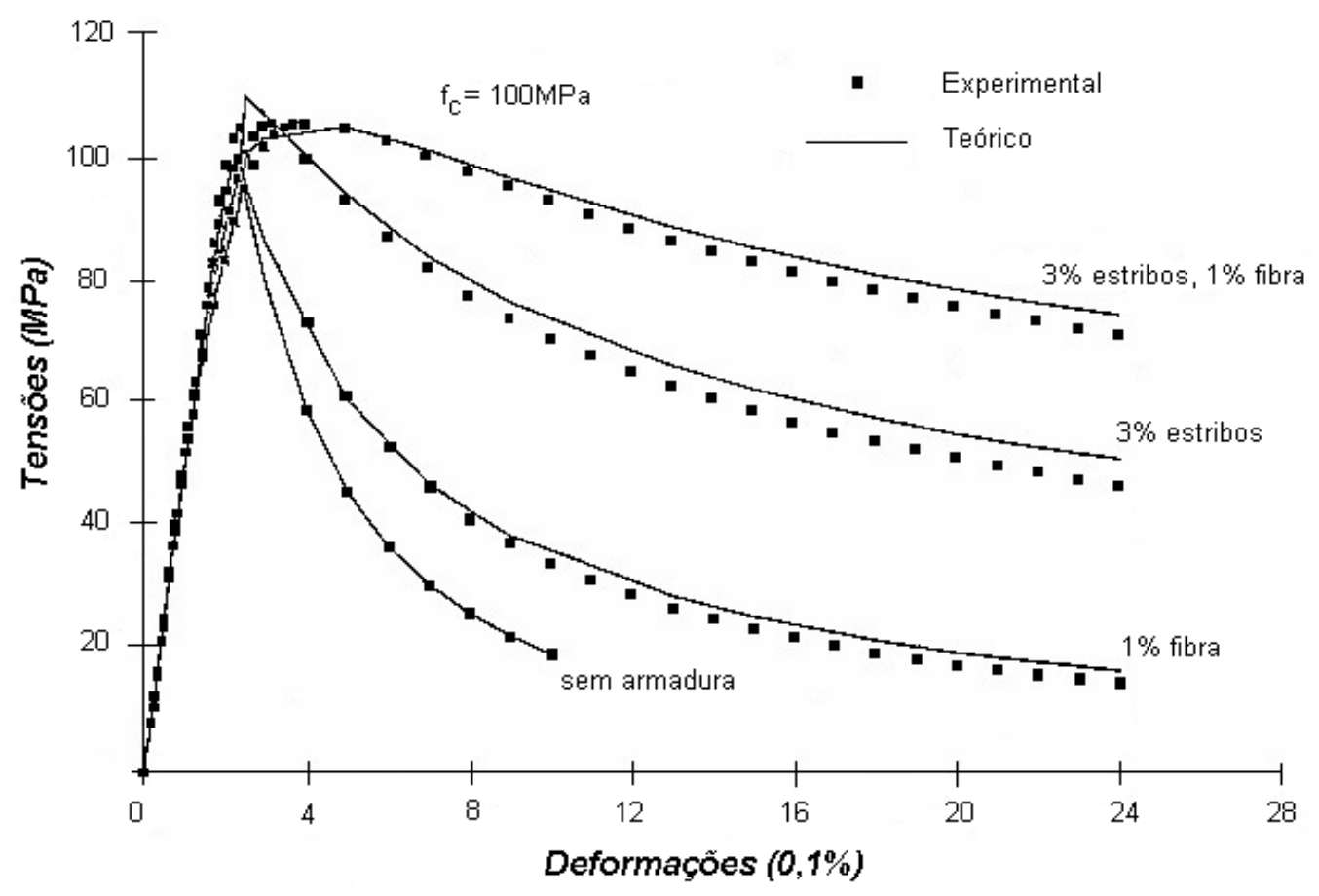

Figura 2.20. Resultados obtidos por MANSUR e WEE ${ }^{10}$

2.12.8. COLLINS et al. (1993)

Indicam a expressão a seguir para o trecho ascendente do diagrama tensão $x$ deformação:

$$
\frac{f_{c}}{f_{c}^{\prime}}=\frac{\varepsilon_{c}}{\varepsilon_{c}^{\prime}} \cdot \frac{n}{n-1+\left(\frac{\varepsilon_{c}}{\varepsilon_{c}^{\prime}}\right)^{n}}
$$

onde:

$\mathrm{f}_{\mathrm{c}}$ - tensão de compressão;

$\mathrm{f}_{\mathrm{c}}{ }_{\mathrm{C}}$ - tensão máxima;

$\varepsilon_{\mathrm{c}}$ - deformação de compressão;

$\varepsilon^{\prime}{ }_{c}$ - deformação máxima;

$\mathrm{n}$ - fator de adequação da curva. 


\subsubsection{LIMA (1997)}

LIMA (1997) propôs uma relação para o trecho ascendente do diagrama tensão $x$ deformação baseando-se em resultados de ensaios com deformação controlada de corpos-de-prova cilíndricos de $100 \mathrm{~mm} \times 200 \mathrm{~mm}$. A aproximação do modelo aos valores experimentais forneceu uma função polinomial de $3^{\circ}$ grau apresentada a seguir:

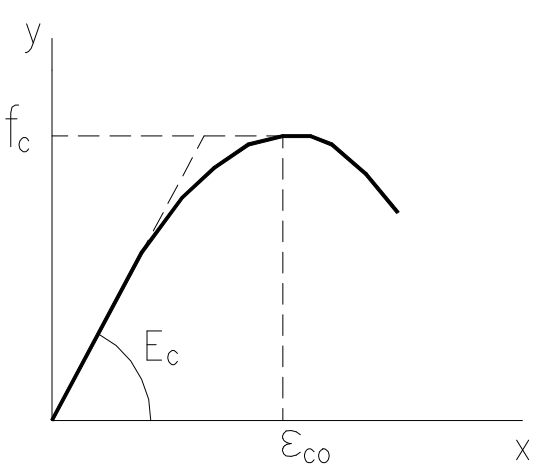

Figura 4.21. Aproximação para o diagrama tensão x deformação experimental, LIMA (1997)

A relação tensão $x$ deformação pode ser expressa como mostra a equação (trecho ascendente):

$$
\sigma_{\mathrm{c}}=\frac{\left(-2 \mathrm{f}_{\mathrm{c}}+\mathrm{E}_{\mathrm{c}} \cdot \varepsilon_{\mathrm{co}}\right)}{\varepsilon_{\mathrm{co}}^{3}} \cdot \varepsilon_{\mathrm{c}}^{3}+\frac{\left(3 \mathrm{f}_{\mathrm{c}}-2 \mathrm{E}_{\mathrm{c}} \cdot \varepsilon_{\mathrm{co}}\right)}{\varepsilon_{\mathrm{co}}^{2}} \cdot \varepsilon_{\mathrm{c}}^{2}+\mathrm{E}_{\mathrm{c}} \cdot \varepsilon_{\mathrm{c}}
$$

\subsection{Considerações finais}

Neste breve ensaio sobre o Concreto de Alta Resistência pode-se constatar que este se apresenta como um material com amplas possibilidades para a Engenharia Civil, sendo a tendência de sua utilização praticamente irreversível. $O$ surgimento do CAR abriu novas fronteiras para o concreto estrutural, antes particamente insuperáveis ao concreto de baixa resistência.

O estudo das características mecânicas do Concreto de Alta Resistência mostrou também que ainda não existe uniformidade, pela maioria das normas e recomendações, quanto ao comportamento do material. A situação atual aponta para a necessidade de um maior número de pesquisas sobre o CAR. 


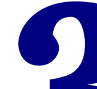 Análise teórica de pilares de CAR}

\subsection{Histórico da pesquisa}

Como visto no capítulo anterior, uma das aplicações mais difundidas do concreto de alta resistência está em pilares de edifícios altos. Por esta razão o comportamento de pilares de CAR tem sido exaustivamente estudado em universidades de diversos países do mundo, em anos recentes.

No Brasil, pesquisas com pilares de CAR foram desenvolvidas por AGOSTINI (1992), realizando estudo experimental de pilares de seção quadrada submetidos à compressão simples, e PAIVA (1995), que estudou pilares de seção retangular também sujeitos à compressão simples. No âmbito da EESC-USP já foram realizados, e estão em andamento, diversos trabalhos experimentais com elementos moldados com concreto de alta resistência. Dentre eles citam-se o estudo de pilares de concreto de alta resistência submetidos àcompressão simples e à flexo-compressão, realizado por GIONGO, LIMA e TAKEYA (1997), realizado com projeto de Auxílio à Pesquisa, processo FAPESP número 95/2458-4, que possibilitou a tese de LIMA (1997), e a análise de pilares de concreto de alta resistência reforçados com fibras, desenvolvido por GIONGO, GUIMARÃES e TAKEYA (1997), realizado com projeto de Auxílio à Pesquisa, processo FAPESP número 97/00932-6. Em ambas as pesquisas, os modelos foram ensaiados no pórtico de reação do Laboratório de Estruturas (figura 3.32). BACCIN (1998) 
realizou estudo teórico sobre pilares de CAR, com ênfase ao dimensionamento de pilares usuais de edifícios.

As pesquisas experimentais indicaram a formação do núcleo resistente de concreto, definido geometricamente pelas armaduras longitudinais e transversais. Nos ensaios realizados por PAIVA (1995) foram avaliados pilares de seção retangular com dimensões de $80 \mathrm{~mm}$ x 100mm x 480mm (altura). Nos pilares moldados com concreto de baixa resistência as deformações médias dos pilares tanto para armados como para os não armados são coincidentes na fase elástica, ou seja, toda a seção transversal participa como seção resistente, inclusive a parte relativa ao cobrimento da armadura nas peças armadas.

Nos pilares de CAR, PAIVA (1995) verificou que além de ter ocorrido ruptura brusca, as deformações médias dos pilares armados, na fase elástica, eram maiores que as deformações médias dos pilares não armados. Tal fato levou à conclusão que, independente da forma da seção transversal do pilar, as armaduras (barras longitudinais e estribos) definem um núcleo resistente de concreto e que, para evitar ruptura brusca, seria necessário dispor armadura transversal com seção e espaçamento adequados. PAIVA (1995) concluiu que, para taxas de armadura transversal de 2,20\% e armadura longitudinal de 3,20\%, a ruptura era dúctil, verificando-se a formação do núcleo de concreto.

CLAESON et al. (1996) observaram que, para pilares de CAR, a área de concreto efetivamente confinada pela armadura é menor do que a área normal do núcleo limitada pelo perímetro dos estribos e varia em função da configuração e espaçamento da armadura transversal. A forma do núcleo é, aproximadamente, a da figura 3.1.

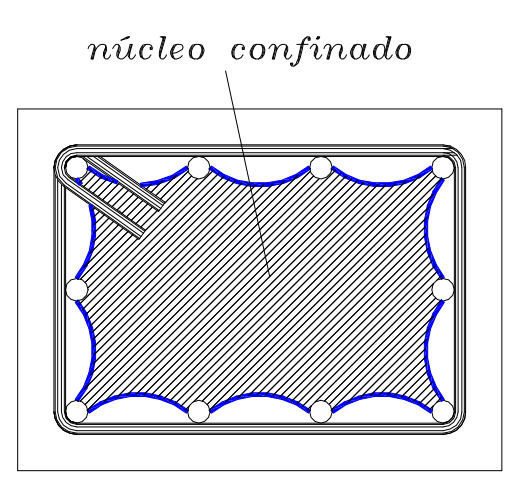

Figura 3.1. Forma aproximada do núcleo resistente de concreto 
O comportamento de pilares de CAR submetidos à compressão simples pode ser descrito através do diagrama da figura 3.2, e apresenta as seguintes particularidades, quando comparado ao de pilares de concreto de baixa resistência, como, por exemplo, 20MPa:

- maior módulo de elasticidade e linearidade do trecho ascendente do diagrama força $x$ deformação;

- ruptura frágil, exigindo grandes taxas de armadura transversal para se obter ductilidade;

- ruptura prematura do cobrimento;

- apresentam menores incrementos de resistência quando comparados a pilares de concreto de baixa resistência, AL-HUSSAINI et al. (1993).

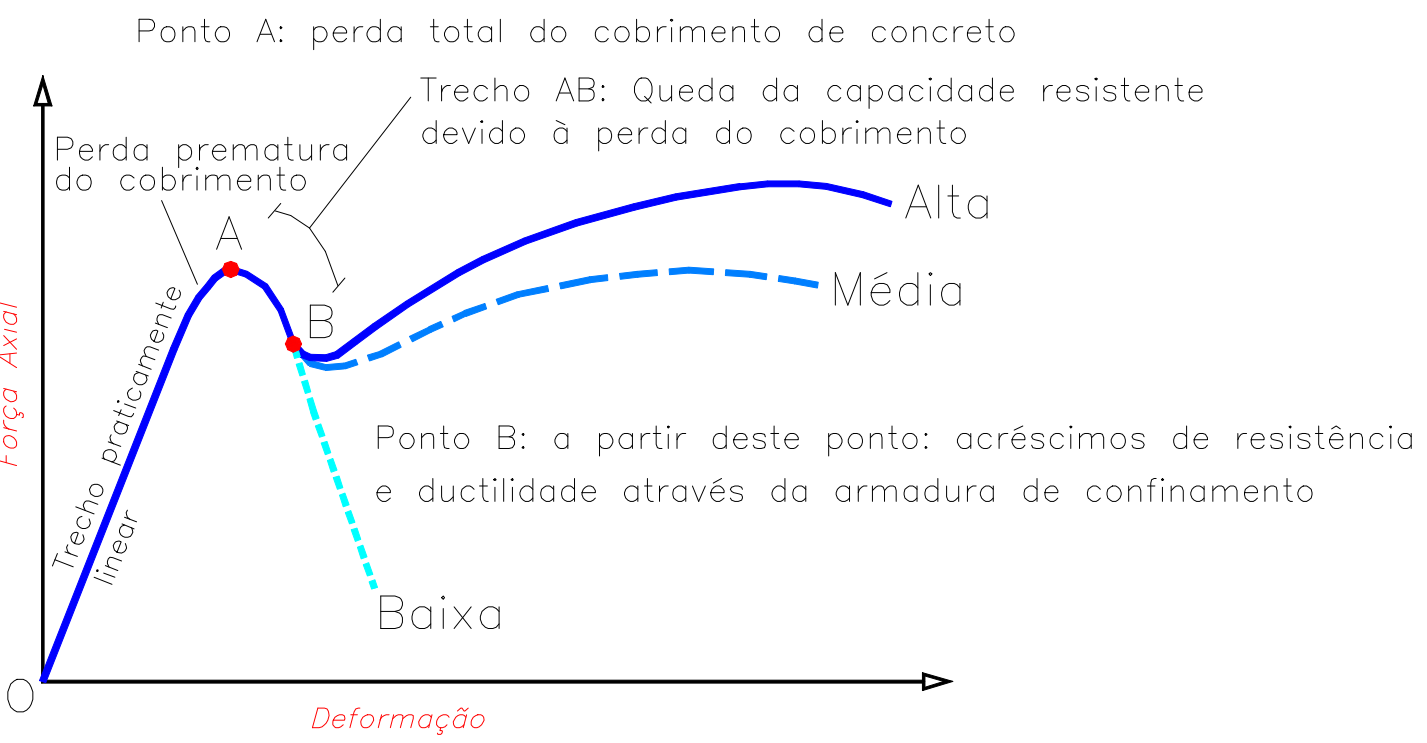

Figura 3.2. Diagrama força $x$ deformação para pilares de CAR

O trecho OA do diagrama é praticamente linear, tornando-se curvo a partir do início da ruptura do cobrimento. No ponto $A$ do diagrama todo cobrimento já se encontra destacado do núcleo definido pelas armaduras longitudinais e transversais. Percebe-se, então, queda na resistência do pilar até o ponto $B$. Segundo CUSSON e PAULTRE (1992), o decréscimo de resistência no trecho AB variou de $10 \%$ a $15 \%$ do valor máximo da força em $A$. A partir daí podem se distinguir três comportamentos distintos para o elemento estrutural, determinados pela eficiência da armadura transversal: 
- baixa eficiência: caracteriza a ruptura frágil. A armadura transversal não é suficiente para promover acréscimos à resistência do concreto do núcleo; a armadura transversal não atinge a resistência de escoamento $f_{y}$;

- média eficiência: a armadura transversal atinge o patamar de escoamento, propiciando pressões de confinamento no núcleo, figura 3.3. O pilar ganha ductilidade;

- alta eficiência: substanciais acréscimos de resistência são obtidos, podendo o pilar atingir forças superiores à correspondente ao ponto $\mathrm{A}$ do diagrama.

Concreto em estado triaxial de tensões (acréscimos de resistência)
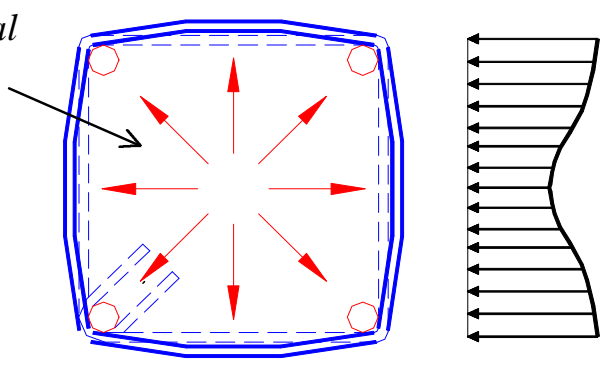

Pressão lateral de confinamento oriunda da resistência da armadura à expansão lateral do concreto - Efeito Poisson

Figura 3.3. Pressões laterais de confinamento

CUSSON e PAULTRE (1994) avaliaram, para diferentes resistências do concreto, o efeito das seguintes variáveis no comportamento de pilares de CAR submetidos àcompressão simples:

- resistência à compressão do concreto;

- resistência de escoamento das barras dos estribos;

- configuração dos estribos;

- quantidade de armadura transversal;

- espaçamento entre estribos;

- quantidade de armadura longitudinal.

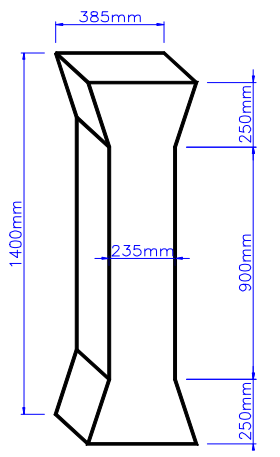

Figura 3.4. Modelos utilizados por CUSSON e

PAULTRE (1994)

Ao todo foram moldados 27 pilares de CAR com resistência à compressão variando de $60 \mathrm{MPa}$ a $120 \mathrm{MPa}$. As dimensões dos modelos são apresentadas na figura 3.4. Das observações de CUSSON e PAULTRE (1994) enumeram-se as seguintes:

(a) pressão de confinamento diretamente proporcional à quantidade de armadura transversal; 
(b) menor expansão lateral do CAR em relação ao concreto de baixa resistência, o que se traduz em menor eficiência do confinamento. Os acréscimos de resistência em pilares com eficiente armadura de confinamento foram maiores em pilares de CRN do que em pilares de CAR. Ganhos de resistência de $50 \%$ e $100 \%$ a mais do que o concreto não confinado, foram observados para os modelos bem confinados moldados com concreto de 100MPa e 50MPa, respectivamente;

(c) ductilidade do concreto inversamente proporcional à resistência. Acréscimos em ductilidade de 10 e 20 vezes foram observados em modelos bem confinados de CAR de 100MPa e 50MPa, respectivamente;

(d) a importância da configuração adotada para a armadura transversal na determinação da área de concreto efetivamente confinada, figura 3.5. Uma configuração de estribos, como a da figura 3.5(b) pode prover acréscimos substanciais de resistência e ductilidade ao pilar;

(e) o menor espaçamento entre estribos garante maior área para a seção crítica do núcleo efetivamente confinado e reduz o risco de flambagem localizada das barras da armadura longitudinal. A seção crítica do núcleo, situada à meia distância entre estribos sucessivos, tem sua área definida em função do espaçamento adotado (figura 3.6).

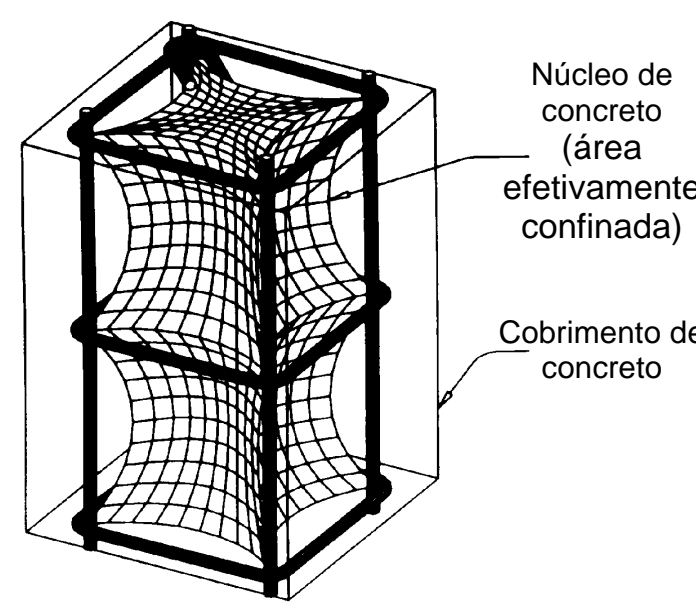

(a)

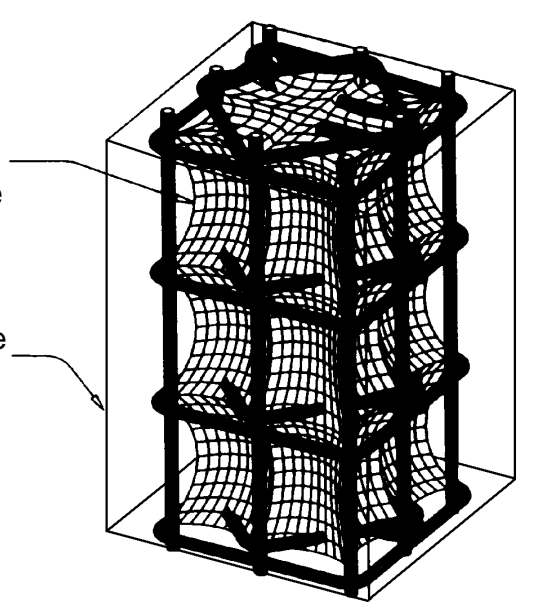

(b)

Figura 3.5. Efeito da configuração e espaçamento da armadura transversal sobre o confinamento do núcleo: (a) Configuração de estribos com grande espaçamento; (b) Configuração de estribos mais eficiente, com pequeno espaçamento, CUSSON e PAULTRE (1994) 


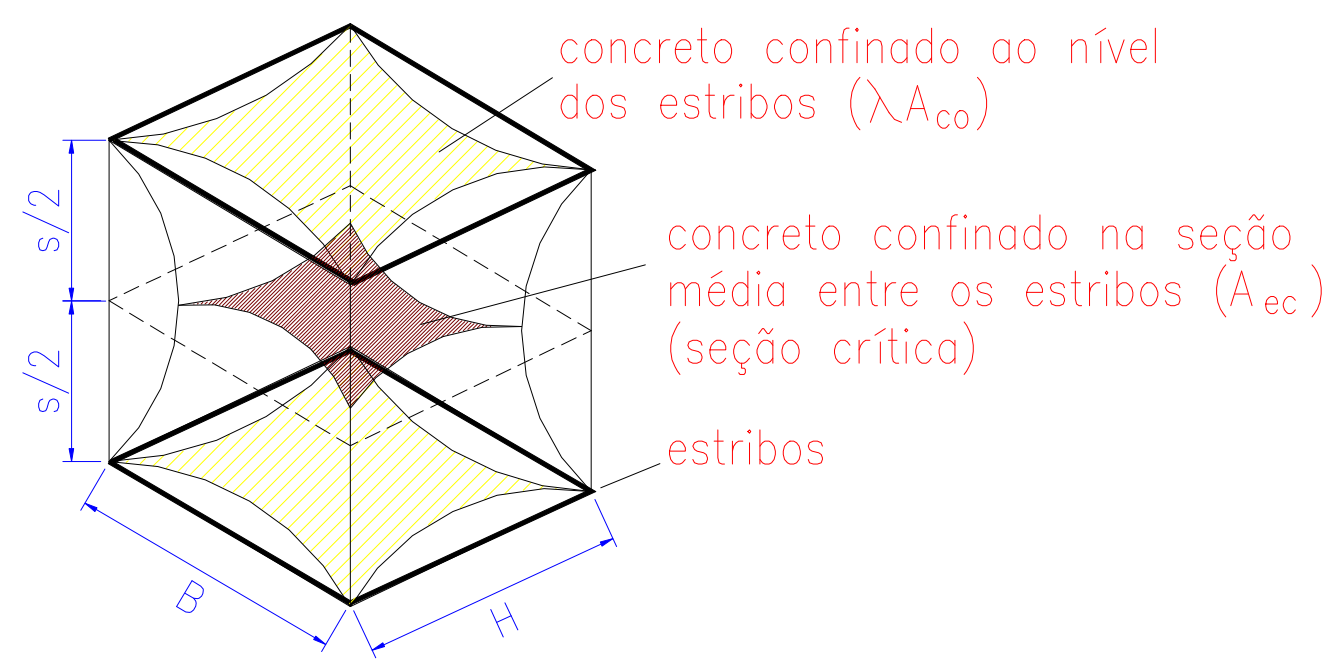

Figura 3.6. Efeito do espaçamento entre estribos para a definição da área de concreto efetivamente confinada, seção crítica, $A_{e c}$, SHEIKH e UZUMERI (1982)

CUSSON e PAULTRE (1992) concluíram que, para o cálculo da seção resistente de pilares moldados em CAR, o cobrimento pode ser desprezado e apenas a área do núcleo definida pela linha-de-centro dos estribos mais externos pode ser considerada para a contribuição na resistência axial total. O cobrimento, nestes casos, figura apenas como proteção física da armadura contra a corrosão e o fogo.

Quanto à perda prematura do cobrimento, CUSSON e PAULTRE (1993) sugerem a seguinte explicação: a baixa permeabilidade do CAD possibilita que apenas o concreto de cobrimento possa secar-se, enquanto o núcleo permanece úmido. Em conseqüência disto, tensões de tração se desenvolvem no cobrimento devido a retração em torno do núcleo impermeável, figura 3.7(a). Além disso, devido à tendência da armadura de impedir a retração do concreto, formam-se fissuras axiais em torno das barras da armadura longitudinal, figura 3.7(b). A soma destes efeitos contribui para o aspecto final da seção, figura 3.7(c), e conseqüênte perda do cobrimento. 

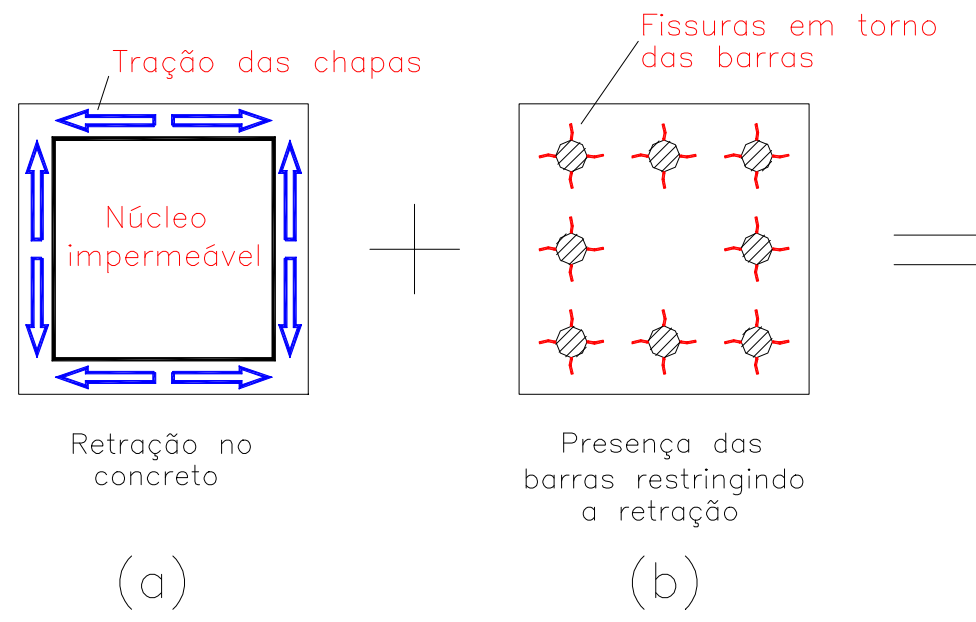

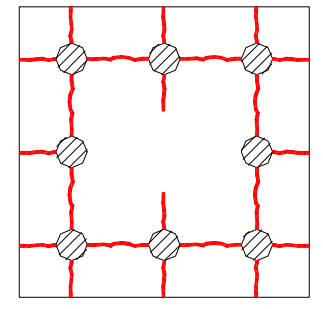

Resultante da propagação das fissuras e destacamento do cobrimento de concreto

Figura 3.7. Causas da ruptura do cobrimento, CUSSON e PAULTRE (1993)

Segundo PAULTRE et al. (1996) a separação prematura do cobrimento em colunas de CAR agravou-se quando concreto de resistência elevada - 100MPa ou mais - foi utilizado. Uma armadura densa e encurtamentos diferenciados criaram planos de falha entre o núcleo de concreto e o cobrimento. Como mostrado na figura 3.8, sob elevada força axial, a "chapa" de concreto sofreu flambagem. Dependendo da resistência do concreto e da inércia das cascas formadas pelo cobrimento, a força de flambagem das chapas era alcançada antes da força teórica de esmagamento das mesmas, dada por $0,85 \mathrm{f}_{\mathrm{c}}{ }^{\prime}$, como proposto pelo código $\mathrm{ACl}$ 318 (1990).

Ainda segundo PAULTRE et al. (1996), considerando-se o cobrimento como uma chapa de espessura $t$ e comprimento $L$ e ambas as extremidades fixas (engastadas), a equação de Euler fornece a seguinte tensão crítica de flambagem:

$$
\sigma_{\mathrm{cr}}=\frac{\pi^{2} \mathrm{E}}{3\left(1-v^{2}\right)}\left(\frac{\mathrm{t}}{\mathrm{L}}\right)^{2} \text {, onde: }
$$

E - módulo de elasticidade;

$v$ - coeficiente de Poisson do concreto;

$\mathrm{t}$ - espessura da chapa;

L - comprimento da chapa. Portanto, a tensão máxima que pode ser suportada pelo cobrimento é limitada superiormente pelos valores $0,85 f_{\mathrm{c}}$ ' ou $\sigma_{\mathrm{cr}}$. 

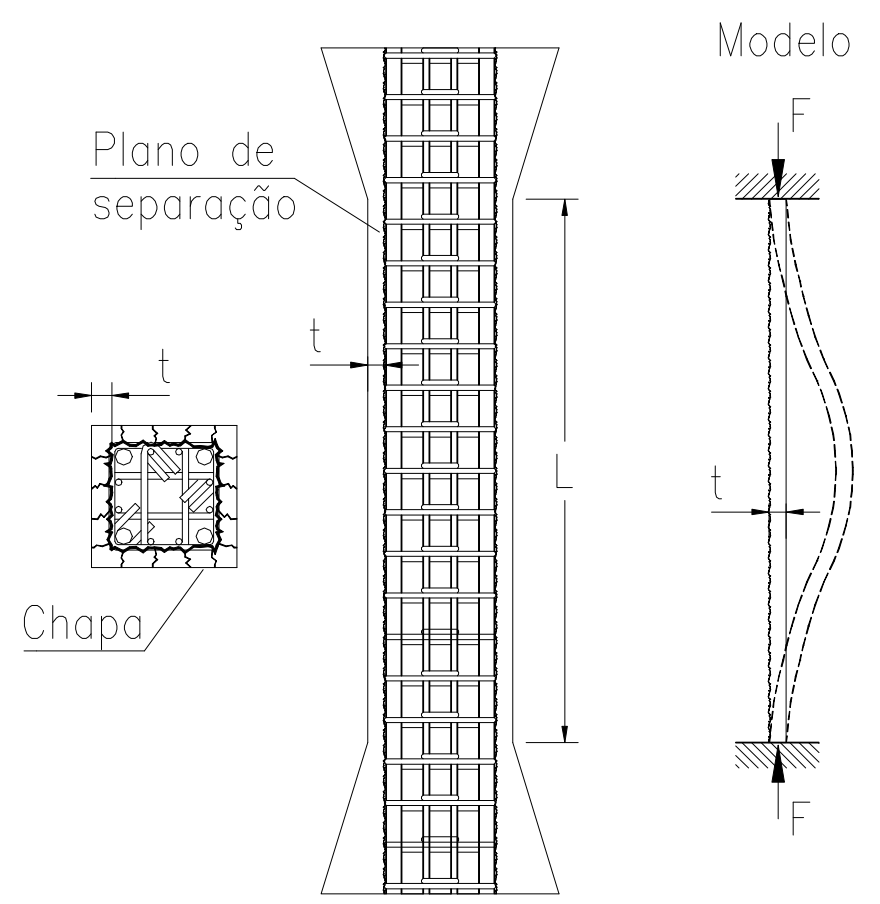

Figura 3.8. Separação do cobrimento, PAULTRE et al. (1996)

Dos ensaios conduzidos por CLAESON et al. (1996), verificou-se que:

a. Para pilares curtos executados com concreto de baixa resistência, o cobrimento separava-se do núcleo definido pela armadura, porém de forma lenta, gradual, obtendo-se um significativo trecho descendente da curva força aplicada $x$ deslocamento (figura 3.9).

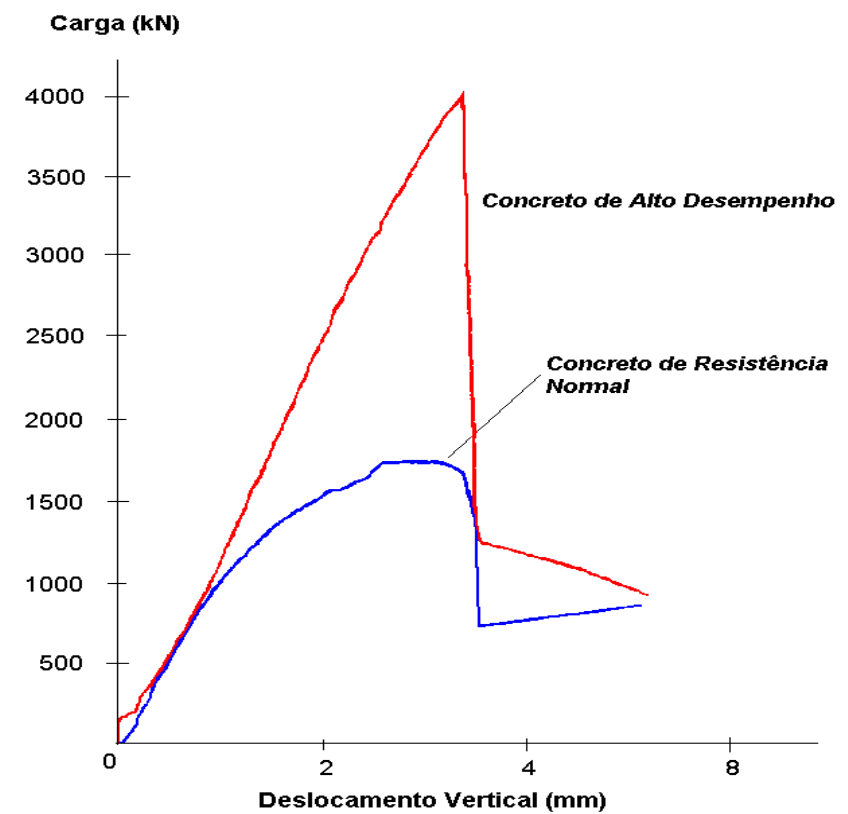

Figura 3.9. Diagrama força $x$ deslocamento para CAR e CRN, CLAESON et al. (1996) 
b. Para pilares curtos de $C A R$, a ruptura se deu de forma inesperada e com desagregação do concreto. Altas tensões de compressão na região do cobrimento, conduziram-na à flambagem. Os estribos que estavam presentes entre o núcleo e o cobrimento formaram um plano natural de separação. Isto conduziu à perda completa da capacidade do cobrimento. A redução da resistência ocorreu quando o confinamento do núcleo não foi suficiente para compensar a instabilidade do cobrimento. Nos dois pilares ensaiados os estribos estavam espaçados de $10 \mathrm{~mm}$ e $18 \mathrm{~mm}$;

c. No caso de pilares com suficiente armadura de confinamento, as armaduras induziram a tensões de compressão no núcleo, oriundas da deformação lateral (transversal) do concreto (efeito Poisson). Quando o pilar foi submetido a força axial, o cobrimento não estava "confinado" e tornou-se área inefetiva após atingir sua resistência à compressão. Entretanto, o núcleo de concreto continuou conduzindo tensões sob elevada deformação, revelando, portanto, maior ductilidade;

d. O uso da armadura de confinamento aumenta a ductilidade e a capacidade resistente dos pilares. A relevância deste aumento depende da quantidade, diâmetro e configuração da armadura, do tamanho e forma dos elementos ensaiados, da resistência do concreto e do modo de ruína.

Quanto àforma de ruptura de pilares de CAR observou-se que:

- Nos modelos "bem confinados" (suficiente taxa de armadura transversal), ocorreu ruptura dos estribos situados no terço médio da altura do pilar, CUSSON e PAULTRE (1992);

- Nos modelos com insuficiente taxa de armadura transversal ocorreu flambagem localizada das barras da armadura longitudinal, CUSSON e PAULTRE (1992), RANGAN e LLOYD (1994), figura 3.10; 


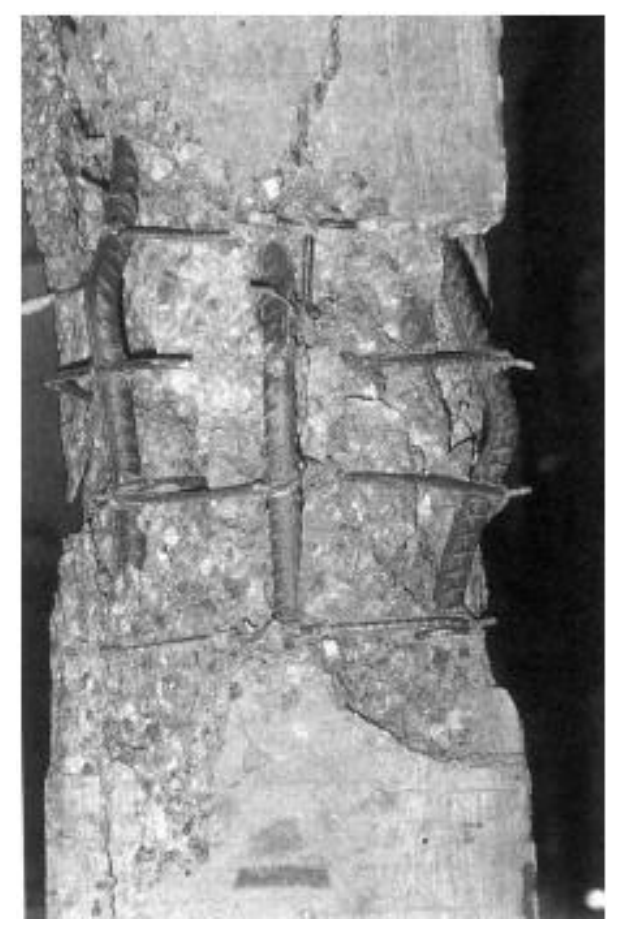

Figura 3.10. Flambagem das barras da armadura longitudinal, RANGAN e LLOYD (1994)

- Formaração de superfícies de cisalhamento dividindo o núcleo em duas cunhas. A inclinação da superfície de cisalhamento com o plano vertical $(\theta)$ variou de $25^{\circ}$ para modelos com baixo confinamento, até $45^{\circ}$, para modelos com alto confinamento, CUSSON e PAULTRE (1992).

- Para se evitar ruptura localizada por efeito de ponta das barras da armadura longitudinal, especial atenção é dada ao detalhamento das extremidades dos modelos. Diferentes esquemas de proteção já foram utilizados, como:

- o "encamisamento" das extremidades por placas metálicas, RANGAN e LLOYD (1994), (figura 3.11);

- maior concentração de armadura transversal (armadura de fretagem), nas extremidades, LIMA (1997), QUEIROGA e GIONGO (1998), (figura 3.12);

- através do alargamento da seção transversal nas extremidades dos modelos, SHEIKH e UZUMERI (1980), CUSSON e PAULTRE (1994), figura 3.13 . 


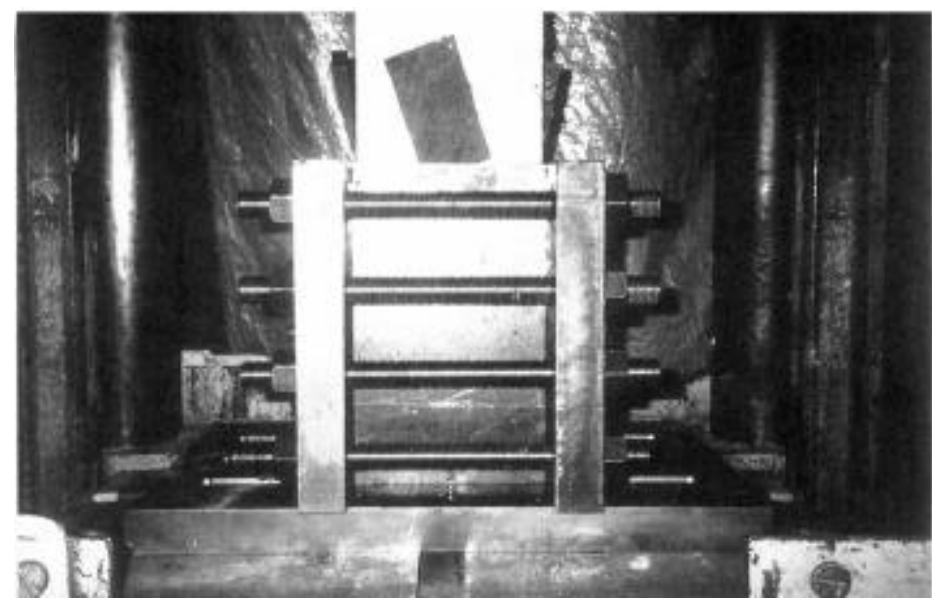

Figura 3.11. Esquema de proteção da extremidades dos modelos, RANGAN e LLOYD (1994)

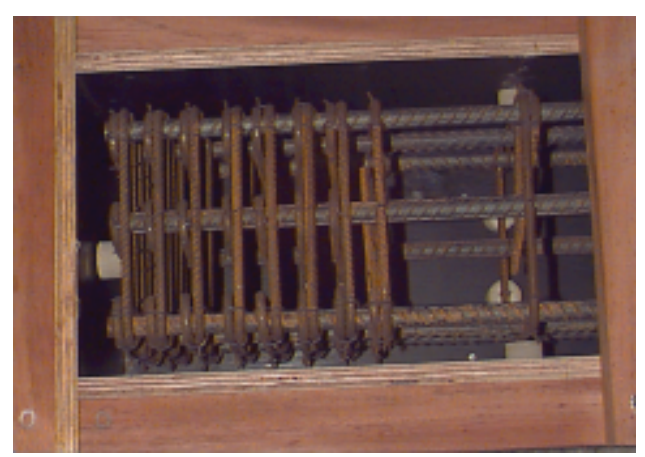

Figura 3.12. Detalhe da armadura de fretagem, QUEIROGA e GIONGO (1998)

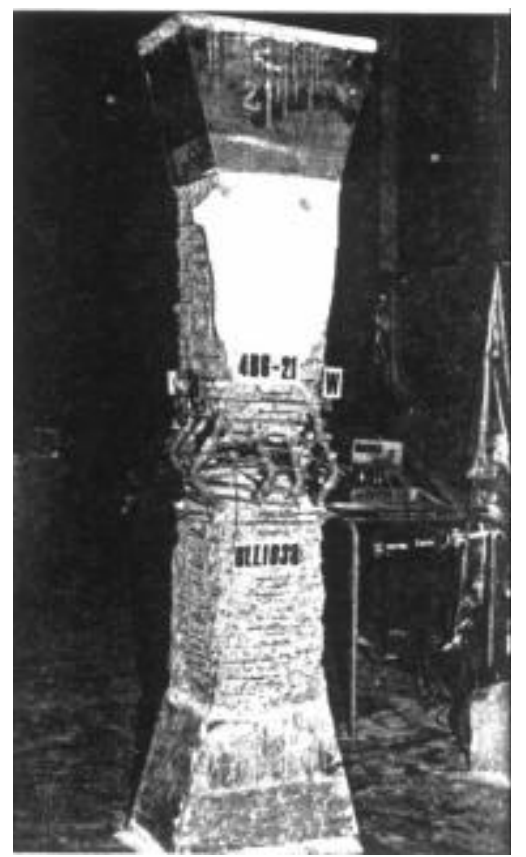

Figura 3.13. Esquema de proteção da extremidades dos modelos através do alargamento da seção, SHEIKH e UZUMERI (1980) 


\subsection{Modelos Teóricos para confinamento e diagrama tensão $x$}

\section{deformação}

O estudo do confinamento em pilares não é recente. As mais antigas referências encontradas pelo autor datam de 1946 (KING), figura 3.14, e BRESLER e GILBERT (1961) figura 3.15.

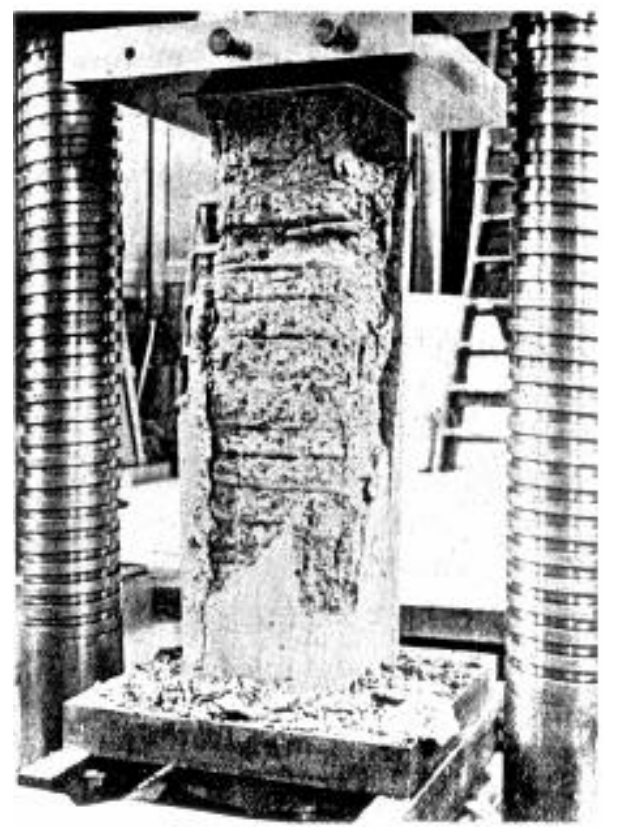

Figura 3.14. Ensaio realizado por KING (1946)

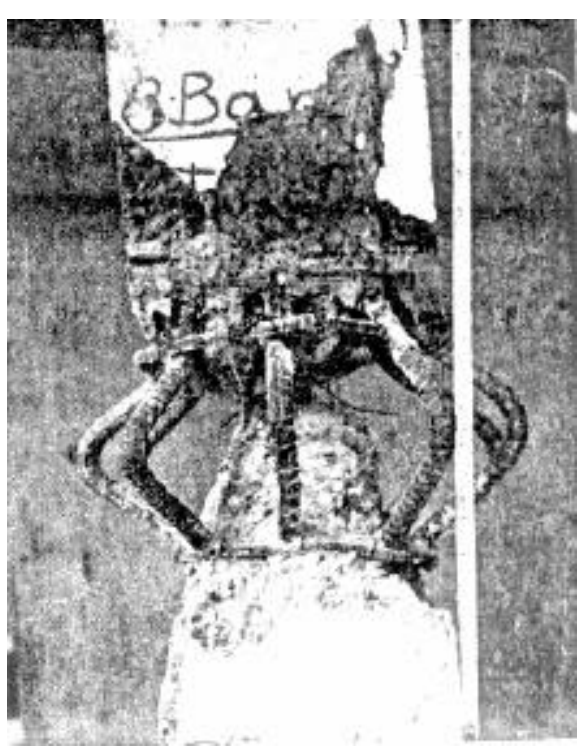

Figura 3.15. Detalhe da flambagem das barras da armadura longitudinal em ensaio realizado por BRESLER e GILBERT (1961) 
São mencionados aqui alguns modelos para confinamento e diagrama tensão $x$ deformação para pilares de concreto com armadura lateral. Estas sugestões, frutos da revisão bibliográfica sobre o assunto, se baseiam em ensaios conduzidos tanto com concretos de resistência usual, SHEIKH e UZUMERI (1982), MANDER et al. (1988), como com Concretos de Alta Resistência, COLLINS et al. (1993), CUSSON e PAULTRE (1994), KÖNIG e SIMSCH (1996), LIMA (1997).

\subsubsection{Modelos para confinamento}

\subsubsection{Concreto de baixa resistência}

\section{a. SHEIKH e UZUMERI (1982)}

A área efetivamente confinada de concreto é determinada pelo espaçamento entre estribos, pela distribuição da armadura longitudinal ao redor do perímetro do núcleo e pela configuração resultante da armadura transversal. Uma melhor distribuição da armadura longitudinal e um pequeno espaçamento entre estribos resulta em substanciais acréscimos de resistência e ductilidade do núcleo de concreto. O ganho de resistência devido ao confinamento pode ser expresso em função de algumas variáveis, como mostra a equação a seguir:

$$
f_{c c}=f_{c p}+f\left(\rho_{s}, s, f_{s}^{\prime}, \lambda, \eta\right) \text {, onde: }
$$

$\mathrm{f}_{\mathrm{cc}}$ - resistência àcompressão do concreto confinado;

$\mathrm{f}_{\mathrm{cp}}$ - resistência àcompressão do concreto não confinado;

$\rho_{\mathrm{s}}$ - razão entre o volume total da armadura lateral e o volume do núcleo;

$s$ - espaçamento entre estribos;

$f^{\prime}$ - tensão na armadura lateral;

$\lambda$ - fator que estima a configuração da seção e a distribuição das barras longitudinais ao redor do perímetro do núcleo;

$\eta$ - representa o efeito das dimensões da seção.

A pressão de confinamento, no caso de armadura transversal compostra por estribos, não é aplicada uniformemente em toda a extensão do volume do núcleo. Para altas deformações, quando o cobrimento destaca-se do núcleo, uma porção deste também começa a ser menos efetiva na resistência àforça aplicada.

A área de concreto não confinada pode ser estimada como mostrado na figura 3.16. Neste modelo é assumido que a separação entre o concreto efetivamente confinado e o concreto não confinado é na forma de uma série de arcos entre as 
barras da armadura longitudinal. $\mathrm{O}$ arco pode ser localizado entre um triângulo e uma parábola, com ângulo inicial da tangente à curva com a horizontal, $\theta$. A área sob a curva é $\frac{\mathrm{c}^{2}}{6} \cdot \cot \theta$, para uma parábola, e $\frac{\mathrm{c}^{2}}{4} \cdot \cot \theta$ para um triângulo, em que c é a distância entre os eixos das barras da armadura longitudinal.

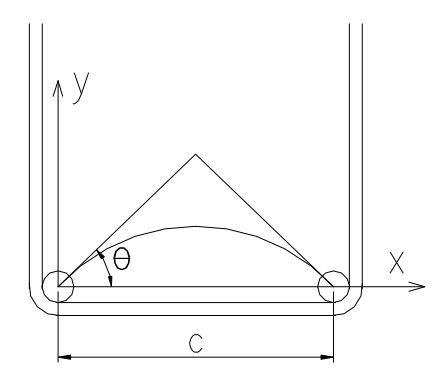

Figura 3.16. Estimativa da área não confinada de concreto, SHEIKH e UZUMERI (1982)

A área de concreto efetivamente confinada ao nível dos estribos pode ser escrita como:

$A_{c o}-\sum_{i=1}^{n} \frac{c_{i}^{2}}{\alpha}$, onde:

$A_{c o}$ - área do núcleo definida pelas linhas de centro dos ramos dos estribos;

$\mathrm{n}$ - número de arcos;

c - distância entre os eixos das barras da armadura longitudinal.

Se o fator $\lambda$ é definido como a razão entre a área efetivamente confinada de concreto e a área do núcleo ao nível dos estribos, tem-se:

$$
\lambda=1-\frac{\sum_{i=1}^{n} c_{i}^{2}}{\alpha \cdot A_{c o}}
$$

A área não confinada do núcleo é mostrada na figura 3.17 (corte vertical). A curva é assumida como uma parábola. 


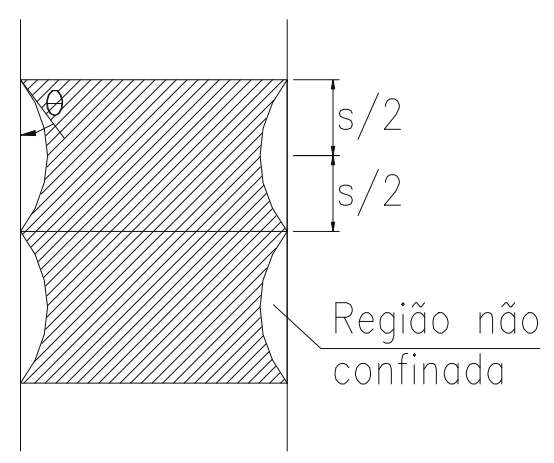

Figura 3.17. Região não confinada entre níveis da armadura transversal, SHEIKH e UZUMERI (1982)

A forma exata desta curva não é muito significativa neste caso. A resistência do pilar é definida pela seção de menor área que está na posição média entre dois estribos sucessivos. Visto que a região confinada de concreto é uma superfície em três dimensões (figura 3.6), fica difícil determinar a área exata de concreto efetivamente confinada da seção crítica, particularmente quando os perfis das curvas são desconhecidos. SHEIKH e UZUMERI (1982) sugerem uma metodologia de cálculo para a área da seção crítica (figura 3.6):

- Área do núcleo $=\mathrm{A}_{\mathrm{co}}=\mathrm{B} \cdot \mathrm{H}$

- Área de concreto efetivamente confinada no nível dos estribos $=\lambda \cdot A_{c o}$

- Desprezando-se a redução de $\mathrm{A}_{c o}$ no nível dos estribos, a área do núcleo de concreto efetivamente confinada na seção média entre dois estribos $=\left(B-2 y_{m}\right)\left(H-2 y_{m}\right)$

- Área resultante de concreto efetivamente confinada como seção crítica $A_{e c}=\lambda\left(B-2 y_{m}\right)\left(H-2 y_{m}\right)$

onde $\mathrm{B}$ e $\mathrm{H}$ são as distâncias de centro-a-centro do eixo dos estribos do núcleo; $y_{m}$ é o máximo valor de $y$, na distância média entre dois estribos consecutivos, $y_{m}=0,25 \cdot s \cdot \tan \theta$ (ver figura 3.6 e 3.17)

$A$ área de concreto efetivamente confinada, $A_{c e}$, pode ser relacionada àárea do núcleo através da seguinte relação:

$$
A_{c e}=\lambda \cdot(B-0,5 \cdot \mathrm{s} \cdot \tan \theta) \cdot(H-0,5 \cdot \mathrm{s} \cdot \tan \theta)=\lambda^{*} A_{c o}
$$


$O$ valor de $\theta$ é determinado experimentalmente. $O$ termo $\lambda^{*}$ pode ser definido como a razão entre a área da seção crítica $\left(A_{c e}\right)$ e a área do núcleo $\left(A_{c o}\right)$. Enquanto $\lambda$ considera apenas o efeito da configuração dos estribos, $\lambda^{*}$ leva em conta o efeito combinado da configuração e do espaçamento entre estribos (figura 3.18). O efeito destas variáveis é mostrado na figura 3.18 para pilares de seção quadrada. Fica evidente que, quando o espaçamento entre estribos é duas vezes a dimensão do núcleo (B), o confinamento não é efetivo no acréscimo de resistência do concreto.

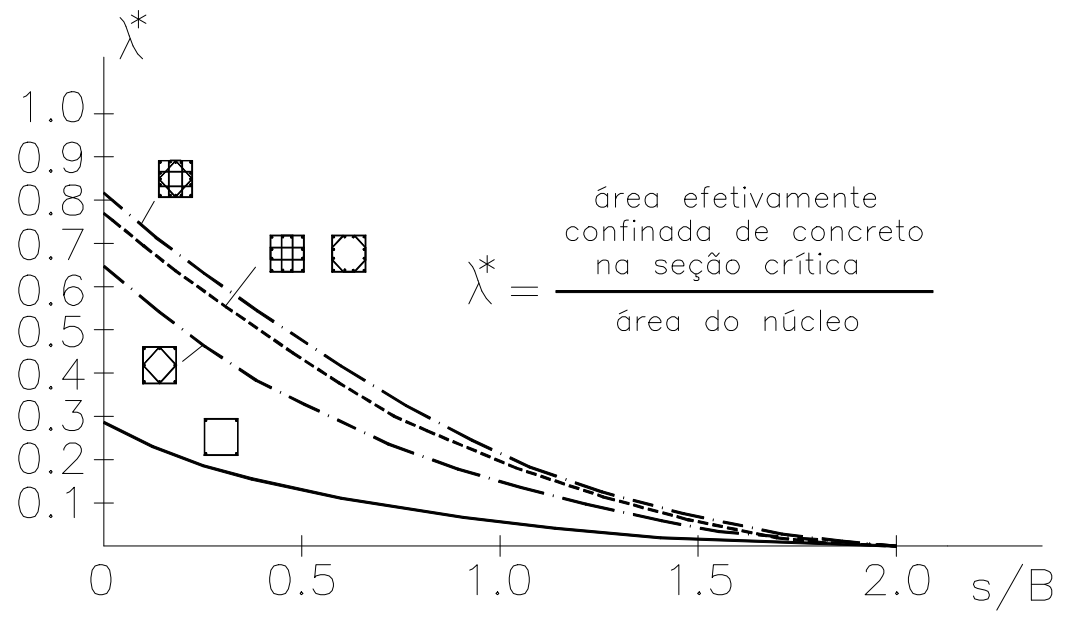

Figura 3.18. Coeficiente $\lambda^{*}$ em função do espaçamento entre estribos e da dimensão do núcleo para várias configurações de estribos em pilares de seção quadrada, SHEIKH e UZUMERI (1982)

b. MANDER et al. (1988)

O modelo proposto por MANDER et al. (1988) assume que a pressão de confinamento exercida pela armadura transversal distribui-se em forma de arcos como mostrado na figura 3.19. Na seção média entre dois níveis sucessivos de armadura transversal, a área de concreto efetivamente confinada atingirá seu valor mínimo, tornando-se, então, a seção crítica. 

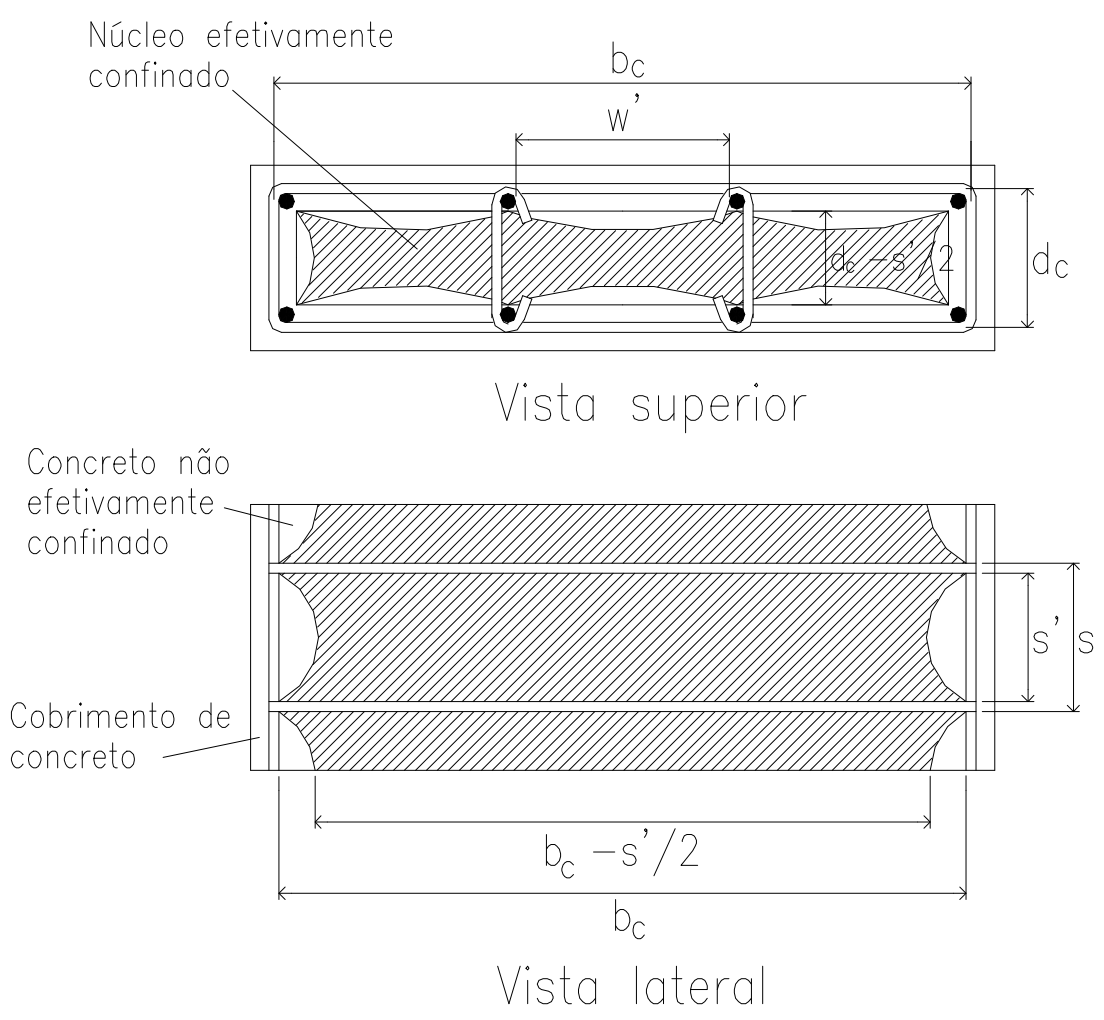

Figura 3.19. Núcleo efetivamente confinado de concreto para armadura transversal composta por estribos, MANDER et al. (1988)

Quando a relação tensão $x$ deformação é utilizada para calcular a resistência e ductilidade de pilares, se adota, por conveniência, que a área do concreto confinado é corresponde àsituada no interior do perímetro definido pelas linhas de centro dos estribos ou espirais $\left(A_{c c}\right)$. Devido ao fato de $A_{e}<A_{c c}$, é considerado que a compressão lateral causada pelo confinamento é igual a:

$f_{1}^{\prime}=f_{l} \cdot k_{e}$

onde:

$f_{l}$ é a compressão lateral causada pela armadura lateral, assumida como uniformemente distribuída através de toda a superfície do núcleo;

$\mathrm{k}_{\mathrm{e}}=\frac{\mathrm{A}_{\mathrm{e}}}{\mathrm{A}_{\mathrm{cc}}}$, coeficiente de confinamento;

$A_{e}$ - área do núcleo efetivamente confinada;

$A_{c c}=A_{c} \cdot\left(1-\rho_{c c}\right)$;

$\rho_{\mathrm{cc}}$ - razão entre a área da armadura longitudinal e a área da seção do núcleo; 
$A_{c}$ é a área do núcleo definida pelas linhas de centro do perímetro da armadura transversal.

Sendo $w_{i}^{\prime}$ a distância entre as barras da armadura longitudinal e $\mathrm{n}$ o número de barras (ver figura 3.19), a área não confinada de concreto, ao nível dos estribos, pode ser obtida pela expressão:

$$
A_{i}=\sum_{i=1}^{n} \frac{\left(w_{i}\right)^{2}}{6}
$$

Incorporando a este termo a influência da área não efetiva ao confinamento mostrada da vista lateral (figura 3.19), a área efetivamente confinada de concreto na distância média entre dois estribos sucessivos será:

$$
A_{c}=\left(b_{c} d_{c}-\sum_{i=1}^{n} \frac{\left(w_{i}\right)^{6}}{6}\right) \cdot\left(1-\frac{s^{\prime}}{2 \cdot b_{c}}\right) \cdot\left(1-\frac{s^{\prime}}{2 \cdot d_{c}}\right)
$$

onde $b_{c}$ e $d_{c}$ são as dimensões das linhas de centro do perímetro dos estribos. Neste caso o coeficiente de confinamento é dado por:

$$
\mathrm{k}_{\mathrm{e}}=\frac{\left(1-\sum_{\mathrm{i}=1}^{\mathrm{n}} \frac{\left(\mathrm{w}_{\mathrm{i}}\right)^{6}}{6}\right) \cdot\left(1-\frac{\mathrm{s}^{\prime}}{2 \cdot \mathrm{b}_{\mathrm{c}}}\right) \cdot\left(1-\frac{\mathrm{s}^{\prime}}{2 \cdot \mathrm{d}_{\mathrm{c}}}\right)}{\left(1-\rho_{\mathrm{cc}}\right)}
$$

A tensão de compressão do concreto confinado $\left(\mathrm{f}_{\mathrm{cc}}{ }^{\prime}\right)$ pode ser obtida através do ábaco a seguir (figura 3.20):

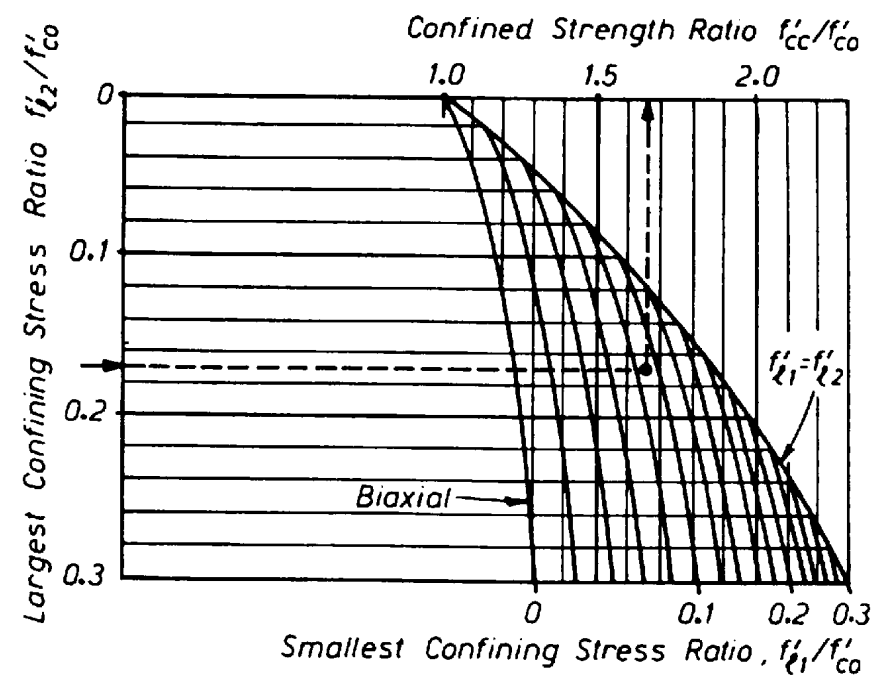

Figura 3.20. Determinação da resistência de confinamento para tensões laterais de confinamento em pilares de seção retangular, MANDER et al. (1988) 


\subsubsection{Concreto de Alta Resistência}

a. KÖNIG e SIMSCH (1996)

Adotam modelos semelhantes para a consideração da área efetiva de confinamento do concreto em pilares de seção retangular (figura 3.21).
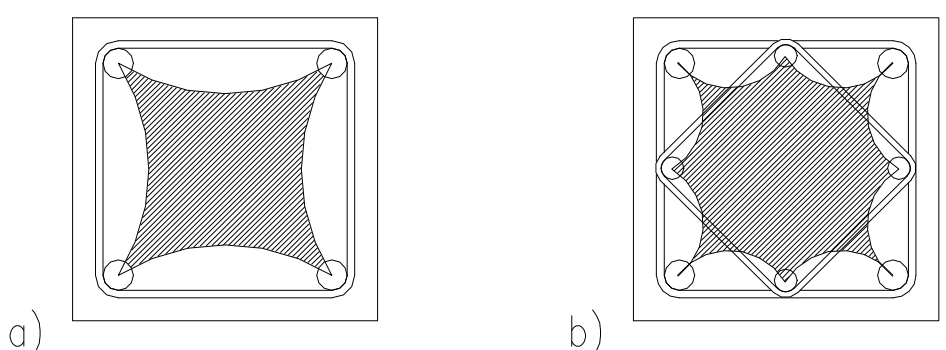

Figura 3.21. Área efetiva de confinamento em pilares de seção retangular, KÖNIG e SIMSCH (1996)

O ponto principal do modelo adotado por KÖNIG e SIMSCH (1996) é o comportamento do concreto sob estado triaxial de tensões devido ao confinamento. No núcleo existem áreas com estado de tensão axial-biaxial e triaxial. Mas só o estado triaxial é responsável pelo aumento da capacidade de força e da ductilidade. Então, em primeiro lugar, o volume do núcleo efetivamente confinado (sujeito a estado triaxial de tensões) deve ser calculado.

O fator de redução $k_{e}$, é definido como:

$$
\mathrm{k}_{\mathrm{e}}=\frac{\mathrm{V}_{\text {triaxial }}}{\mathrm{V}_{\text {nucleo }}}
$$

e relacionado àseção transversal:

$$
\mathrm{k}_{\mathrm{e}}=\frac{\mathrm{A}_{\text {efetiva }}}{\mathrm{A}_{\text {confinada }}}
$$

com $A_{\text {confinada }}=A_{c} \cdot\left(1-\rho_{l}\right)$ e $A_{\text {efetiva }}=$ menor seção transversal efetivamente confinada. $O$ volume efetivamente confinado nos pilares retangulares é mostrado na figura 3.21 e é calculado pelas equações a seguir. 
Para pilares com seção retangular, a área não confinada no plano dos estribos é $\Sigma \frac{\left(w_{i}\right)^{2}}{6}$. Para estribos, os arcos de compressão desenvolvem-se na direção diagonal:

$$
\begin{aligned}
& \mathrm{A}_{\text {efetiva }}=\left(\mathrm{b}_{\mathrm{c}} \cdot \mathrm{d}_{\mathrm{c}}-\sum \frac{\left(\mathrm{w}_{\mathrm{i}}\right)^{2}}{6}\right) \cdot\left(1-\frac{\mathrm{s}}{\left(2 \cdot \mathrm{b}_{\mathrm{c}} \cdot \sqrt{2}\right)}\right) \cdot\left(1-\frac{\mathrm{s}}{\left(2 \cdot \mathrm{d}_{\mathrm{c}} \cdot \sqrt{2}\right)}\right) \\
& \mathrm{k}_{\mathrm{e}}=\left(1-\sum \frac{\left(\mathrm{w}_{\mathrm{i}}\right)}{6 \cdot \mathrm{b}_{\mathrm{c}} \cdot \mathrm{d}_{\mathrm{c}}}\right) \cdot\left(1-\frac{\mathrm{s}}{\left(2 \cdot \mathrm{b}_{\mathrm{c}} \cdot \sqrt{2}\right)}\right) \cdot \frac{\left(1-\frac{\mathrm{s}}{\left(2 \cdot \mathrm{d}_{\mathrm{c}} \cdot \sqrt{2}\right)}\right)}{\left(1-\rho_{\mathrm{l}}\right)}
\end{aligned}
$$

Para pilares com seção quadrada a equação é simplificada para:

$$
\mathrm{k}_{\mathrm{e}}=\frac{1}{3} \cdot \frac{\left(1-\frac{\mathrm{s}}{\left(2 \cdot \mathrm{d}_{\mathrm{c}} \cdot \sqrt{2}\right)}\right)^{2}}{\left(1-\rho_{\mathrm{l}}\right)}
$$

No caso de outros arranjos de armaduras, como mostrado na figura $3.21 \mathrm{~b}$, os arcos de compressão verticais também são perpendiculares aos lados da seção transversal.

$$
\begin{aligned}
& A_{\text {efetiva }}=\left(b_{c} \cdot d_{c}-\sum \frac{\left(w_{i}\right)}{6}\right) \cdot\left(1-\frac{s}{\left(2 \cdot b_{c}\right)}\right) \cdot\left(1-\frac{s}{\left(2 \cdot d_{c}\right)}\right) \\
& k_{e}=\left(1-\sum \frac{\left(w_{i}\right)^{2}}{6 \cdot b_{c} \cdot d_{c}}\right) \cdot\left(1-\frac{s}{\left(2 \cdot b_{c}\right)}\right) \cdot \frac{\left(1-\frac{s}{\left(2 \cdot d_{c}\right)}\right)}{\left(1-\rho_{l}\right)}
\end{aligned}
$$

Para pilares de seção quadrada a equação é simplificada, resultando:

$$
k_{e}=\left(1-n \cdot \frac{w^{2}}{6 \cdot d^{2} c}\right) \cdot \frac{\left(1-\frac{s}{\left(2 \cdot d_{c}\right)}\right)^{2}}{\left(1-\rho_{l}\right)}
$$

A capacidade de força do núcleo confinado pode agora ser calculada através das equações:

$$
\begin{aligned}
& \overline{f_{c}}=f_{c}{ }^{1}+\Delta f \\
& f_{c}{ }^{1}=\alpha \cdot f_{c k}
\end{aligned}
$$

com $\alpha=1,0$ para ruptura por flexão em pilares carregados excentricamente (e/d $>1 / 6)$ e $\alpha=0,85$ para ruína por cisalhamento em pilares carregados 
concentricamente. $\bar{f}_{c}$ é a resistência do concreto do núcleo confinado, $f_{c}{ }^{1}$ é a resistência do concreto para o pilar e $\Delta$ f é o acréscimo de resistência do concreto devido ao confinamento.

A tensão lateral de compressão, $\mathrm{f}_{2}$, pode ser calculada facilmente através do modelo da figura 3.22. Uma tensão lateral uniforme será alcançada com a condição de tensão uniforme na armadura de confinamento.
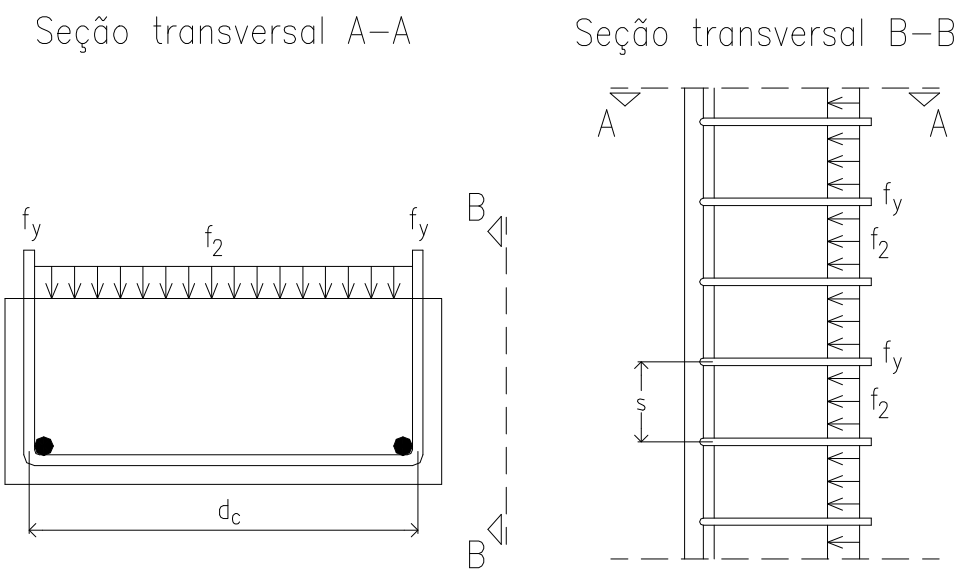

Figura 3.22. Tensão lateral provocada pela armadura de confinamento, KÖNIG e SIMSCH (1996)

A tensão lateral é calculada por:

$$
f_{2}=\frac{\left(A_{s l} \cdot f_{y d}\right)}{\left(d_{c} \cdot s\right)} \text {, onde: }
$$

$A_{s l}$ é a seção transversal do conjunto da armadura lateral, notando-se que, $\mathrm{f}_{\mathrm{y}}$ (tensão de escoamento da armadura lateral) terá valor máximo de $420 \mathrm{MPa}$;

$\mathrm{d}_{\mathrm{c}}$ é o diâmetro do núcleo;

s é o espaçamento entre as barras da armadura transversal.

Tensões resultantes devidas a armadura local devem ser distribuídas acima do núcleo interno. Para diferentes relações de armaduras transversais nas direções $x$ e y, deve ser levada em conta a quantia menor.

Assim as seguintes equações simplificadas podem ser dadas para armaduras retangulares:

$$
f_{2}=\rho_{\text {lat }, x} \cdot f_{y} \quad \text { ou } \quad \rho_{\text {lat }, x} \cdot f_{y}
$$


A tensão lateral considera apenas os efeitos do núcleo efetivamente confinado, pois a resistência àcompressão sofre acréscimos apenas nesta área. Este efeito é percebido em $\Delta$ f pelo fator de redução $k_{e}$.

O aumento da resistência à compressão influenciado pela tensão lateral pode ser calculado através da equação:

$$
\frac{\Delta f}{f_{2}}=\frac{1}{v}
$$

onde $v$ é o coeficiente de Poisson do concreto (para $C R N=0,2$ a 0,25 e para $\mathrm{CAR}=0,25$ a 0,3$)$. Substituindo $v$ por seu valor para CAR, 0,25 , tem-se:

$$
\Delta f=4 f_{2}
$$

Que corresponde àrecomendação do Boletim nº 197 do CEB/FIP (1990).

b. CUSSON e PAULTRE (1993)

Sugerem uma expressão para a pressão lateral $\left(f_{l}\right)$, baseada no equilíbrio da pressão lateral no núcleo de concreto e as forças na armadura de confinamento em ambas as direções ortogonais:

$$
f_{1}=\frac{f_{h c c}}{s}\left(\frac{A_{\text {shx }}+A_{\text {shy }}}{c_{x}+c_{y}}\right)
$$

onde:

$\mathrm{f}_{\text {hcc }}$ é a tensão na armadura transversal correspondente à resistência máxima do concreto confinado;

S é o espaçamento entre estribos;

$A_{\text {shx }}$ e $A_{\text {shy }}$ são as seções transversais totais das barras laterais perpendiculares aos eixos $x$ e y, respectivamente;

$c_{x}$ e $c_{y}$ são das dimensões do núcleo de concreto paralelas aos eixos $x$ e y, respectivamente, figura 3.23 . 

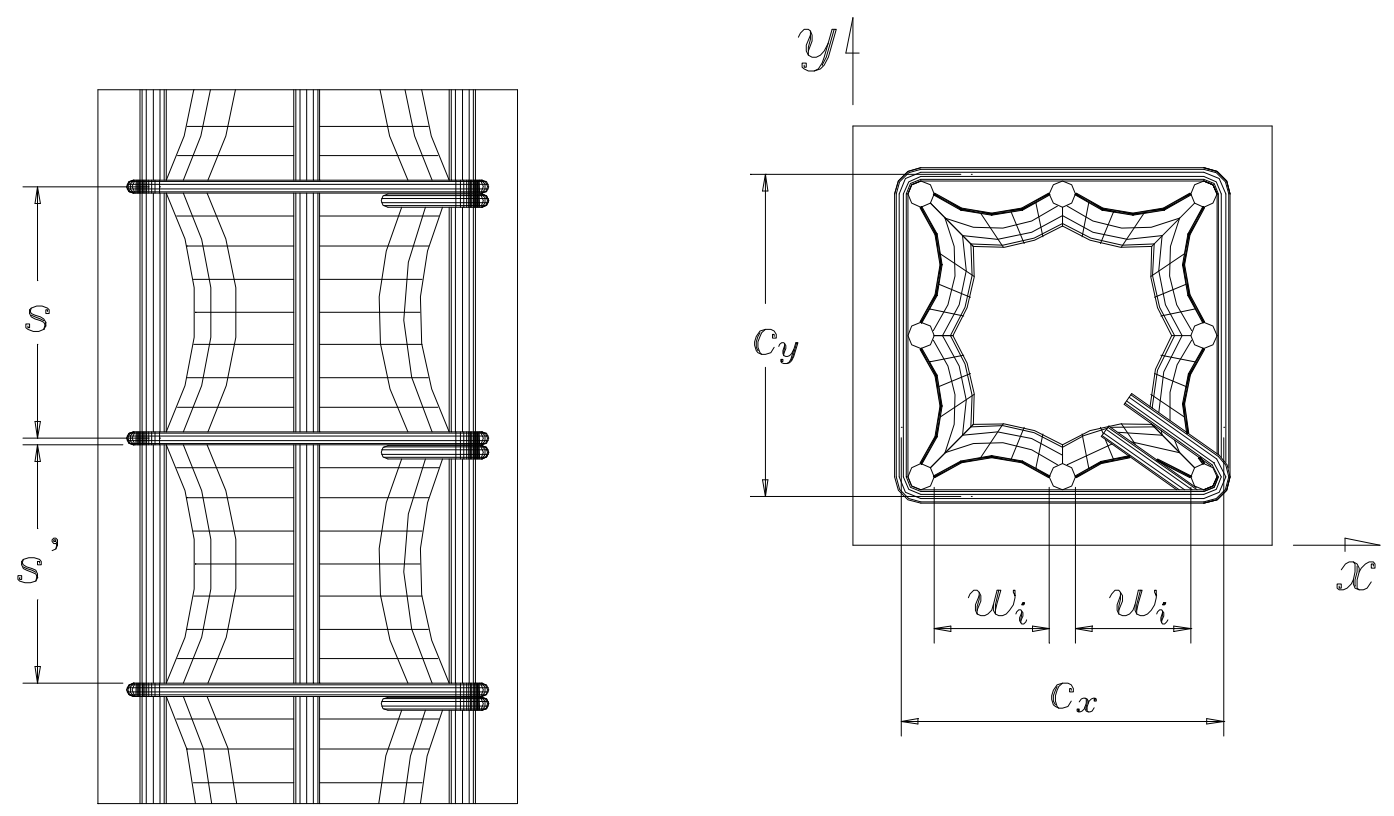

Figura 3.23. Variáveis geométricas para o modelo sugerido por CUSSON e PAULTRE

Coeficiente de confinamento efetivo:

$$
\mathrm{K}_{\mathrm{e}}=\frac{\left(1-\frac{\sum \mathrm{w}_{\mathrm{i}}^{2}}{6 \mathrm{c}_{\mathrm{x}} \cdot \mathrm{c}_{y}}\right) \cdot\left(1-\frac{\mathrm{s}^{\prime}}{2 \mathrm{c}_{\mathrm{x}}}\right) \cdot\left(1-\frac{\mathrm{s}^{\prime}}{2 \mathrm{c}_{y}}\right)}{\left(1-\rho_{\mathrm{c}}\right)}
$$

onde:

$\Sigma \mathrm{w}_{\mathrm{i}}^{2}$ é a soma dos quadrados de todos os espaços livres entre as barras adjacentes da armadura longitudinal na seção retangular;

s' é o espaço livre entre estribos adjacentes;

$\rho_{c}$ é a taxa de armadura longitudinal na seção do núcleo. Note que, caso s' $\geq 2 c_{x}$ ou $s^{\prime} \geq 2 c_{y}$, a armadura de confinamento torna-se inefetiva.

$\mathrm{O}$ coeficiente de confinamento efeitivo, $\mathrm{K}_{\mathrm{e}}$, representa a razão entre a menor área efetivamente confinada de concreto, $\mathrm{K}_{\mathrm{e}}$. $\mathrm{A}_{\mathrm{cc}}$, situada à meia altura entre duas camadas sucessivas de estribos, e a área de concreto efetivamente confinada ao nível dos estribos. Desta forma, a pressão efetiva de confinamento aplicada no núcleo de concreto é igual ao produto da pressão nominal de confinamento pelo coeficiente $\mathrm{K}_{\mathrm{e}}$ :

$$
f_{l e}=K_{e} \cdot f_{l}
$$


CUSSON e PAULTRE (1993) sugerem ainda um estimador para a eficiência do confinamento, o Índice Efetivo de Confinamento. Este índice considera o efeito de arco ocorrendo no núcleo de concreto, e, para as tensões reais na armadura transversal, é proposto como:

$$
\text { Índice de Eficiência do Confinamento }=\frac{\mathrm{f}_{\mathrm{le}}}{\mathrm{f}_{\mathrm{co}}}
$$

De acordo com este índice três diferentes classes são definidas (tabela 3.1):

Tabela 3.1. Classificação segundo a eficiência do confinamento, CUSSON e PAULTRE (1993)

\begin{tabular}{||l|l|}
\hline \hline Classe 1 (baixo confinamento) & $0 \%<\frac{\mathrm{f}_{\mathrm{le}}}{\mathrm{f}_{\mathrm{co}}}<5 \%$ \\
\hline Classe 2 (médio confinamento) & $5 \%<\frac{\mathrm{f}_{\mathrm{le}}}{\mathrm{f}_{\mathrm{co}}}<20 \%$ \\
\hline Classe 3 (alto confinamento) & $\frac{\mathrm{f}_{\mathrm{le}}}{\mathrm{f}_{\mathrm{co}}}>20 \%$ \\
\hline
\end{tabular}

Segundo CUSSON e PAULTRE (1993), pilares pertencentes à Classe 1 apresentam pequena ductilidade e nenhum ganho de resistência por efeito do confinamento, podendo ser empregados apenas em regiões onde efeitos sísmicos não sejam considerados no projeto. Pilares situados na Classe 2 apresentam acréscimos moderados de resistência e comportamento dúctil após a tensão de pico. Os situados na Classe 3 apresentam elevados acréscimos de resistência e grande ductilidade.

Segundo estes pesquisadores, os pilares com a configuração simples de estribos (configuração A, figura 3.24a), com apenas quatro barras longitudinais, tiveram índices de eficiência inferiores a $5 \%$ (Classe 1), independentemente do espaçamento entre estribos utilizado nos modelos (5 e 10cm). 


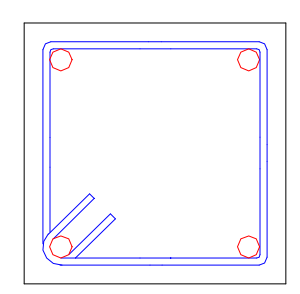

(A)

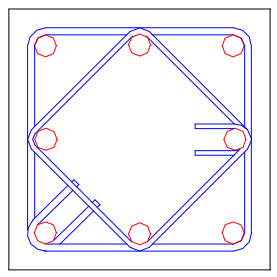

(B)

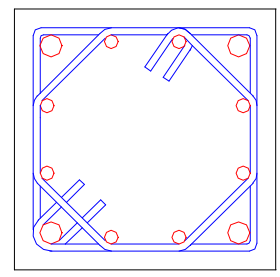

(C)

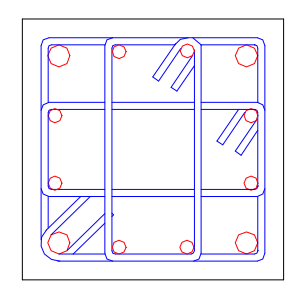

(D)

Figura 3.24. Configurações de estribos utilizadas por CUSSON e PAULTRE (1993)

Ao comparar as configurações de estribos da figura 3.24, CUSSON e PAULTRE (1993) observaram que a configuração B (com 8 barras longitudinais) é tão eficiente quanto æ̀s configurações C (12 barras longitudinais) e D (12 barras longitudinais) para acréscimos de resistência e ductilidade do concreto confinado. Entretanto, todos os modelos com a configuração A para os estribos, mostraram poucos incrementos de resistência e ductilidade em relação ao concreto não confinado.

A seguir apresenta-se uma verificação da eficiência do confinamento segundo o modelo sugerido por CUSSON e PAULTRE (1993) para o pilar P2, ensaiado por QUEIROGA e GIONGO (1998).

Pilar P2: Dados: Seção transversal: $20 \mathrm{~cm} \times 20 \mathrm{~cm} ; c_{x}=c_{y}=15,37 \mathrm{~cm} ; \mathrm{w}=$ $5,5 \mathrm{~cm}$ (oito arcos distribuídos como mostra a figura 3.25 ); $\mathrm{s}=15 \mathrm{~cm}$; $\mathrm{s}^{\prime}=$ 14,37cm; Armadura longitudinal: 8 barras de $\phi=12,5 \mathrm{~mm}$, proporcionando taxa de armadura, em relação ao núcleo confinado, de $\rho_{c}=4,23 \%$; Armadura transversal: estribos de $\phi=6,3 \mathrm{~mm}$; tensão de escoamento: $\mathrm{f}_{\mathrm{y}}=595,6 \mathrm{MPa}$; deformação no escoamento: $\varepsilon_{y}=3,37 \%$; deformação máxima nos estribos (valor médio): $\varepsilon_{y u}=1,05 \%$, que corresponde a uma tensão na armadura transversal igual a $\mathrm{f}_{\text {hcc }}=185,6 \mathrm{MPa}$; resistência média à compressão do concreto aos 15 dias (corpos-de-prova de $10 \mathrm{~cm} \times 20 \mathrm{~cm}$ ) igual a $64,4 \mathrm{MPa}\left(\mathrm{f}_{\mathrm{c}}\right)$, proporcionando, no modelo, resistência de $\mathrm{f}_{\mathrm{co}}=0,85 \cdot 64,4=54,7 \mathrm{MPa}$. 

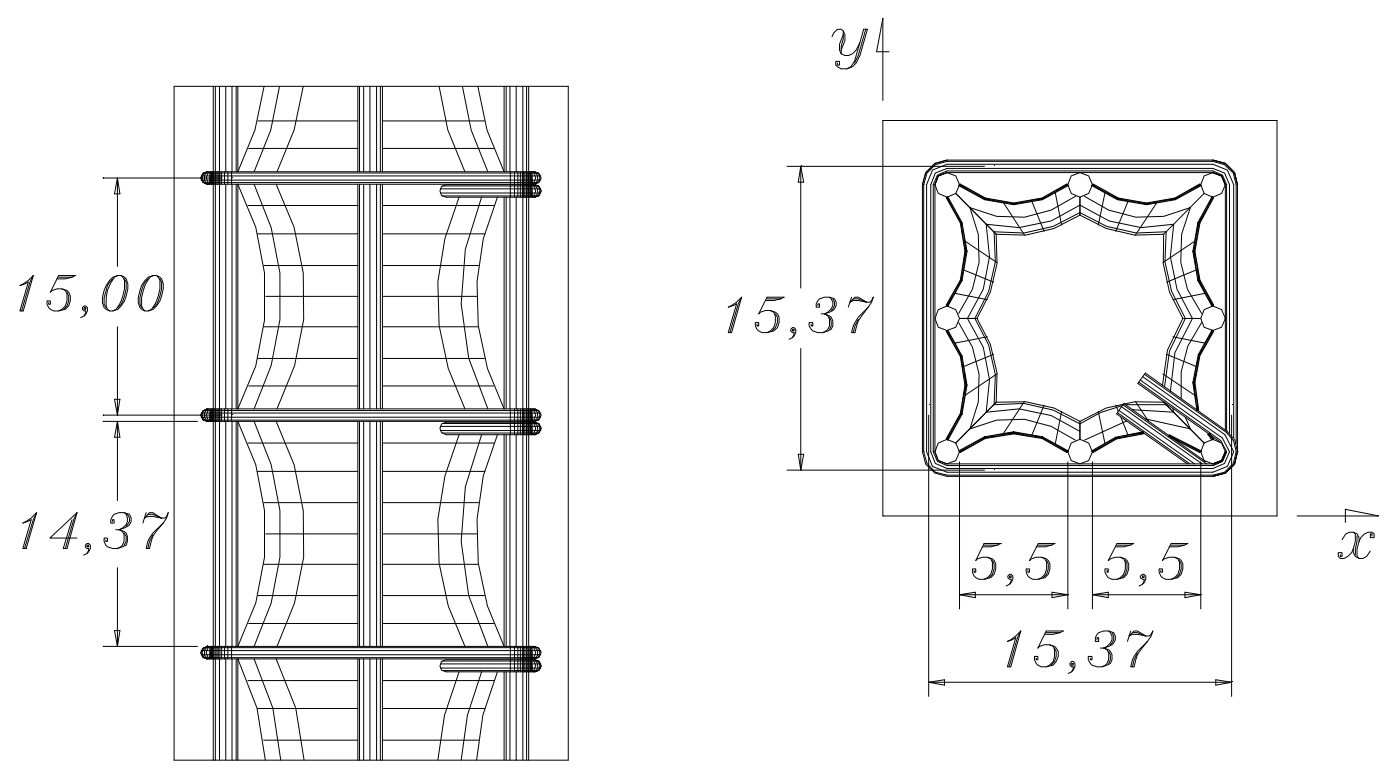

Figura 3.25. Aplicação do modelo de CUSSON e PAULTRE (1993) ao Pilar P3

Cálculo de $f_{1}$ :

$$
f_{\text {I }}=\frac{185,6}{15}\left(\frac{0,63+0,63}{15,37+15,37}\right)=0,49
$$

Cálculo de $\mathrm{K}_{\mathrm{e}}$ :

$$
\mathrm{K}_{\mathrm{e}}=\frac{\left(1-\frac{8 \cdot 5,5^{2}}{6 \cdot 15,37}\right) \cdot\left(1-\frac{14,37}{2 \cdot 15,37}\right) \cdot\left(1-\frac{14,37}{2 \cdot 15,37}\right)}{(1-0,0397)}=0,26
$$

Logo, a pressão efetiva de confinamento vale:

$$
\mathrm{f}_{\mathrm{le}}=\mathrm{K}_{\mathrm{e}} \cdot \mathrm{f}_{\mathrm{l}}=0,49 \cdot 0,26 \approx 0,13
$$

Nesta caso, para o pilar P3, o índice de eficiência do confinamento vele:

$$
\frac{f_{l e}}{f_{c o}}=\frac{0,13}{54,7}=0,24 \%
$$

Para o pilar P3 verifica-se então, segundo CUSSON e PAULTRE (1993), baixa eficiência do confinamento (Classe I). 


\subsubsection{Comentário sobre os modelos apresentados}

Todos os modelos apresentados possuem pontos em comum, tanto para concretos de baixa resistência como para concretos de alta resistência, assim como:

- A forma do núcleo: definida, através das armaduras longitudinais e transversais, por uma série de arcos (figuras 3.1,5,6,16,19,21,23);

- A atuação de pressões de confinamento no núcleo de concreto proporcionadas pelas armaduras, devido a deformabilidade transversal do concreto sob força centrada;

- A ductilização dos pilares em decorrência de eficiente distribuição para a armadura transversal;

- Substanciais acréscimos de resistência provenientes do confinamento (concreto em estado triaxial de tensões);

- O cobrimento como área inefetiva nos modelos sob compressão com forças próximas àforça última. Neste aspecto, entretanto, os pilares de CAR apresentam-se em condição desfavorável, pois, além da influência das deformações diferenciais para a perda do cobrimento (deformação no núcleo > deformação do cobrimento), somam-se a este os fatores mencionados em 3.1 .

Observa-se que, em todas as sugestões, a formulação matemática dos modelos é semelhante. Por exemplo, a equação proposta para $K_{e}$ por MANDER et al. (1988) é idêntica a proposta por CUSSON e PAULTRE (1993). Nestes e em outros modelos para confinamento, as diferenças residem nos parâmetros experimentais para a definição do modelo, como o coeficiente $\theta$ do modelo proposto por SHEIKH e UZUMERI (1982).

\subsubsection{Diagramas tensão $x$ deformação}

São apresentados alguns modelos de diagramas tensão $x$ deformação para pilares de CRN e CAR obtidos na bibliografia. 


\begin{tabular}{|c|c|}
\hline \multicolumn{2}{|c|}{ Concreto de Baixa Resistência } \\
\hline $\begin{array}{l}\sum_{0} \underbrace{}_{\epsilon_{s 1}} \underbrace{0,3 f_{c c}}_{\epsilon_{s 2} \epsilon_{s 85}} \\
\text { SHEIKH e UZUMERI (1982) }\end{array}$ & $\begin{array}{l}\text { Este modelo reconhece o efeito do } \\
\text { confinamento proporcionado pela armadura } \\
\text { lateral. A área efetivamente confinada, } \\
\text { interior àquela definida pelo perímetro dos } \\
\text { estribos, apresenta-se delimitada por uma } \\
\text { série de arcos, cujo arranjo depende da } \\
\text { configuração das armaduras longitudinais e } \\
\text { transversais. }\end{array}$ \\
\hline 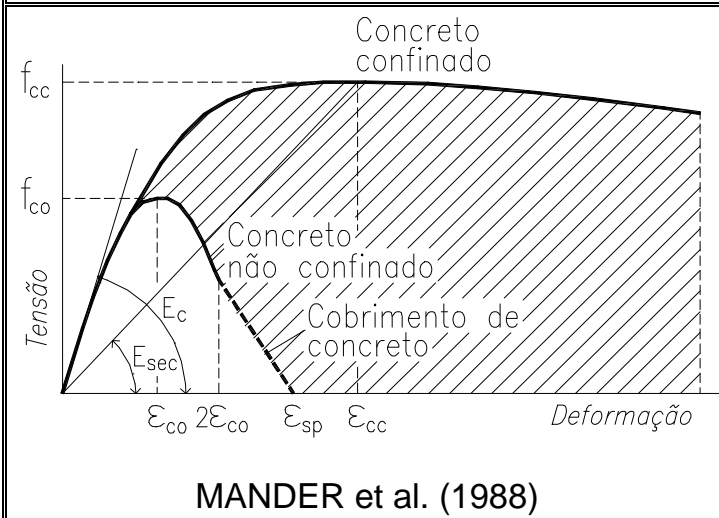 & $\begin{array}{l}\text { É utilizado o conceito de área efetivamente } \\
\text { confinada (ver figura 3.16) para o cálculo da } \\
\text { pressão de confinamento na seção de } \\
\text { concreto. Dados de ensaios com modelos de } \\
\text { grande escala foram utilizados no } \\
\text { desenvolvimento do modelo. }\end{array}$ \\
\hline $\begin{array}{l}\epsilon_{C C} \epsilon_{C 85 C}{\text { deformaça } \tilde{a}^{\circ}} \\
\text { SAATCIOGLU e RAZVI (1992) }\end{array}$ & $\begin{array}{l}\text { A resistência do concreto confinado e a } \\
\text { deformação correspondente são definidas } \\
\text { em termos da pressão lateral uniforme } \\
\text { proporcionada pela armadura de } \\
\text { confinamento. Baseia-se em resultados } \\
\text { experimentais com modelos de grande } \\
\text { escala. }\end{array}$ \\
\hline $\begin{array}{l}\epsilon_{20 c} \text { deformaç̃̃o } \\
\text { SAMRA (1991) }\end{array}$ & $\begin{array}{l}\text { Modelo analítico composto de três partes: } \\
\text { (i) parte ascendente (parábola), trecho } \mathrm{AB} \text {; } \\
\text { (ii) trecho descendente (linha reta até a } \\
\text { deformação correspondente a } 20 \% \text { da } \\
\text { resistência última), trecho } \mathrm{BC} \text {, e (iii) trecho } \\
\text { horizontal (trecho } \mathrm{CD} \text { ). }\end{array}$ \\
\hline
\end{tabular}




\begin{tabular}{|c|c|}
\hline \multicolumn{2}{|c|}{ Concreto de Alta Resistência } \\
\hline 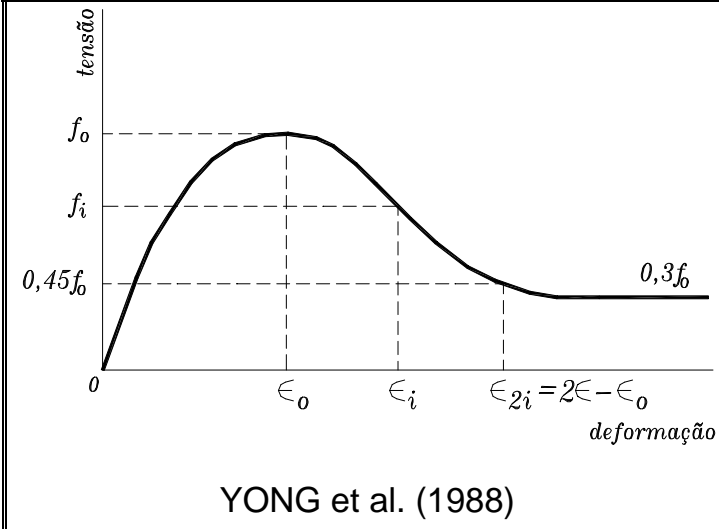 & $\begin{array}{l}\text { Foi desenvolvido através de resultados de } \\
\text { ensaios com modelos de pequena escala, } \\
\text { com e sem cobrimento. A curva pode ser } \\
\text { definida através de três parâmetros ou } \\
\text { coordenadas: (i) a tensão de pico }\left(f_{0}, \varepsilon_{0}\right) \text {; (ii) o } \\
\text { ponto de inflexão da curva no trecho } \\
\text { descendente }\left(\mathfrak{f}_{\mathrm{i}}, \varepsilon_{\mathrm{i}}\right) \text { e (iii) ponto no trecho } \\
\text { descendente }\left(\mathrm{f}_{2 \mathrm{i}}, \varepsilon_{2 \mathrm{i}}\right) \text { onde } \varepsilon_{2 \mathrm{i}}=2_{\varepsilon i}-\varepsilon_{0} \text {. }\end{array}$ \\
\hline $\begin{array}{l}\epsilon_{C c} \quad \epsilon_{C 85 C} \\
\text { BJERKELI et al. (1990) }\end{array}$ & $\begin{array}{l}\text { O comportamento do diagrama é } \\
\text { controlado por três parâmetros: (i) a } \\
\text { resistência à compressão do concreto; (ii) a } \\
\text { pressão lateral de confinamento e (iii) a } \\
\text { geometria da seção, incluindo também os } \\
\text { arranjos das armaduras longitudinais e } \\
\text { transversais. O modelo foi elaborado a partir } \\
\text { de vários ensaios com modelos de pequena } \\
\text { e grande escala. }\end{array}$ \\
\hline $\begin{array}{l}\epsilon_{\text {C50c }} \text { deformasa } \tilde{a} o \\
\text { et al. (1992) }\end{array}$ & $\begin{array}{l}\text { Modelo baseado no conceito de área } \\
\text { efetivamente confinada introduzido por } \\
\text { SHEIKH e UZUMERI (1982). Considera o } \\
\text { crescimento da resistência, deformação e } \\
\text { ductilidade do concreto confinado. Para o } \\
\text { desenvolvimento do diagrama, foram } \\
\text { utilizados resultados de ensaios com } \\
\text { modelos de grande escala. }\end{array}$ \\
\hline $\begin{array}{l}\epsilon_{c o} \epsilon_{c 500} \epsilon_{c c} \quad \epsilon_{c 50 c} \quad \text { deformaç } \tilde{\alpha} 0 \\
\text { CUSSON e PAULTRE (1993) }\end{array}$ & $\begin{array}{l}\text { Leva em conta a pressão efetiva de } \\
\text { confinamento a área efetivamente confinada } \\
\text { (região delimitada por uma série de arcos, } \\
\text { definida conforme o ítem 3.2.1.2b) além dos } \\
\text { acréscimos de resistência e ductilidade } \\
\text { devidos ao confinamento. }\end{array}$ \\
\hline
\end{tabular}




\subsection{Modelos Numéricos}

CLAESON et al. (1996) utilizaram elementos finitos para análise numérica dos pilares ensaiados. O modelo tridimensional adotado, baseado na fratura mecânica não-linear, com elementos sólidos de 20 nós (figura 3.26), mostrou boa concordância com os resultados experimentais.

Nesta análise numérica foram utilizadas duas curvas tensão $x$ deformação: a do Eurocode-2 e a do BBK 94 (figura 3.27). Os resultados para uma série de ensaios àflexo-compressão, levam àconcluir que a forma do diagrama é essencial para obter resultados que refletem o comportamento de pilares de forma correta. Como pode ser visto na figura 3.28 a curva idealizada pelo BBK 94 ajusta-se melhor aos resultados do que a curva dada pelo Eurocode-2. De qualquer forma, as duas curvas predizem igualmente alta capacidade de força axial.

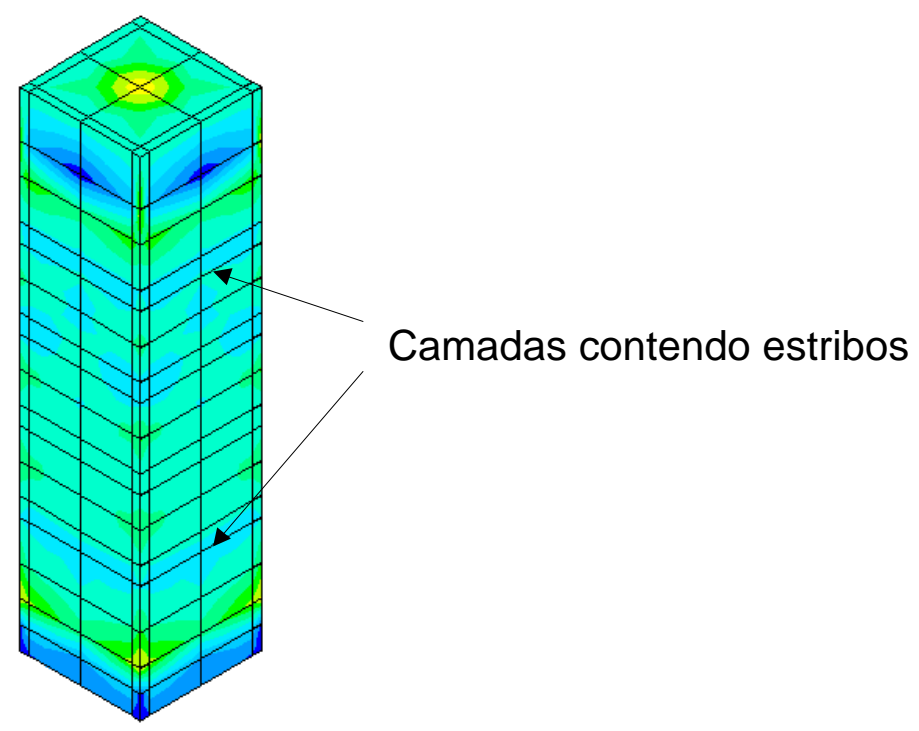

Figura 3.26. Pilar de CAR discretizado em elementos finitos, CLAESON ${ }^{1}$

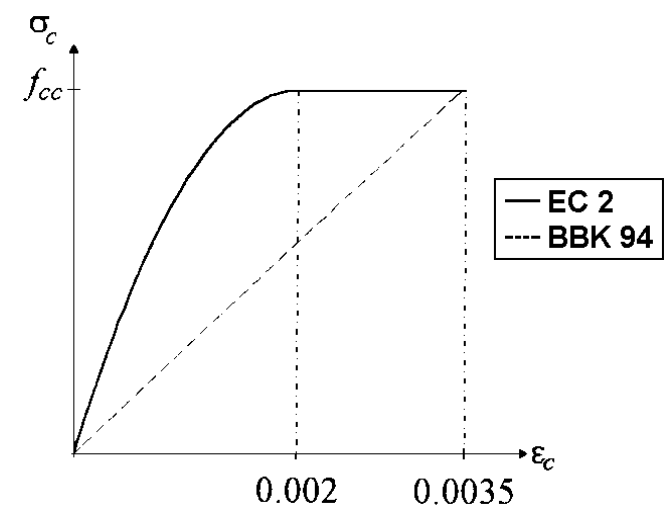

Figura 3.27. Curvas tensão $x$ deformação para concretos comprimidos de acordo com o Eurocode 2 e o BBK 94, CLAESON et al. (1996) 


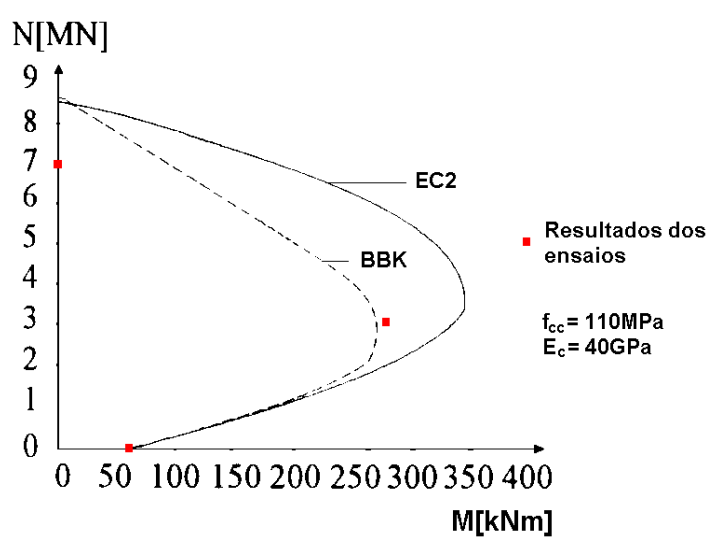

Figura 3.28. Curva de colapso no diagrama momento - força axial. Os pontos marcam os resultados experimentais, CLAESON et al. (1996)

CLAESON et al. (1996) observaram que a diferença de resistência do concreto nos pilares ensaiados (50MPa e 120MPa), não influenciou na flecha à meia altura sob força máxima. Apesar disto, um menor espaçamento entre estribos, mesmo não provendo acréscimos à capacidade de força, dá aos pilares um comportamento mais dúctil, permitindo deformação lateral maior antes do colapso.

Desta análise, CLAESON et al. (1996) também observaram que o efeito de confinamento dos estribos foi maior na área em torno dos estribos, e menor entre dois estribos adjacentes, o que confirma a forma da seção do núcleo efetivamente confinado, como mostrada na figura 3.1.

Segundo WEBB (1993) a influência da armadura longitudinal é pequena para o confinamento do núcleo de concreto. Um pilar muito mais dúctil pode ser obtido através de um maior número de estribos (menor espaçamento). Se um número suficiente de estribos é distribuído ao longo do pilar, uma significativa resistência residual irá permanecer mesmo após o cobrimento se destacar do núcleo.

Segundo o Boletim $\mathrm{n}^{\circ} 197$ do CEB/FIP (1990), o confinamento lateral causado pela armadura produz dois efeitos benéficos nos comportamentos de pilares de concreto: acréscimo de resistência do núcleo e maior deformação axial, permitindo ruptura gradual e dúctil. $O$ acréscimo de resistência à compressão causado pela armadura de confinamento é baseado na seguinte relação:

$$
\Delta f_{1 c}=4,0 \cdot f_{2} \text {, sendo: }
$$

$\Delta f_{1 c}$ - acréscimo àresistência àcompressão; 
$\mathrm{f}_{2}$ - pressão lateral de confinamento (idealizado). O fator de confinamento, 4, é determinado experimentalmente.

XIE et al. (1995) mostram o efeito favorável do confinamento sobre a resistência final de elementos submetidos a carregamento triaxial. Aumentando-se a pressão de confinamento, grandes acréscimos na resistência final e nas deformações correspondentes foram obtidos (figuras 3.29 a 3.31). Também se verifica a redução da inclinação do trecho descendente da curva tensão $x$ deformação devida ao acréscimo de resistência do concreto.

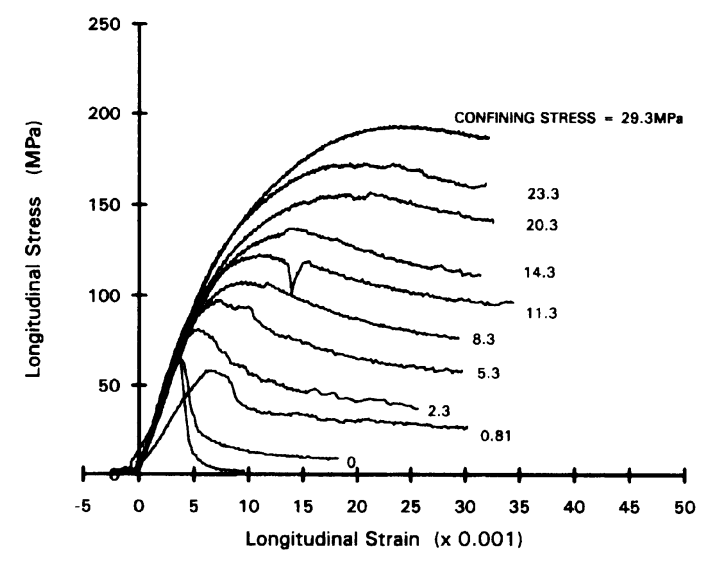

Figura 3.29. Diagrama tensão longitudinal versus deformação longitudinal para ensaios de compressão triaxial com concreto de 60MPa, XIE et al. (1995)

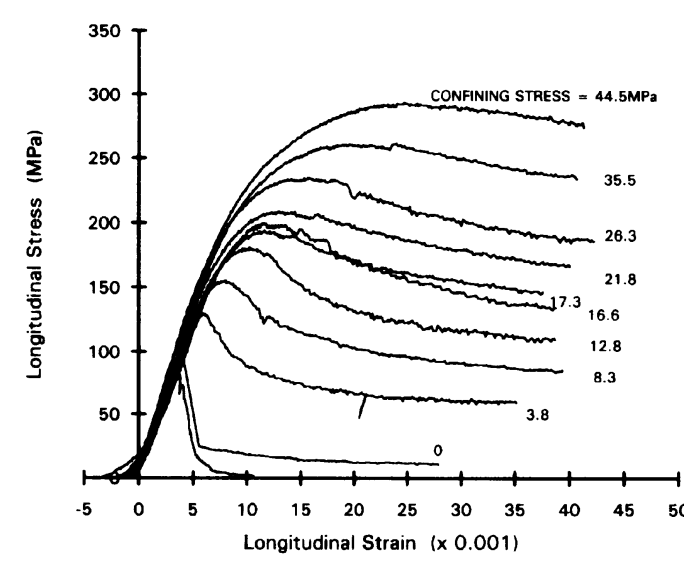

Figura 3.30. Diagrama tensão longitudinal versus deformação longitudinal para ensaios de compressão triaxial com concreto de 90MPa, XIE et al. (1995) 


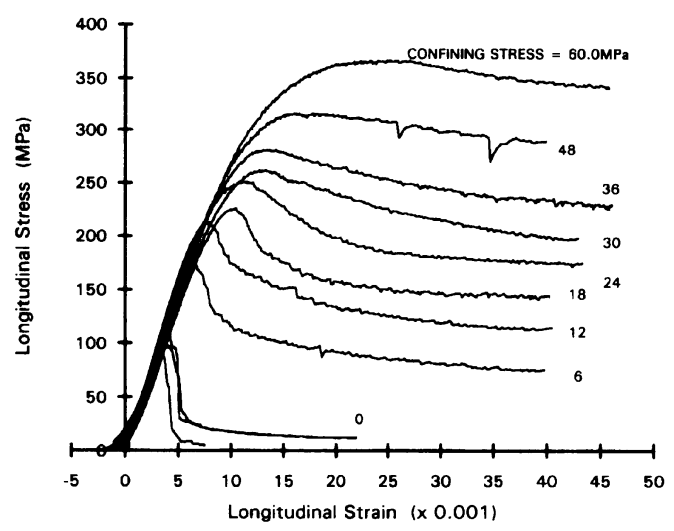

Figura 3.31. Diagrama tensão longitudinal versus deformação longitudinal para ensaios de compressão triaxial com concreto de 120MPa, XIE et al. (1995)

\subsection{Ensaios realizados por LIMA (1997)}

A pesquisa realizada por LIMA (1997) no Laboratório de Estruturas da EESCUSP, voltou-se ao estudo de pilares de Concreto de Alto Desempenho, com resistência média à compressão de $80 \mathrm{MPa}$, submetidos à compressão centrada e à flexo-compressão. Os modelos ensaiados à compressão simples possuíam seção transversal quadrada $(20 \mathrm{~cm} \times 20 \mathrm{~cm})$ e retangular $(15 \mathrm{~cm} \times 30 \mathrm{~cm})$ e altura correspondendo a seis vezes a menor seção transversal do pilar: $120 \mathrm{~cm}$ e $90 \mathrm{~cm}$, respectivamente. Portanto, os modelos da presente pesquisa guardaram as mesmas dimensões dos pilares estudados por LIMA (1997).

O esquema dos ensaios é mostrado na figura 3.32 e as características dos pilares estão na tabela 3.2.

Tabela 3.2. Características dos modelos ensaiados por LIMA (1997).

\begin{tabular}{|c|c|c|c|c|c|c|c|c|c|c|c|c|}
\hline Pilar & $\begin{array}{c}f_{c} \\
M P a\end{array}$ & $\begin{array}{c}b \\
c m\end{array}$ & $\begin{array}{c}H \\
\mathrm{~cm}\end{array}$ & $\begin{array}{c}\ell \\
\mathrm{cm}\end{array}$ & $\begin{array}{c}f_{y} \\
M P a\end{array}$ & $\begin{array}{l}\text { Arm. } \\
\text { long. }\end{array}$ & $\begin{array}{c}A_{s} \\
\mathrm{~cm}^{2}\end{array}$ & $\begin{array}{l}\rho I \\
\%\end{array}$ & $\begin{array}{l}\text { Arm. } \\
\text { Trans. }\end{array}$ & $\begin{array}{c}c \\
m m\end{array}$ & $\begin{array}{c}\rho_{w} \\
\%\end{array}$ & $\begin{array}{c}F_{\text {exp }} \\
k N\end{array}$ \\
\hline$P 1 / 1$ & 83,8 & 20 & 20 & 120 & 543,3 & $8 \phi 12,5$ & 10,16 & 2,54 & $6,3 \mathrm{c} / 5$ & 17,5 & 1,03 & 2630 \\
\hline \begin{tabular}{|l|}
$P 1 / 2$ \\
\end{tabular} & 83,8 & 20 & 20 & 120 & 543,3 & $8 \phi 12,5$ & 10,16 & 2,54 & $6,3 \mathrm{c} / 5$ & 17,5 & 1,03 & 2701 \\
\hline \begin{tabular}{|l|}
$P 1 / 3$ \\
\end{tabular} & 83,8 & 20 & 20 & 120 & 543,3 & $8 \phi 12,5$ & 10,16 & 2,54 & $6,3 \mathrm{c} / 5$ & 17,5 & \begin{tabular}{|l|}
1,03 \\
\end{tabular} & 2834 \\
\hline$P 1 r / 2$ & 85,1 & 20 & 20 & 120 & 543,3 & $8 \phi 12,5$ & 10,16 & 2,54 & $6,3 \mathrm{c} / 5$ & 17,5 & 1,03 & 3063 \\
\hline \begin{tabular}{|l|}
$P 1 r / 3$ \\
\end{tabular} & 85,1 & 20 & 20 & 120 & 543,3 & $8 \phi 12,5$ & 10,16 & 2,54 & $6,3 \mathrm{c} / 5$ & 17,5 & \begin{tabular}{|l|}
1,03 \\
\end{tabular} & 2820 \\
\hline$P 2 / 2$ & 87,4 & 20 & 20 & 120 & 543,3 & $8 \phi 12,5$ & 10,16 & 2,54 & $6,3 c / 10$ & 17,5 & 0,51 & 2950 \\
\hline$P 2 / 3$ & 92,0 & 20 & 20 & 120 & 543,3 & $8 \phi 12,5$ & 10,16 & 2,54 & $6,3 \mathrm{c} / 10$ & 17,5 & 0,51 & 3210 \\
\hline$P 3 / 1$ & 94,9 & 30 & 15 & 90 & 543,3 & $8 \phi 12,5$ & 10,16 & 2,26 & $6,3 \mathrm{c} / 5$ & $20 / 22,5$ & 1,01 & 3415 \\
\hline$P 3 / 2$ & 94,9 & 30 & 15 & 90 & 543,3 & $8 \phi 12,5$ & 10,16 & 2,26 & $6,3 \mathrm{c} / 5$ & $20 / 22,5$ & 1,01 & 3750 \\
\hline$P 3 / 3$ & 94,9 & 30 & 15 & 90 & 543,3 & $8 \phi 12,5$ & 10,16 & 2,26 & $6,3 c / 5$ & $20 / 22,5$ & 1,01 & 3230 \\
\hline$P 4 / 1$ & 80,5 & 30 & 15 & 90 & 543,3 & $8 \phi 12,5$ & 10,16 & 2,26 & $6,3 c / 2,5$ & $20 / 22,5$ & 2,02 & 3000 \\
\hline$P 4 / 2$ & 80,5 & 30 & 15 & 90 & 543,3 & $8 \phi 12,5$ & 10,16 & 2,26 & $6,3 \mathrm{c} / 2,5$ & $20 / 22,5$ & \begin{tabular}{|l|}
2,02 \\
\end{tabular} & 2650 \\
\hline$P 4 / 3$ & 80,5 & 30 & 15 & 90 & 543,3 & $8 \phi 12,5$ & 10,16 & 2,26 & $6,3 c / 2,5$ & $20 / 22,5$ & 2,02 & 2610 \\
\hline
\end{tabular}




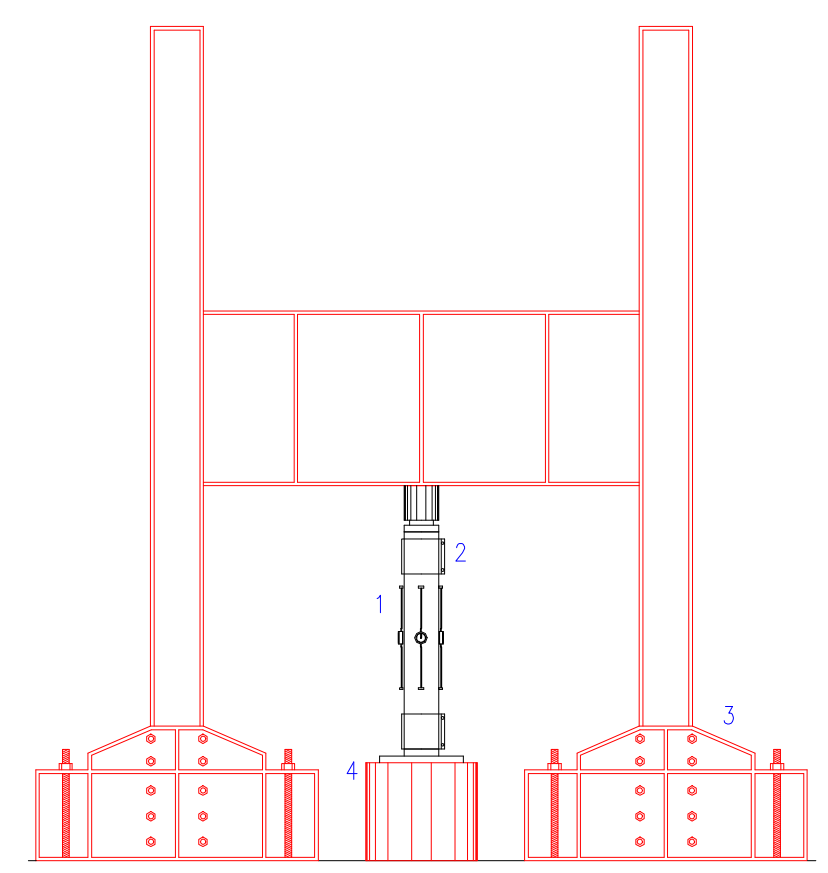

Figura 3.32. Esquema dos ensaios realizados por LIMA (1997): 1. Pilar instrumentado; 2. Confinamento metálico das extremidades do pilar; 3. Pórtico de reação; 4. Célula de carga (capacidade nominal de $5000 \mathrm{kN}$ )

Os resultados para a força última experimental $\left(F_{\text {exp }}\right)$ dos pilares ensaiados à compressão simples estão na tabela 3.3. Aqui estes são comparados àforça última teórica considerando-se a seção íntegra de concreto $\left(F_{\text {teo }}\right)$ e àforça última teórica para o núcleo de concreto $\left(\mathrm{F}_{\text {teo,n }}\right)$.

Tabela 3.3. Modelos ensaiados à compressão centrada: resultados, LIMA (1997).

\begin{tabular}{|c|c|c|c|c|c||}
\hline Modelo & $\begin{array}{c}\boldsymbol{F}_{\text {exp }} \\
\boldsymbol{K N}\end{array}$ & $\begin{array}{c}\boldsymbol{F}_{\text {teo }} \\
\mathbf{K N}\end{array}$ & $\begin{array}{c}\boldsymbol{F}_{\text {teo, } \boldsymbol{n}} \\
\mathbf{k N}\end{array}$ & $\boldsymbol{F}_{\text {exp }} / \boldsymbol{F}_{\text {teo }}$ & $\boldsymbol{F}_{\text {exp }} / \boldsymbol{F}_{\text {teo, },}$ \\
\hline $\boldsymbol{P 1 / 1}$ & 2630 & 3492 & 2375 & 0,75 & 1,11 \\
\hline $\boldsymbol{P 1 / 2}$ & 2701 & 3492 & 2375 & 0,77 & 1,14 \\
\hline $\boldsymbol{P 1 / 3}$ & 2834 & 3492 & 2375 & 0,81 & 1,19 \\
\hline $\boldsymbol{P 1 r / 2}$ & 3063 & 3538 & 2403 & 0,87 & 1,27 \\
\hline $\boldsymbol{P 1 r / 3}$ & 2820 & 3538 & 2403 & 0,80 & 1,17 \\
\hline $\boldsymbol{P 2 / 2}$ & 2950 & 3618 & 2454 & 0,82 & 1,20 \\
\hline $\boldsymbol{P 2 / 3}$ & 3210 & 3780 & 2554 & 0,85 & 1,26 \\
\hline $\boldsymbol{P 3 / 1}$ & 3415 & 4309 & 2668 & 0,79 & 1,28 \\
\hline $\boldsymbol{P 3 / 2}$ & 3750 & 4309 & 2668 & 0,87 & 1,41 \\
\hline $\boldsymbol{P 3 / 3}$ & 3230 & 4309 & 2668 & 0,75 & 1,21 \\
\hline $\boldsymbol{P 4 / 1}$ & 3000 & 3739 & 2347 & 0,80 & 1,28 \\
\hline $\boldsymbol{P 4 / 2}$ & 2650 & 3739 & 2347 & 0,71 & 1,13 \\
\hline $\boldsymbol{P 4 / 3}$ & 2610 & 3739 & 2347 & 0,70 & 1,11 \\
\hline \hline
\end{tabular}


Observando que a relação entre a força experimental $\left(F_{\text {exp }}\right)$ e a força teórica considerando-se a seção íntegra de concreto $\left(F_{\text {teo }}\right)$ é sempre inferior a 1 , e que a relação entre a força experimental e a força teórica considerando-se o núcleo de concreto $\left(F_{\text {teo,n }}\right)$ é superior à unidade, LIMA (1997) concluiu que, para pilares de Concreto de alta resistência, no caso em torno de $80 \mathrm{MPa}$, a seção resistente é a seção do núcleo de concreto. Isto veio a confirmar as conclusões de AGOSTINI (1992), PAIVA (1994) e CUSSON e PAULTRE (1993).

A presente pesquisa também procura verificar a validade destas conclusões para o caso de pilares de concreto com resistência média àcompressão de 60MPa.

\subsection{Análise da seção resistente}

Para pilares de concreto de alta resistência, o dimensionamento à compressão simples, no Estado Limite Último, pode ser feito de dois modos:

- Considerando-se a seção íntegra de concreto. Neste caso adota-se coeficiente de redução para levar em conta que o cobrimento não participa da seção resistente;

- Considerando-se apenas a área do núcleo de concreto como seção resistente. Aqui, por questões de dimensionamento, o núcleo é considerado como a região definida pelo eixo da armadura transversal mais externa (figura 3.33);

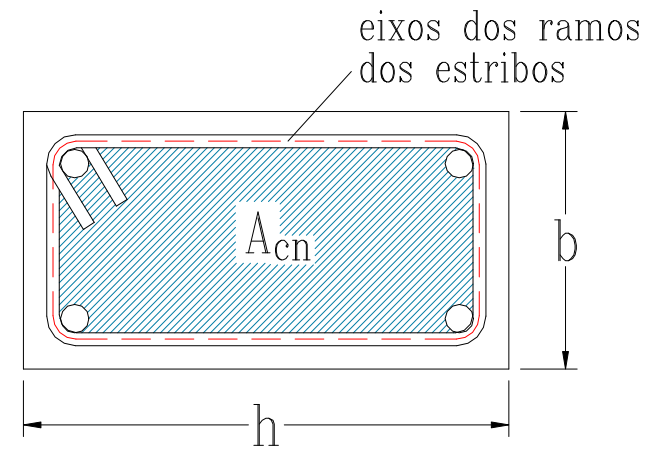

Figura 3.33. Seção transversal do pilar

Admitindo-se que sejam conhecidos os valores de:

F - força normal aplicada, sem majoração; 
$\mathrm{f}_{\mathrm{c}}$ - valor da resistência do concreto medida através de corpos-de-prova cilíndricos de $100 \mathrm{~mm} \times 200 \mathrm{~mm}$. No caso da presente pesquisa este valor da resistência era determinado aos 15 dias;

$\sigma_{s}$ - valor da resistência do aço comprimido para uma determinada deformação $\left(\varepsilon_{\mathrm{c}}\right)$ do concreto, obtido através do diagrama tensão $x$ deformação do aço;

$A_{c}$ - área da seção íntegra de concreto $=b \times h$;

$A_{c n}$ - área do núcleo de concreto definido pelo perímetro dos estribos;

$A_{s}$ - área da seção transversal da armadura longitudinal comprimida;

Tem-se então:

a. Caso toda a seção de concreto participe como seção resistente

Verifica-se a seguinte condição:

$$
F=C \cdot f_{c} \cdot\left(A_{c}-A_{s}\right)+f_{y} \cdot A_{s}
$$

Onde C é o coeficiente utilizado para considerar diferenças na moldagem do concreto, vibração e cura e para diferenças na velocidade de carregamento.

b. Caso apenas o núcleo de concreto participe como seção resistente

Neste caso tem-se a seguinte condição:

$$
F=f_{c} \cdot A_{c n}+f_{y} \cdot A_{s}
$$

\subsection{Seção resistente segundo COLLINS et al. (1993)}

Segundo COLLINS et al. (1993) a capacidade resistente de pilares de concreto com estribos ou espirais, com cobrimento, pode ser expressa por:

$$
F=k_{3} \cdot f_{c}^{\prime} \cdot\left(A_{g}-A_{s t}\right)+f_{y} \cdot A_{s t}
$$

onde:

$A_{g}$ - área da seção transversal do pilar;

$A_{s t}$ - área da seção transversal das barras da armadura longitudinal; 
$f_{y}$ - resistência de escoamento das barras da armadura longitudinal;

$\mathrm{f}_{\mathrm{c}}{ }^{\prime}$ - resistência àcompressão do concreto;

$\mathrm{k}_{3}$ - coeficiente (determinado experimentalmente) igual a:

$=0,6+\frac{10}{f_{c},}$ e $k_{3} \leq 0,85$

Desta forma, COLLINS et al. (1993) utilizam a seção íntegra para o cálculo da capacidade resistente do pilar e inserem o coeficiente de redução $k_{3}$ para considerar a não participação do cobrimento na seção resistente de concreto. 


\section{Experimentação e Resultados}

\subsection{Considerações Iniciais}

Esta pesquisa se enquadra em plano mais amplo em desenvolvimento no Laboratório de Estruturas da EESC - USP, sob coordenação do Orientador desta Dissertação. Em uma primeira etapa foram estudados pilares de CAR com resistência média compressão de $80 \mathrm{MPa}$ submetidos à compressão simples e a flexo-compressão.

Neste item foram apresentadas as dosagens utilizadas para a obtenção de resistência média à compressão de $60 \mathrm{MPa}$ aos 15 dias. A primeira dosagem que proporcionou esta resistência, com a qual moldaram-se os dois primeiros modelos, não proporcionou boa trabalhabilidade ao concreto. Portanto, paralelamente aos ensaios dos pilares, continuou-se com o estudo de dosagem, procurando-se obter um concreto trabalhável, que atendesse as exigências construtivas.

São também apresentados todos os arranjos de armaduras, fôrmas e instrumentação dos modelos. As principais variáveis do problema em estudo eram a forma da seção transversal e o espaçamento entre estribos, produzindo diferentes taxas volumétricas de armadura transversal. 


\subsection{Estudo de Dosagem}

A dosagem inicial foi adaptada de estudo de DAL MOLIN (1995), que avaliou a influência da sílica ativa nas diversas propriedades do concreto. Após várias tentativas, obteve-se uma dosagem (Dosagem 1) que proporcionou concreto com resistência média à compressão próxima de $60 \mathrm{MPa}$ aos 15 dias. A dosagem proposta por DAL MOLIN (1995) para 60MPa foi 1:0,86:2,44, com fator a/(c+sa) igual a 0,32 e teor de sílica ativa de 10\%. A Dosagem 1, obtida experimentalmente usando os materiais disponíveis na região de São Carlos, foi de 1:0,9:2,8. O fator água/materiais cimentantes foi de 0,35 . O consumo de sílica ativa foi fixado em $10 \%$ do consumo de cimento, conforme indicado por DAL MOLIN (1995); NEVILLE e ÄTCIN (1993); LIMA (1997). O consumo de superplastificante correspondia a $1,5 \%$ do consumo total de material aglomerante (cimento + sílica ativa). A tabela 4.1 traz o consumo de materiais para a Dosagem 1.

Com esta dosagem foram moldados dois modelos com seção transversal quadrada (Pilares P1 e P2) e doze corpos-de-prova. Devido a reduzida trabalhabilidade da mistura ( slump $=3 \mathrm{~cm}$ ), uma nova dosagem foi estudada (Dosagem 2), procurando melhorar esta característica do concreto, tabela 4.2. 0 ponto de partida para a segunda dosagem foi a adição de superplastificante em teor de 2,5\% (superior ao da dosagem anterior, 1,5\%). A tabela 5.2 traz os resultados do ensaio à compressão para as duas primeiras dosagens. Com a Dosagem 2 moldaram-se todos os demais modelos. $\mathrm{O}$ abatimento do cone ficou em torno de $8 \mathrm{~cm}$ para a Dosagem 2.

Previa-se também uma nova dosagem, com maior quantidade de argamassa (Dosagem 3). Em trabalho futuro pretende-se também avaliar o efeito da retirada da sílica ativa (Dosagem 4) do concreto, substituindo a mesma por igual quantidade de cimento. Esta atitude baseia-se em NEVILLE e ÄTCIN (1993), que afirmaram que resistências de 60MPa a $80 \mathrm{MPa}$ podem ser obtidas sem o uso de sílica ativa. 
Tabela 4.1. Consumo unitário de Materiais (Dosagem 1)

\begin{tabular}{||l|r||}
\hline \multicolumn{1}{|c|}{ Material } & Consumo $\left(\mathrm{kg} / \mathrm{m}^{\mathbf{3}}\right)$ \\
\hline Cimento & 430,0 \\
\hline Sílica ativa & 43,0 \\
\hline Areia & 435,2 \\
\hline Pedra britada & 1324,4 \\
\hline Água & 165,6 \\
\hline Superplastificante & 7,1 \\
\hline TOTAL & 2405,2 \\
\hline
\end{tabular}

Tabela 4.2. Consumo unitário de Materiais (Dosagem 2)

\begin{tabular}{||l|r||}
\hline \multicolumn{1}{|c|}{ Material } & Consumo $\left(\mathrm{kg} / \mathrm{m}^{3}\right)$ \\
\hline Cimento & 430,0 \\
\hline Sílica ativa & 43,0 \\
\hline Areia & 435,2 \\
\hline Pedra britada & 1324,4 \\
\hline Água & 165,6 \\
\hline Superplastificante & 11,8 \\
\hline TOTAL & 2410,0 \\
\hline
\end{tabular}

Tabela 4.3. Resistência à compressão do concreto aos 15 dias (Dosagem 1 e 2)

\begin{tabular}{||l|c|c|c|c||}
\cline { 2 - 5 } \multicolumn{1}{c|}{} & \multicolumn{4}{c||}{ Resistência à compressão (MPa) } \\
\hline Dosagem & Cp1 & cp2 & cp3 & Média \\
\hline Dosagem 1 & 58,4 & 62,3 & 57,9 & 59,6 \\
\hline Dosagem 2 & 51,2 & 53,3 & 55,8 & 53,4 \\
\hline
\end{tabular}

O gráfico a seguir mostra a evolução da resistência à compressão do concreto com o tempo para as duas dosagens (Dosagem 1: 1,5\% de superplastificante; Dosagem 2: 2,5\% de superplastificante). 


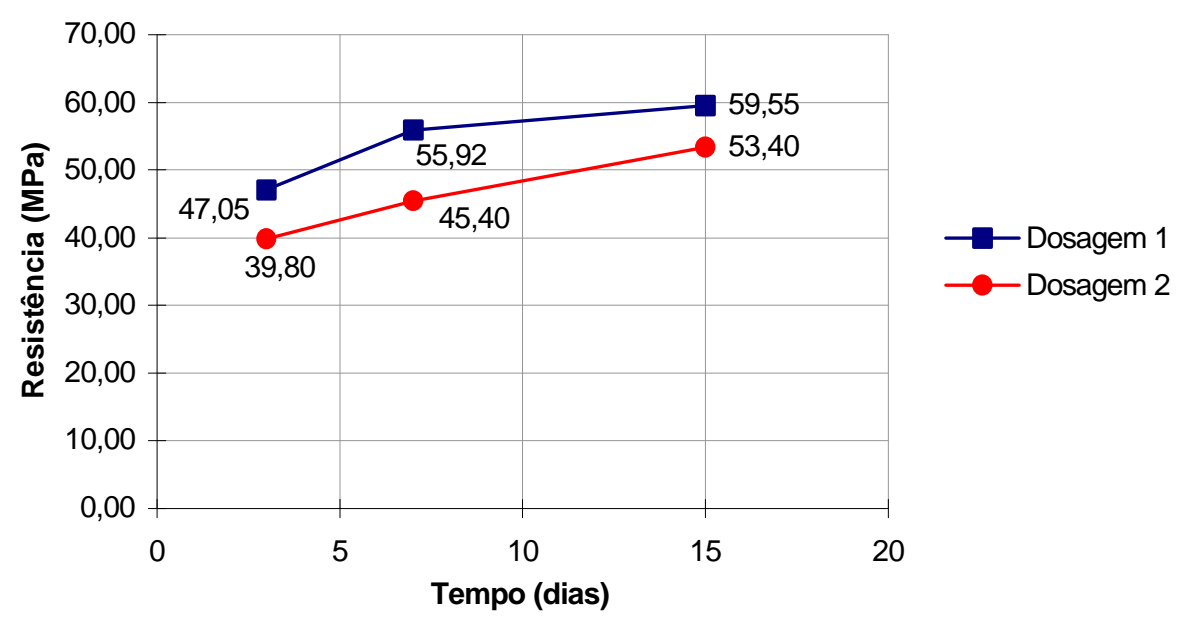

Figura 4.1. Evolução da resistência com o tempo

Do gráfico pode-se deduzir que a grande quantidade de superplastificante empregada na Dosagem 2 (2,5\%) influenciou no tempo de pega do concreto, agindo como retardador de pega. Observa-se que, para o concreto com Dosagem 2, a resistência aos 3 dias foi bem inferior que a do concreto com Dosagem 1, voltando o mesmo a reassumir o ritmo normal de crescimento da resistência.

\subsection{Materiais utilizados}

\subsubsection{Cimento}

Em todas as dosagens, o cimento Portland utilizado foi o de alta resistência inicial, CP V ARI, cedido mediante convênio informal com CAMARGO CORRÊA INDUSTRIAL S/A. A utilização deste tipo de cimento possibilitou alcançar alta resistência com pouca idade, viabilizando o cronograma de ensaios no Laboratório de Estruturas da EESC - USP.

Segundo o fabricante, a massa específica do cimento empregado era de 3120 $\mathrm{kg} / \mathrm{m}^{3}$, determinado como prescreve a NBR 6474/84.

\subsubsection{Sílica ativa}

A sílica ativa empregada estava na forma não densificada, SILMIX ND, cedido mediante convênio informal com CAMARGO CORRÊA CIMENTOS S/A, com massa específica, determinada pelo fabricante, de $2222 \mathrm{~kg} / \mathrm{m}^{3}$. 


\subsubsection{Agregado graúdo}

Como agregado graúdo foi utilizada pedra britada de origem basáltica encontrada na região de São Carlos. A análise granulométrica foi realizada como prescreve a NBR 7217/87 no Laboratório de Construção Civil da EESC - USP. A dimensão máxima característica do agregado foi de $19 \mathrm{~mm}$, não atendendo, portanto, às recomendações sobre agregados graúdos para concretos de alta resistência (item 2.8.2.1).

A massa específica, determinada segundo a NBR 9776/87, foi de 2,86 g/ $/ \mathrm{cm}^{3}$. A massa unitária, determinada conforme a NBR 7251/82, foi igual a 1,48 g/dm

\subsubsection{Agregado miúdo}

Foi utilizada areia do tipo quartzosa proveniente do Rio Mogi Guaçu. A análise granulométrica foi realizada no Laboratório de Construção Civil da EESC USP, conforme a NBR-7217/87. O módulo de finura, determinado segundo a NBR $7211 / 83$, foi igual a 3,30 (areia média), caracterizando uma areia apropriada ao concreto de alta resistência (item 2.8.2.2.).

A massa específica, segundo a NBR 9776/87, foi de 2,68, enquanto a massa unitária, conforme a NBR 7251/82, foi igual a 1,44.

\subsubsection{Aditivo superplastificante}

Foi utilizado o aditivo superplastificante $R X 3000$ com massa específica de $1,16 \mathrm{~kg} / \mathrm{dm}^{3}$, cedido mediante convênio informal com REAX INDÚSTRIA e COMÉRCIO LTDA.

\subsection{6. Água}

Para o amassamento do concreto utilizou-se água da rede pública de abastecimento da cidade de São Carlos.

\subsubsection{Aço}

Para compor as armaduras foram utilizadas barras com as especificações indicadas na tabela 4.4: 
Tabela 4.4. Características do aço empregado - resultados do ensaio à tração

\begin{tabular}{||c|c|c|c||}
\hline \multicolumn{1}{|c|}{$\phi_{\text {nominal }}(\mathrm{mm})$} & $\boldsymbol{f}_{\mathrm{y}}(\mathrm{MPa})$ & $\varepsilon_{y}(\%)$ & $E_{s}(\mathrm{MPa})$ \\
\hline 6,3 (estribos) & 595,6 & 3,37 & 194,7 \\
\hline 12,5 (arm. Longitudinal) & 502,1 & 2,99 & 168,8 \\
\hline
\end{tabular}

\subsection{Instrumentação utilizada}

Os modelos foram ensaiados na máquina de ensaios INSTRON adquirida pelo Laboratório de Estruturas da EESC - USP, através de Projeto Integrado FAPESP coordenado pelo professor João Bento de Hanai. Esta máquina hidráulica, servo-controlada e computadorizada de última geração, pode ser empregada em ensaios estáticos ou dinâmicos. Possui capacidade de $2.500 \mathrm{kN}$ (força estática máxima), altura útil de ensaio de $4 \mathrm{~m}$. A utilização da INSTRON permitiu a aplicação de deslocamentos com velocidade controlada $(\mathrm{mm} / \mathrm{s})$, variando-se a mesma à medida que as forças últimas teóricas previstas para os modelos se aproximavam (tabela 4.6).

A aquisição de dados dos instrumentos de medida de deformação (extensômetros) e deslocamento (relógios comparadores), foi realizada, para a Série 1, através do sistema SYSTEM 4000, e, nas séries seguintes, através do sistema SYSTEM 5000.
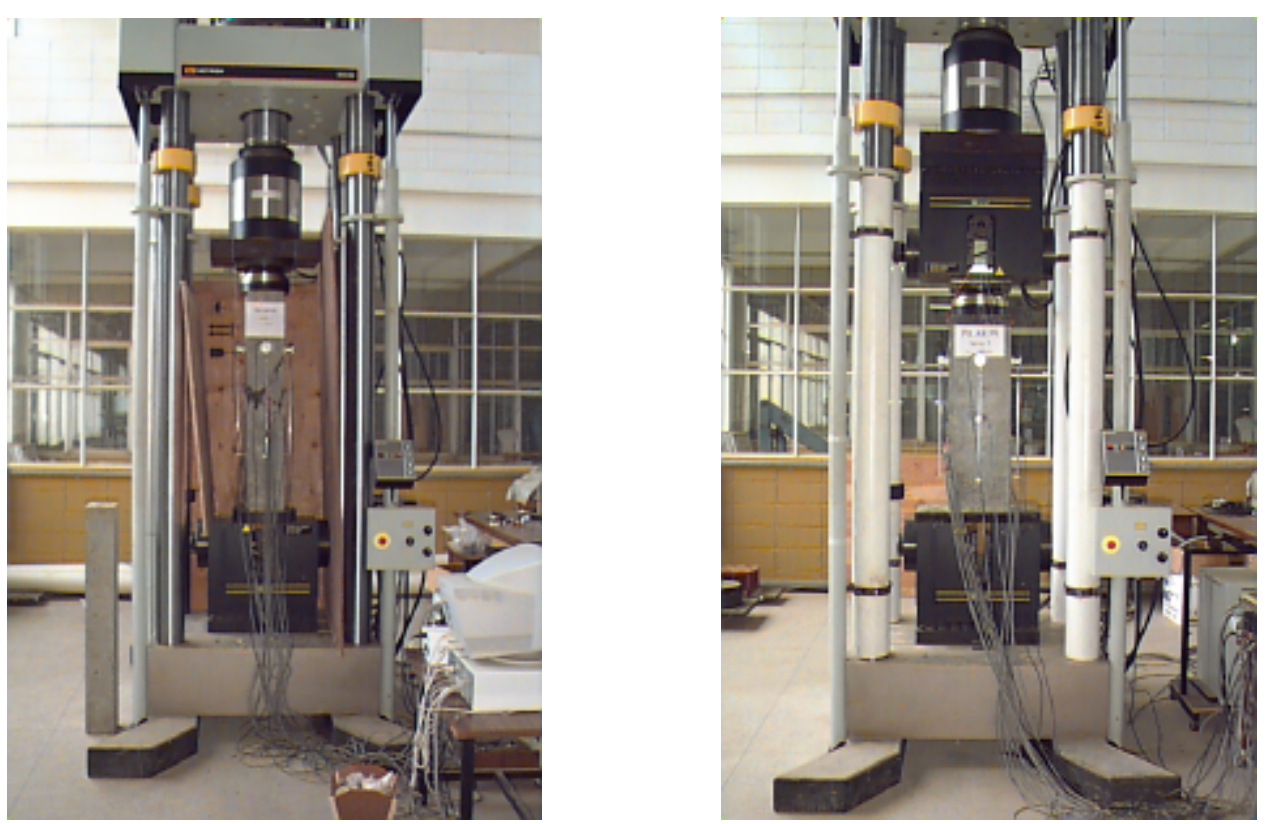

Figura 4.2. Visão parcial da máquina INSTRON com pilares de seção quadrada e retangular posicionados para os ensaios 
Máquina INSTRON, servocontrolada e computadorizada de última geração

- capacidade: $2500 k N$ (estático)

- altura útil de ensaio: $4 \mathrm{~m}$

Sistema de aquisição de dados SYSTEM 4000 ou 5000
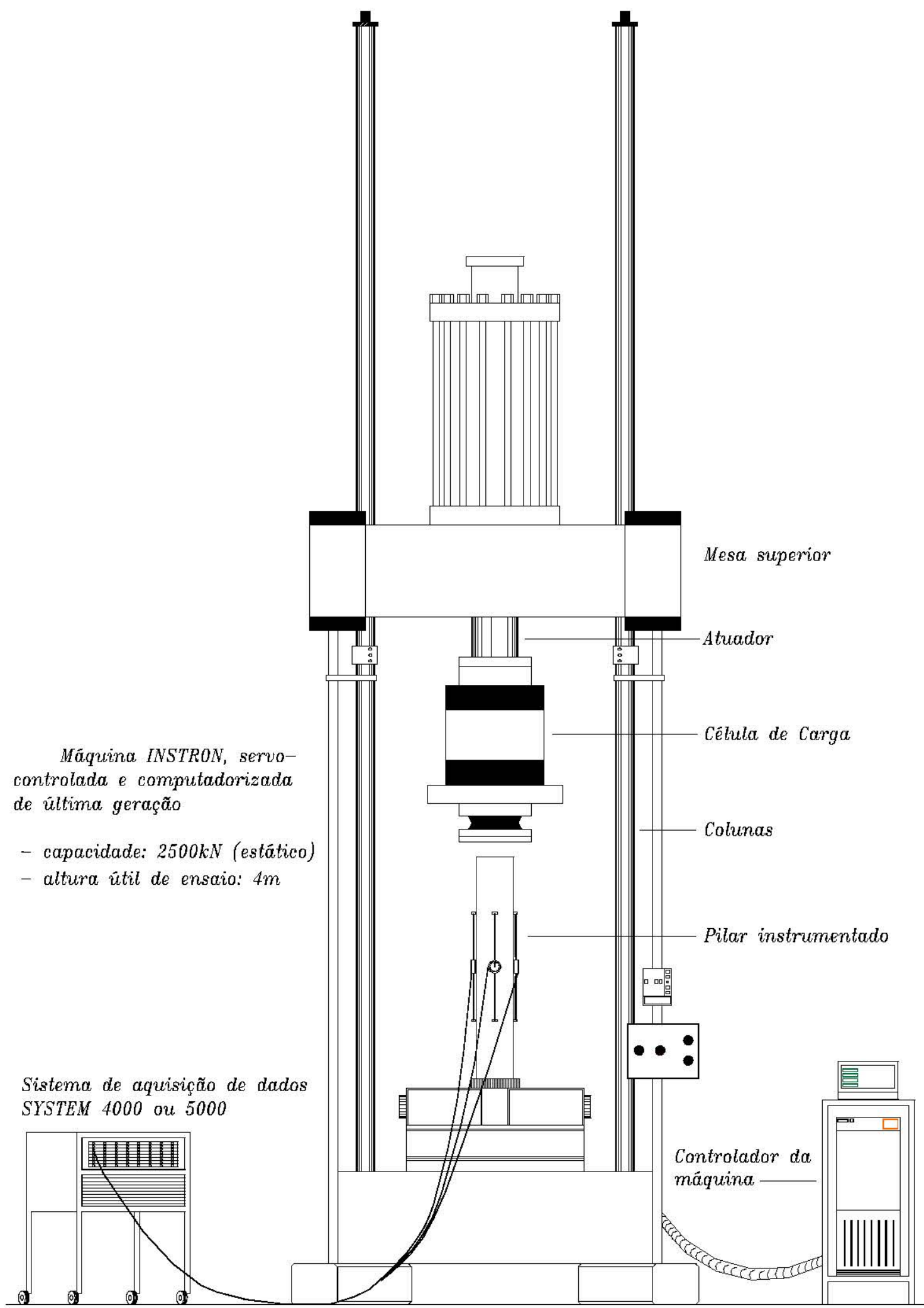

Figura 4.3. Detalhe da aparelhagem utilizada nos ensaios 


\subsection{Modelos ensaiados}

Foram utilizados pilares com seção transversal quadrada $(20 \mathrm{~cm} \times 20 \mathrm{~cm})$ e retangular $(15 \mathrm{~cm} \times 30 \mathrm{~cm}) \mathrm{com}$ altura igual a $120 \mathrm{~cm}$ e $90 \mathrm{~cm}$, respectivamente (seis vezes a menor dimensão da seção transversal). A escolha destas dimensões para os modelos foi uma forma de aproximá-las às dimensões usuais dos pilares de edifícios, uma vez que, nas pesquisas anteriores, devido às limitações dos aparelhos de ensaio, as dimensões dos modelos eram bem reduzidas.

A armadura dos pilares ensaiados foi estabelecida de tal forma que séries sucessivas tinham taxas geométricas de armadura transversal $\left(\rho_{\mathrm{w}}\right)$ crescentes, obtidas através de menores espaçamentos, ficando o diâmetro das barras inalterado em todos os modelos. O objetivo destes acréscimos era avaliar qual a taxa mínima de armadura transversal que garantisse a ductilização do pilar. A armadura longitudinal $\left(\rho_{\mathrm{sl}}\right)$ não variou nos modelos de mesma seção. A tabela 4.5 traz as características das armaduras empregadas.

Tabela 4.5. Armaduras dos pilares

\begin{tabular}{|c|c|c|c|c|c|}
\hline \multicolumn{6}{|c|}{ Concreto de resistência média de $60 \mathrm{MPa}$ aos 15 dias } \\
\hline \multirow{2}{*}{\multicolumn{2}{|c|}{ Pilares }} & \multicolumn{2}{|c|}{ Dimensões da seção } & \multirow[t]{2}{*}{ Estribos } & \multirow{2}{*}{$\begin{array}{l}\text { Armadura } \\
\text { longitudinal }\end{array}$} \\
\hline & & $b(\mathrm{~cm})$ & $h(\mathrm{~cm})$ & & \\
\hline \multirow[t]{2}{*}{ SÉRIE 1} & $\mathrm{P} 1^{*}$ & 20 & 20 & $\phi 6,3 c / 15$ & $8 \phi 12,5$ \\
\hline & $\mathrm{P}^{*}$ & 20 & 20 & $\phi 6,3 c / 15$ & $8 \phi 12,5$ \\
\hline \multirow[t]{2}{*}{ SÉRIE 2} & $\mathrm{P}^{* *}$ & 20 & 20 & $\phi 6,3 c / 10$ & $8 \phi 12,5$ \\
\hline & $\mathrm{P} 4^{* *}$ & 20 & 20 & $\phi 6,3 c / 10$ & $8 \phi 12,5$ \\
\hline \multirow[t]{2}{*}{ SÉRIE 3} & $P 5^{\star *}$ & 20 & 20 & $\phi 6,3 c / 5$ & $8 \phi 12,5$ \\
\hline & $P 6^{* \star}$ & 20 & 20 & $\phi 6,3 c / 5$ & $8 \phi 12,5$ \\
\hline \multirow[t]{2}{*}{ SÉRIE 4} & $\mathrm{P} 7^{* *}$ & 15 & 30 & $\phi 6,3 c / 15$ & $8 \phi 12,5$ \\
\hline & $P 8^{* \star}$ & 15 & 30 & $\phi 6,3 c / 15$ & $8 \phi 12,5$ \\
\hline \multirow[t]{2}{*}{ SÉRIE 5} & $\mathrm{Pg}^{\star \star}$ & 15 & 30 & $\phi 6,3 c / 10$ & $8 \phi 12,5$ \\
\hline & $\mathrm{P} 10^{* *}$ & 15 & 30 & $\phi 6,3 c / 10$ & $8 \phi 12,5$ \\
\hline \multirow[t]{2}{*}{ SÉRIE 6} & $\mathrm{P} 11^{* *}$ & 15 & 30 & $\phi 6,3 c / 5$ & $8 \phi 12,5$ \\
\hline & $\mathrm{P} 12^{* *}$ & 15 & 30 & $\phi 6,3 c / 5$ & $8 \phi 12,5$ \\
\hline
\end{tabular}

Obs:* utilizou-se a Dosagem 1; ${ }^{* *}$ utilizou-se a Dosagem 2 


\subsubsection{Previsão para a força última}

Tendo em vista a limitação da máquina de ensaio para força estática ( $2500 \mathrm{kN})$, foi calculada previamente a força última para a seção íntegra de concreto (sem perda do cobrimento) e para o núcleo de concreto definido pela linha de centro dos estribos da armadura transversal. Neste cálculo desprezaram-se os possíveis acréscimos na resistência do concreto devido ao confinamento. O coeficiente adotado para correlacionar a resistência à compressão do concreto, obtida através dos corpos-de-prova, com a do modelo foi $k=0,90$. A tabela $4 \cdot 6$ traz os resultados para as forças últimas. Para fins de cálculo, considerou-se, inicialmente, $f_{c}$ igual a $60 \mathrm{MPa}$. Porém, no cálculo definitivo de $F_{\text {teo }}$ e $F_{\text {teo,n }}$, serão usados os valores de $f_{c}$ obtidos através dos ensaios dos corpos-de-prova aos 15 dias.

Tabela 4.6. Previsão da força última de ruptura dos pilares $\left(A_{s}=10 \mathrm{~cm}^{2}-8\right.$ barras de

$$
\phi=12,5 \mathrm{~mm})
$$

\begin{tabular}{|c|c|c|c|c|c|c|c|c|c||}
\hline Pilar & $\begin{array}{c}\boldsymbol{b} \\
(\mathbf{c m})\end{array}$ & $\begin{array}{c}\boldsymbol{h} \\
(\mathbf{c m})\end{array}$ & $\begin{array}{c}\mathbf{A}_{c} \\
\left(\mathbf{c m}^{2}\right)\end{array}$ & $\begin{array}{c}\mathbf{A}_{c n} \\
\left(\mathbf{c m}^{2}\right)\end{array}$ & $\begin{array}{c}\boldsymbol{f}_{c} \\
(\mathbf{M P a})\end{array}$ & $\begin{array}{c}\mathbf{0 . 9 f _ { c }} \\
(\mathbf{M P a})\end{array}$ & $\begin{array}{c}\boldsymbol{f}_{\mathbf{y}} \\
(\mathbf{M P a})\end{array}$ & $\begin{array}{c}\boldsymbol{F}_{\text {teo }} \\
(\mathbf{k N})\end{array}$ & $\begin{array}{c}\boldsymbol{F}_{\text {teo, } \boldsymbol{n}} \\
(\mathbf{k N})\end{array}$ \\
\hline P1 & 20 & 20 & 400 & 251,9 & 60 & 54 & 502 & 2608 & 1862 \\
\hline P2 & 20 & 20 & 400 & 251,9 & 60 & 54 & 502 & 2608 & 1862 \\
\hline P3 & 20 & 20 & 400 & 251,9 & 60 & 54 & 502 & 2608 & 1862 \\
\hline P4 & 20 & 20 & 400 & 251,9 & 60 & 54 & 502 & 2608 & 1862 \\
\hline P5 & 20 & 20 & 400 & 251,9 & 60 & 54 & 502 & 2608 & 1862 \\
\hline P6 & 20 & 20 & 400 & 251,9 & 60 & 54 & 502 & 2608 & 1862 \\
\hline P7 & 15 & 30 & 450 & 263,1 & 60 & 54 & 502 & 2878 & 1922 \\
\hline P8 & 15 & 30 & 450 & 263,1 & 60 & 54 & 502 & 2878 & 1922 \\
\hline P9 & 15 & 30 & 450 & 263,1 & 60 & 54 & 502 & 2878 & 1922 \\
\hline P10 & 15 & 30 & 450 & 263,1 & 60 & 54 & 502 & 2878,1 & 1922,8 \\
\hline P11 & 15 & 30 & 450 & 263,1 & 60 & 54 & 502 & 2878,1 & 1922,8 \\
\hline P12 & 15 & 30 & 450 & 263,1 & 60 & 54 & 502 & 2878,1 & 1922,8 \\
\hline \hline
\end{tabular}




\subsection{Concretagem}

\subsubsection{Fôrmas}

As fôrmas foram produzidas pela Oficina de Marcenaria da EESC-USP. Os desenhos das fôrmas para os pilares de $20 \mathrm{~cm} \times 20 \mathrm{~cm} \times 120 \mathrm{~cm}$ e $15 \mathrm{~cm} \times 30 \mathrm{~cm} \times$ $90 \mathrm{~cm}$ são mostrados na figura 4.4 .

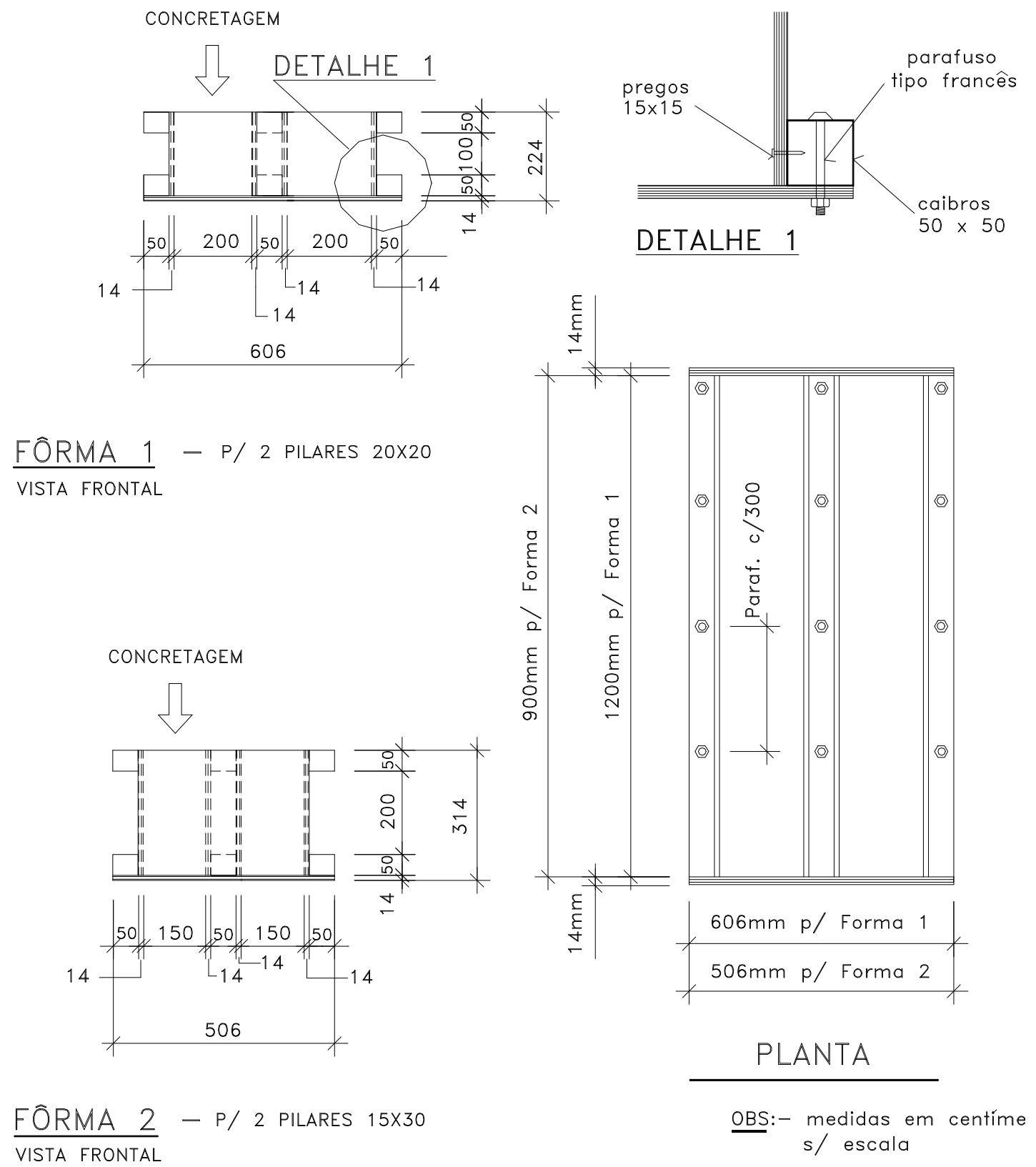

Figura 4.4. Esquema de fôrmas para os pilares 


\subsubsection{Mistura}

Para a mistura dos materiais utilizou-se o misturador do Laboratório de Estruturas, com capacidade de 200 litros, marca CIBI, figura 4.5. Os componentes foram colocados no misturador na seguinte ordem: pedra britada $+20 \%$ de água, cimento $+30 \%$ de água, sílica ativa, restante da água + superplastificante, areia.

Em cada moldagem de dois pilares foram executados 12 corpos-de-prova cilíndricos de $100 \mathrm{~mm}$ x $200 \mathrm{~mm}$ para o controle da resistência à compressão, tabela 4.7. O objetivo destes ensaios é o de determinar-se a evolução da resistência do concreto com o tempo.

Tabela 4.7. Corpos-de-prova

\begin{tabular}{|c|c|c||}
\hline$N^{0}$ de corpos-de-prova & Data do ensaio & $\begin{array}{c}\text { Tipo de ensaio } \\
\text { Compressão }\end{array}$ \\
\hline 3 & 3 dias & Compressão \\
\hline 3 & 7 dias & Compressão \\
\hline 3 & 15 dias & de força \\
\hline 3 & 15 dias & $\begin{array}{c}\text { Compressão com controle } \\
\end{array}$
\end{tabular}

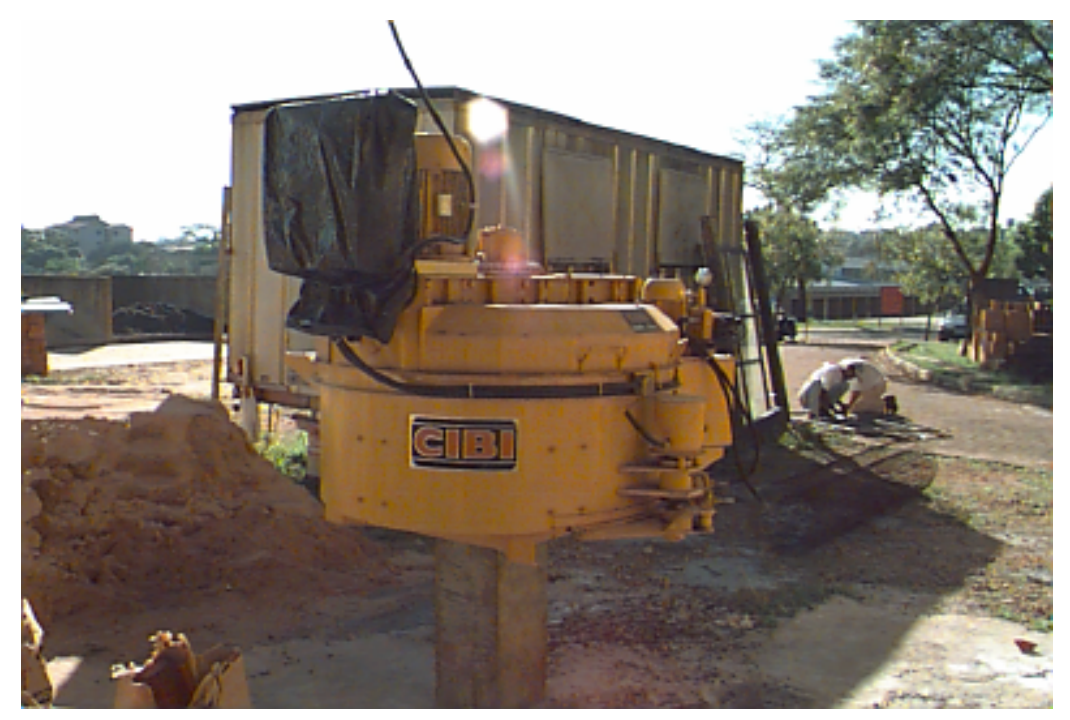

Figura 4.5. Misturador 


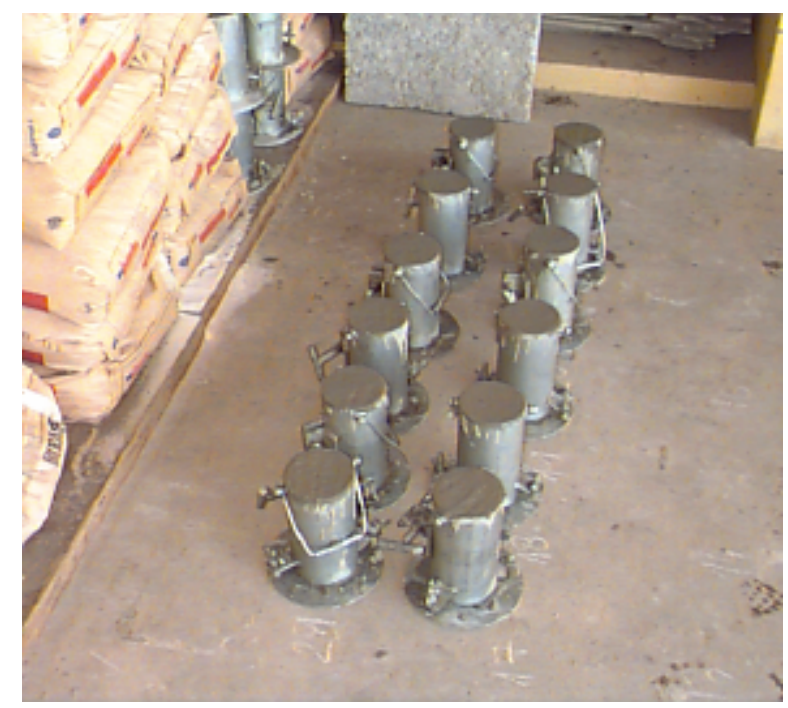

Figura 4.6. Detalhe dos corpos-de-prova moldados para cada série de pilares

\subsubsection{Adensamento}

Tanto os corpos-de-prova como os pilares foram vibrados nas mesas vibratórias do Laboratório de Estruturas da EESC-USP (figura 4.7).

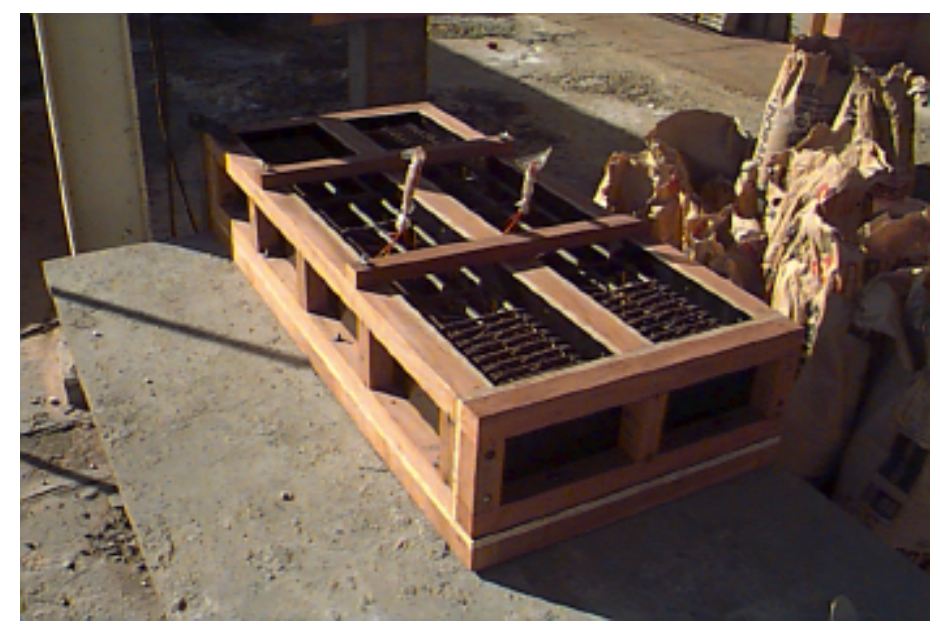

Figura 4.7. Detalhe da mesa vibratória com a fôrma já posicionada para concretagem

\subsubsection{Acabamento}

Logo em seguida era dado acabamento com colher de pedreiro à face livre dos modelos, de tal maneira a obter superfície lisa, sem imperfeições que 
pudessem prejudicar a colagem dos extensômetros. Na figura 4.8 são mostrados os pilares P1 e P2 logo após o acabamento.

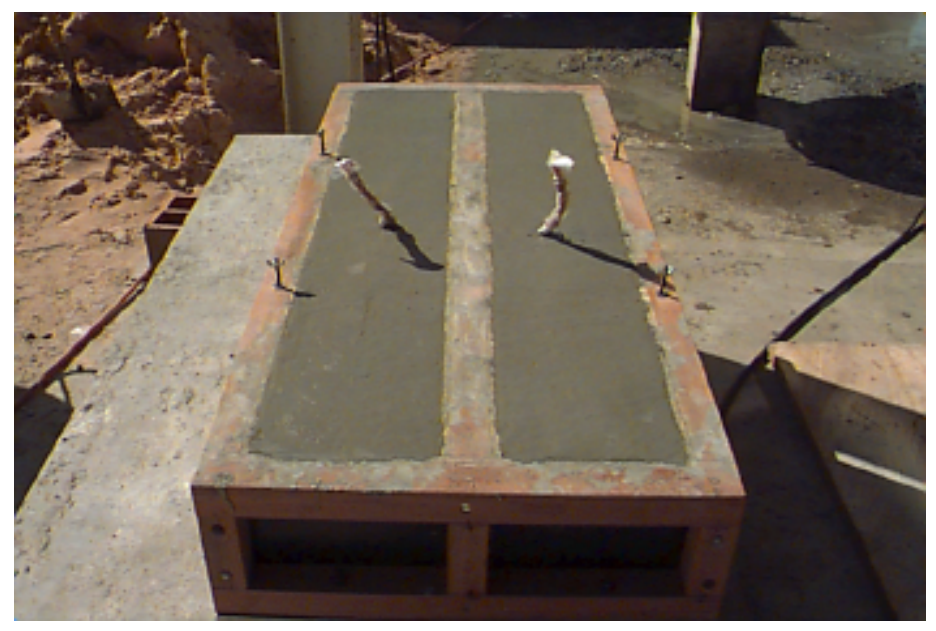

Figura 4.8. Modelos com superfície acabada

\subsubsection{Cura}

Logo após a moldagem dos pilares, estes permaneceram na fôrma por sete dias, sendo curados com o uso de manta de espuma de borracha permanentemente embebida em água. Em seguida eram desmoldados e colocados no ambiente do laboratório até a data do ensaio, figura 4.9.

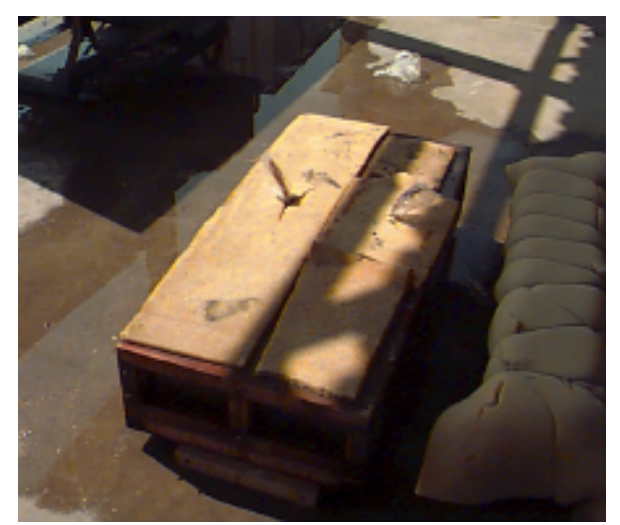

a). Cura.tmido

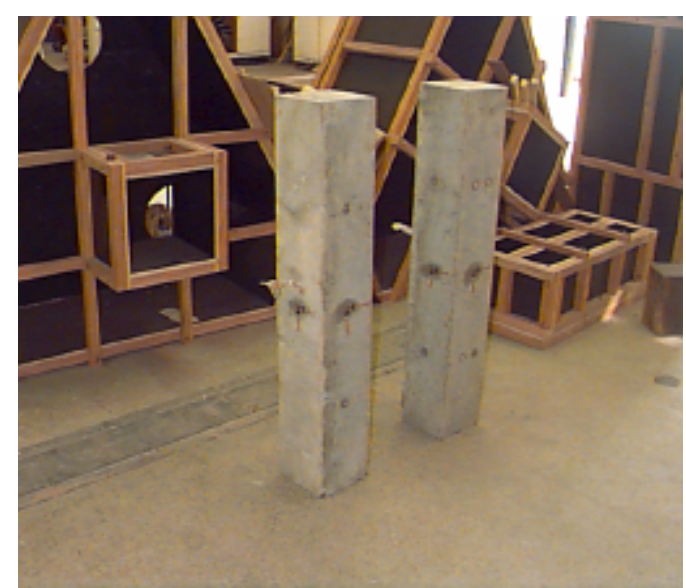

b). Em. ambiente de laborat trio

Figura 4.9. Etapas de cura dos pilares

Os corpos-de-prova, logo após a desmoldagem, foram imersos em água, ficando no tanque até um dia antes da data dos ensaios dos modelos. 


\subsubsection{Determinação das deformações}

a. Na armadura

As deformações nas barras das armaduras foram medidas por extensômetros elétricos fixados à meia altura das barras da armadura longitudinal e nos ramos dos estribos situados na seção média do pilar, como mostra a figura 4.11.

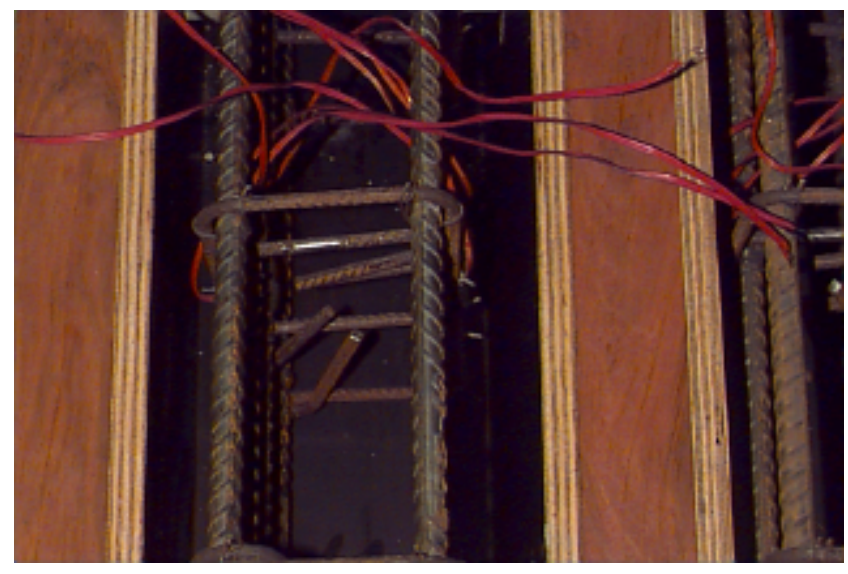

Figura 4.10. Detalhe da seção instrumentada

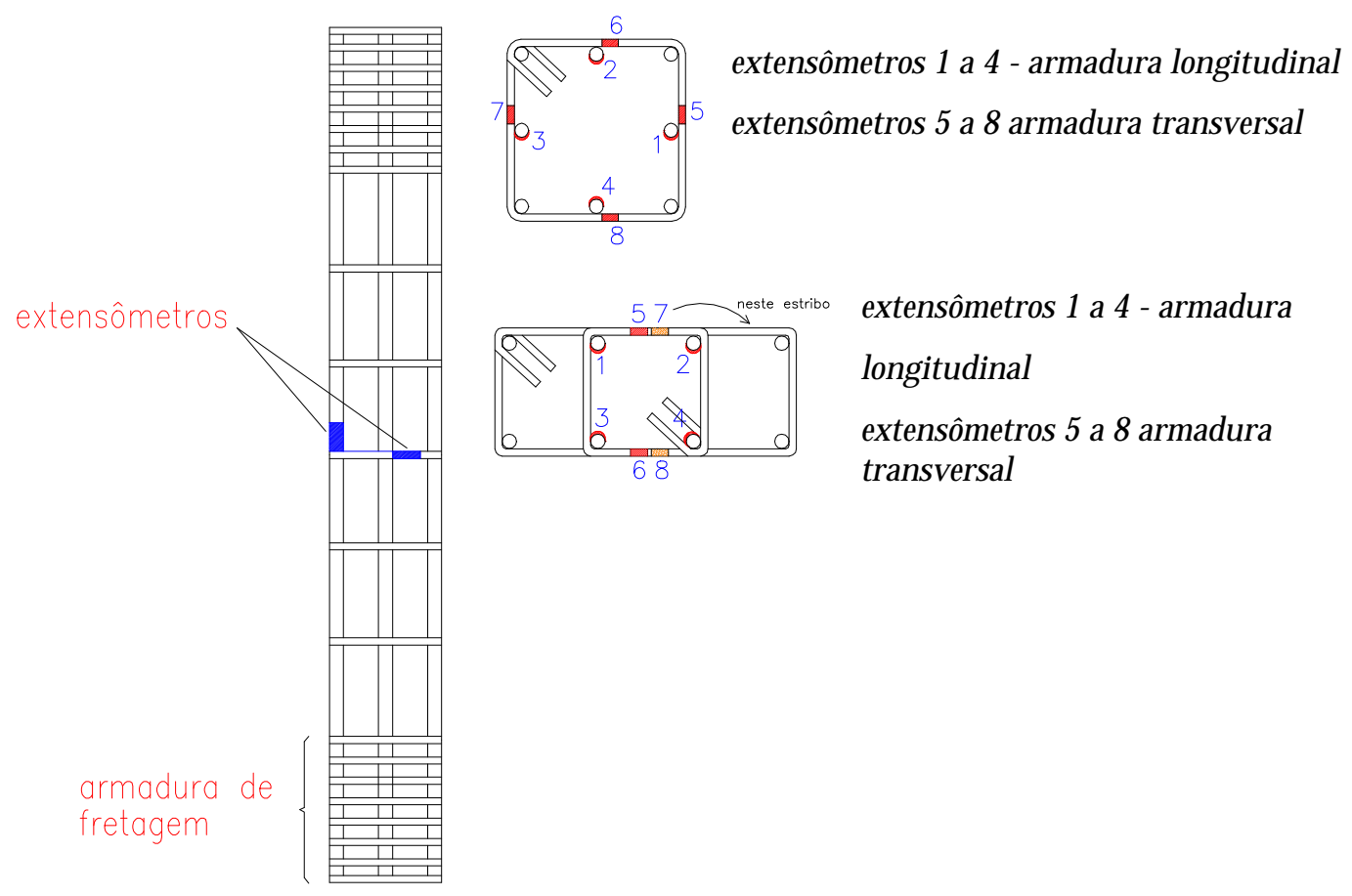

Figura 4.11. Localizacão dos extensômetros 


\section{b. No concreto}

Nas faces dos modelos as deformações no concreto foram medidas por extensômetros elétricos, nas quatro faces do pilar, situados à altura da seção transversal da armadura instrumentada. Dois extensômetros foram colados por face, perpendiculares entre si, de tal forma a se determinarem as deformações longitudinais e transversais no concreto, figura 4.12 .

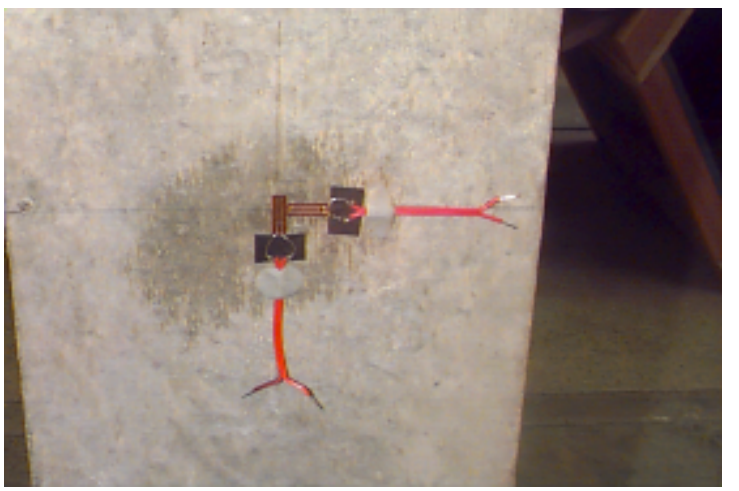

Figura 4.12. Detalhe do posicionamento dos extensômetros em uma face do pilar

A medição dos deslocamentos realizou-se através de defletômetros posicionados nas quatro faces do pilar, figura 4.13 .
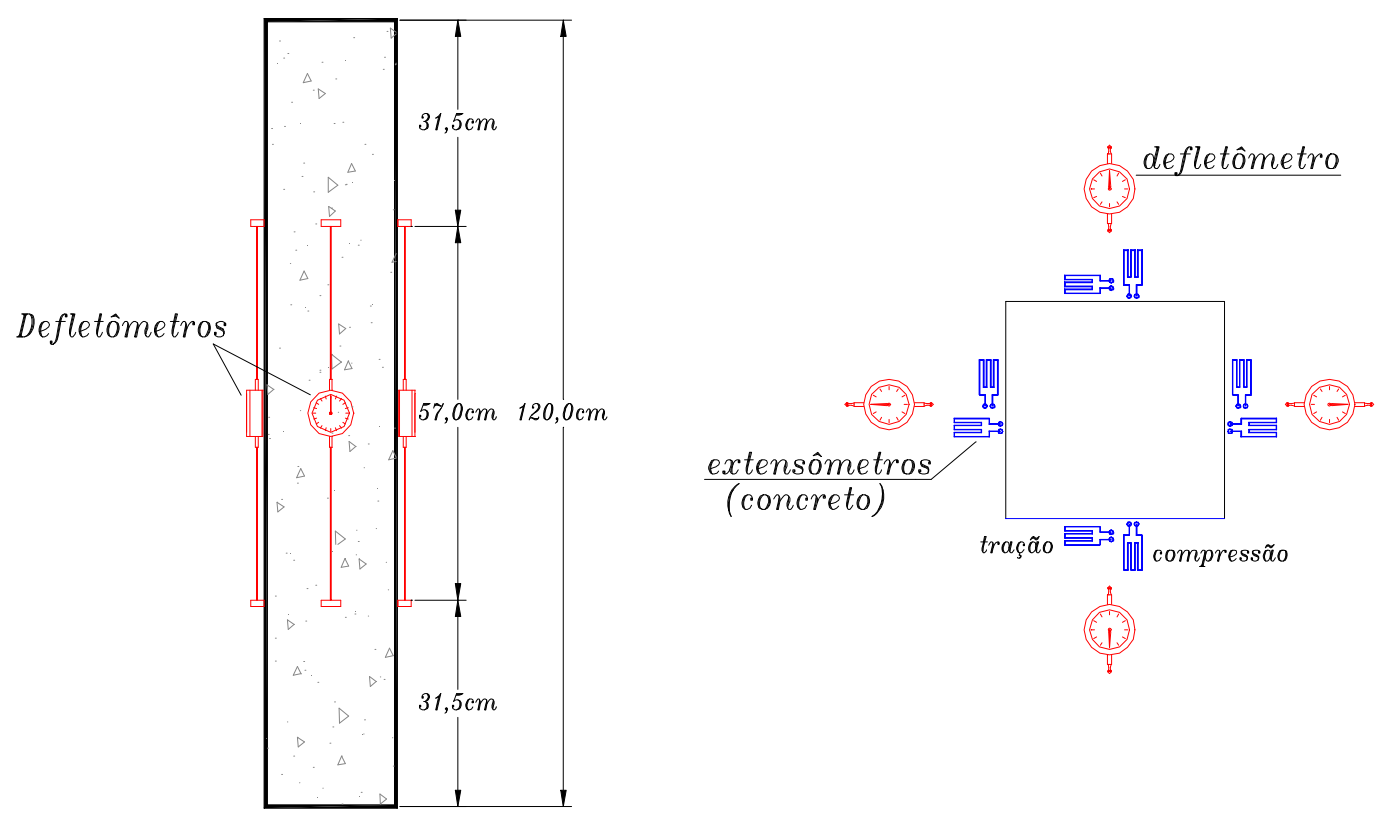


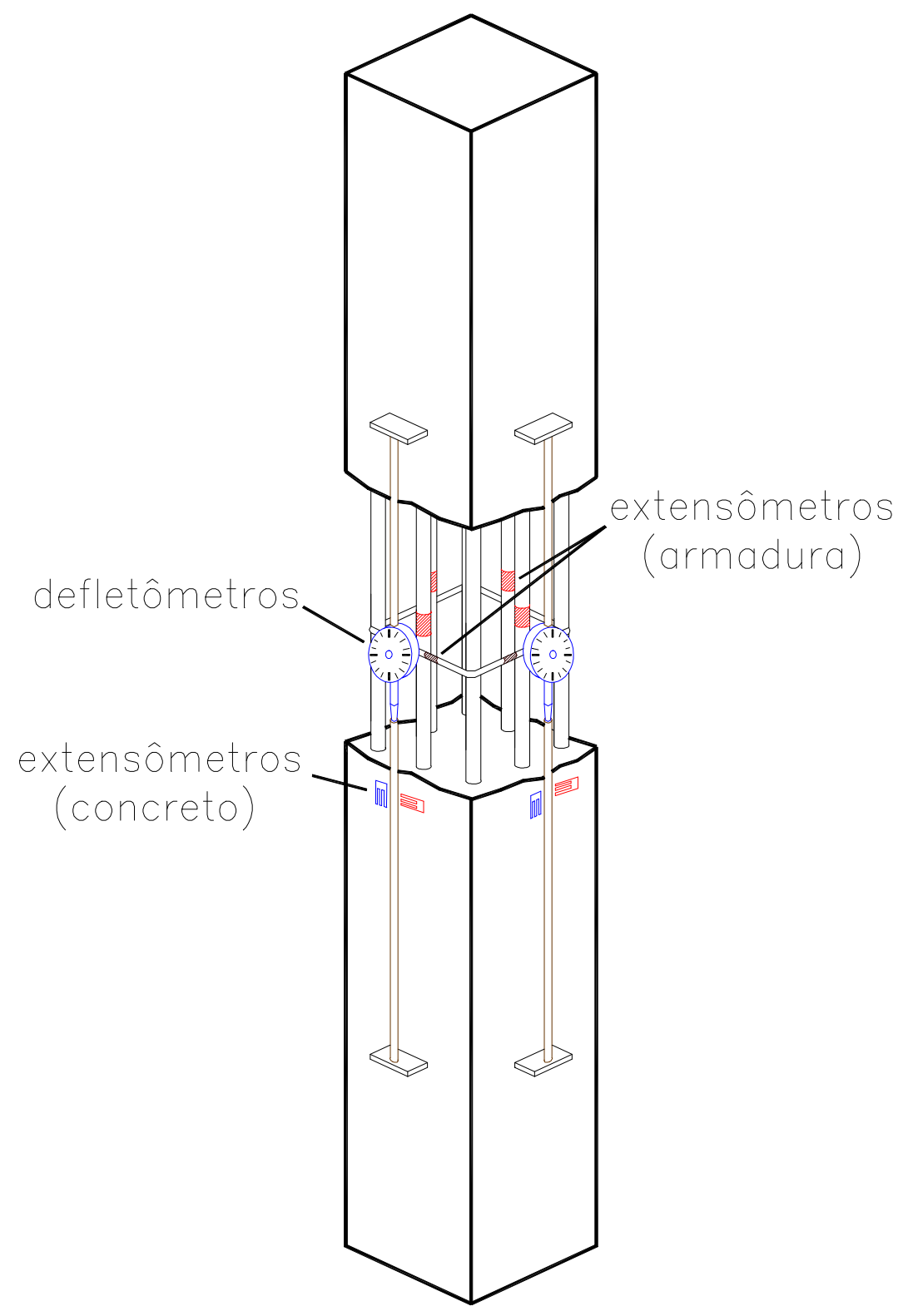

c) Vista geral da instrumentação

Figura 4.13. Esquema de instrumentação do pilar

\subsubsection{Execução das armaduras}

\section{a. Armadura longitudinal}

Era composta por oito barras de $12,5 \mathrm{~mm}$ de diâmetro, dispostas como mostra a figura 4.14. Utilizaram-se espaçadores de argamassa para garantir o cobrimento da armadura, figura 4.15 . 


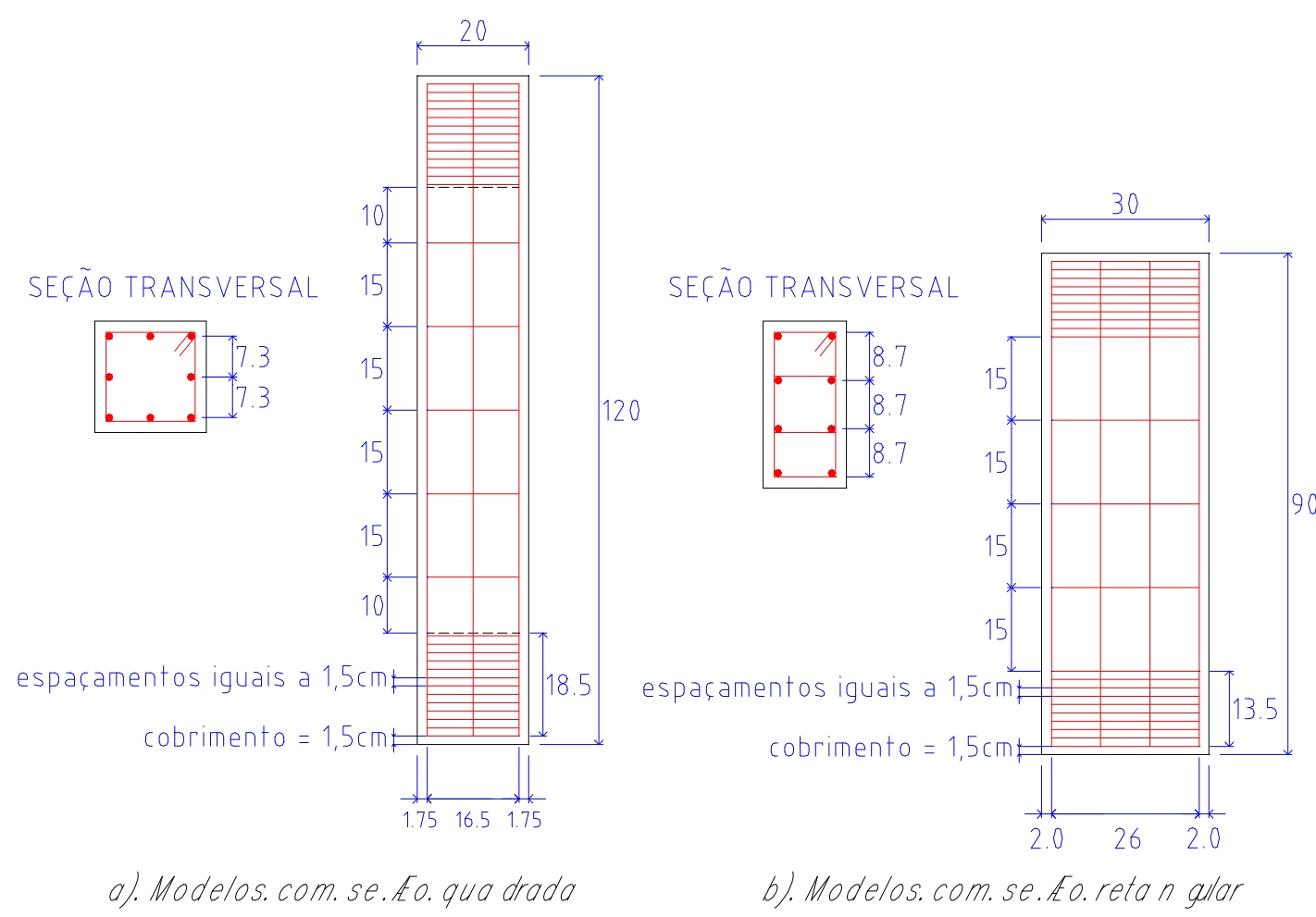

Figura 4.14. Detalhe das armaduras

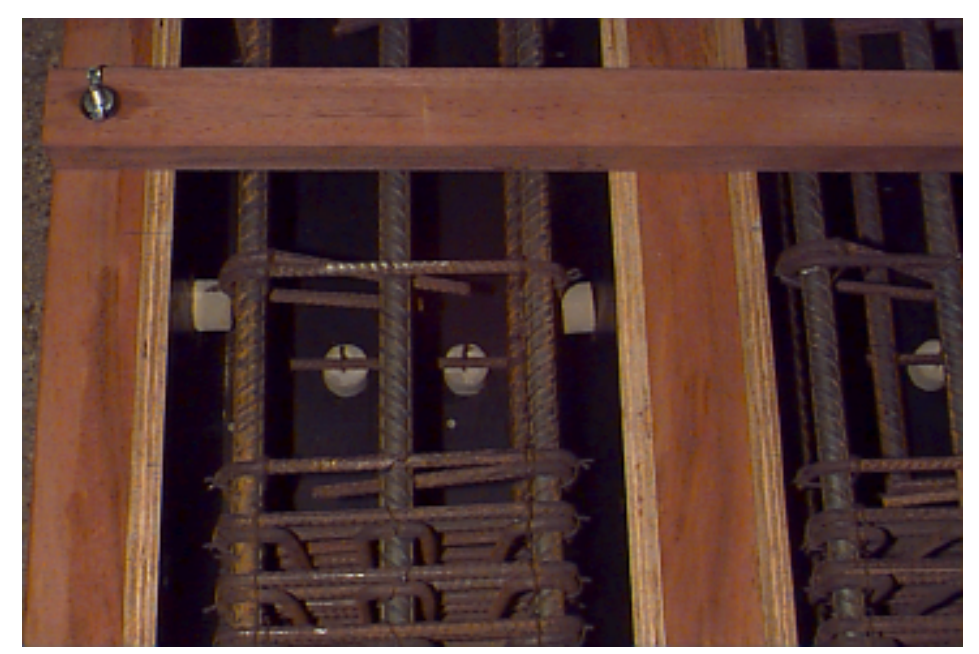

Figura 4.15. Detalhe dos espaçadores

b. Armadura transversal

Era composta por estribos a $90^{\circ}$ com bitolas e espaçamentos escolhidos para proporcionar diferentes valores para $\rho_{\mathrm{w}}$ (taxa volumétrica de armadura transversal). A tabela 4.8 traz os valores para $\rho_{\mathrm{w}}$. As configurações para os estribos nos modelos de seção transversal quadrada e retangular podem ser vistas na figura 4.16. 


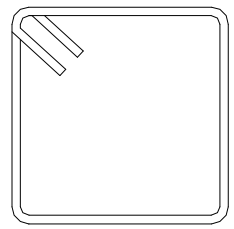

$\phi 6,3 c / 15$ (Série 1) $\phi 6,30 / 10$ (Série 2) $\phi 6,3 c / 5$ (Série 3)

Seção quadrada

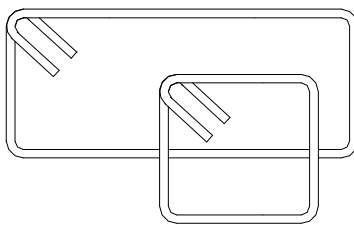

$\phi 6,3 c / 15$ (Série 4) $\phi 6,3 \mathrm{c} / 10$ (Série 5) $\phi 6,3 c / 5$ (Série 6)

Figura 4.16. Configurações para os estribos dos modelos de seção transversal quadrada e retangular

Tabela 4.8. Taxa geométrica de armadura transversal $\left(\rho_{\mathrm{w}}\right)$

\begin{tabular}{|c|c|c|c|c|c|c|c|}
\hline \multicolumn{8}{|c|}{ Concreto de resistência média de $60 \mathrm{MPa}$ aos 15 dias } \\
\hline \multicolumn{2}{|c|}{ Pilares } & \multicolumn{2}{|c|}{$\begin{array}{c}\text { Dimensões da } \\
\text { seção }\end{array}$} & \multirow[t]{2}{*}{ Estribos } & \multirow[t]{2}{*}{$\begin{array}{c}\text { Cobrimento } \\
\text { (cm) }\end{array}$} & \multirow[t]{2}{*}{$\rho_{w}(\%)$} & \multirow[t]{2}{*}{$\rho_{s l}(\%)$} \\
\hline & & $b(\mathrm{~cm})$ & $h(\mathrm{~cm})$ & & & & \\
\hline \multirow[t]{2}{*}{ SÉRIE 1} & $P 1$ & 20 & 20 & $\phi 6,3 c / 15$ & 1,75 & 0,34 & 2,5 \\
\hline & $P 2$ & 20 & 20 & $\phi 6,3 c / 15$ & 1,75 & 0,34 & 2,5 \\
\hline \multirow[t]{2}{*}{ SÉRIE 2} & $P 3$ & 20 & 20 & $\phi 6,3 c / 10$ & 1,75 & 0,51 & 2,5 \\
\hline & $P 4$ & 20 & 20 & $\phi 6,3 c / 10$ & 1,75 & 0,51 & 2,5 \\
\hline \multirow[t]{2}{*}{ SÉRIE 3} & $P 5$ & 20 & 20 & $\phi 6,3 c / 5$ & 1,75 & 1,03 & 2,5 \\
\hline & $P 6$ & 20 & 20 & $\phi 6,3 c / 5$ & 1,75 & 1,03 & 2,5 \\
\hline \multirow[t]{2}{*}{ SÉRIE 4} & $P 7$ & 15 & 30 & $\phi 6,3 c / 15$ & 2,00 & 0,34 & 2,2 \\
\hline & $P 8$ & 15 & 30 & $\phi 6,3 c / 15$ & 2,00 & 0,34 & 2,2 \\
\hline \multirow[t]{2}{*}{ SÉRIE 5} & $P 9$ & 15 & 30 & $\phi 6,3 c / 10$ & 2,00 & 0,51 & 2,2 \\
\hline & $P 10$ & 15 & 30 & $\phi 6,3 c / 10$ & 2,00 & 0,51 & 2,2 \\
\hline \multirow[t]{2}{*}{ SÉRIE 6} & $P 11$ & 15 & 30 & $\phi 6,3 c / 5$ & 2,00 & 1,03 & 2,2 \\
\hline & $P 12$ & 15 & 30 & $\phi 6,3 c / 5$ & 2,00 & 1,03 & 2,2 \\
\hline
\end{tabular}

c. Armadura de fretagem

Foi disposta nas extremidades dos pilares com a finalidade de proteger estes locais da ruptura prematura por efeito de ponta das barras da armadura longitudinal (figura 4.17 e 4.18 ). 
As extremidades dos modelos, por serem zonas de aplicação de forças, se constituem em regiões descontínuas, ou regiões de regularização de tensões, segundo o princípio de Saint-Venant.

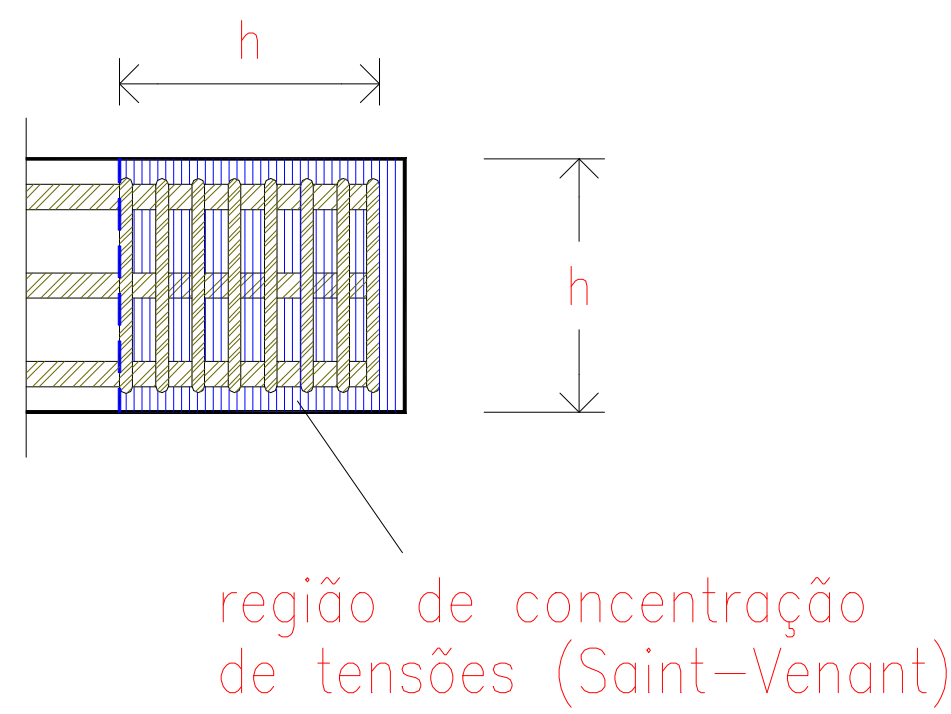

Figura 4.17. Armadura de fretagem

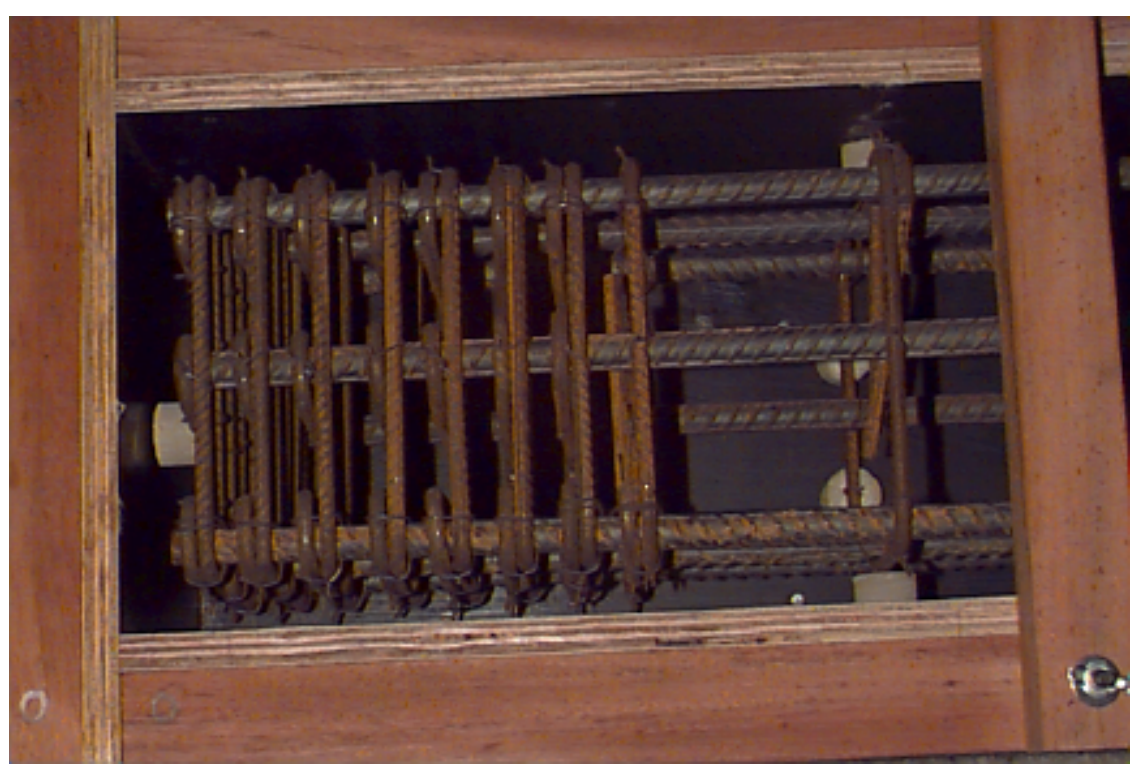

Figura 4.18. Detalhe da armadura de fretagem 


\subsection{Resultados dos Ensaios}

Neste item são apresentados e discutidos os resultados dos ensaios dos doze modelos. Os gráficos força $x$ deformação foram fornecidos para cada pilar. São também apresentados os valores médios para as deformações últimas.

\subsubsection{Série 1}

Os modelos da Série 1, pilares P1 e P2, possuíam seção transversal quadrada, $20 \mathrm{~cm} \times 20 \mathrm{~cm}$, e altura $120 \mathrm{~cm}$. A armadura transversal era composta por estribos espaçados de $15 \mathrm{~cm}$, resultando em taxa volumétrica de armadura transversal $\left(\rho_{w}\right)$ igual a $0,34 \%$, valor mínimo para esta variável adotado na pesquisa. Os modelos foram moldados com a Dosagem 1 (tabela 4.1) e ensaiados aos 15 dias $\left(P 1-f_{c}=59,60 M P a\right)$ e 16 dias $\left(P 2-f_{c}=64,35 M P a\right)$.

\section{a. Pilar P1 - 1aㅡ Etapa}

Para o pilar $\mathrm{P} 1$ a força última prevista, considerando $\mathrm{f}_{\mathrm{c}}$ igual a $60 \mathrm{MPa}$ - tabela 4.6 - era de $2608 \mathrm{kN}$, para a seção íntegra de concreto, e $1862 \mathrm{kN}$ considerando-se a seção de concreto definida pelos eixos dos estribos. Esperava-se que a força última se posicionasse entre a força última teórica para a seção íntegra $\left(F_{\text {teo }}\right)$ e a prevista para o núcleo de concreto $\left(\mathrm{F}_{\text {teo,n }}\right)$.

Este modelo teve seu ensaio prejudicado pela perda inesperada de pressão da bomba para o pistão da máquina INSTRON. No início do ensaio o deslocamento foi aplicado à velocidade de $0,005 \mathrm{~mm} / \mathrm{s}$, até o valor da força igual a $1800 \mathrm{kN}$, prosseguindo à velocidade de $0,001 \mathrm{~mm} / \mathrm{s}$ até $2115 \mathrm{kN}$, que permaneceu estável devido a perda de pressão da bomba. Diante disto o ensaio teve de ser encerrado mesmo com o modelo já apresentando alguns sinais que indicavam a proximidade da ruína, como algumas fissuras na região situada à meia-altura do pilar.

Para saber qual seria a força última para o pilar $\mathrm{P} 1$, o ensaio foi recomeçado, agora com maior velocidade de aplicação de deslocamento $(0,05 \mathrm{~mm} / \mathrm{s})$. A força de ruptura foi de $2278 \mathrm{kN}$. Os resultados obtidos para o Pilar P1 nas duas etapas do ensaio são apresentados nos gráficos a seguir.

A ruptura do pilar ocorreu por esmagamento do concreto na região próxima à seção situada à meia altura do pilar (seção instrumentada). Não houve problemas de esmagamento do concreto nas extremidades do modelo, indicando a eficiência da armadura de fretagem na proteção destas regiões. 


\section{Gráficos - Pilar P1 - 1a Etapa}
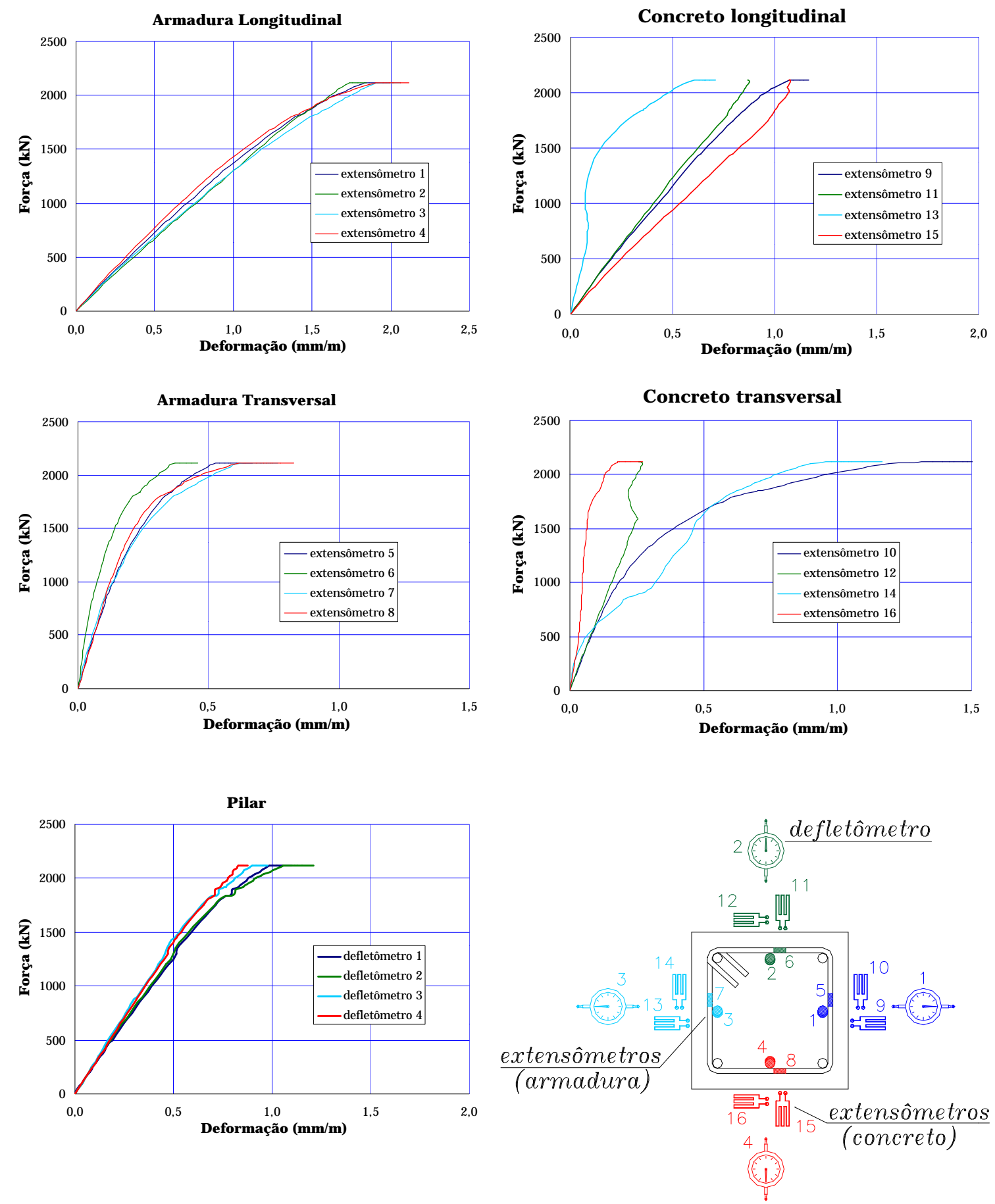

Figura 4.19. Diagramas força $x$ deformação para o pilar $\mathrm{P} 1$ - 1를 Etapa Características geométricas e físicas:

$$
\begin{gathered}
\mathrm{s}=15 \mathrm{~cm} ; \rho_{\mathrm{l}}=2,5 \% ; \rho_{\mathrm{w}}=0,34 \% \\
\mathrm{f}_{\mathrm{c}}=59,60 \mathrm{MPa} ; \mathrm{F}_{\text {fase } 1}=2115 \mathrm{kN}
\end{gathered}
$$


Convêm lembrar, a princípio, que o pilar P1, nesta primeira etapa de ensaio, não chegou à ruptura por motivo já exposto anteriormente. Por esta razão, nos comentários a seguir, não se faz referência à força última $\left(F_{\mathrm{u}}\right)$, mas à força máxima $\left(F_{\text {fase } 1}=2115 \mathrm{kN}\right)$, com a qual houve a interrupção da aplicação de força pela máquina.

Observa-se também que algumas leituras apresentaram-se bem distantes da média das demais. Para o pilar P1 - $1^{\text {a }}$ etapa - os problemas se deram com os extensômetros 13 (concreto - compressão), 12 e 16 (concreto - tração), todos situados em faces opostas do modelo. Podem-se apontar algumas causas genéricas para explicar erros deste tipo:

1. Formação de fissuras na região instrumentada pelos extensômetros;

2. Erros referentes ao sistema de aquisição e leitura de dados;

3. Imperfeições na colagem dos extensômetros na superfície do modelo. Apesar dos cuidados durante toda a etapa experimental da pesquisa, erros como este são suscetíveis a acontecer.

No caso dos extensômetros citados, como as variações de leitura foram observadas desde valores baixos para a força aplicada, torna-se evidente que uma possível fissuração na região de fixação dos extensômetros não seria a causa das diferenças de leitura.

Para o Pilar P1 - 1a etapa, podem-se listar, a partir dos gráficos, algumas observações referentes a seu comportamento. A disposição dos gráficos e as escalas utilizadas procuram facilitar a visualização e comparação dos resultados. $A$ figura 4.19 também traz o esquema de instrumentação utilizado, com a respectiva numeração dos extensômetros e defletômetros.

- Armadura longitudinal. As leituras apresentaram-se bem próximas. O aspecto do gráfico mostra que a armadura estava no início do escoamento, embora não tivesse atingindo a deformação de escoamento determinada pelo ensaio à tração, 2,99\%. A deformação última foi de 2,26\%。 (valor médio);

- Concreto - Compressão. Apresentou leituras em um extensômetro distantes da média das outras três. Este fato pode ser explicado por problemas com o sistema de leitura e aquisição de dados ou, como 
parece mais provável, a imperfeições na fixação dos extensômetros na superfície de concreto;

- Armadura Transversal. Apresentou comportamento uniforme para os quatro extensômetros. A deformação máxima (valor médio) foi de $0,70 \%$;

- Concreto - Tração. A partir de valores para a força correspondentes a $0,25 \%$ da força máxima aplicada, dois extensômetros (12 e 16) apresentaram leituras distantes das demais. A deformação última foi aproximadamente igual a $1 \%$, desprezando-se os valores registrados nos extensômetros 12 e 16;

- Pilar. As leituras nos defletômetros foram bem uniformes, descrevendo o comportamento do pilar até a força máxima aplicada. O diagrama mostra a linearidade do trecho ascendente da curva, caracterizando desta forma o pilar de CAR. O pilar apresentou deformação máxima aproximadamente igual a 0,9\%o, não atingindo, portanto, o limite de deformação para elementos comprimidos (2\%). A intensa formação de fissuras superficiais próximo à interrupção do ensaio revelou a iminência da ruína.

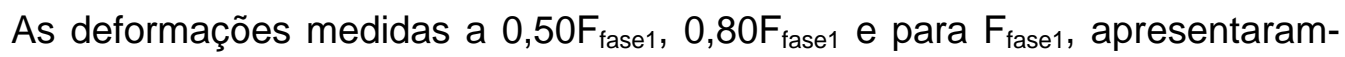
se próximas para o pilar e para o concreto à compressão, tabela 4.9. Porém, comparando-se estes valores aos da armadura longitudinal, as deformações se aproximam apenas para valores da força iguais a $0,50 \mathrm{~F}_{\text {fase1. }}$. Para força superior a

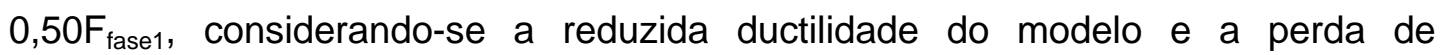
aderência do concreto com as barras da armadura, as deformações nas barras da armadura longitudinal se distanciam das registradas para o pilar e para as medidas nas faces do modelo (concreto - compressão).

Tabela 4.9. Valores das deformações para o pilar P1 - 1를 Etapa (\%o)

\begin{tabular}{|l|c|c|c|c|c|c||}
\cline { 2 - 7 } \multicolumn{1}{c|}{} & $\begin{array}{c}\text { Armadura } \\
\text { Longitudinal } \\
(\mathbf{A L})\end{array}$ & $\begin{array}{c}\text { Concreto - } \\
\text { Compressão } \\
(\mathbf{C C})\end{array}$ & $\begin{array}{c}\text { Pilar } \\
\mathbf{( P )}\end{array}$ & $\mathbf{A L / C C}$ & $\mathbf{A L} / \mathbf{P}$ & $\mathbf{C C / P}$ \\
\hline Deformação a $0,50 \mathrm{~F}_{\text {fase } 1=1058 \mathrm{kN}}$ & 0,7 & $0,6^{*}$ & 0,4 & 1,1 & 1,75 & 1,5 \\
\hline Deformação a $0,80 \mathrm{~F}_{\text {fase } 1=1692 \mathrm{kN}}$ & 1,3 & $0,9^{*}$ & 0,6 & 1,4 & 2,2 & 1,5 \\
\hline Deformação a $\mathrm{F}_{\text {fase } 1=2115 \mathrm{kN}}$ & 2,0 & $1,1^{*}$ & 1,0 & 1,8 & 2,0 & 1,1 \\
\hline
\end{tabular}

* Sem considerar-se a leitura no extensômetro 13 
Os valores superiores a 1 para a relação $A L / C C$ e $A L / P$ revelam que as deformações no núcleo* foram bem superiores às medidas nas faces do modelo, tornando-se ainda maiores com o acréscimo de força. Isto demonstra que, mesmo após os valores últimos para a deformação no concreto terem sido atingidos, o núcleo ainda continua a deformar-se.

* Obs: Admitindo-se que as deformações do concreto do núcleo sejam aproximadamente iguais à $s$ da armadura longitudinal devido ao fenômeno da aderência (até valores da ordem de $2 \%$ ), comparando-se as deformações do concreto (compressão) medidas na face do pilar - região de cobrimento - às da armadura longitudinal observa-se que as deformações no cobrimento são inferiores à s do núcleo. Isto confirma a existência de deformações diferenciais entre o concreto do núcleo e o concreto de cobrimento.

A tabela 4.10 traz os valores das deformações registradas a $0,50 \mathrm{~F}_{\text {fase } 1}$, $0,80 \mathrm{~F}_{\text {fase1 }}$ e para $\mathrm{F}_{\text {fase1 }}$ para a armadura transversal e concreto à tração. Comparando-se os resultados, observa-se que as deformações nos estribos e no concreto apresentam-se ligeiramente distantes durante todas as etapas do ensaio, com o concreto deformando-se mais em conseqüência da provável instabilidade do cobrimento.

Tabela 4.10. Valores das deformações para o pilar P1 - 1를 Etapa (\%o)

\begin{tabular}{|l|c|c|c|}
\cline { 2 - 4 } \multicolumn{1}{c|}{} & $\begin{array}{c}\text { Concreto - } \\
\text { Tração (CT) }\end{array}$ & $\begin{array}{c}\text { Armadura } \\
\text { Transversal (AT) }\end{array}$ & T/AT \\
\hline Deformação a 0,50F fase1 $=1058 \mathrm{kN}$ & 0,18 & 0,13 & 1,4 \\
\hline Deformação a $0,80 \mathrm{~F}_{\text {fase } 1=1692 \mathrm{kN}}$ & 0,33 & 0,27 & 1,2 \\
\hline Deformação a $\mathrm{F}_{\text {fase1 }}=2115 \mathrm{kN}$ & 0,85 & 0,70 & 1,2 \\
\hline
\end{tabular}

\section{b. Pilar P1- $2^{a}$ Etapa}

Na repetição do ensaio do pilar $\mathrm{P} 1$, ao atingir-se a força última para o modelo, esperava-se que a leitura dos valores da força aplicada se estabilizasse por alguns instantes, com acréscimos de deformação do pilar (gerando um patamar no diagrama), e viesse a cair de forma a poder ser registrada pelo computador. Porém os valores caíram muito rapidamente, de tal forma que o trecho descendente da curva força $x$ deformação não pôde ser obtido, revelando a reduzida ductilidade do modelo. 


\section{Gráficos - Pilar P1 - 2a Etapa}
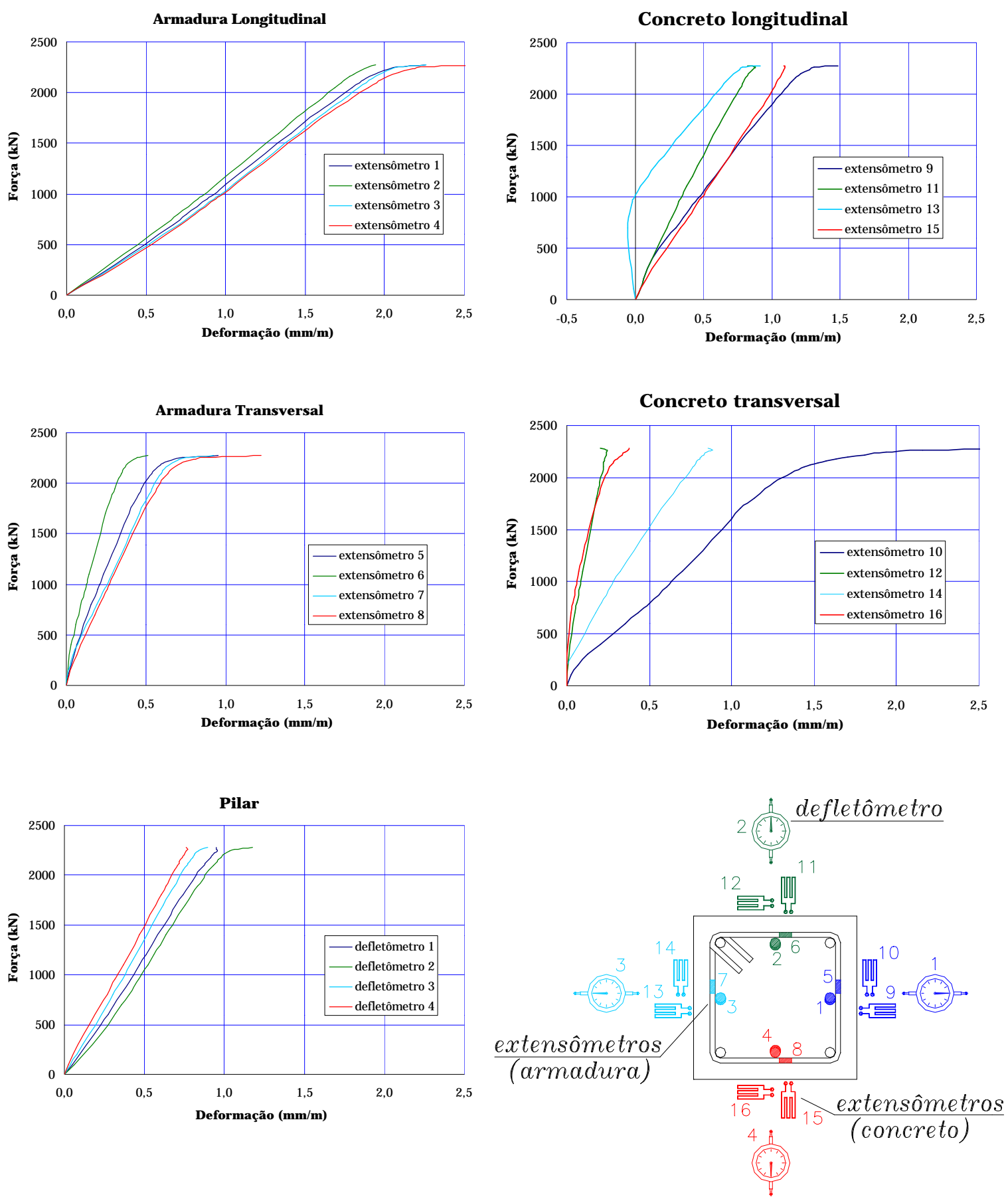

Figura 4.20. Diagramas força $x$ deformação para o pilar $\mathrm{P} 1$ - $2^{\mathrm{a}}$ Etapa Características geométricas e físicas:

$$
\begin{gathered}
s=15 \mathrm{~cm} ; \rho_{\mathrm{l}}=2,5 \% ; \rho_{\mathrm{w}}=0,34 \% \\
\mathrm{f}_{\mathrm{c}}=59,60 \mathrm{MPa} ; \mathrm{F}_{\mathrm{u}}=2278 \mathrm{kN}
\end{gathered}
$$


A exemplo do que aconteceu na etapa anterior, os extensômetros 13 (concreto - compressão), 12 e 16 (concreto - tração), forneceram registros distantes da média dos demais.

Nesta segunda etapa de ensaio, o pilar P1 foi levado à ruína, que ocorreu sob força de $2278 \mathrm{kN}$. Houve esmagamento do concreto, com flambagem das barras da armadura longitudinal. Os gráficos revelam o comportamento do modelo e servem para verificar a validade da repetição do ensaio.

- Armadura longitudinal. As leituras nos extensômetros não apresentaram grandes diferenças. A deformação última para as barras foi de $2,27 \%$. O aspecto do gráfico mostra que as barras da armadura longitudinal já estavam escoando quando da ruína do modelo;

- Concreto - Compressão. Apresentou comportamento irregular causado pelas leituras no extensômetro 13. A deformação última foi igual a 1,1\%, desprezando-se a leitura fornecida por este extensômetro;

- Armadura Transversal. A deformação última foi de 1\%o. Embora este valor seja inferior à deformação de escoamento no ensaio à tração $\left(\varepsilon_{y}=3,37 \%\right.$ ), observou-se o início da formação de patamar de escoamento no diagrama força $x$ deformação. Percebe-se então que, somente para valores muito próximos à força última, os estribos passam a ser solicitados com mais intensidade através da deformação transversal do concreto. Este fato indica que a taxa de armadura transversal empregada $\left(\rho_{w}=0,34 \%\right)$ não é suficiente para prover acréscimos de ductilidade ao elemento estrutural;

Outro fato que pode explicar as grandes deformações nos estribos próximo à ruína do pilar é a flambagem das barras da armadura longitudinal, cujo mecanismo vem a solicitar com grande intensidade os estribos naquela região, figura 4.21;

- Concreto - Tração. Como observado na primeira etapa, os extensômetros 12 e 16 voltaram a fornecer resultados distantes das outras leituras. A média das deformações últimas ficou em 1,1\%o, portanto, próxima ao valor obtido para a armadura transversal; 
- Pilar. A deformação última foi igual a $0,95 \%$, próxima ao limite atingido pelas leituras nas faces do modelo.

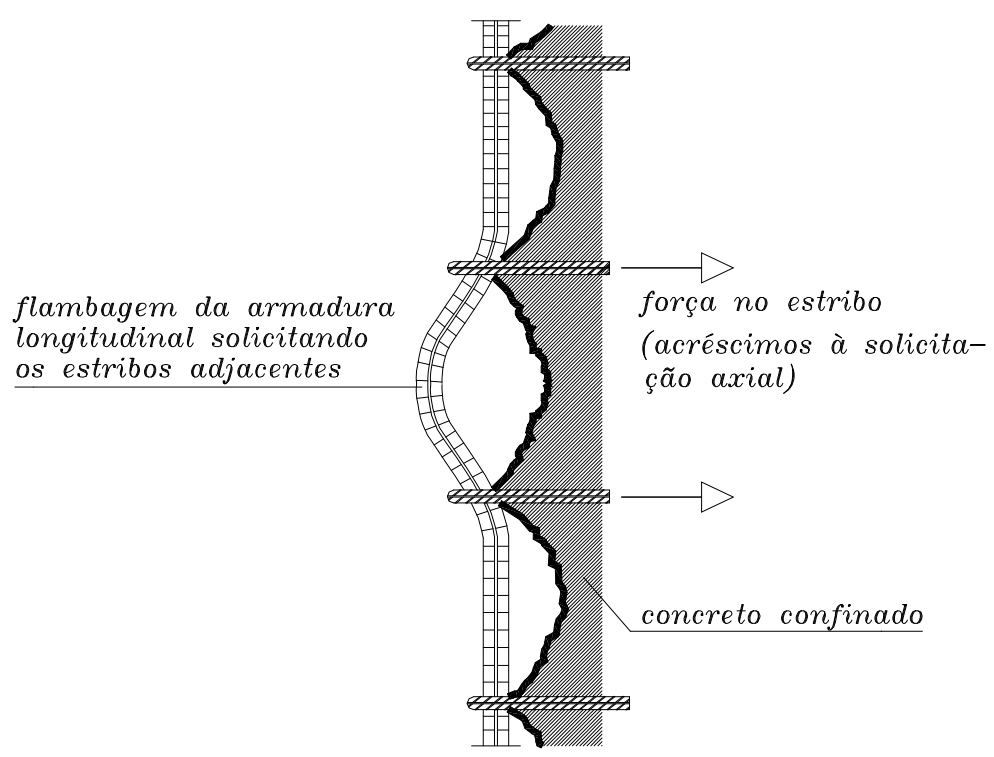

Figura 4.21. Esquema de solicitação dos estribos através da flambagem das barras da armadura longitudinal

Da apreciação dos gráficos, percebe-se que o comportamento do pilar não foi significativamente alterado devido à repetição do ensaio. Os aspectos dos diagramas são bem semelhantes aos da primeira etapa, levando à conclusão que a repetição do ensaio pode ser considerada para a determinação da força última de ruptura do pilar.

Tabela 4.11. Valores das deformações para o pilar P1 - 2ª Etapa (\%o)

\begin{tabular}{|l|c|c|c|c|c|c||}
\cline { 2 - 7 } \multicolumn{1}{c|}{} & $\begin{array}{c}\text { Armadura } \\
\text { Longitudinal } \\
(\mathbf{A L})\end{array}$ & $\begin{array}{c}\text { Concreto - } \\
\text { Compressão } \\
(\mathbf{C C})\end{array}$ & $\begin{array}{c}\text { Pilar } \\
\mathbf{( P )}\end{array}$ & $\mathbf{A L / C C}$ & $\mathbf{A L} / \mathbf{P}$ & $\mathbf{C C} / \mathbf{P}$ \\
\hline Deformação a $0,50 \mathrm{~F}_{\mathrm{u}}=1140 \mathrm{kN}$ & 1,05 & 0,40 & 0,46 & 2,62 & 2,28 & 0,87 \\
\hline Deformação a $0,80 \mathrm{~F}_{\mathrm{u}}=1822 \mathrm{kN}$ & 1,60 & 0,75 & 0,72 & 2,13 & 2,22 & 1,04 \\
\hline Deformação a $\mathrm{F}_{\mathrm{u}}=2278 \mathrm{kN}$ & 2,27 & 1,10 & 0,95 & 2,06 & 2,38 & 1,16 \\
\hline
\end{tabular}

Cabe observar que as relações AL/CC e AL/P superiores a 2 (desde o início da aplicação de força) mostram que, na repetição do ensaio, o cobrimento já se apresentava como região inefetiva, com deformações bem inferiores às do núcleo, que, por sua vez, resistia isoladamente à força aplicada. 
Tabela 4.12. Valores das deformações para o pilar P1 - 2ª Etapa (\%o)

\begin{tabular}{|l|c|c|c|}
\cline { 2 - 4 } \multicolumn{1}{c|}{} & $\begin{array}{c}\text { Concreto - } \\
\text { Tração }(\mathrm{CT})\end{array}$ & $\begin{array}{c}\text { Armadura } \\
\text { Transversal (AT) }\end{array}$ & CT/AT \\
\hline Deformação a $0,50 \mathrm{~F}_{\mathrm{u}}=1140 \mathrm{kN}$ & 0,31 & 0,25 & 1,24 \\
\hline Deformação a $0,80 \mathrm{~F}_{\mathrm{u}}=1822 \mathrm{kN}$ & 0,53 & 0,43 & 1,23 \\
\hline Deformação a $\mathrm{F}_{\mathrm{u}}=2278 \mathrm{kN}$ & 1,10 & 1,05 & 1,05 \\
\hline
\end{tabular}

As diferenças se explicam pela progressiva perda da "placa" de cobrimento, para forças próximas a $F_{u}$, ver figura 3.8.

Fica aqui esclarecido que o ensaio do pilar P1, por ter sido o primeiro modelo rompido, e considerando-se que, naquela ocasião, o conhecimento sobre o funcionamento da máquina ainda não era total, apresentou as dificuldades anteriormente expostas que, no entanto, não invalidaram a apreciação do pilar nem sua posterior comparação com os modelos teóricos propostos pela literatura.

\section{c. Pilar P2}

O pilar P2, com as mesmas características geométricas de $\mathrm{P} 1$, possuía valores idênticos para as forças últimas teóricas previstas para o primeiro pilar da série $\left(F_{\text {teo }}=2608 \mathrm{kN} ; F_{\text {teo,n }}=1862 \mathrm{kN}\right)$. Como também ocorreu com o pilar P1, a ruptura foi brusca, com desagregação do concreto e flambagem localizada das barras da armadura longitudinal (figura 4.22), não sendo possível a obtenção do trecho descendente do diagrama força $x$ deformação.
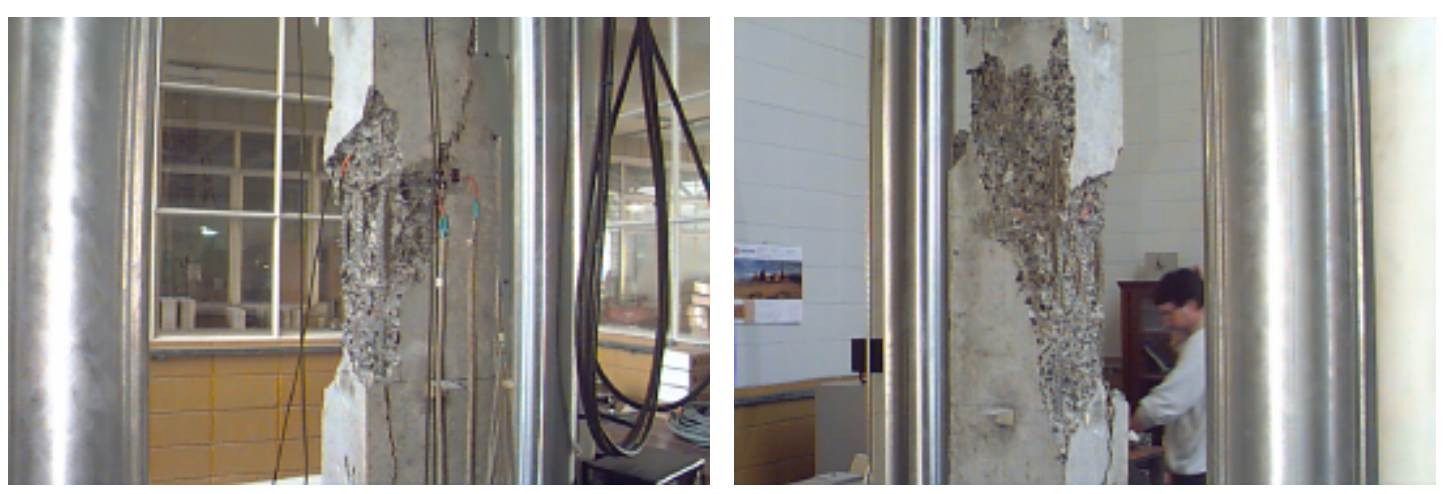

Figura 4.22. Aspecto do pilar P2 após a ruína 


\section{Gráficos - Pilar P2}
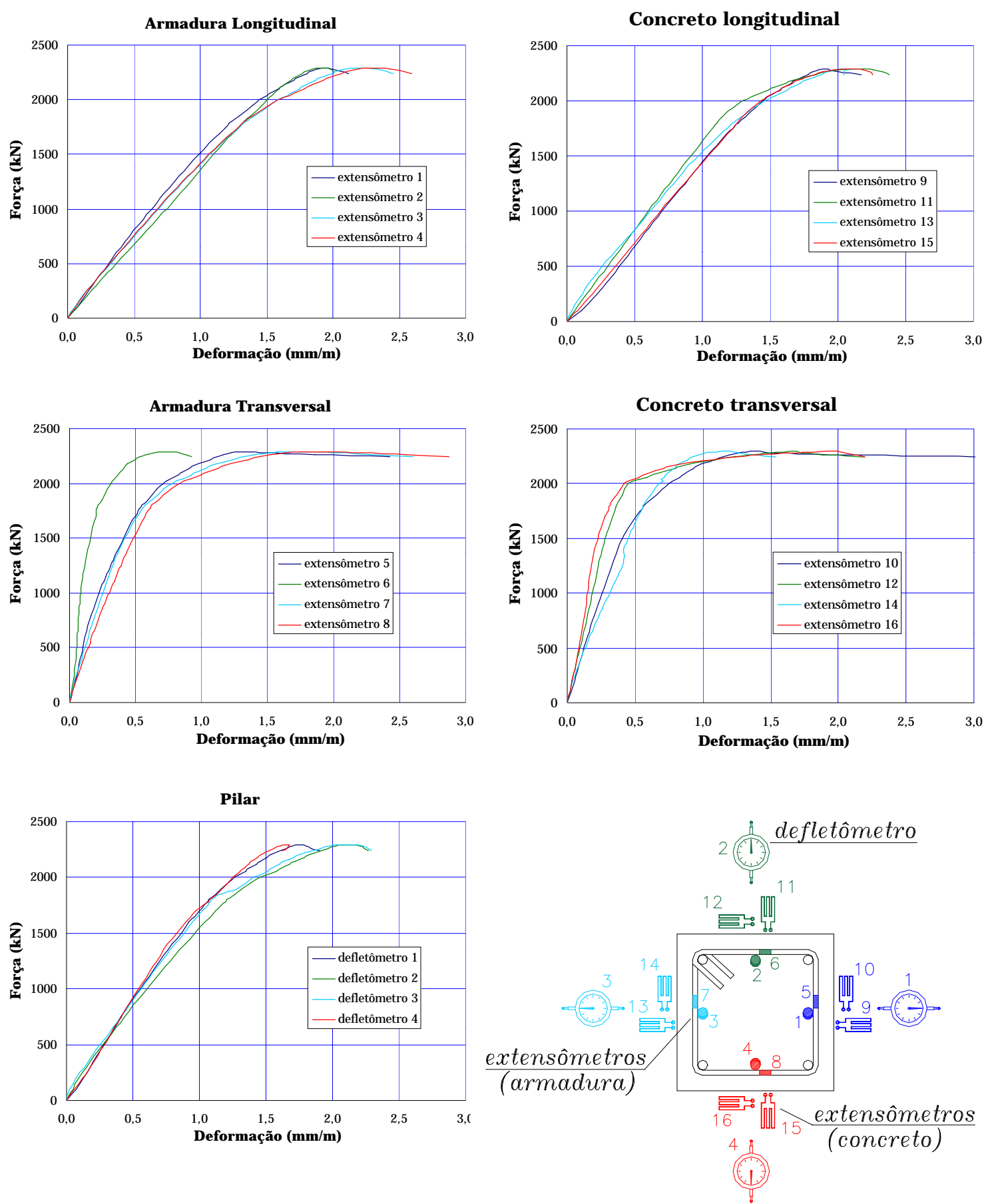

Figura 4.23. Diagramas força $x$ deformação para o pilar P2 Características geométricas e físicas:

$s=15 \mathrm{~cm} ; \rho_{l}=2,5 \% ; \rho_{w}=0,34 \%$

$\mathrm{f}_{\mathrm{c}}=64,35 \mathrm{MPa} ; \mathrm{F}_{\mathrm{u}}=2292 \mathrm{kN}$ 
A força última foi de $2292 \mathrm{kN}$, situando-se portanto, entre os valores teóricos previstos. Avalia-se agora o comportamento do diagrama força $x$ deformação para as armaduras, concreto e pilar:

- Armadura longitudinal. A armadura longitudinal apenas se aproximou do patamar de escoamento ( $\varepsilon_{\mathrm{ul}}=2,30 \%$, valor médio);

- Concreto - Compressão. Apresentou comportamento semelhante ao da armadura longitudinal, com deformação última para o concreto de 2,20\%. Os valores da deformação medida na face do pilar, sendo ligeiramente inferiores aos observados para a armadura longitudinal, indicam a existência de encurtamentos diferenciados para 0 cobrimento e o núcleo;

- Armadura Transversal. A deformação última foi de 2,21\%. Observa-se a formação do patamar de escoamento para a armadura. A leitura através do extensômetro 6 ficou distante das demais. A grande solicitação dos estribos para valores próximos a $F_{\mathrm{u}}$ se deve a fatores como a flambagem da armadura transversal, figura 4.21;

- Concreto - Tração. Apresentou deformação última igual a 2,27\%. Seu comportamento foi semelhante ao da armadura transversal, com deformações próximas às dos estribos;

- Pilar. A deformação última foi igual a 2,02\%, próxima ao limite atingido pelas leituras nas faces do modelo e pela armadura longitudinal.

Os gráficos mostraram que o pilar P2 veio a sanar as deficiências observadas para o primeiro modelo da Série 1. A tabela 4.13 compara as deformações medidas na armadura longitudinal, concreto e pilar, para valores da força iguais a $0,50 \mathrm{~F}_{u}$, $0,80 F_{u}$ e $F_{u}$.

Tabela 4.13. Valores das deformações para o pilar P2 (\%)

\begin{tabular}{|l|c|c|c|c|c|c||}
\cline { 2 - 7 } \multicolumn{1}{c|}{} & $\begin{array}{c}\text { Armadura } \\
\text { Longitudinal } \\
(\mathbf{A L})\end{array}$ & $\begin{array}{c}\text { Concreto - } \\
\text { Compressão } \\
(\mathbf{C C})\end{array}$ & $\begin{array}{c}\text { Pilar } \\
(\mathbf{P})\end{array}$ & $\mathbf{A L} / \mathrm{CC}$ & $\mathbf{A L / P}$ & $\mathbf{C C} / \mathbf{P}$ \\
\hline Deformação a $0,50 \mathrm{~F}_{\mathrm{u}}=1146 \mathrm{kN}$ & 0,79 & 0,75 & 0,59 & 1,05 & 1,34 & 1,27 \\
\hline Deformação a $0,80 \mathrm{~F}_{\mathrm{u}}=1834 \mathrm{kN}$ & 1,35 & 1,23 & 1,13 & 1,10 & 1,22 & 1,09 \\
\hline Deformação a $\mathrm{F}_{\mathrm{u}}=2292 \mathrm{kN}$ & 2,30 & 2,20 & 2,02 & 1,05 & 1,14 & 2,16 \\
\hline
\end{tabular}


As deformações nas barras da armadura longitudinal são ligeiramente superiores às do pilar e às medidas no concreto, o que demonstra que, mesmo para o baixo valor de $\rho_{\mathrm{w}}$ adotado nesta série $(0,34 \%)$, verificou-se, através dos encurtamentos diferenciados, a formação do núcleo resistente.

A tabela 4.14 traz os valores das deformações nos estribos e no concreto (tração) para $0,50 F_{u}, 0,80 F_{u}$ e $F_{u}$.

Tabela 4.14. Valores das deformações para o pilar P2 (\%)

\begin{tabular}{|l|c|c|c|}
\cline { 2 - 4 } \multicolumn{1}{c|}{} & $\begin{array}{c}\text { Concreto - } \\
\text { Tração (CT) }\end{array}$ & $\begin{array}{c}\text { Armadura } \\
\text { Transversal (AT) }\end{array}$ & CT/AT \\
\hline Deformação a $0,50 \mathrm{~F}_{\mathrm{u}}=1146 \mathrm{kN}$ & 0,26 & 0,25 & 1,04 \\
\hline Deformação a $0,80 \mathrm{~F}_{\mathrm{u}}=1834 \mathrm{kN}$ & 0,47 & 0,53 & 0,89 \\
\hline Deformação a $\mathrm{F}_{\mathrm{u}}=2292 \mathrm{kN}$ & 2,27 & 2,21 & 1,03 \\
\hline \hline
\end{tabular}

\subsubsection{Série 2}

A Série 2 era composta pelos pilares P3 e P4, de seção transversal quadrada com estribos espaçados de $10 \mathrm{~cm}$, proporcionando taxa volumétrica de armadura transversal $\left(\rho_{\mathrm{w}}\right)$ igual a $0,51 \%$. Os dois pilares ensaiados tiveram comportamento dúctil, com a separação quase total do cobrimento de concreto antes de alcançada a força última. A conclusão preliminar destas observações é que a taxa de armadura transversal adotada para a Série 2 garantiria comportamento dúctil aos pilares.

\section{a. Pilar P3}

A força máxima para o Pilar P3 foi $1835 \mathrm{kN}$, atingida com acréscimos de deslocamento de $0,005 \mathrm{~mm} / \mathrm{s}$ (até $1500 \mathrm{kN}$ ) e $0,002 \mathrm{~mm} / \mathrm{s}$ (até o final do ensaio). Quando a força última foi atingida o pilar continuou a deformar-se com forças cada vez menores, obtendo-se considerável trecho descendente do diagrama. $O$ ensaio foi interrompido para a força de $1050 \mathrm{kN}$. A ruína se deu pelo esmagamento do concreto na região próxima à seção situada à meia altura do pilar (seção instrumentada). 


\section{Gráficos - Pilar P3}
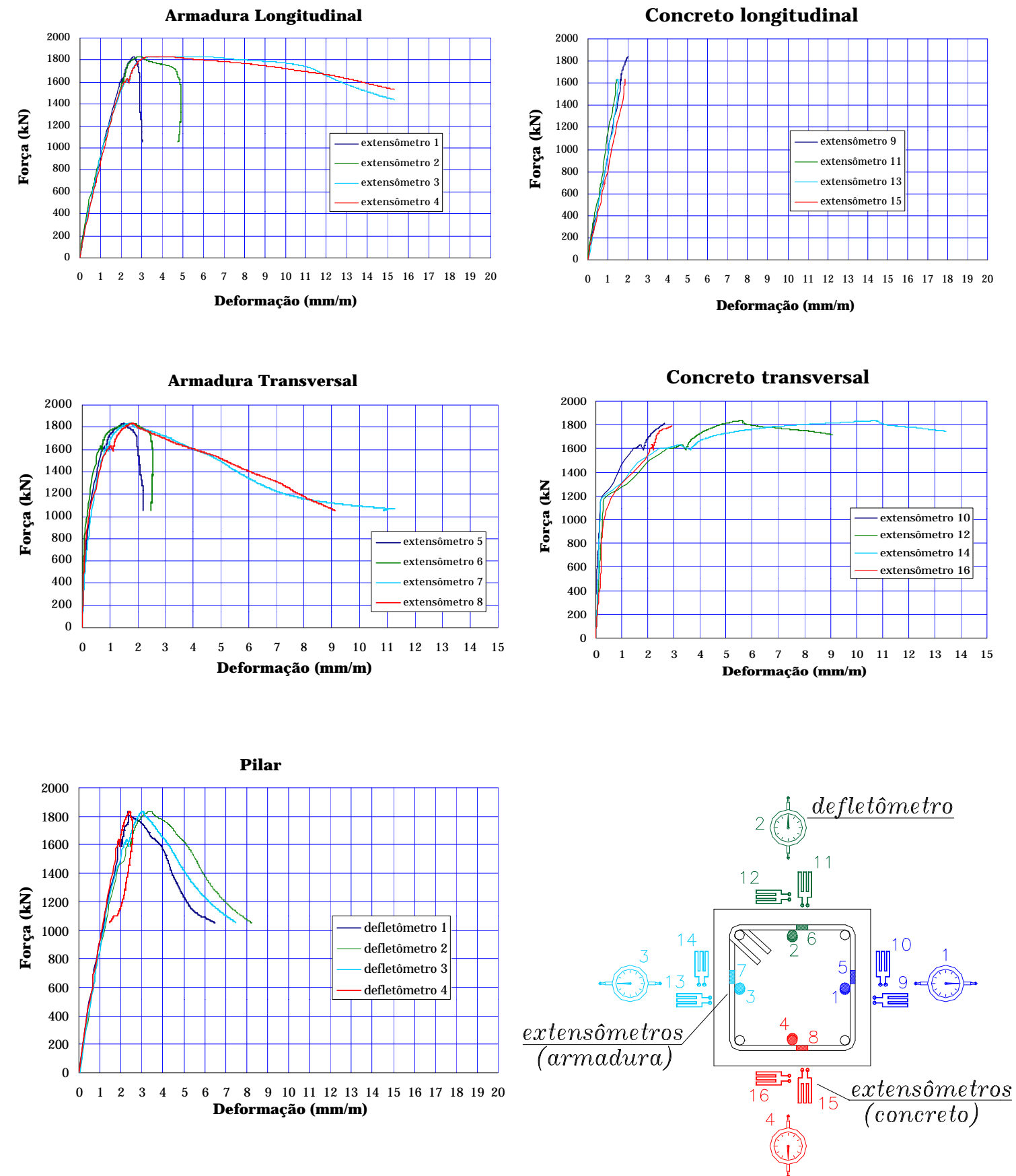

Figura 4.24. Diagramas força $x$ deformação para o pilar $P 3$ Características geométricas e físicas:

$$
\begin{gathered}
\mathrm{s}=10 \mathrm{~cm} ; \rho_{\mathrm{l}}=2,5 \% ; \rho_{\mathrm{w}}=0,51 \% \\
\mathrm{f}_{\mathrm{c}}=53,40 \mathrm{MPa} ; \mathrm{F}_{\mathrm{u}}=1835 \mathrm{kN}
\end{gathered}
$$


Comentários sobre os diagramas força x deformação:

- Armadura longitudinal. Observa-se do diagrama que a armadura longitudinal atingiu patamar de escoamento e grandes deformações, atingindo valores da ordem de $15 \%$, como registrado pelos extensômetros 3 e 4 . Comparando-se o diagrama obtido para a armadura longitudinal com os diagramas para o pilar e para 0 concreto observa-se que:

1. A armadura continua se deformando mesmo após atingidas as deformações últimas para o concreto, medidas pelos extensômetros posicionados nas faces do modelo, figura 4.13;

2. O aspecto do diagrama para a armadura revela 0 comportamento dúctil proporcionado pelo núcleo confinado. A área sob o diagrama é considerada como indicador de ductilidade. Para efeito de comparação, são dispostos os diagramas força $x$ deformação para os pilares P2 e P3, com a mesma escala para os valores da deformação, figura 4.25. As áreas sob os diagramas vêm a justificar a forma de ruína apresentada por cada modelo;

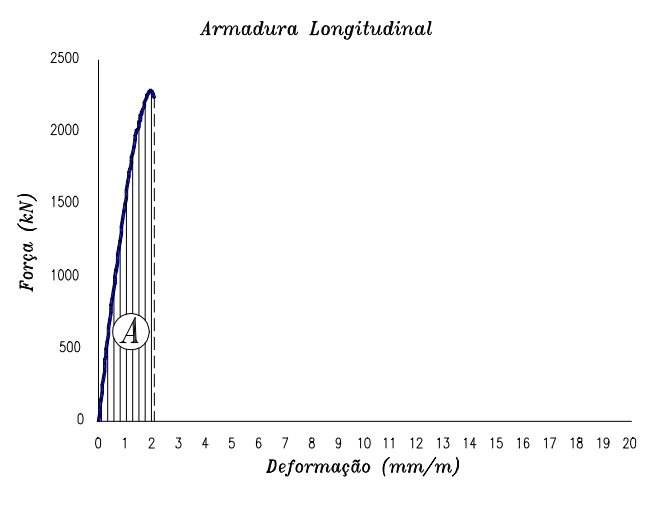

Pilar P2 - reduzida ductilidade

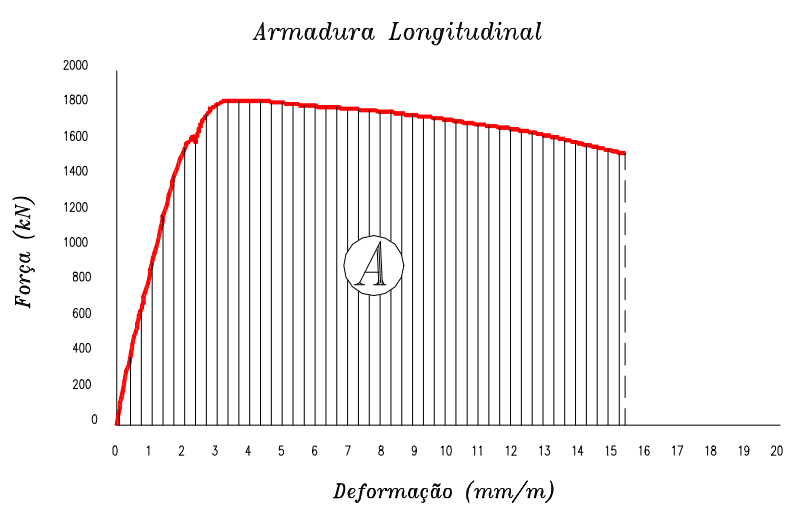

Pilar P3 - comportamento dúctil

Figura 4.25. Comparação entre os diagramas força $x$ deformação para a armadura longitudinal, pilares P2 e P3 
- Concreto - Compressão. Apresentou apenas trecho ascendente, atingindo deformação última em torno de $2 \%$ (valor correspondente à força última, $\left.F_{u}\right)$. A fissuração na superfície do pilar interferiu na leitura dos extensômetros;

- Armadura Transversal. A deformação última foi de 1,72\%. trecho descendente do diagrama pode ser justificado igualmente pelos acréscimos de deformações oriundos da flambagem da armadura longitudinal;

- Concreto - Tração. A deformação última obtida foi de 5,4\%. As leituras nos extensômetros 10 e 16 foram prejudicadas devido à intensa fissuração nas faces correspondentes do modelo;

- Pilar. A obtenção do trecho descendente no diagrama força $x$ deformação para o pilar, mostra que seu comportamento foi dúctil. A deformação última (valor médio) foi de 2,80\%.

A tabela 4.15 compara os valores das deformações na armadura longitudinal, concreto à compressão e pilar, para valores da força iguais a $0,50 F_{u}, 0,80 F_{u}$ e $F_{u}$. $A$ tabela 4.16 faz o mesmo para a armadura transversal e concreto à tração.

Tabela 4.15. Valores das deformações para o pilar P3 (\%o)

\begin{tabular}{|l|c|c|c|c|c|c||}
\cline { 2 - 7 } \multicolumn{1}{c|}{} & $\begin{array}{c}\text { Armadura } \\
\text { Longitudinal } \\
(\mathbf{A L})\end{array}$ & $\begin{array}{c}\text { Concreto - } \\
\text { Compressão } \\
(\mathbf{C C})\end{array}$ & $\begin{array}{c}\text { Pilar } \\
(\mathbf{P})\end{array}$ & $\mathbf{A L} / \mathrm{CC}$ & $\mathbf{A L} / \mathbf{P}$ & $\mathbf{C C} / \mathbf{P}$ \\
\hline Deformação a $0,50 \mathrm{~F}_{\mathrm{u}}=918 \mathrm{kN}$ & 1,05 & 0,96 & 0,98 & 1,01 & 1,07 & 0,98 \\
\hline Deformação a $0,80 \mathrm{~F}_{\mathrm{u}}=1468 \mathrm{kN}$ & 1,82 & 1,52 & 1,55 & 1,20 & 1,17 & 0,98 \\
\hline Deformação a $\mathrm{F}_{\mathrm{u}}=1835 \mathrm{kN}$ & 9,2 & 2,0 & 2,80 & 4,60 & 3,30 & 0,71 \\
\hline
\end{tabular}

Quanto aos valores para a relação $A L / C C$ e $A L / P$ superiores à unidade, se verificam também aqui as mesmas observações dos modelos anteriores quanto às deformações diferenciais entre o núcleo e o cobrimento. 
Tabela 4.16. Valores das deformações

\begin{tabular}{|l|c|c|c|}
\cline { 2 - 4 } \multicolumn{1}{c|}{} & $\begin{array}{c}\text { Concreto - } \\
\text { Tração (CT) }\end{array}$ & $\begin{array}{c}\text { Armadura } \\
\text { Transversal (AT) }\end{array}$ & CT/AT \\
\hline Deformação a $0,50 \mathrm{~F}_{\mathrm{u}}=1140 \mathrm{kN}$ & 0,19 & 0,24 & 0,80 \\
\hline Deformação a $0,80 \mathrm{~F}_{\mathrm{u}}=1822 \mathrm{kN}$ & 1,50 & 0,69 & 2,17 \\
\hline Deformação a $\mathrm{F}_{\mathrm{u}}=2278 \mathrm{kN}$ & 5,40 & 1,72 & 3,14 \\
\hline
\end{tabular}

b. Pilar P4

O pilar P4 atingiu 1864kN para a força última. As velocidades de aplicação de deslocamentos foram iguais às utilizadas para o pilar P3. A exemplo do que aconteceu com P3, o pilar P4 não apresentou ruína com desagregação do concreto ao atingir a força máxima, mas continuou a deformar-se sob forças cada vez menores, com sinais visíveis da separação entre o cobrimento e o núcleo de concreto. O ensaio foi interrompido para a força de $914 \mathrm{kN}$. A figura 4.26 mostra o estado do modelo após o ensaio.
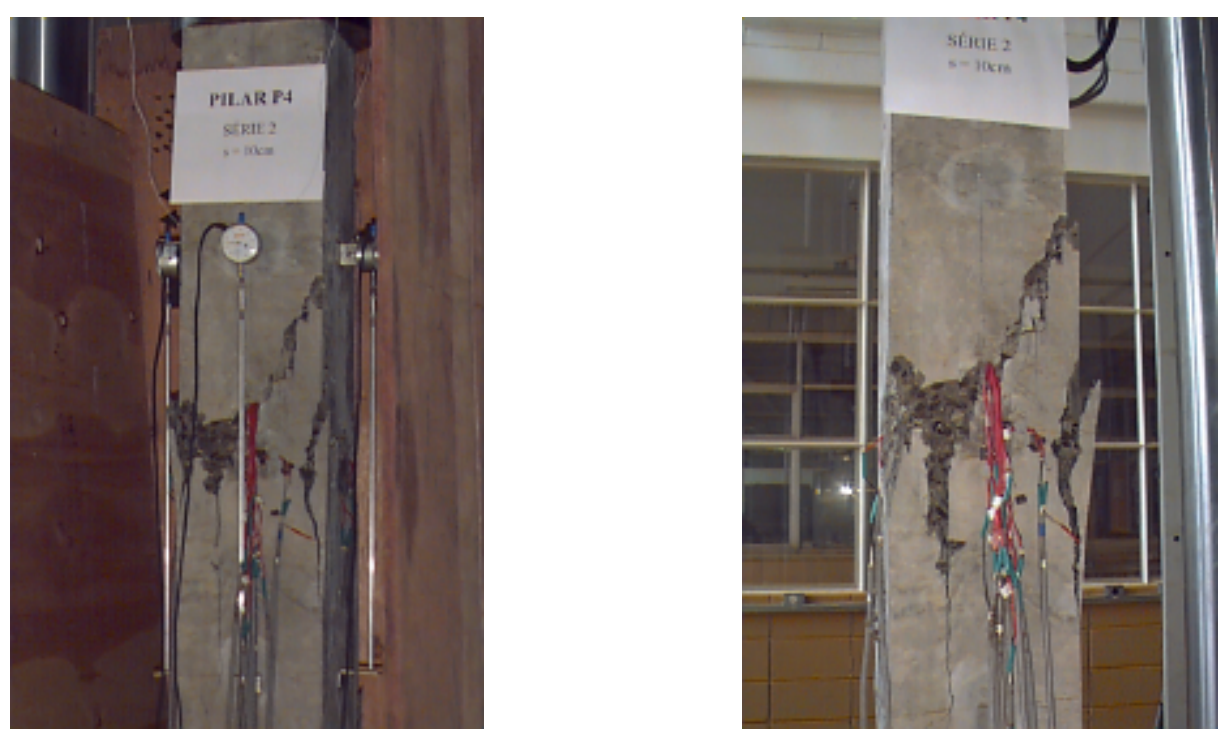

Figura 4.26. Aspecto do Pilar P4 após a ruína 


\section{Gráficos - Pilar P4}
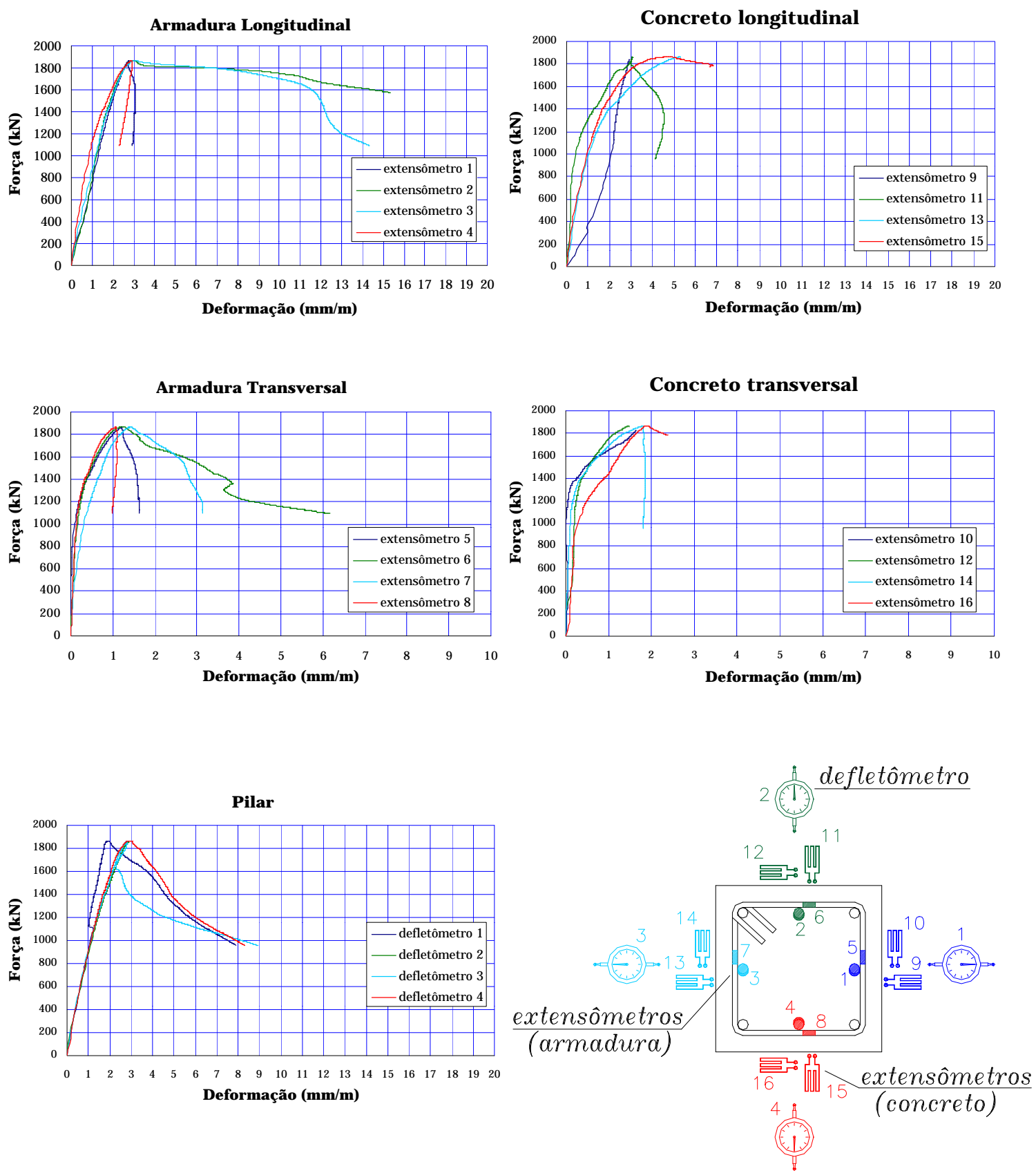

Figura 4.27. Diagramas força $x$ deformação para o pilar $P 4$ Características geométricas e físicas:

$$
\begin{gathered}
\mathrm{s}=10 \mathrm{~cm} ; \rho_{\mathrm{l}}=2,5 \% ; \rho_{\mathrm{w}}=0,51 \% \\
\mathrm{f}_{\mathrm{c}}=53,40 \mathrm{MPa} ; \mathrm{F}_{\mathrm{u}}=1864 \mathrm{kN}
\end{gathered}
$$


Através dos gráficos observa-se que:

- Armadura longitudinal. À semelhança de P3, apresenta patamar de escoamento, caracterizando o comportamento dúctil do pilar. A deformação última foi de 2,94\%, tabela 4.17;

- Concreto - Compressão. Os valores médios para o concreto acompanharam os da armadura longitudinal, apresentando, porém, apenas o trecho ascendente do diagrama. A deformação última foi de $3,27 \%$;

- Armadura Transversal. A deformação última foi igual a 1,25\%. Apresentou trecho descendente do diagrama semelhante ao do obtido para o pilar P3;

- Concreto - Tração. Obteve deformação última igual a 1,63\%, com deformações médias próximas às da armadura transversal para o trecho ascendente do diagrama;

- Pilar. A deformação última foi igual a 1,93\%。 para o pilar. O aspecto do diagrama lembra o comportamento de pilares caracterizados pela Baixa eficiência da armadura de confinamento, como sugere a figura 3.2. Porém, a obtenção do trecho descendente do diagrama e as grandes deformações atingidas pela armadura, mostram que o modelo com taxa volumétrica de armadura transversal de 0,51\%, apresentou comportamento dúctil.

Tabela 4.17. Valores das deformações para o pilar P4 (\%o)

\begin{tabular}{|l|c|c|c|c|c|c||}
\cline { 2 - 7 } \multicolumn{1}{c|}{} & $\begin{array}{c}\text { Armadura } \\
\text { Longitudinal } \\
\text { L(AL) }\end{array}$ & $\begin{array}{c}\text { Concreto - } \\
\text { Compressão } \\
(\mathbf{C C})\end{array}$ & $\begin{array}{c}\text { Pilar } \\
\mathbf{( P )}\end{array}$ & $\mathbf{A L / C C}$ & $\mathbf{A L / P}$ & $\mathbf{C C} / \mathbf{P}$ \\
\hline Deformação a $0,50 \mathrm{~F}_{\mathrm{u}}=932 \mathrm{kN}$ & 1,03 & 1,01 & 1,03 & 1,02 & 1,00 & 0,98 \\
\hline Deformação a $0,80 \mathrm{~F}_{\mathrm{u}}=1491 \mathrm{kN}$ & 1,85 & 2,13 & 1,80 & 0,87 & 1,02 & 1,18 \\
\hline Deformação a $\mathrm{F}_{\mathrm{u}}=1864 \mathrm{kN}$ & 2,94 & 3,27 & 1,93 & 0,90 & 1,52 & 1,70 \\
\hline
\end{tabular}

As deformações nas barras da armadura longitudinal, até a força última $\left(F_{u}\right)$, são próximas às do pilar e às medidas no concreto. 
Tabela 4.18. Valores das deformações para o pilar P4 (\%o)

\begin{tabular}{|l|c|c|c|}
\cline { 2 - 4 } \multicolumn{1}{c|}{} & $\begin{array}{c}\text { Concreto - } \\
\text { Tração (CT) }\end{array}$ & $\begin{array}{c}\text { Armadura } \\
\text { Transversal (AT) }\end{array}$ & CT/AT \\
\hline Deformação a $0,50 \mathrm{~F}_{\mathrm{u}}=932 \mathrm{kN}$ & 0,13 & 0,13 & 1,00 \\
\hline Deformação a $0,80 \mathrm{~F}_{\mathrm{u}}=1491 \mathrm{kN}$ & 0,63 & 0,55 & 1,15 \\
\hline Deformação a $\mathrm{F}_{\mathrm{u}}=1864 \mathrm{kN}$ & 1,63 & 1,25 & 1,30 \\
\hline
\end{tabular}

\subsubsection{Série 3}

A Série 3, composta pelos modelos P5 e P6, foi a última série que utilizou seção transversal quadrada. Dentro da metodologia proposta, que consistia em avaliar o efeito do espaçamento entre estribos no comportamento do pilar, a Série 3 apresentava o menor espaçamento, $5 \mathrm{~cm}$, proporcionando taxa volumétrica de armadura transversal $\left(\rho_{\mathrm{w}}\right)$ de $1,03 \%$.

Após os resultados positivos quanto à ductilidade obtidos pelos modelos da Série 2 ( $\left.\mathrm{s}=10 \mathrm{~cm} ; \rho_{\mathrm{w}}=0,51\right)$, previa-se que os pilares P5 e P6 apresentariam comportamento dúctil, obtendo grandes deformações para a armadura longitudinal e para o pilar. Aplicando-se para os modelos da Série 3 as mesmas considerações do pilar P3 para o diagrama força $x$ deformação da armadura longitudinal, figura 4.25, observa-se que a área sob o diagrama, figura 4.28 , bem superior aos modelos da Série $1\left(\mathrm{~s}=15 \mathrm{~cm} ; \rho_{\mathrm{w}}=0,34\right)$, indica a ductilidade que caracterizou os modelos.

\section{a. Pilar P5}

Chegou à ruína para a força máxima de $2158 \mathrm{kN}$. Obtiveram-se grandes deformações para o modelo após a força última, o que se observa através dos diagramas para o pilar e para a armadura longitudinal. A velocidade de aplicação de deslocamentos foi de $0,005 \mathrm{~mm} / \mathrm{s}$ (até $1500 \mathrm{kN}$ ) e de $0,01 \mathrm{~mm} / \mathrm{s}$ até a força última. Com a queda da resistência do pilar (observada através do painel da INSTRON), reduziu-se a velocidade $(0,001 \mathrm{~mm} / \mathrm{s})$ com o fim de se obter todo o trecho descendente do diagrama.

A ruína aconteceu por esmagamento do concreto na região próxima à seção instrumentada. Não se observou flambagem nas barras da armadura longitudinal. 


\section{Gráficos - Pilar P5}
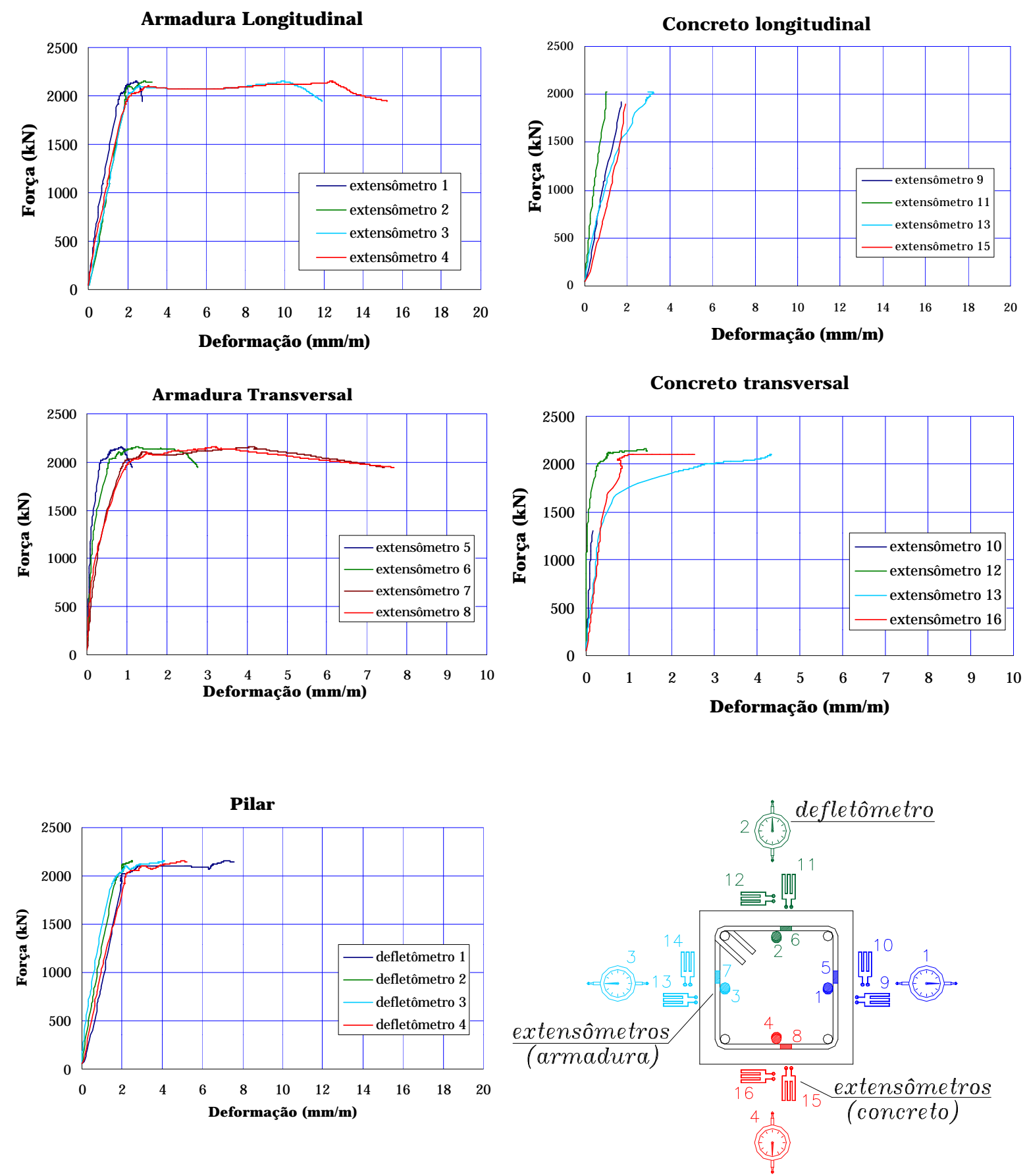

Figura 4.28. Diagramas força $x$ deformação para o pilar P5 Características geométricas e físicas:

$$
\begin{gathered}
\mathrm{s}=5 \mathrm{~cm} ; \rho_{\mathrm{l}}=2,5 \% ; \rho_{\mathrm{w}}=1,03 \% \\
\mathrm{f}_{\mathrm{c}}=55,90 \mathrm{MPa} ; \mathrm{F}_{\mathrm{u}}=2158 \mathrm{kN}
\end{gathered}
$$


- Armadura longitudinal. Houve patamar de escoamento da armadura a partir de deformações da ordem de $2 \%$. A deformação última foi igual a $\varepsilon_{\mathrm{ul}}=6,94 \%$, valor médio;

- Concreto - Compressão. Este diagrama apresentou apenas trecho ascendente, devido a perda de leitura dos extensômetros ocasionada pela intensa fissuração nas faces do pilar. A deformação máxima para o concreto foi de 2,01\%;

- Armadura Transversal. A deformação última foi de $2,40 \%$. Também apresentou patamar de escoamento a partir de valores para a força aplicada próximos de $\mathrm{F}_{\mathrm{u}}=2158 \mathrm{kN}$;

- Concreto - Tração. Apresentou deformação última igual a 1,41\%;

- Pilar. A deformação última foi de 4,76\%. O diagrama exibiu o aspecto característico de pilares com Média eficiência da armadura de confinamento, conforme indica a figura 3.2.

Tabela 4.19. Valores das deformações para o pilar P5 (\%॰)

\begin{tabular}{|l|c|c|c|c|c|c||}
\cline { 2 - 7 } \multicolumn{1}{c|}{} & $\begin{array}{c}\text { Armadura } \\
\text { Longitudinal } \\
(\mathbf{A L})\end{array}$ & $\begin{array}{c}\text { Concreto - } \\
\text { Compressão } \\
(\mathbf{C C})\end{array}$ & $\begin{array}{c}\text { Pilar } \\
(\mathbf{P})\end{array}$ & $\mathbf{A L} / \mathrm{CC}$ & $\mathbf{A L} / \mathbf{P}$ & $\mathbf{C C} / \mathbf{P}$ \\
\hline Deformação a $0,50 \mathrm{~F}_{\mathrm{u}}=1079 \mathrm{kN}$ & 0,92 & 0,91 & 0,93 & 1,01 & 0,99 & 0,98 \\
\hline Deformação a $0,80 \mathrm{~F}_{\mathrm{u}}=1726 \mathrm{kN}$ & 1,56 & 1,62 & 1,57 & 0,96 & 0,99 & 1,03 \\
\hline Deformação a $\mathrm{F}_{\mathrm{u}}=2158 \mathrm{kN}$ & 6,94 & 2,01 & 4,76 & 3,10 & 1,31 & 0,42 \\
\hline \hline
\end{tabular}

Tabela 4.20. Valores das deformações para o pilar P5 (\%०)

\begin{tabular}{|l|c|c|c|}
\cline { 2 - 4 } \multicolumn{1}{c|}{} & $\begin{array}{c}\text { Concreto - } \\
\text { Tração (CT) }\end{array}$ & $\begin{array}{c}\text { Armadura } \\
\text { Transversal (AT) }\end{array}$ & CT/AT \\
\hline Deformação a $0,50 \mathrm{~F}_{\mathrm{u}}=1079 \mathrm{kN}$ & 0,16 & 0,18 & 0,89 \\
\hline Deformação a $0,80 \mathrm{~F}_{\mathrm{u}}=1726 \mathrm{kN}$ & 0,53 & 0,51 & 1,04 \\
\hline Deformação a $\mathrm{F}_{\mathrm{u}}=2158 \mathrm{kN}$ & 1,41 & 2,40 & 0,60 \\
\hline
\end{tabular}

\section{b. Pilar P6}

Atingiu força última igual a $2312 \mathrm{kN}$. A força última teórica, considerando seção íntegra, era de $2608 \mathrm{kN}$, e, para o núcleo, de $1862 \mathrm{kN}$, tabela 4.6. A ruptura se deu de forma idêntica a P5, com grandes deformações após a força de pico, obtendo-se significativo trecho descendente dos diagramas. Também não se observou flambagem localizada das barras da armadura longitudinal. 


\section{Gráficos - Pilar P6}
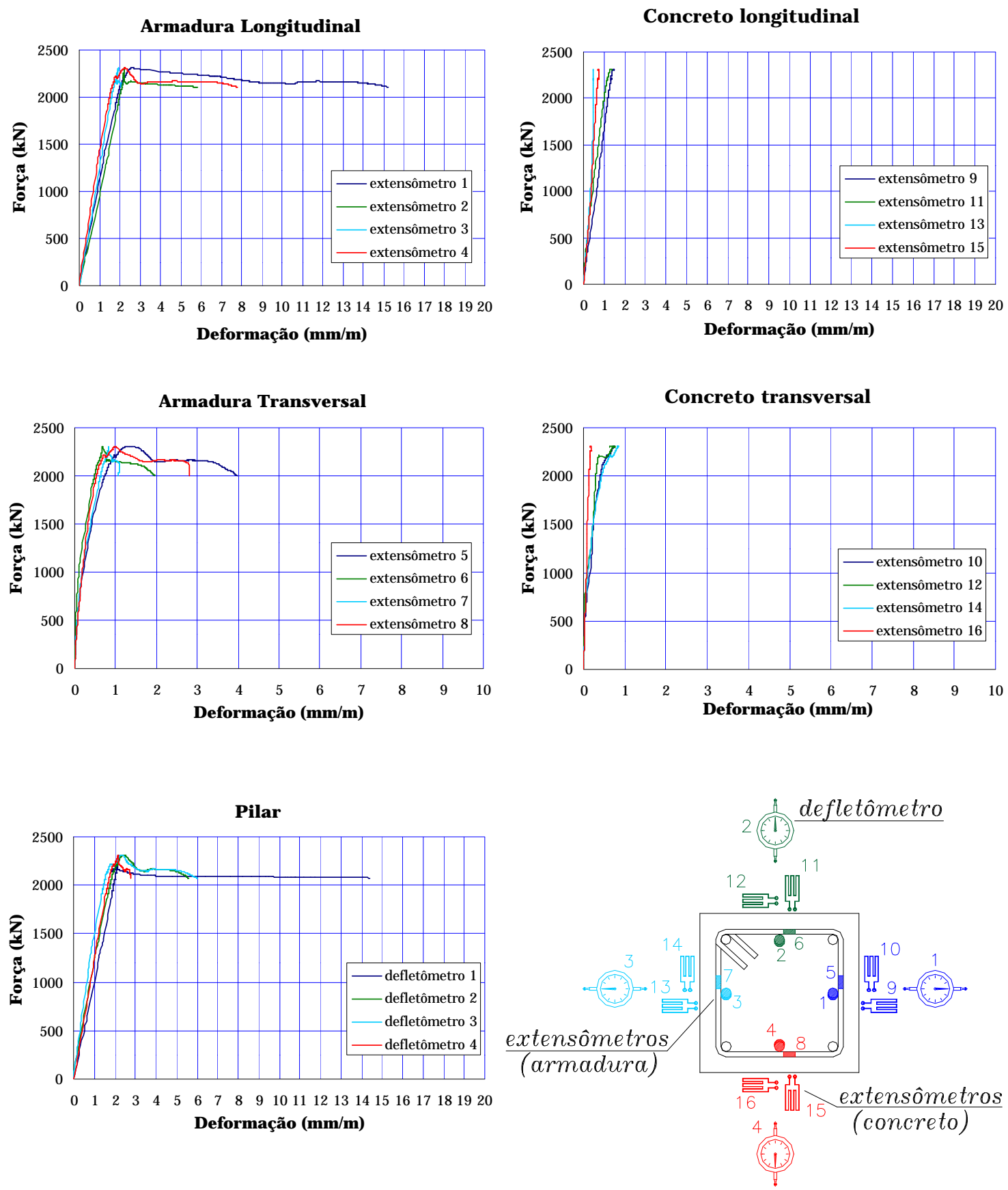

Figura 4.29. Diagramas força $x$ deformação para o pilar P6 Características geométricas e físicas:

$$
\begin{gathered}
\mathrm{s}=5 \mathrm{~cm} ; \rho_{\mathrm{l}}=2,5 \% ; \rho_{\mathrm{w}}=1,03 \% \\
\mathrm{f}_{\mathrm{c}}=55,90 \mathrm{MPa} ; \mathrm{F}_{\mathrm{u}}=2312 \mathrm{kN}
\end{gathered}
$$


Quanto aos diagramas obtidos para P6, as considerações são semelhantes às do pilar P5:

- Armadura longitudinal. Também apresentou considerável patamar de escoamento, caracterizando o comportamento dúctil do pilar. A deformação última foi de 2,30\%o, valor médio;

- Concreto - Compressão. Deformação última igual a 2,01\%;

- Armadura Transversal. A deformação última foi de 0,96\%;

- Concreto - Tração. Apresentou deformação última igual a 1,23\%;

- Pilar. A deformação última foi igual a 2,25\%. Para valores em torno de $0,80 \mathrm{~F}_{\mathrm{u}}$ observou-se intensa fissuração na superfície do modelo, caracterizando o início da separação do cobrimento. Na ruína do pilar, esta camada já estava completamente separada do núcleo definido pelas armaduras, figura 4.30.

Tabela 4.21. Valores das deformações para o pilar P6 (\%)

\begin{tabular}{|l|c|c|c|c|c|c||}
\cline { 2 - 7 } \multicolumn{1}{c|}{} & $\begin{array}{c}\text { Armadura } \\
\text { Longitudinal } \\
\text { (AL) }\end{array}$ & $\begin{array}{c}\text { Concreto - } \\
\text { Compressão } \\
(\mathbf{C C})\end{array}$ & $\begin{array}{c}\text { Pilar } \\
(\mathbf{P})\end{array}$ & AL/CC & AL/P & CC/P \\
\hline Deformação a $0,50 \mathrm{~F}_{\mathrm{u}}=1156 \mathrm{kN}$ & 0,91 & 1,00 & 0,94 & 0,91 & 0,97 & 1,06 \\
\hline Deformação a $0,80 \mathrm{~F}_{\mathrm{u}}=1850 \mathrm{kN}$ & 1,60 & 1,54 & 1,56 & 1,04 & 1,03 & 0,99 \\
\hline Deformação a $\mathrm{F}_{\mathrm{u}}=2312 \mathrm{kN}$ & 2,30 & 2,01 & 2,25 & 1,15 & 3,40 & 1,02 \\
\hline
\end{tabular}

Tabela 4.22. Valores das deformações para o pilar P6 (\%०)

\begin{tabular}{|l|c|c|c|}
\cline { 2 - 4 } \multicolumn{1}{c|}{} & $\begin{array}{c}\text { Concreto - } \\
\text { Tração (CT) }\end{array}$ & $\begin{array}{c}\text { Armadura } \\
\text { Transversal (AT) }\end{array}$ & CT/AT \\
\hline Deformação a $0,50 \mathrm{~F}_{\mathrm{u}}=1156 \mathrm{kN}$ & 0,23 & 0,19 & 1,21 \\
\hline Deformação a $0,80 \mathrm{~F}_{\mathrm{u}}=1850 \mathrm{kN}$ & 0,55 & 0,52 & 1,06 \\
\hline Deformação a $\mathrm{F}_{\mathrm{u}}=2312 \mathrm{kN}$ & 1,23 & 0,96 & 1,28 \\
\hline
\end{tabular}

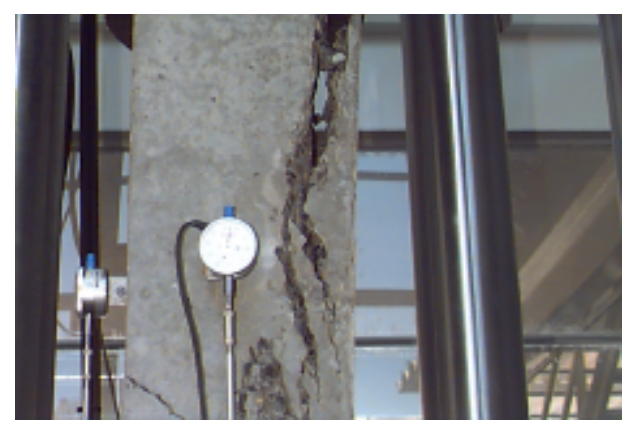

Figura 4.30. Aspecto do Pilar P6 após a ruína. A figura mostra a nítida separação da camada de cobrimento 


\subsubsection{Série 4}

A partir da Série 4, pilares P7 e P8, foram ensaiados os modelos de seção transversal retangular, $15 \mathrm{~cm} \times 30 \mathrm{~cm}$ e altura de $90 \mathrm{~cm}$. A Série 4 apresenta espaçamento entre estribos igual a $15 \mathrm{~cm}$, proporcionando taxa volumétrica de armadura transversal de 0,34\%. Neste caso, pretendia-se verificar se as mesmas conclusões apresentadas para os modelos de seção quadrada seriam válidas para os modelos de seção retangular. PAIVA (1994) confirmou a aplicabilidade das conclusões de AGOSTINI (1992) para pilares de seção retangular moldados em CAR de resistência média à compressão de $80 \mathrm{MPa}$.

Para a verificação do comportamento destes modelos foram seguidos os mesmos critérios aplicados aos pilares de seção quadrada, variando-se a taxa volumétrica de armadura transversal $\left(\rho_{\mathrm{w}}\right)$ através da adoção de menores espaçamentos entre estribos para cada série.

O comportamento dos modelos revelou que as mesmas observações registradas para pilares de seção transversal quadrada são válidas para pilares de seção retangular.

\section{a. Pilar P7}

Correspondia ao pilar P1 nos modelos de seção quadrada. Nos ensaios dos pilares das séries 4 a 6 , a velocidade inicial de aplicação de deslocamento foi de $0,005 \mathrm{~mm} / \mathrm{s}$, até valores da força em torno de $2000 \mathrm{kN}$, sendo elevada para $0,01 \mathrm{~mm} / \mathrm{s}$ até a proximidade da força última teórica para o modelo. A forma de ruptura revelou reduzida ductilidade do pilar P7, não sendo possível obter-se 0 trecho descendente dos diagramas força $x$ deformação, dada a perda brusca de resistência. Neste aspecto o Pilar P7 assemelha-se aos pilares de seção quadrada P1 e P2. A figura 4.31 traz os diagramas força $x$ deformação obtidos no ensaio à compressão simples. Os diagramas força $x$ deformação são apresentados na figura 4.31 . 


\section{Gráficos - Pilar P7}
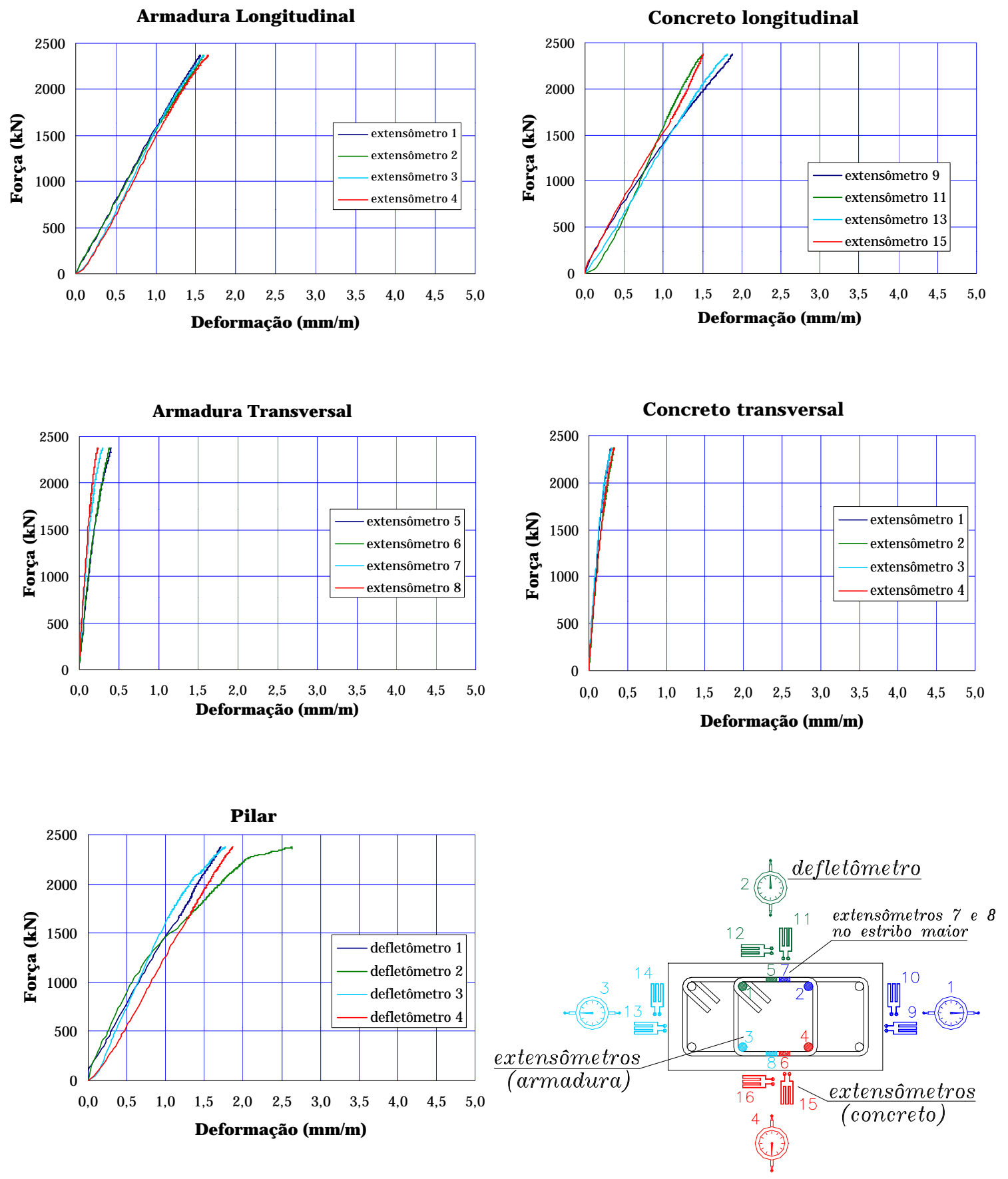

Figura 4.31. Diagramas força $x$ deformação para o pilar $P 7$ Características geométricas e físicas:

$$
\begin{gathered}
\mathrm{s}=15 \mathrm{~cm} ; \rho_{\mathrm{I}}=2,2 \% ; \rho_{\mathrm{w}}=0,34 \% \\
\mathrm{f}_{\mathrm{c}}=66,90 \mathrm{MPa} ; \mathrm{F}_{\mathrm{u}}=2373 \mathrm{kN}
\end{gathered}
$$




\section{Observações:}

- Armadura longitudinal. À semelhança dos modelos da Série 1, o diagrama para a armadura longitudinal foi linear até a ruptura, não apresentando patamar de escoamento. A deformação última (valor médio) foi de $1,65 \%$;

- Concreto - Compressão. Acompanhou o comportamento do diagrama da armadura longitudinal. A deformação última foi de $1,55 \%$;

- Armadura Transversal. Não apresentou patamar de escoamento, atingindo deformação última de 0,32\%;

- Concreto - Tração. Teve comportamento próximo ao da armadura transversal, com deformação última igual a 0,35\%;

- Pilar. O aspecto do diagrama, com apenas o trecho ascendente, mostra o comportamento frágil do modelo. A deformação última foi em torno de $2 \%$. O comportamento do gráfico o enquadra entre os pilares com Baixa eficiência da armadura de confinamento, como mostrado na figura 3.2;

Fica então demonstrado, tanto para pilares de seção transversal quadrada como de seção retangular, a impossibilidade de se obter ductilidade com a taxa volumétrica de armadura transversal empregada nas séries 1 e $4\left(\rho_{w}=0,34 \%\right)$.

\section{b. Pilar P8}

Apresentou comportamento idêntico ao do pilar P7, o que pode ser observado através dos diagramas. A utilização de dois modelos idênticos por Série justifica-se pela preocupação em se detectar possíveis diferenças ou anomalias nos resultados. Porém, excetuando-se os modelos da Série 1, todas as demais séries apresentaram resultados bem próximos para os modelos, não havendo, a princípio, necessidade de se moldarem dois pilares idênticos por série. Os diagramas força $x$ deformação são apresentados na figura 4.32. 


\section{Gráficos - Pilar P8}
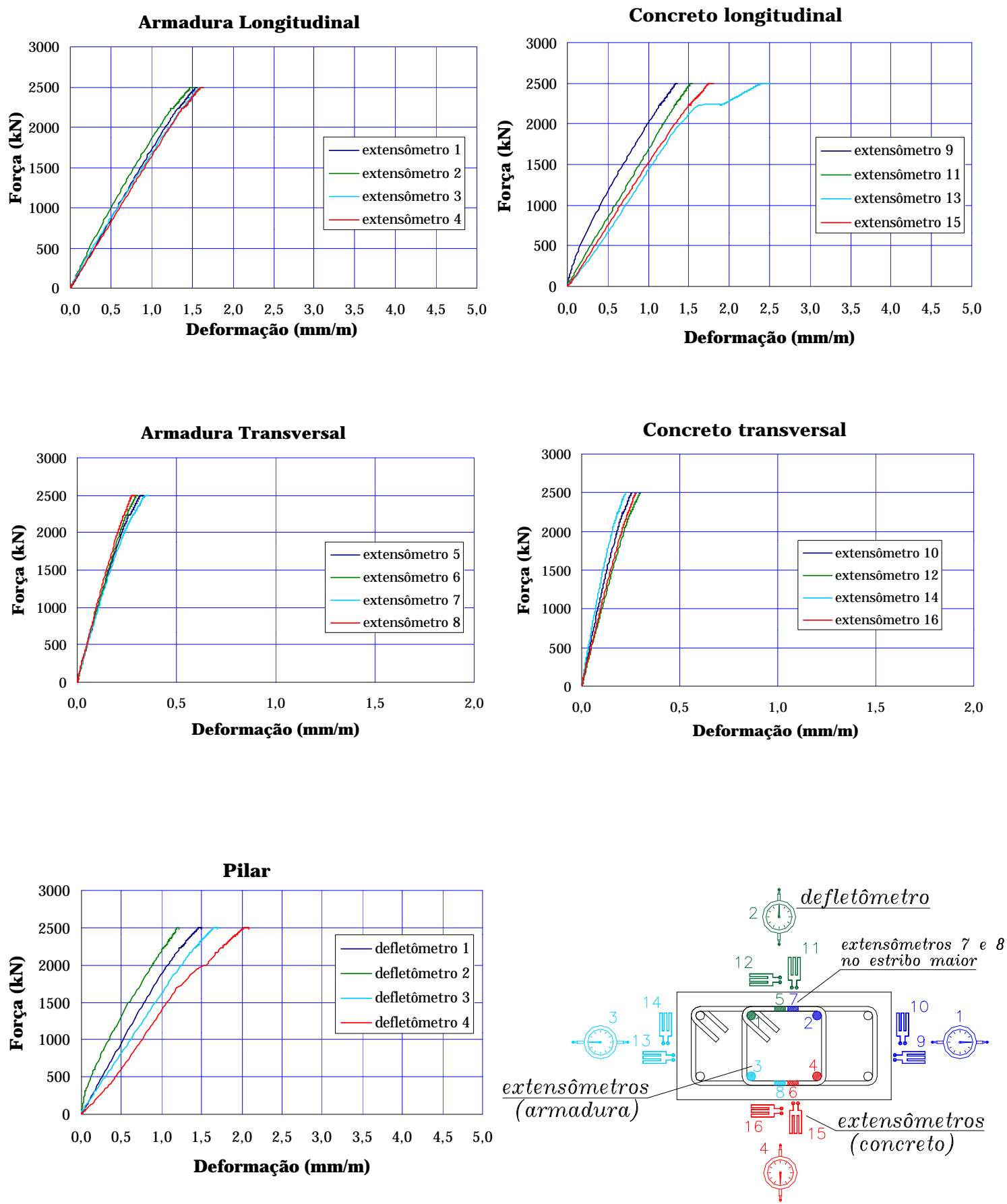

Figura 4.32. Diagramas força $x$ deformação para o pilar $P 8$ Características geométricas e físicas:

$s=15 \mathrm{~cm} ; \rho_{\mathrm{l}}=2,2 \% ; \rho_{\mathrm{w}}=0,34 \%$

$\mathrm{f}_{\mathrm{c}}=66,90 \mathrm{MPa} ; \mathrm{F}_{\mathrm{u}}=2496 \mathrm{kN}$ 
Os gráficos se assemelham aos de $\mathrm{P} 7$, ressaltando-se apenas os valores últimos para as deformações:

- Armadura longitudinal. A deformação última foi de 1,55\%. Como aconteceu com P7, o comportamento do diagrama já revela a ineficiência da armadura de confinamento na ductilização do pilar;

- Concreto - Compressão. A deformação última foi de 1,50\%;

- Armadura Transversal. A deformação última foi de 0,33\%;

- Concreto - Tração. Apresentou deformação última igual a 0,28\%;

- Pilar. A deformação última foi igual a 1,50\% para o pilar.

\subsubsection{Série 5}

Os modelos da série cinco, pilares P9 e P10, apresentavam espaçamento entre estribos iguais a $10 \mathrm{~cm}$, resultando em taxa volumétrica de armadura transversal de $0,51 \%$. A força última teórica prevista para a resistência do concreto de $60 \mathrm{MPa}$ era de $2878 \mathrm{kN}$, considerando a seção íntegra de concreto, $F_{\text {teo, }}$ e $1923 \mathrm{kN}$, considerando apenas o núcleo resistente, $F_{\text {teo,n }}$. A velocidade de aplicação de deslocamento foi igual em ambos os modelos. Através dos diagramas percebese que o comportamento dos modelos da série 5 foi semelhante ao dos modelos da Série 2 (P3 e P4). A ruptura foi dúctil para os pilares ensaiados, com significativo trecho descendente do diagrama força $\mathrm{x}$ deformação sendo obtido.

\section{a. Pilar P9}

A força última para o pilar P9 foi de $2446 \mathrm{kN}$. Como nos demais modelos ensaiados, o cobrimento destacou-se do núcleo para forças aproximadamente iguais a $80 \%$ da força última. 


\section{Gráficos - Pilar P9}
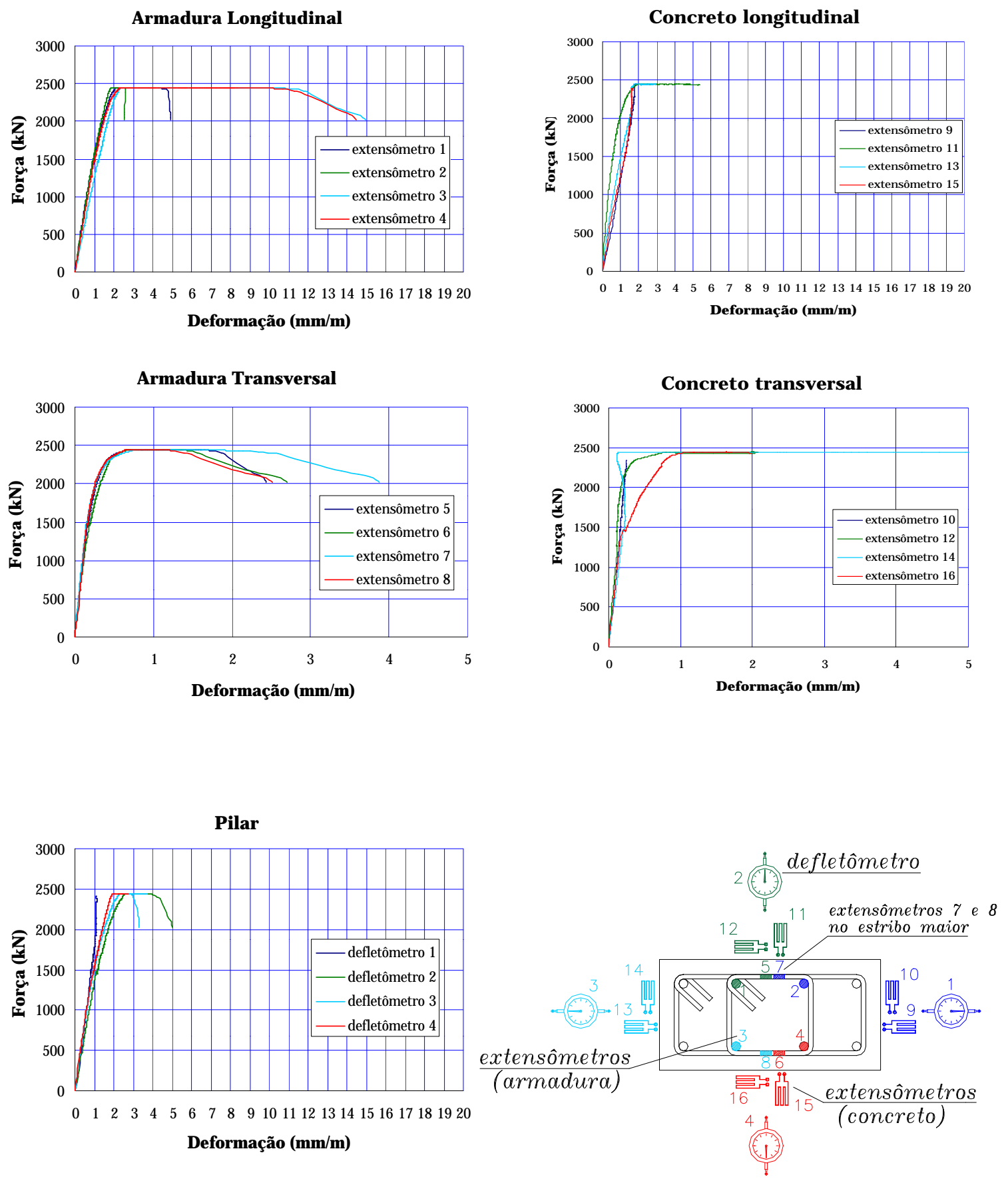

Figura 4.33. Diagramas força $x$ deformação para o pilar P9 Características geométricas e físicas:

$s=10 \mathrm{~cm} ; \rho_{\mathrm{l}}=2,2 \% ; \rho_{\mathrm{w}}=0,51 \%$

$\mathrm{f}_{\mathrm{c}}=63,88 \mathrm{MPa} ; \mathrm{F}_{\mathrm{u}}=2446 \mathrm{kN}$ 
Para os diagramas tem-se que:

- Armadura longitudinal. O diagrama apresentou patamar de escoamento e grandes valores para as deformações, que, comparadas às do pilar e do concreto, confirmam a hipótese de que o núcleo trabalha isoladamente para forças próximas à força última. A deformação última foi de 2,80\%;

- Concreto - Compressão. A deformação última foi de 2,7\%;

- Armadura Transversal. Apresentou patamar de escoamento, indicando a provável solicitação dos estribos pela deformação transversal do concreto do núcleo. A deformação última foi de 2,3\%;

- Concreto - Tração. Apresentou deformação última igual a 2,10\%;

- Pilar. A deformação última foi igual a 2,54\%. Observa-se também que, como mencionado no item 3.1, a forma do diagrama força $x$ deformação para o pilar revela a ductilidade do modelo através da eficiência do confinamento lateral provido pelas armaduras. Também para efeito de comparação apresentam-se os diagramas força x deformação (na mesma escala) para os pilares P7 e P9. Como comentado no caso da armadura longitudinal, a área sob o diagrama também apresenta-se como indicador para a ductilidade do pilar, figura 4.34 .

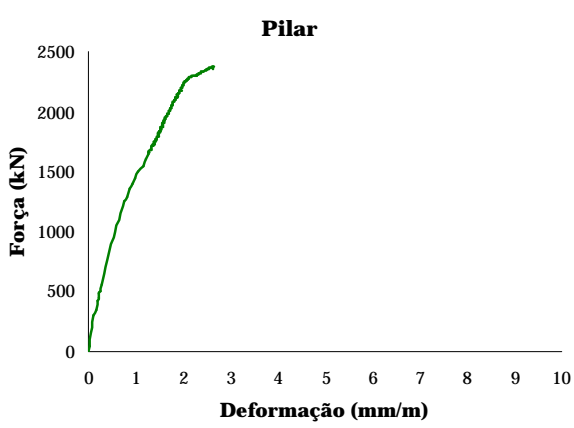

Pilar P7 - reduzida ductilidade

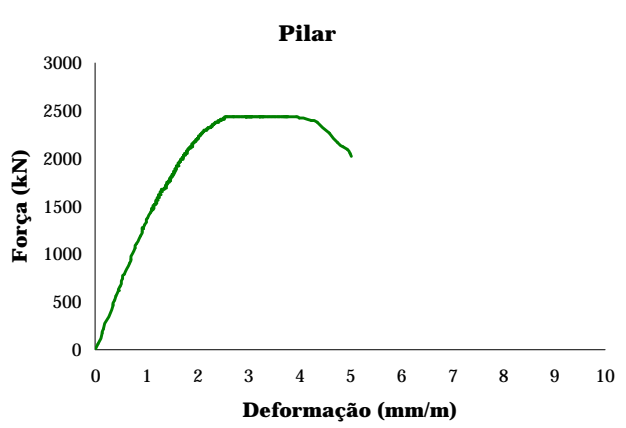

Pilar P9 - comportamento dúctil

Figura 4.34. Comparação entre os diagramas força $x$ deformação para o pilar

\section{b. Pilar P10}

Apresentou comportamento similar ao de P9. A força última atingida foi de $2440 \mathrm{kN}$. A ruptura foi dúctil, obtendo-se, com facilidade, parte do trecho descendente do diagrama. Os diagramas são apresentados na figura 4.35. 


\section{Gráficos - Pilar P10}
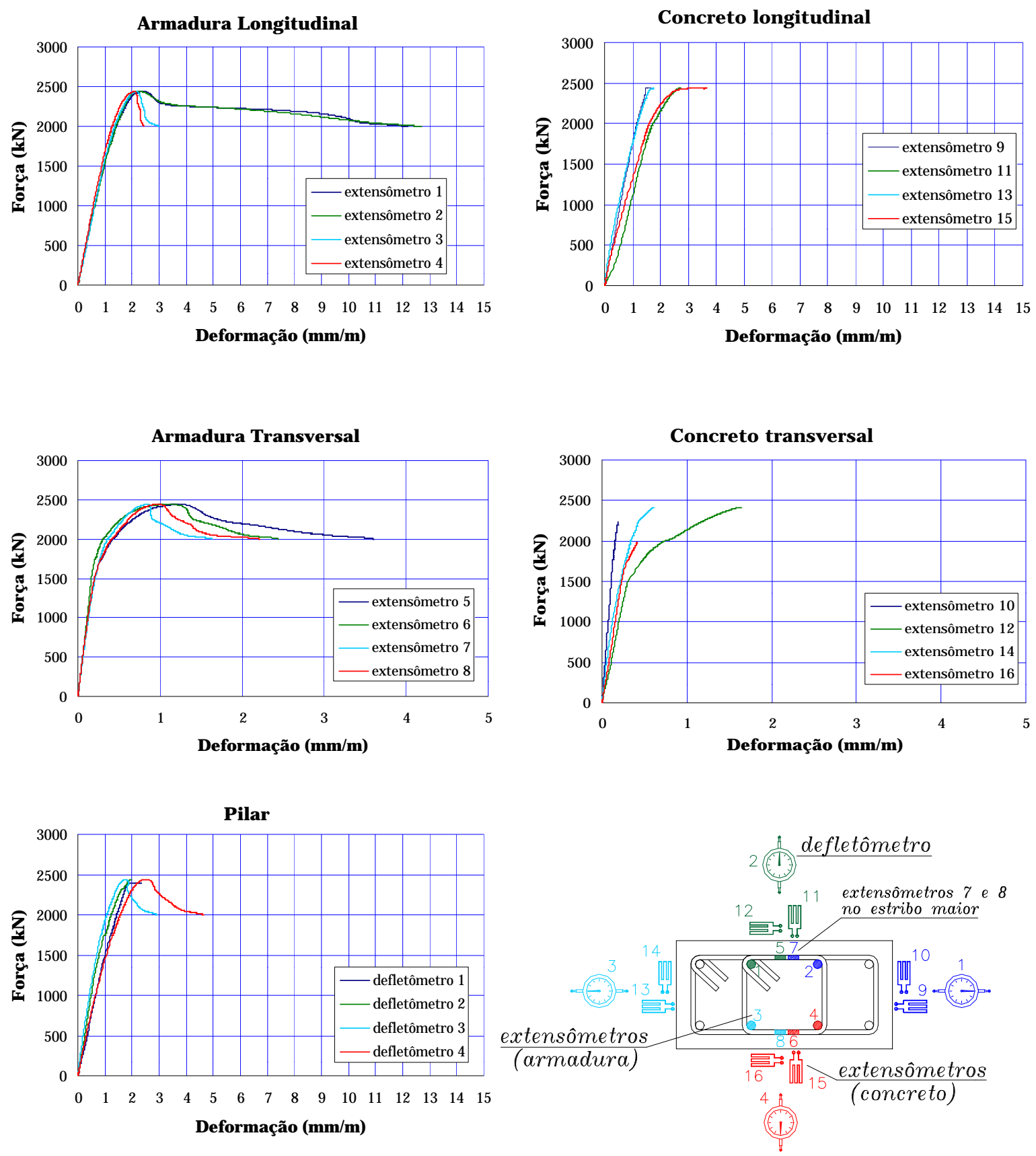

Figura 4.35. Diagramas força $x$ deformação para o pilar P10 Características geométricas e físicas:

$$
\begin{gathered}
\mathrm{s}=10 \mathrm{~cm} ; \rho_{\mathrm{l}}=2,2 \% ; \rho_{\mathrm{w}}=0,51 \% \\
\mathrm{f}_{\mathrm{c}}=63,88 \mathrm{MPa} ; \mathrm{F}_{\mathrm{u}}=2440 \mathrm{kN}
\end{gathered}
$$


Através dos gráficos observa-se que:

- Armadura longitudinal. A deformação última foi de 2,20\%;

- Concreto - Compressão. Os valores médios também acompanharam os valores para a armadura longitudinal, porém, apresentando apenas trecho ascendente. A deformação correspondente à força última foi de 2,27\%;

- Armadura Transversal. A deformação última foi de 1,03\%. Apresentou também trecho descendente semelhante ao obtido para o pilar P3;

- Concreto - Tração. Apresentou deformação última igual a 0,80\%. Apresentou deformações médias próximas às da armadura transversal;

- Pilar. A deformação última foi igual a 2,06\% para o pilar. O aspecto do diagrama lembra o de pilares caracterizados pela Baixa eficiência da armadura de confinamento, como sugere a figura 3.2.

\subsubsection{Série 6}

Os pilares da Série seis, P11 e P12, apresentavam espaçamento entre estribos de $5 \mathrm{~cm}$, resultando em taxa volumétrica de armadura transversal igual a 1,03\%. Correspondem aos modelos de seção quadrada da Série 3 (P5 e P6). A observação dos gráficos mostra que conclusões semelhantes às daqueles modelos são válidas para pilares de seção transversal retangular, moldados em CAR, com resistência média à compressão de 60MPa.

\section{a. Pilar P11}

Atingiu força máxima de $2288 \mathrm{kN}$, obtendo-se, logo após, certa porção do trecho descendente do diagrama para as barras da armadura longitudinal e transversal. A ruptura foi dúctil, com o pilar, especialmente as armaduras, apresentando grandes deformações. Os acréscimos na velocidade de deslocamento do pistão também foram dados na mesma velocidade das Séries anteriores. Os diagramas força x deformação são apresentados na figura 4.36. 


\section{Gráficos - Pilar P11}
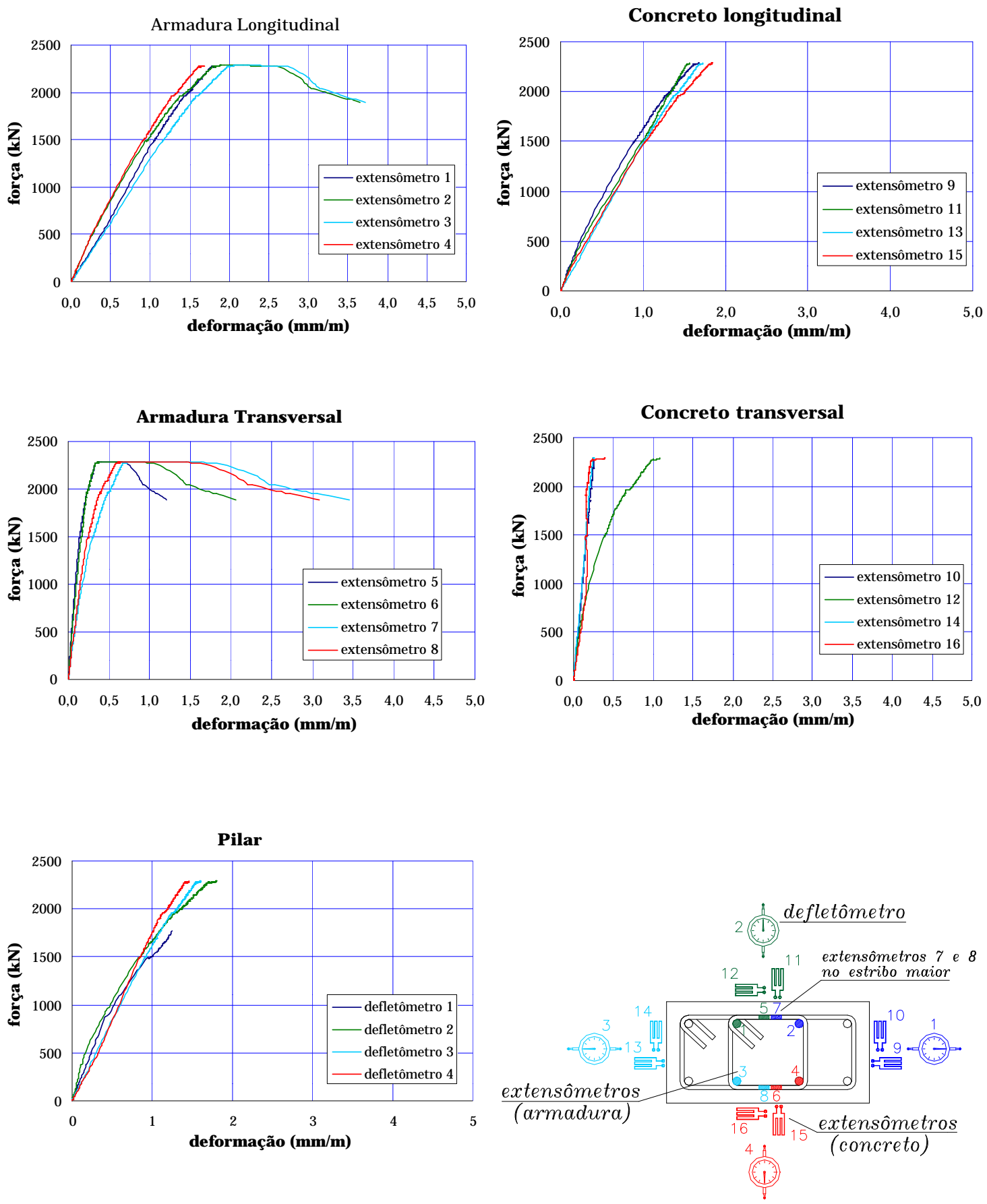

Figura 4.36. Diagramas força $x$ deformação para o pilar $\mathrm{P} 11$

Características geométricas e físicas:

$$
\begin{gathered}
\mathrm{s}=5 \mathrm{~cm} ; \rho_{\mathrm{l}}=2,2 \% ; \rho_{\mathrm{w}}=1,03 \% \\
\mathrm{f}_{\mathrm{c}}=65,47 \mathrm{MPa} ; \mathrm{F}_{\mathrm{u}}=2288 \mathrm{kN}
\end{gathered}
$$


Dos diagramas observa-se que:

- Armadura longitudinal. À semelhança de P5 e P6, apresenta patamar de escoamento que caracteriza o comportamento dúctil do pilar. A deformação correspondente à força última foi de 2,00\%;

- Concreto - Compressão. As leituras nos extensômetros também acompanharam os valores obtidos para a armadura longitudinal no trecho ascendente do diagrama. A deformação última foi de 1,70\%;

- Armadura Transversal. A deformação última foi de $0,53 \%$. Apresentou trecho descendente semelhante ao do obtido para 0 pilar P10;

- Concreto - Tração. Apresentou deformação última igual a 0,50\%. Apresentou igualmente deformações médias bem próximas às da armadura transversal (trecho ascendente);

- Pilar. A deformação correspondente à força última foi igual a 1,64\%o.

\section{b. Pilar P12}

Atingiu força última igual a $2497 \mathrm{kN}$. Como esperado, o comportamento deste modelo foi dúctil, muito próximo ao do pilar da mesma Série, apresentando grandes deformações para o núcleo. Os diagramas para o pilar P12 são apresentados na figura 4.37 .

- Armadura longitudinal. Também apresentou patamar de escoamento e grandes deformações após a força última Ter sido atingida, o que caracterizou o comportamento dúctil do pilar. A deformação última foi de 2,00\%;

- Concreto - Compressão. A deformação última foi de 1,50\%;

- Armadura Transversal. A deformação correspondente à força última foi igual a 0,52\%;

- Concreto - Tração. Apresentou deformação última igual a 0,50\%。 (valor médio).

- Pilar. A deformação correspondente à força última foi igual a 1,30\%。 


\section{Gráficos - Pilar P12}
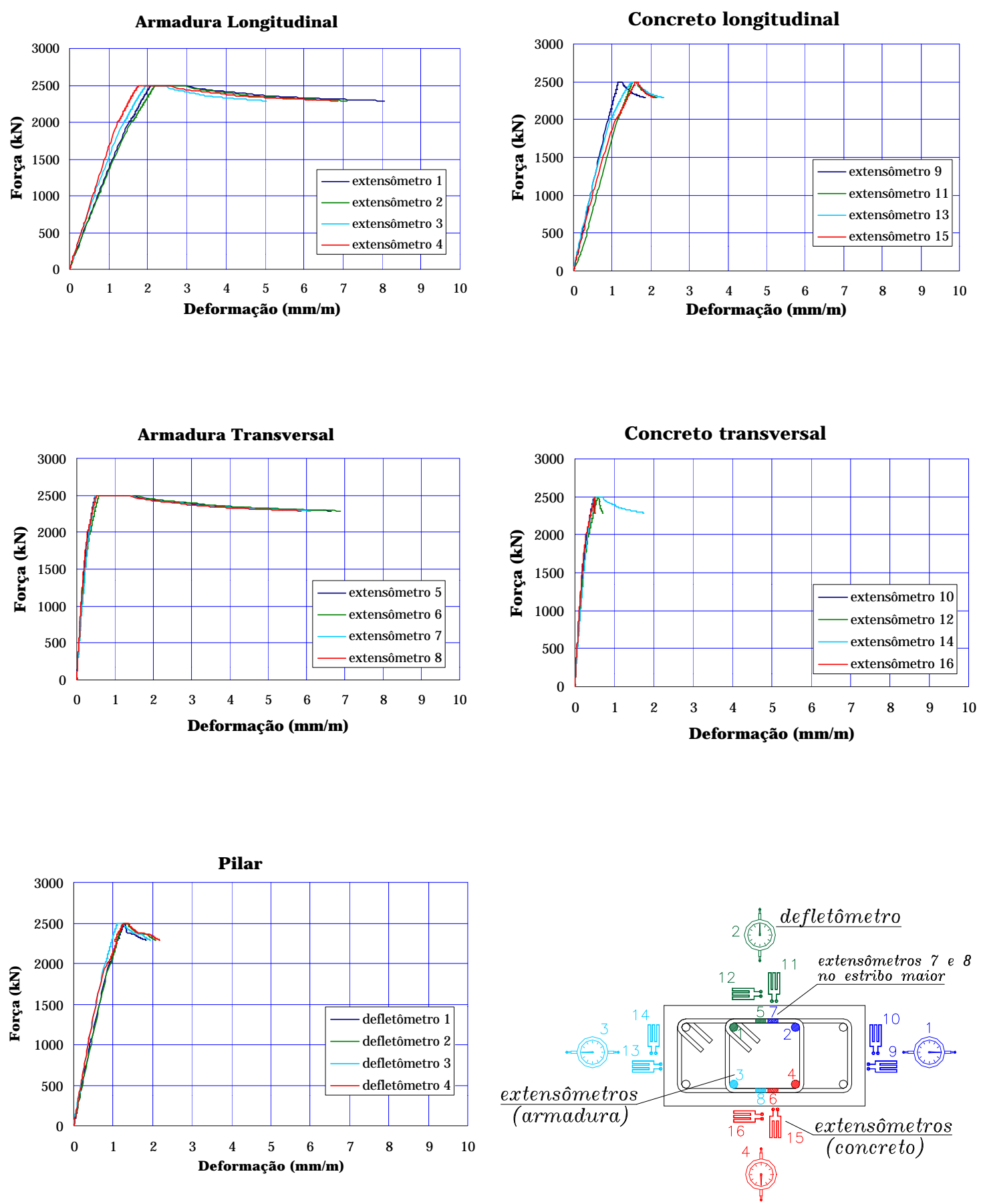

Figura 4.37. Diagramas força $x$ deformação para o pilar $\mathrm{P} 12$ Características geométricas e físicas:

$$
\begin{gathered}
\mathrm{s}=5 \mathrm{~cm} ; \rho_{\mathrm{l}}=2,2 \% ; \rho_{\mathrm{w}}=1,03 \% \\
\mathrm{f}_{\mathrm{c}}=65,47 \mathrm{MPa} ; \mathrm{F}_{\mathrm{u}}=2497 \mathrm{kN}
\end{gathered}
$$




\subsection{Considerações finais}

Nos modelos ensaiados verificou-se que o comportamento dúctil era atingido para taxas volumétricas de armadura transversal $\left(\rho_{\mathrm{w}}\right)$ iguais ou superiores a $0,51 \%$ (modelos das Séries 2, 3, 5 e 6). Tal comportamento era verificado através do trecho descendente do diagrama força $x$ deformação. Entretanto, o confinamento lateral não proporcionou aos modelos acréscimos na resistência após a força de pico $\left(F_{u}\right)$, levando a crer que, para as taxas de armaduras transversais adotadas $(0,34 \%, 0,51 \%$ e $1,03 \%)$, não foi atingido comportamento que se traduzisse por alta eficiência do confinamento, como visto no item 3.1 . 


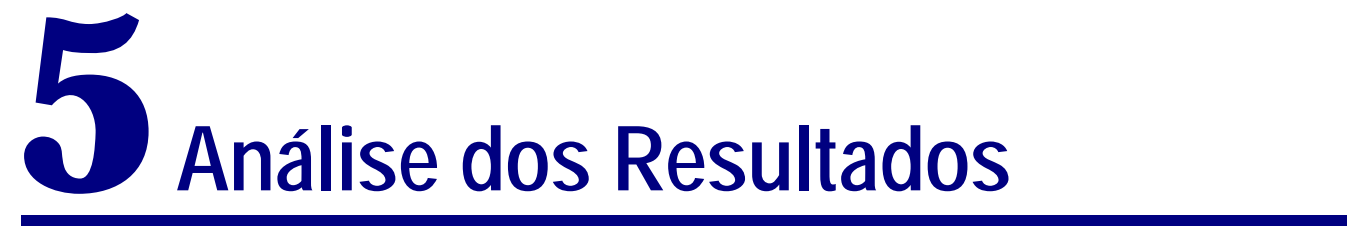

\subsection{Considerações Iniciais}

Neste capítulo serão analisados, para os modelos, os seguintes aspectos de interesse: a seção resistente de concreto e a eficiência do confinamento. A avaliação da seção resistente se fará através da comparação entre os valores experimentais $\left(F_{\text {exp }}\right)$ e os valores teóricos $\left(F_{\text {teo }}, F_{\text {teo,n }}\right)$, considerando seção íntegra e seção definida pelos eixos da armadura transversal, respectivamente. Quanto à eficiência do confinamento, esta será avaliada através dos seguintes fatores: Índice de Eficiência do Confinamento, sugerido por CUSSON e PAULTRE (1993); comportamento do diagrama força $x$ deformação e deformação na armadura transversal.

\subsection{Seção resistente de concreto}

Os resultados dos ensaios mostram que a consideração do núcleo de concreto como seção resistente do pilar fica ligeiramente a favor da segurança, para forças próximas à força última. Os valores das forças últimas obtidas nos ensaios $\left(F_{\text {exp }}\right)$ situam-se entre os obtidos teoricamente, considerando-se: (1) seção íntegra de concreto $\left(F_{\text {teo }}\right)$, e (2) seção do núcleo de concreto $\left(F_{\text {teo,n }}\right)$. Portanto constata-se que: $F_{\text {exp }} / F_{\text {teo }}<1$ e $F_{\text {exp }} / F_{\text {teo,n }}>1$, conforme indicado na tabela 5.1. 
Tabela 5.1. Resumo dos resultados dos ensaios e verificação da seção resistente de concreto

\begin{tabular}{|c|c|c|c|c|c||}
\hline Pilar & $\begin{array}{c}\text { Armadura } \\
\text { Longitudinal }\end{array}$ & $\boldsymbol{A}_{\boldsymbol{~ s l}}\left(\mathbf{c m}^{2}\right)$ & $\begin{array}{c}\text { Armadura } \\
\text { transversal }\end{array}$ & $\boldsymbol{f}_{\boldsymbol{y}}$ & $\boldsymbol{f}_{c}$ \\
\hline P1 & $8 \phi 12,5$ & 10 & $\phi 6,3 \mathrm{c} / 15$ & 502 & 59,60 \\
\hline P2 & $8 \phi 12,5$ & 10 & $\phi 6,3 \mathrm{c} / 15$ & 502 & 64,35 \\
\hline P3 & $8 \phi 12,5$ & 10 & $\phi 6,3 \mathrm{c} / 10$ & 502 & 53,40 \\
\hline P4 & $8 \phi 12,5$ & 10 & $\phi 6,3 \mathrm{c} / 10$ & 502 & 53,40 \\
\hline P5 & $8 \phi 12,5$ & 10 & $\phi 6,3 \mathrm{c} / 5$ & 502 & 55,90 \\
\hline P6 & $8 \phi 12,5$ & 10 & $\phi 6,3 \mathrm{c} / 5$ & 502 & 55,90 \\
\hline P7 & $8 \phi 12,5$ & 10 & $\phi 6,3 \mathrm{c} / 15$ & 502 & 66,90 \\
\hline P8 & $8 \phi 12,5$ & 10 & $\phi 6,3 \mathrm{c} / 15$ & 502 & 66,90 \\
\hline P9 & $8 \phi 12,5$ & 10 & $\phi 6,3 \mathrm{c} / 10$ & 502 & 63,88 \\
\hline P10 & $8 \phi 12,5$ & 10 & $\phi 6,3 \mathrm{c} / 10$ & 502 & 63,88 \\
\hline P11 & $8 \phi 12,5$ & 10 & $\phi 6,3 \mathrm{c} / 5$ & 502 & 65,47 \\
\hline P12 & $8 \phi 12,5$ & 10 & $\phi 6,3 \mathrm{c} / 5$ & 502 & 65,47 \\
\hline
\end{tabular}

Tabela 5.1. Continuação

\begin{tabular}{|c|c|c|c|c|c|}
\hline Pilar & $F_{\text {teo }}(\mathrm{kN})$ & $F_{\text {teo, } n}(\mathrm{kN})$ & $F_{\text {exp }}$ & $F_{\text {exp }} / F_{\text {teo }}$ & $F_{\text {exp }} / F_{\text {teo, } n}$ \\
\hline$P 1$ & 2594,1 & 1769,3 & 2278 & 0,88 & 1,29 \\
\hline$P 2$ & 2760,8 & 1870,3 & 2292 & 0,83 & 1,23 \\
\hline P3 & 2376,4 & 1637,5 & 1835 & 0,77 & 1,12 \\
\hline P4 & 2376,4 & 1637,5 & 1864 & 0,78 & 1,14 \\
\hline$P 5$ & 2464,2 & 1690,6 & 2158 & 0,88 & 1,28 \\
\hline$P 6$ & 2464,2 & 1690,6 & 2312 & 0,94 & 1,37 \\
\hline P7 & 3151,3 & 2086,1 & 2373 & 0,75 & 1,14 \\
\hline P8 & 3151,3 & 2086,1 & 2496 & 0,80 & 1,20 \\
\hline$P 9$ & 3031,7 & 2014,6 & 2446 & 0,81 & 1,21 \\
\hline P10 & 3031,7 & 2014,6 & 2440 & 0,80 & 1,21 \\
\hline P11 & 3094,7 & 2052,3 & 2288 & 0,74 & 1,11 \\
\hline P12 & 3094,7 & 2052,3 & 2497 & 0,81 & 1,22 \\
\hline & & & MÉDIA & 0,82 & 1,21 \\
\hline
\end{tabular}


Observa-se que, para todos os modelos, as forças últimas teóricas calculadas levando-se em consideração as seções íntegras de concreto $\left(F_{\text {teo }}\right)$, são superiores às forças últimas experimentais $\left(F_{\text {exp }}\right)$. Entretanto, quando se considera o núcleo de concreto definido pela armadura transversal (área da seção de concreto limitada pelos estribos), obtiveram-se forças últimas teóricas $\left(F_{\text {teo,n }}\right)$ inferiores ou iguais às forças últimas experimentais $\left(\mathrm{F}_{\text {exp }}\right)$. Daí pode-se concluir que, para pilares de concreto de alta resistência, no caso em torno de $60 \mathrm{MPa}$, a seção resistente é a seção transversal correspondente ao núcleo de concreto. Desta forma verificam-se as observações feitas por AGOSTINI (1992), PAIVA (1994), CUSSON e PAULTRE (1993) e LIMA (1997) para pilares com concreto de resistência média à compressão de 60MPa.

\subsection{Capacidade resistente segundo COLLINS et al. (1993)}

Os resultados obtidos com a expressão proposta por COLLINS et al. (1993) ficaram próximos dos valores experimentais, como indicado na tabela 5.2.

Tabela 5.2. Comparação dos resultados com os valores obtidos através da equação proposta por COLLINS et al. (1993)

\begin{tabular}{|c|c|c|c|c|c|c|}
\hline Pilar & $\begin{array}{c}f_{c} \\
(M P a)\end{array}$ & $\begin{array}{l}0.95 f_{c} \\
(\mathrm{MPa})\end{array}$ & $k_{3}$ & $F_{t e o}(\mathbf{k N})$ & $F_{\text {exp }}$ & $F_{\text {exp }} / F_{\text {teo }}$ \\
\hline P1 & 59,60 & 56,62 & 0,78 & 2217,0 & 2278 & 1,03 \\
\hline P2 & 64,35 & 61,13 & 0,76 & 2322,6 & 2292 & 0,99 \\
\hline P3 & 53,40 & 50,73 & 0,80 & 2079,2 & 1835 & 0,88 \\
\hline$P 4$ & 53,40 & 50,73 & 0,80 & 2079,2 & 1864 & 0,90 \\
\hline P5 & 55,90 & 53,11 & 0,79 & 2134,8 & 2158 & 1,01 \\
\hline P6 & 55,90 & 53,11 & 0,79 & 2134,8 & 2312 & 1,08 \\
\hline$P 7$ & 66,90 & 63,56 & 0,76 & 2620,0 & 2373 & 0,91 \\
\hline P8 & 66,90 & 63,56 & 0,76 & 2620,0 & 2496 & 0,95 \\
\hline P9 & 63,88 & 60,69 & 0,76 & 2544,2 & 2446 & 0,96 \\
\hline P10 & 63,88 & 60,69 & 0,76 & 2544,2 & 2440 & 0,96 \\
\hline P11 & 65,47 & 62,20 & 0,76 & 2584,1 & 2288 & 0,89 \\
\hline P12 & 65,47 & 62,20 & 0,76 & 2584,1 & 2497 & 0,97 \\
\hline
\end{tabular}


Os resultados revelam a excelente aproximação obtida com a sugestão de COLLINS et al.(1993). Além disto está a facilidade em se considerar na formulação do modelo, a seção total de concreto, sem a necessidade de determinação da área do núcleo. Torna-se necessário, portanto, estabelecer este método como referência para a previsão da força última de ruptura em pilares moldados em CAR.

\subsection{Ductilidade}

Define-se ductilidade como a capacidade do material ou do elemento estrutural de se deformar inelasticamente sem perda brusca de resistência. $\mathrm{Na}$ presente pesquisa, após a extensa revisão bibliográfica sobre o assunto e através dos ensaios realizados, verificou-se a importância do confinamento, proporcionado pela armadura transversal, para o aumento da capacidade de deformação do pilar, isto é, a ductilização do mesmo, especialmente em pilares moldados em CAR. A menor deformação transversal do CAR quando comparado aos concretos de baixa resistência, proporciona menor solicitação da armadura transversal, portanto, as tensões laterais resultantes são inferiores. A eficiência do confinamento e, conseqüêntemente, a ductilidade dos pilares, podem ser avaliados segundo os indicadores abaixo relacionados:

- Índice de Eficiência do Confinamento;

- Diagrama força x deformação dos pilares;

- Deformação nas barras da armadura transversal.

\subsection{1. Índice de Eficiência do Confinamento}

$\mathrm{Na}$ avaliação da eficiência do confinamento utilizou-se o índice proposto por CUSSON e PAULTRE (1993) e apresentado no ítem 3.2.1.2. b. O Índice de Eficiência do Confinamento considera os seguintes fatores em sua formulação:

- Geometria do núcleo definido pelas barras das armaduras longitudinais e transversais, tanto a configuração superior como lateral, como mostrado na figura 3.23 para os modelos de seção transversal retangular. A consideração se verifica através do coeficiente de confinamento efetivo $\left(\mathrm{K}_{\mathrm{e}}\right)$; 
- Características geométricas e mecânicas da armadura transversal (área, espaçamento e tensão). Isto acontece através da formulação para a pressão lateral de confinamento $\left(\mathfrak{f}_{1}\right)$;

O esquema a seguir mostra a metodologia de cálculo dos termos necessários ao cálculo do I.E.C. para modelos de seção quadrada e retangular. Nesta parte aplicam-se os conceitos também propostos por KÖNIG e SIMSCH (1996), como a pressão lateral de confinamento.
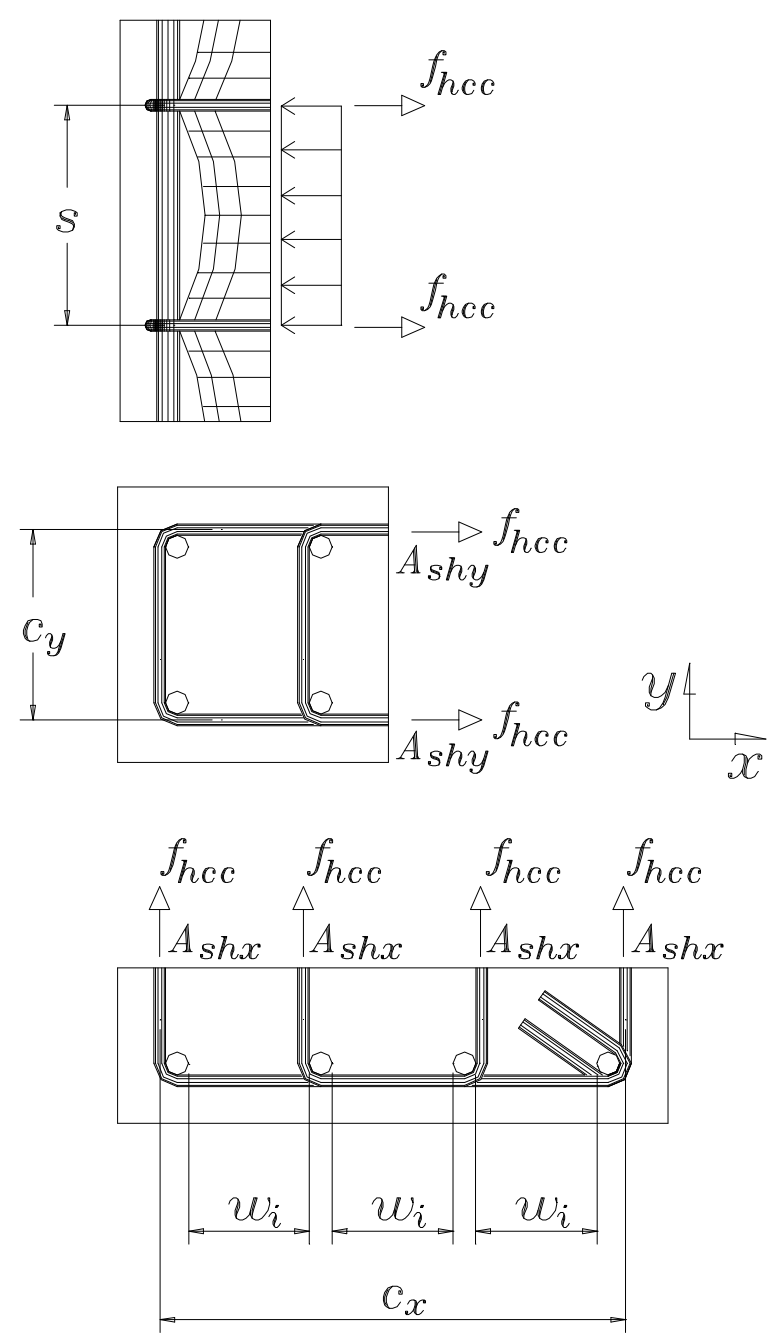

Figura 5.1. Esquema para cálculo da pressão lateral de confinamento $\left(f_{1}\right)$

Os resultados para o I.E.C. para os modelos ensaiados estão apresentados na tabela 5.3. 
Tabela 5.3. Índice de Eficiência do Confinamento para os modelos

\begin{tabular}{||c|c|c|c|c|c|c|c||}
\hline Pilar & $s(\mathbf{c m})$ & $\rho_{w}(\%)$ & $f_{c}(\mathbf{M P a})$ & $\boldsymbol{K}_{\boldsymbol{e}}$ & $\boldsymbol{f}_{1}$ & I.E.C. $(\%)$ & Classe \\
\hline P1 & 15 & 0,34 & 59,60 & 0,26 & 0,44 & 0,23 & $\mathrm{I}$ \\
\hline P2 & 15 & 0,34 & 64,35 & 0,26 & 0,49 & 0,24 & $\mathrm{I}$ \\
\hline P3 & 10 & 0,51 & 53,40 & 0,44 & 1,81 & 1,73 & $\mathrm{I}$ \\
\hline P4 & 10 & 0,51 & 53,40 & 0,44 & 2,32 & 2,22 & $\mathrm{I}$ \\
\hline P5 & 5 & 1,03 & 55,60 & 0,65 & 4,73 & 6,48 & $\mathrm{II}$ \\
\hline P6 & 5 & 1,03 & 55,90 & 0,65 & 4,73 & 6,48 & $\mathrm{II}$ \\
\hline P7 & 15 & 0,34 & 66,90 & 0,26 & 0,16 & 0,07 & $\mathrm{I}$ \\
\hline P8 & 15 & 0,34 & 66,90 & 0,26 & 0,15 & 0,06 & $\mathrm{I}$ \\
\hline P9 & 10 & 0,51 & 63,88 & 0,30 & 2,80 & 1,55 & $\mathrm{I}$ \\
\hline P10 & 10 & 0,51 & 63,88 & 0,30 & 2,34 & 1,29 & $\mathrm{I}$ \\
\hline P11 & 5 & 1,03 & 65,47 & 0,49 & 6,30 & 5,49 & $\mathrm{II}$ \\
\hline P12 & 5 & 1,03 & 65,47 & 0,49 & 6,30 & 5,49 & $\mathrm{II}$ \\
\hline
\end{tabular}

Observa-se dos resultados que os modelos com taxas de armadura transversal iguais a 0,34 e 0,51 apresentam baixa eficiência do confinamento (Classe I), logo, as respectivas taxas de armadura não conferem acréscimos de resistência e ductilidade aos pilares.

\subsubsection{Diagrama força $x$ deformação dos pilares}

De acordo com o comportamento do diagrama força $x$ deformação, ilustrado na figura 3.2, pode-se avaliar a eficiência da armadura transversal no confinamento. Para isto deve-se verificar o trecho descendente do diagrama, isto é, verificar o comportamento do pilar após o primeiro "pico" de força, correspondente ao ponto A do diagrama da figura 3.2. Caso o pilar apresente acréscimos de resistência, caracterizado por um trecho "pós-pico" horizontal ou ascendente, fica claro que as armaduras laterais estão proporcionando consideráveis pressões no núcleo. Um trecho descendente íngreme revela a ineficiência do confinamento para a ductilização da ruptura do pilar.

Para exemplificar este fato, são mostrados três diferentes comportamentos para os diagramas força $x$ deformação, verificados a partir dos ensaios dos pilares de seção quadrada, P1, P4 e P6, figura 5.2, e retangular, P7, 
P9 e P12, figura 5.3. Para espaçamento entre estribos de 15cm (P1, P7), 10cm (P4, P9) e $5 \mathrm{~cm}$ (P6, P12), os aspectos das curvas força $x$ deformação dos pilares assumiam as configurações correspondentes à baixa e média eficiência da armadura de confinamento.

a. Modelos com seção transversal quadrada
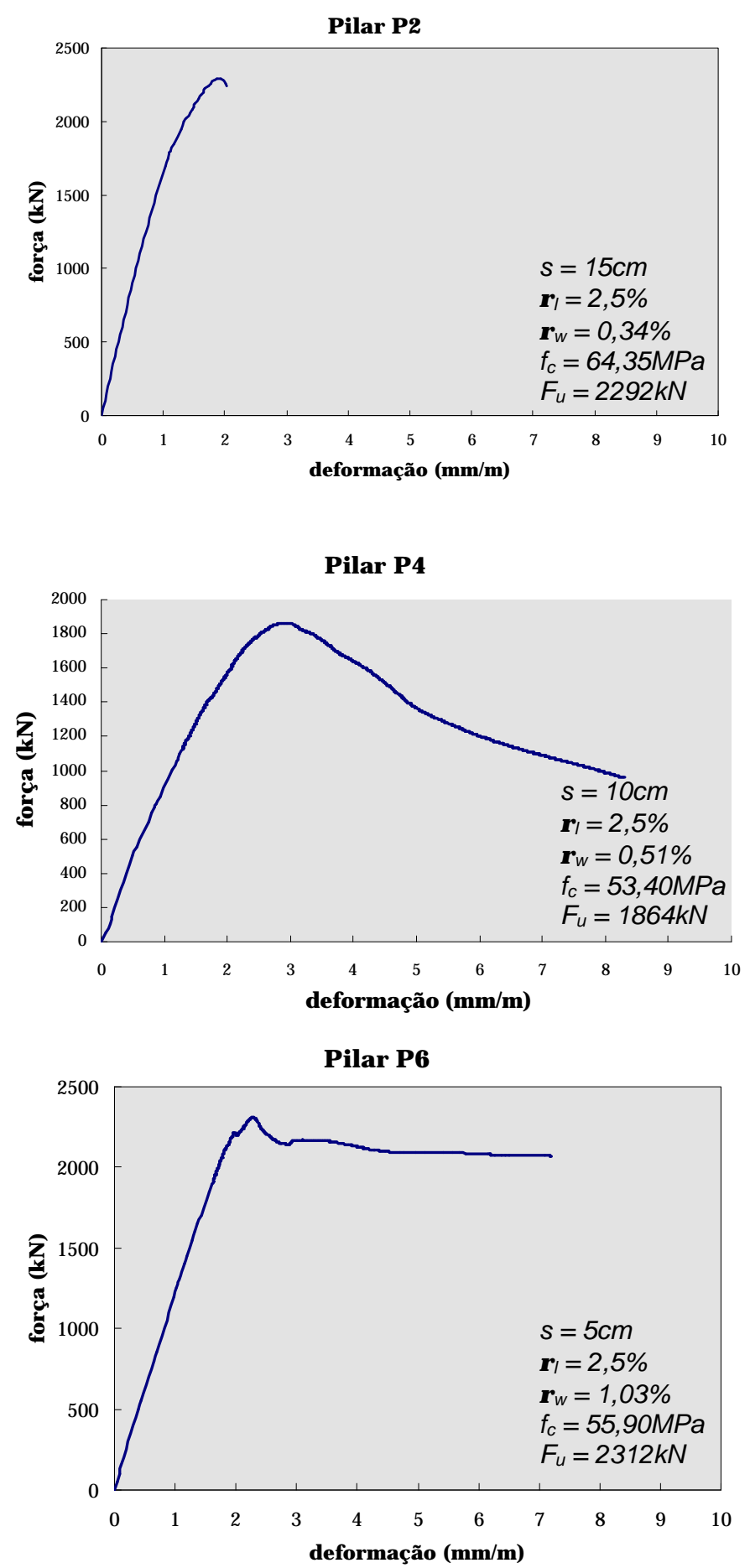

Figura 5.2. Diagramas força $x$ deformação para os pilares P2, P4 e P6 (valores médios) 
Para o pilar P2 observa-se que, após a força máxima ter sido atingida, não há acréscimos de resistência para o modelo. O confinamento não foi suficiente para promover ruptura dúctil, levando o pilar à ruptura antes que as armaduras transversais tivessem alcançado o patamar de escoamento. A não existência do trecho descendente para P1, P2, P7 e P8, todos com $\rho_{w}=0,34 \%$, torna a armadura transversal adotada $(\phi 6,3 \mathrm{c} / 15)$ não recomendável à pilares de CAR com mesma seção, com resistência média à compressão do concreto de $60 \mathrm{MPa}$.

O pilar P4 apresentou trecho descendente pouco suave, porém a armadura transversal atingiu a resistência $f_{y}$ e garantiu ruptura dúctil ao modelo. Para o pilar P6 observa-se o trecho descendente aproximando-se da horizontal, caracterizando, portanto, a eficiência da armadura lateral no confinamento do núcleo. A ruptura foi dúctil. Estas observações concordam com os resultados para o Índice de Eficiência do Confinamento: 0,24\% (P1); 2,22\% (P4) e 6,48\% (P6).

\section{b. Modelos com seção transversal retangular}
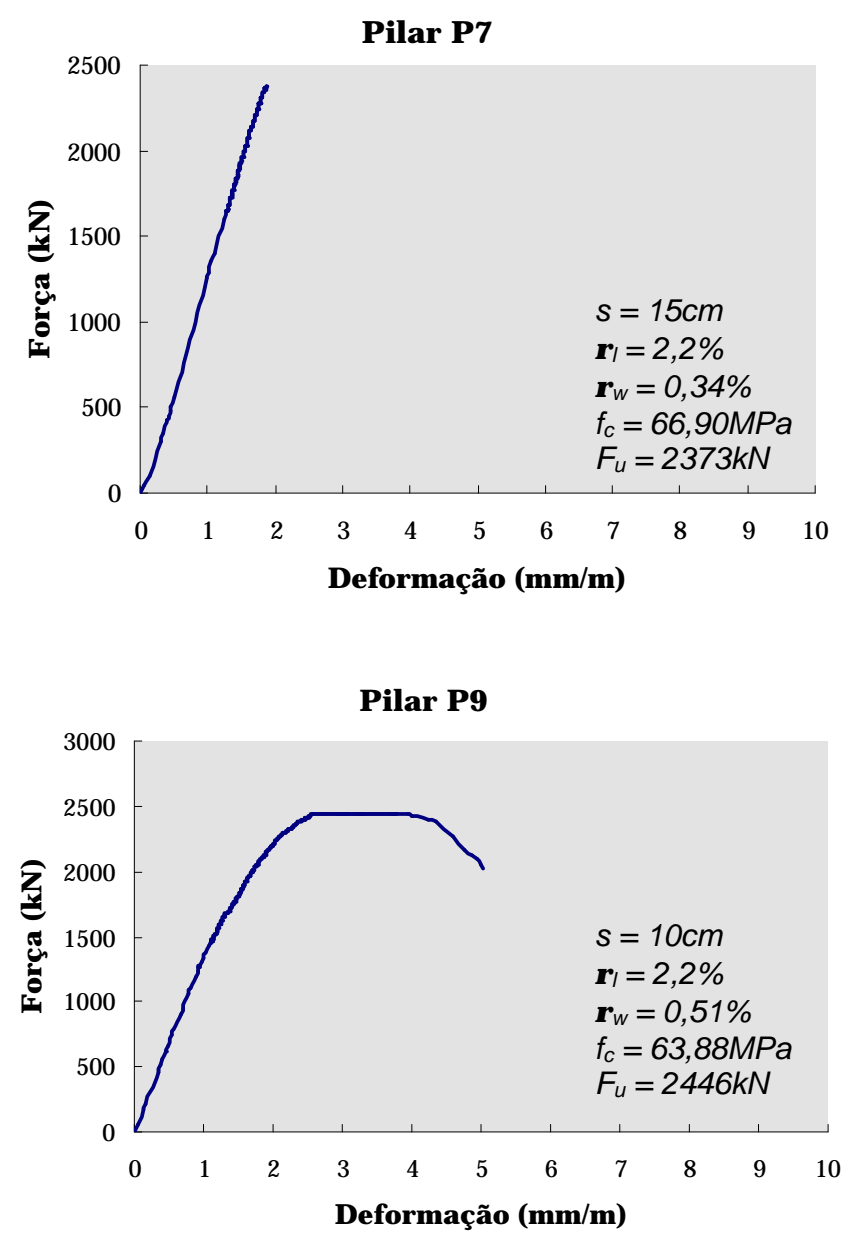


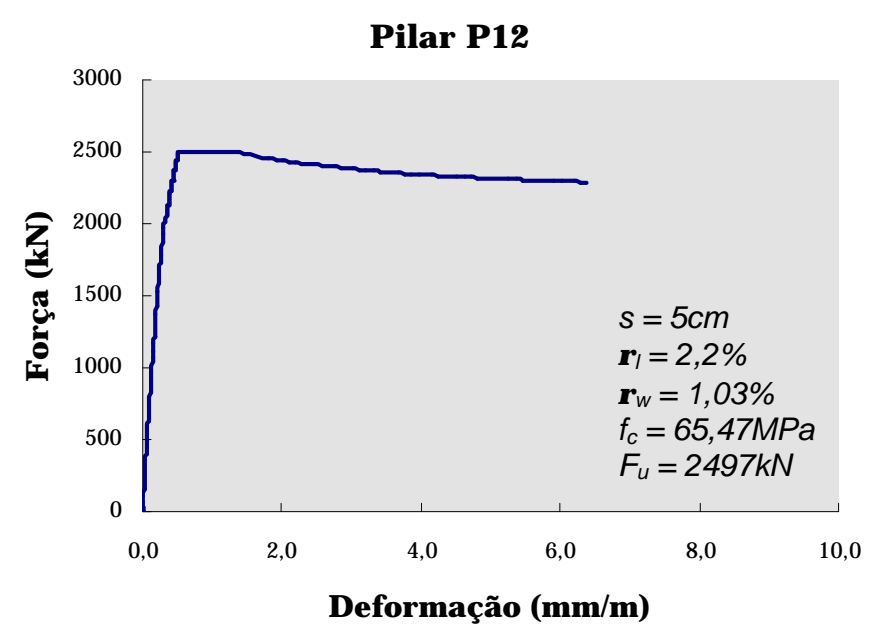

Figura 5.3. Diagramas força $x$ deformação para os pilares P7, P9 e P12

Para os modelos de seção retangular, as observações são semelhantes às dos modelos de seção quadrada. Para o pilar P7 não se observaram ganhos de resistência e ductilidade, o que traduz a ineficiência do confinamento.

O pilar P9 apresentou patamar para a força máxima e trecho descendente pouco suave, mas com comportamento dúctil. Para o pilar P12 observa-se o trecho descendente aproximando-se da horizontal, assim como no pilar P6, caracterizando assim comportamento dúctil e eficiência da armadura lateral. As observações concordam portanto com os resultados para o Índice de Eficiência do Confinamento: 0,23\% (P7); 1,55\% (P9) e 5,49\% (P12).

\subsubsection{Deformação na armadura transversal}

Para que substanciais pressões de confinamento sejam aplicadas ao núcleo, é necessário que as armaduras transversais atinjam seu patamar de escoamento $\left(f_{y}\right)$, deformações superiores a $\varepsilon_{y}$. Deste fato percebe-se que a armadura está realmente "trabalhando", uma vez que, para uma maior pressão lateral aplicada ao núcleo, resulta na maior eficiência do confinamento. A tabela 5.4 traz as deformações máximas obtidas nos estribos verificadas para cada modelo (valores médios). A comparação feita com os valores do I.E.C. mostra que o parâmetro deformação da armadura transversal também é um indicador da eficiência do confinamento. 
Tabela 5.4. Deformações últimas para estribos

\begin{tabular}{||c|c|c||}
\hline Pilar & I.E.C. $(\%)$ & $\varepsilon_{\boldsymbol{s}}(\%)$ \\
\hline P1 & 0,23 & 0,95 \\
\hline$P 2$ & 0,24 & 1,05 \\
\hline$P 3$ & 1,73 & 2,58 \\
\hline$P 4$ & 2,22 & 3,31 \\
\hline$P 5$ & 6,48 & 3,70 \\
\hline$P 6$ & 6,48 & 3,50 \\
\hline$P 7$ & 0,07 & 0,34 \\
\hline$P 8$ & 0,06 & 0,32 \\
\hline$P 9$ & 1,55 & 3,00 \\
\hline$P 10$ & 1,29 & 2,50 \\
\hline$P 11$ & 5,49 & 5,00 \\
\hline$P 12$ & 5,49 & 5,00 \\
\hline
\end{tabular}

\subsection{Armaduras mínimas}

A partir do exame dos ítens anteriores, pode-se verificar a taxa volumétrica de armadura transversal $\left(\rho_{\mathrm{w}}\right)$ que garantiu ruptura dúctil ao pilar. Segundo AGOSTINI (1992), para taxas de armadura longitudinal de $2,54 \%$ e transversal de $1,03 \%$, os pilares apresentaram ruptura dúctil. Na presente pesquisa, para conseguir ruptura dúctil nos pilares foram necessárias taxas de armadura longitudinal de 2,50\% (seção transversal quadrada) e 2,20\% (seção retangular) e transversal superiores a 0,51\%, para pilares de seção quadrada e retangular, correspondendo a espaçamento entre estribos de $10 \mathrm{~cm}$. Estes valores são inferiores aos sugeridos por AGOSTINI (1992).

Para os modelos de seção quadrada, observou-se que a configuração simples de estribos, apesar de contar com oito barras longitudinais, não proporcionava Índices de Eficiência do Confinamento superiores a 20\% (Classe 1), necessitando de pequenos espaçamentos entre estribos para situarem-se na Classe 2 (média eficiência), no caso, os modelos das Séries 3.

Confirmando esta observação está o gráfico proposto por SHEIKH e UZUMERI (1982), figura 3.18, onde se determina, para pilares de seção quadrada, 
o coeficiente $\lambda^{*}$ em função da configuração da armadura transversal, espaçamento entre estribos (s) e dimensão da seção (B). Para os modelos de seção retangular tem-se, tabela 5.5:

Tabela 5.5. Determinação de $\lambda^{*}$, SHEIKH e UZUMERI (1982)

\begin{tabular}{|c|c|c|c||}
\hline $\mathbf{B}$ & $\mathbf{s}$ & $\mathbf{s} / \mathbf{B}$ & $\lambda^{*}$ \\
\hline 20 & 15 & 0,75 & 0,08 \\
\hline 20 & 10 & 0,50 & 0,16 \\
\hline 20 & 5 & 0,25 & 0,20 \\
\hline
\end{tabular}

Como $\lambda^{*}$ é definido como a relação entre a área da seção crítica $\left(A_{c e}\right)$ e a área do núcleo definida pelos eixos dos estribos $\left(A_{c o}\right)$, fica claro que, para espaçamentos de $15 \mathrm{~cm}$, a área da seção crítica de concreto será apenas $8 \%$ da área do núcleo. Para espaçamentos da ordem do dobro da dimensão da seção (s/B $=2)$, o confinamento é inefetivo $\left(\lambda^{*}=0\right)$.

No caso dos modelos com seção retangular, a configuração sugerida também não proporcionou resultados satisfatórios. Apenas os modelos da série 6 (P7 e P8) atingiram I.E.C. superior a 5\% (média eficiência do confinamento).

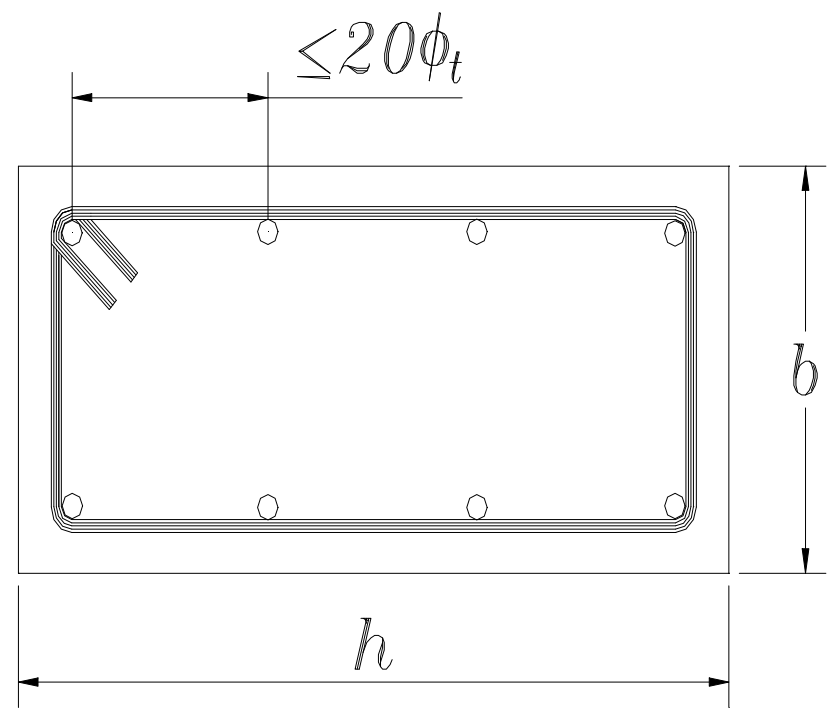

Figura 5.4. Configuração "simples" para a armadura transversal

Segundo a NBR 6118 (1978), as barras da armadura lateral que não tiverem suporte lateral, devem estar afastadas de, no máximo, $20 \phi_{\mathrm{t}}$, onde $\phi_{\mathrm{t}}$ é o diâmetro do 
estribo principal (figura 5.4). Para os modelos de seção retangular ensaiados, as barras da armadura longitudinal apresentavam-se afastadas de 7,8cm $<20 \phi_{\mathrm{t}}=20$. $0,63=12,6 \mathrm{~cm}$. Logo, segundo a norma em vigor, não seria necessário dispor o estribo adicional utilizado nos modelos das séries 4 a 6 . Esta recomendação, para pilares de CAR apresenta-se contra a segurança, uma vez que se traduz em perda de resistência e ductilidade do elemento estrutural.

Para todos os modelos comprovou-se então a necessidade de configurações mais eficientes para a armadura transversal.

\subsection{Considerações finais}

À primeira vista as conclusões deste trabalho apontam para a necessidade de um maior número de pesquisas sobre o comportamento de pilares de CAR envolvendo um maior número de variáveis, como a taxa de armadura longitudinal, que, na presente pesquisa, permaneceu constante. Porém, os resultados obtidos até então, comprovaram as conclusões já expostas por outros pesquisadores como AGOSTINI (1992) e LIMA (1997), mostrando que a resistência aqui estudada, em torno de $60 \mathrm{MPa}$, enquadra-se no comportamento previsto para pilares de CAR. 


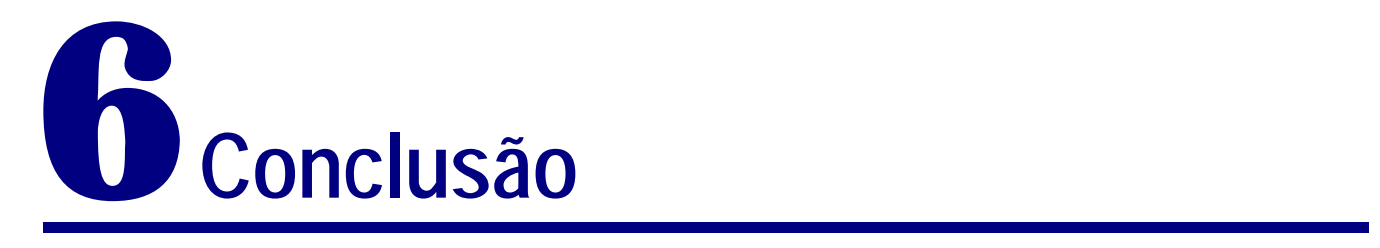

Diante dos resultados e análises feitas até então, torna-se necessário pensar na possibilidade de mudança das normas de detalhamento de pilares, especialmente no tocante aos valores mínimos para armadura transversal e espaçamentos máximos. Para a utilização racional do CAR nas edificações, toda tradição de projeto deve ser revista, uma vez que as exigências até então em vigor, estão baseadas no comportamento de pilares de concreto de baixa resistência (resistência média à compressão inferior aos 40MPa).

Os pilares ensaiados apresentaram pequenas excentricidades que foram observadas de imediato através da leitura dos extensômetros posicionados nas armaduras longitudinais. Em todos os modelos a força última de ruptura $\left(F_{\text {exp }}\right)$ ficou situada entre a força última teórica (para a seção íntegra, $F_{\text {teo }}$ ) e a força última teórica para o núcleo definido pela linha-de-centro dos estribos, $F_{\text {teo,n }}$.

Pode-se observar que a taxa de armadura transversal que garantiu ruptura dúctil para os pilares foi $\rho_{w}=0,51 \%$, com $\phi 6,3 c / 10$, adotada nos modelos da Série 2 e 5 . Este valor é inferior ao valor 2,2\% proposto por AGOSTINI (1992) e PAIVA (1994).

A pesquisa mostrou também a importância de uma configuração eficiente da armadura transversal para garantir acréscimos de resistência e ductilidade ao pilar. Quanto à eficiência da armadura transversal para o confinamento do núcleo, percebe-se que melhores resultados seriam obtidos com o emprego de outras configurações para a armadura. A configuração de estribos adotada na pesquisa 
não provê acréscimos substanciais de resistência e ductilidade, mostrando-se eficaz apenas com reduzido espaçamento. Configurações de estribos como as mostradas na figura 6.1 podem ser mais eficientes quanto a produzir maiores acréscimos de resistência e ductilidade nos pilares.
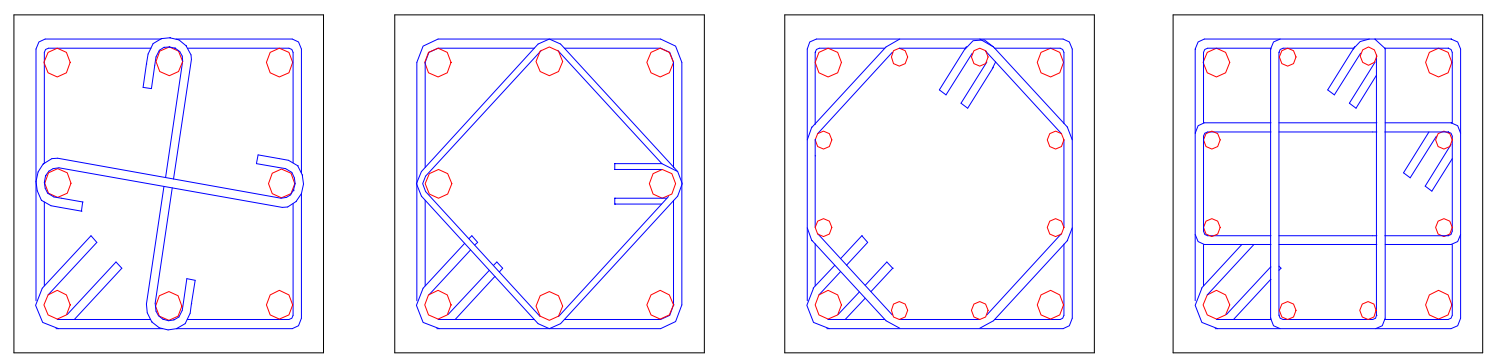

Figura 6.1. Configurações mais eficientes para os estribos

Os resultados da pesquisa também puseram em relevo a necessidade de taxas de armadura transversal, superiores às empregadas em pilares de concreto de baixa resistência. Espaçamentos superiores a $15 \mathrm{~cm}$, dependendo da configuração adotada para estribos, deveriam ser evitados. Isto vai de encontro às recomendações da NBR 6118 (1978) quanto a espaçamentos máximos:

$s \leq\left\{\begin{array}{l}12 \phi_{l}=15 \mathrm{~cm} \\ \text { menor dimensão da seção }: 20 \mathrm{~cm}-\text { sec ão quadrada } ; 15 \mathrm{~cm}-\text { seção re tan gular } \\ 30 \mathrm{~cm}\end{array}\right.$

Outra conclusão importante foi a possibilidade de redução do número de modelos por série. Como os resultados dos ensaios mostraram haver pouca discrepância entre modelos da mesma série, pode-se optar por moldar apenas um pilar por série, viabilizando assim o cumprimento dos objetivos dentro do prazo estipulado.

\subsection{Sugestões para a continuidade da pesquisa}

A principal sugestão para a continuidade da pesquisa está na introdução de outras variáveis para o estudo do comportamento de pilares de CAR com a mesma resistência do concreto. Logo, para pilares de CAR com resistência média à 
compressão de $60 \mathrm{MPa}$, o efeito de outras variáveis poderia ser estudado, tais como:

- quantidade de armadura longitudinal $\left(\rho_{1}\right)$;

- configuração da armadura transversal;

- diâmetro de estribos $\left(\phi_{t}\right)$;

Propor critérios para o projeto de pilares de concreto com resistências médias à compressão 60MPa submetidos à compressão simples, a partir das observações experimentais.

Para efeito de comparação com os resultados experimentais, pode-se também recorrer à análise numérica dos modelos através de um programa de M.E.F., com a consideração da não linearidade física do material.

Outra proposta para a continuidade da pesquisa está na análise experimental de pilares de concreto com resistência média à compressão de 40MPa. Esta sugestão justifica-se pelos seguintes aspectos:

- O avanço na tecnologia do concreto, com a melhor qualidade do cimento e a introdução de novos aditivos e adições, como a sílica ativa e o superplastificante, determina a necessidade de estudo de novos procedimentos de dosagem para concretos com resistência média à compressão da ordem de 40MPa;

- Em virtude dos novos materiais empregados e das conseqüências disto na microestrutura do concreto, torna-se indispensável o estudo experimental de elementos estruturais compostos com os materiais e técnicas atualmente disponíveis. O comportamento de elementos estruturais comprimidos com concreto de resistência $40 \mathrm{MPa}$ (limite superior para concretos da Classe I) pode não ser semelhante ao observado no caso de concreto com resistência à compressão de 20MPa;

- O estudo de pilares de concreto com resistência média à compressão de $40 \mathrm{MPa}$, irá complementar as análises experimentais já concluídas e em andamento deste elemento estrutural com CAR de resistência média à compressão de $80 \mathrm{MPa}$ e 60MPa. Ter-se-ia, portanto, conhecimento do 
comportamento de pilares de concreto armado numa faixa de resistências entre 40MPa e 80MPa. 


\section{Referências Bibliográficas}

AGOSTINI, L. R. S. (1992). Pilares de concreto de alta resistência. São Paulo. Tese (Doutorado) - Escola Politécnica, Universidade de São Paulo. (Orientador: Péricles Brasiliense Fusco).

AÏ TCIN, P. C.; NEVILLE, A. (1993). High-Performace Concrete Demystified. Concrete International, v.15, no.1, p. 21-26.

AL-HUSSAINI, A.; REGAN, P.E.; XUE, H. Y.; RAMDANE, K. E. (1993). The Behaviour of HSC Columns under Axial Load. In: INTERNATIONAL SYMPOSIUM ON UTILIZATION OF HIGH-STRENGTH CONCRETE, 3., Norway, 1993. Proceedings.

AMERICAN CONCRETE INSTITUTE (1990). ACI 318/90 - Building code requiriments for reinforced concrete. Detroit, 113p.

AMERICAN CONCRETE INSTITUTE (1992). ACI 363/92 - State-of-the-art report on high strength concrete. Detroit, 55p.

AMERICAN CONCRETE INSTITUTE (1997). ACI 441/97 - High-Strength Concrete Columns: State of the art. Comittee Report. ACI Structural Journal, May - June. p. 323-335.

ASSOCIAÇÃO BRASILEIRA DE NORMAS TÉCNICAS (1987). NBR 7217 Agregado - determinação da composição granulométrica. Rio de Janeiro. 
ASSOCIAÇÃO BRASILEIRA DE NORMAS TÉCNICAS (1983). NBR 7211 Agregados para concreto. Rio de Janeiro.

ASSOCIAÇÃO BRASILEIRA DE NORMAS TÉCNICAS (1978). NBR 6118 - Projeto e execução de obras de concreto armado. Rio de Janeiro.

BACCIN, A. G. C. (1998). Fundamentos do concreto de alto desempenho e sua aplicação ao projeto de pilares. Dissertação (Mestrado) - Escola de Engenharia de São Carlos, Universidade de São Paulo. (Orientador: Libânio Miranda Pinheiro).

BEEDLE, L.S. (1992). Tall buildings around the world. Bethlehem: COUNCIL ON TALL BUILDINGS AND URBAN HABITAT. 8p. (Council Report, 903.432).

BJERKELI, L.; TOMASZEWICZ, A.; JANSEN, J. J. (1990). Deformation Properties and Ductility of High-strength Concrete. ACl Materials Journal, Abstracts SP 121-12, p. 215-238, nov-dec.

BRESLER, B.; GILBERT, P. H. (1961). Tie Requirements for Reinforced Concrete Columns. Journal of American Concrete Institute, p. 555-569, nov.

CHIN, M. S.; MANSUR, M. A.; WEE, T. H. (1997). Effects of shape, size, and casting direction of specimens on stress-strain curves of high-strength concrete. ACI Materials Journal, p. 209-219, may - june.

CLAESON, C.; GYLLTOFT, K.; GRAUERS, M. (1996). Experiments and numerical analyses of reinforced high strength concrete columns. In: INTERNATIONAL SYMPOSIUM ON THE UTILIZATION OF HIGH-STRENGTH/ HIGHPERFORMACE CONCRETE, 4., 1996. Proceedings. p. 797-806.

COLLINS, M. P.; MITCHEL, D. MACGREGOR, J. G. (1993). Structural design considerations for high-strength concrete. Concrete International, p. 27-34, may. 
CUSSON, D.; PAULTRE, P. (1992). Behavior of High-strength concrete columns confined by retangular ties under Concentric Loading. Department of Civil Engineering, Faculty of Applied Sciences, University of Sherbrooke, aug.

CUSSON, D.; PAULTRE, P. (1993). Confinement Model for High-Strength Concrete Tied Columns. Department of Civil Engineering, Faculty of Applied Sciences, University of Sherbrooke, may.

CUSSON, D.; PAULTRE, P. (1994). High-strength concrete columns confined by retangular ties. Journal of structural engineering, ASCE, v.120, n.3, p. 783-804, march.

DAL MOLIN (1995). Contribuição ao estudo das propriedades mecânicas dos concretos de alta resistência com e sem adição de sílica ativa. São Paulo. 286p. Tese (Doutorado) - Escola Politécnica, Universidade de São Paulo. (Orientador: Paulo J. M. Monteiro).

DEHUAI, W.; ZHAOYUAN, C.; WEIZU, Q. (1997). Computerized Mix Proportioning for HPC. Concrete International, p.42-45, sep.

DINIZ, S. M. C.; FRANGOPOL, D. M. (1997). Strength and ductility simulation of high-strength concrete columns. Journal of Structural Engineering, p. 13651374 , oct.

DUCATTI, V. A. (1993). Concreto de elevado desempenho - estudo da aderência com a armadura. São Paulo. Tese (Doutorado) - Escola Politécnica, Universidade de São Paulo. (Orientador: Vahan Agopian).

FAFITIS, A.; SHAH, S. P. (1985). Lateral reinforcement for high-strength concrete columns. High-Strength Concrete, SP-87, American Concrete Institute, p.213232. 
FERNANDES, G. B. (1992). Cisalhamento em Vigas de Concreto de Alta Resistência. São Paulo. Tese (Doutorado) - Escola Politécnica, Universidade de São Paulo. (Orientador: Péricles Brasiliense Fusco).

FIP-CEB Working Group on High-strenght Concrete (1990). High strength concrete - state of the art report. CEB Bulletin d'Information, n. 197, ago 1990.

GIONGO, J. S.; LIMA, F. B.; TAKEYA, T. (1996). Análise experimental de pilares de concreto armado de alto desempenho solicitados à compressão simples e a flexão normal composta. Relatório de Auxílio à Pesquisa. Processo FAPESP número: 95/2458-4.

GIONGO, J. S.; GUIMARÃES, A. E. P.; TAKEYA, T. (1997). Análise Experimental de Pilares de Concreto Armado de Alto Desempenho com Adição de Fibras. Relatório de Auxílio àPesquisa. Processo FAPESP número 97/00932-6.

GUIMARÃES, A.E.P.; GIONGO, J.S.; LIMA, F.B. (1997). Obtenção de um concreto de alta resistência com adição de sílica ativa e fibras metálicas para utilização em pilares. In: REUNIÃO DO IBRACON, 39., São Paulo, 5-8 agosto. São Paulo, IBRACON, 1997. v.2, p.595-610

HELENE, P. R. L.; TERZIAN, P. (1992). Manual de dosagem e controle do concreto. São Paulo, Pini, 349p.

HSU, L. S.; HSU, C. T. T. (1994). Complete stress-strain behaviour of high-strength concrete under compression. Magazine of Concrete Research, n. 169, p. 301312 , dec.

IBRAHIM, H. H. H.; MAcGREGOR J. G. (1997). Modification of the ACI rectangular stress block for high-strength concrete. ACI Structural Journal. p. 40-48, jan fev.

KING, J. W. H. (1946). Further notes on reinforcement concrete columns. The Structural Engineer, v. 24, p. 609-616, nov 
KING, J. W. H. (1946). The effect of lateral reinforcement in reinforced concrete columns. The Structural Engineer, v. 24, p. 355-388, jul

KÖNIG, G.; SIMSCH, G. (1996). Failure mechanism and load-deformation behaviour of high-strength concrete columns with confining reinforcement. In: INTERNATIONAL SYMPOSIUM ON THE UTILIZATION OF HIGH-STRENGTH/ HIGH-PERFORMACE CONCRETE, 4., 1996. Proceedings. p. 777-786.

LIMA, F. B. (1997). Pilares de concreto de alto desempenho: fundamentos e experimentação. São Carlos. Tese (Doutorado) - Escola de Engenharia de São Carlos, Universidade de São Paulo. (Orientador: José Samuel Giongo).

LIMA, F.B.; GIONGO, J.S.; TAKEYA, T. (1997). Análise experimental de pilares de concreto de alto desempenho solicitados a compressão centrada. In: REUNIÃO DO IBRACON, 39., São Paulo, 5-8 agosto. São Paulo, IBRACON, 1997. v.2, p.521-536.

LIMA, F.B.; GIONGO, J.S.; TAKEYA, T. (1997). Pilares de concreto de alto desempenho submetidos a compressão excêntrica. In: REUNIÃO DO IBRACON, 39., São Paulo, 5-8 agosto 1997. São Paulo, IBRACON, v.2, p.505519.

LIMA, F.B.; GIONGO, J.S.; PINHEIRO, L.M. (1997). Ultimate capacity of high performance concrete columns under axial load. In: TOPPING, B.H.V.; LEEMING, M.B., eds. Innovation in civil and structural engineering (The Mouchel Centenary Conference On Innovation in Civil and Structural Engineering, Cambridge, England, 19-21 August). Edinburgh, Civil-Comp Press, 1997. p.125-134.

LIMA, F.B.; GIONGO, J.S.; PINHEIRO, L.M. (1997). Capacidade última de pilares de concreto de alto desempenho. In: JORNADAS SUL-AMERICANAS DE ENGENHARIA ESTRUTURAL, 28., São Carlos, 1-5 set. Estruturas e 
fundações. São Carlos, Departamento de Engenharia de Estruturas-EESCUSP / Associação Sulamericana de Engenharia Estrutural, v.2, p.467-476.

LIMA, F.B.; GIONGO, J.S.; TAKEYA, T. (1997). Compressão excêntrica de pilares de concreto de alto desempenho: análise teórica e experimentação. In: JORNADAS SUL-AMERICANAS DE ENGENHARIA ESTRUTURAL, 28., São Carlos, 1-5 set. Estruturas e fundações. São Carlos, Departamento de Engenharia de Estruturas-EESC-USP / Associação Sulamericana de Engenharia Estrutural. v.2, p.567-576.

LLOYD, N. A.; RANGAN, B. V. (1995). High-Strength Concrete Columns. In: ACI INTERNATIONAL CONFERENCE ON HIGH-PERFORMACE CONCRETE, Singapore, 1994. Proceedings. p. 379-390.

MANDER, J. B.; PRIESTLEY, M. J. N.; PARK, R. (1998). Theoretical Stress-Strain Model for Confined Concrete. ASCE Journal of Structural Engineering, vol 114, n. 8, p. 1804-1825, aug.

MEHTA, P. K; MONTEIRO, P. J. M. (1994). Concreto: estrutura, propriedade e materiais. São Paulo, Pini, 573p.

MORENO JÚNIOR, A. L. (1996). Cisalhamento em Vigas de Concreto de Alta Resistência submetidas à Flexo-Compressão. São Paulo. Tese (Doutorado) Escola Politécnica, Universidade de São Paulo. (Orientador: Péricles Brasiliense Fusco).

MUGURUMA, H.; WATANABE, F. (1990). Ductility Improvement of High-Strength Concrete Columns with Lateral Confinement. In: INTERNATIONAL SYMPOSIUM ON UTILIZATION OF HIGH-STRENGTH CONCRETE, 2., Berkeley, 1990. Proceedings.

PAIVA, N. M. B. (1994). Pilares de concreto de alta resistência com seção transversal retangular solicitados à compressão simples. Dissertação 
(Mestrado) - Faculdade de Engenharia Civil, Universidade Estadual de Campinas. (Orientador: Luís Roberto Sobreira de Agostini).

PAULTRE, P. et all. (1996). Structural performance of some special concretes. In: Fourth International Simposium on the UTILIZATION OF HIHG STRENGTH/ HIGH PERFORMANCE CONCRETE. Paris, França, 29-31 May. Proceedings vol.3. p. 787-796.

PEREIRA NETO, P. M.; DJANIKIAN, J. G. (1995). Algumas características do concreto de alta resistência com microssílica. São Paulo, EPUSP, 13p. (BT/PCC/143).

PINTO JÚNIOR, N. O. (1992). Flexão em Vigas de Concreto de Alta Resistência. São Paulo. Tese (Doutorado) - Escola Politécnica, Universidade de São Paulo. (Orientador: Péricles Brasiliense Fusco).

QUEIROGA, M. V. M.; GIONGO, J. S. (1998). Análise Experimental de Pilares de Concreto de Alto Desempenho Submetidos à Compressão Simples. Relatório de Bolsa de Mestrado número 1 apresentado à FAPESP. Processo número 97/13378-7.

RAZVI, S. R.; SAATCIOGLU, M. (1994). Strength and deformability of confined high-strength concrete columns. ACI Structural Journal, p. 678-687, nov - dec.

SAATCIOGLU, M.; RAZVI, S. (1992). Strength and Ductility of Confined Concrete. ASCE Journal of Structural Engineering, v. 118, n. 6, june.

SAMRA, R. M. (1991). Ductility Analysis of Confined Columns. ASCE Journal of Structural Engineering, v. 116, p. 3148-3161, nov.

SANCHEZ, E. (1997). Consoles curtos de concreto de alta resistência. In: JORNADAS SUL-AMERICANAS DE ENGENHARIA ESTRUTURAL, 28., São Carlos, 1-5 set. Estruturas e fundações. São Carlos, Departamento de 
Engenharia de Estruturas-EESC-USP / Associação Sulamericana de Engenharia Estrutural. v.2, p.615-624.

SHEIKH, S. A. (1993). Deformability of High-Strength Concrete Columns. INTERNATIONAL SYMPOSIUM ON UTILIZATION OF HIGH-STRENGTH CONCRETE, 3., Lillehammer, Norway, 1993. Proceedings. p. 346-353.

SHEIKH, S. A.; SHAH, D. V.; KHOURY, S. S. (1994). Confinement of high-strength concrete columns. ACI Structural journal, v.91, n.1, p. 100-111, jan - fev.

SHEIKH, S. A.; UZUMERI, S. M. (1980). Strength and Ductility of Tied Concrete Columns. ASCE Journal of Structural Engineering, v. 106, p. 1079-1101, may.

SHEIKH, S. A.; UZUMERI, S. M. (1982). Analytical Model for Concrete Confinement in Tied Columns. ASCE Journal of Structural Engineering, v. 108, p. 2703-2722, dec.

XIE, J.; ELWI, A. E., MACGREGOR, J. G. (1995). Mechanical Properties of highStrength Concretes Containing Silica Fume. ACI Materials Journal. p. 135-145, march - april.

VANDERLEI, R. D.; GIONGO, J. S. (1998). Análise Teórico-Experimental de Pilares de Concreto Armado de Alta Resistência sob Flexão Normal Composta. Relatório de Bolsa de Mestrado número 1 apresentado à FAPESP. Processo número 97/12850-4.

VASCONCELOS, P. H. C. O; RIBAS SILVA, M. (1998). Cálculo de dosagem de concreto de alto desempenho: uso do Procad 1.0. In: REUNIÃO DO IBRACON, 39., São Paulo, 5-8 agosto 1997. São Paulo, IBRACON, v.2, p.627-642.

YONG, Y.; NOUR, M. G.; NAWY, E. G. (1988). Behavior of Laterally Confined Highstrength Concrete under Axial Compression. ASCE Journal of Structural Engineering, v. 114, p. 332-351, feb. 
WANG, Q.; ZHAO, G. LIN, L. (1994). Effect of Axial Load Ratio and Stirrups Volume Ratio on Ductility of High-Strength Concrete Columns. $\mathrm{ACl}$ INTERNATIONAL CONFERENCE ON HIGH-PERFORMACE CONCRETE, Singapore, 1994. Proceedings. p. 433-448.

WEBB, J. (1993). High-strength concrete: Economics, Design and ductility. Concrete International. p. 27-32, jan. 


\section{Bibliografia Complementar}

ABDEL-FATTAH, H.; AHMAD, S. H. (1989). Behavior of hoop-confined highstrength concrete under axial and shear loads. ACl Structural journal, Detroit, v.86, n.6, p.652-659, set-out.

AII TICN, P.C. ; LAPLANTE, P. (1992). The development of high performance concrete in North America. In: HIGH PERFORMANCE CONCRETE: FROM MATERIAL TO STRUCTURE, London, 1992.

AMERICAN CONCRETE INSTITUTE (1997). ACI 234/95 - Abstract of: Guide for the use of Silica Fume in Concrete. ACI Materials Journal, p. 323-335, july aug.

AMARAL, C. K. (1988). Microssílica em concretos e argamassas de alta resistência. In: REUNIÃO ANUAL DO IBRACON, 30., Rio de Janeiro, 1988, Anais. v. 1, p. 67-80.

AMARAL FILHO, E. M. (1993). Concreto de alta resistência. São Paulo. Associação Brasileira de Cimento Portland. 75p.

ATTARD, M.; MENDIS, P. A. (1998). Ductility of high-strength concrete columns. Australian Civil Engr. Trans. CE35(4), 295-305.

ATTARD, M.; STEWART, M. G. (1998). A Two Parameter Stress Block for HighStrength Concrete. ACI Structural Journal, p. 305-317, may-june. 
CARINO, N.J.; CLIFTON, J.R. (1991). High - performance concrete: research needs to enhance its use. Concrete International, v.13, n.9, p.70-76.

CARRASQUILLO, R.; NILSON, A. H.; SLATE, F. O. (1981). Properties of High Strength Concrete Subject to Short-Term Loads. ACl Journal, p.171-178, mayjune.

CIVIL ENGINEERING RESEARCH FOUNDATION (1993). High-performance construction materials and systems: an essential program for America and its infrastructure. Washington, CERF/ASCE. Technical Report 93-5011.

DAL MOLIN, D. C. C. (1995). Contribuição ao estudo das propriedades mecânicas dos concretos de alta resistência com adição de microssílica. São Paulo, 1995. Tese (Doutorado) - Escola Politécnica, Universidade de São Paulo.

DAL MOLIN, D. C.; WOLF, J. (1991). Viabilidade técnico-econômica da utilização de concretos de alta resistência em edifícios altos. In: CICLO DE PALESTRAS SOBRE NOVAS TENDÊNCIAS DE AUMENTO DA RESISTÊNCIA DO CONCRETO, CB-18, ABNT, Porto Alegre, abr. 1991.

DRAKE, K.D. (1985). High strength in Seattle. In: HIGH STRENGTH CONCRETE. Proceedings. Detroit: American Concrete Institute, 1985. p.21-34, (ACI Special Publication, 87).

DUCATTI, V. A.; AGOPYAN, V. (1995). Concreto de elevado desempenho: estudo da aderência com a armadura. Colóquio de Estruturas de Concreto. Universidade Federal de Juíz de Fora. Juíz de Fora, Abril.

FERNANDEZ CANOVAS, M.; GUTIERREZ, P. A. (1992). Composición y dosificación de los hormigones de alta resistencia. Cemento-hormigón Barcelona, n. 709, p. 971-990, ago.

FORSTER, S. (1994). High-Performace Concrete - Stretching the Paradigm. Concrete International, p. 33,34, oct. 
GJORV, O.E. (1992). High-strength concrete. In: ADVANCES IN CONCRETE TECHNOLOGY, Athens, 1992. Proceedings... Montreal: CANMET, p.21-77.

GONÇALVES, J.R.A.; ALMEIDA, I.R.; SHEHATA, L.C.D. (1994). Influência do tipo de agregado graúdo nas propriedades do concreto de alta resistência. In: REUNIÃO ANUAL DO IBRACON, 36., 1994, Porto Alegre. Anais... São Paulo: IBRACON, v.1, p.339-352.

HELD, M.; KÖNIG, G.; SIMSCH, G. (1993). Ductility of large high-strength concrete columns in high-rise buildings. In: UTILIZATION OF HIGH STRENGTH CONCRETE. Proceedings. Lillehammer, Norway, p. 200-208.

HERRMANN, E.; CAMERATO, C. R. (1988). Estudo e aplicação de concreto de alta resistência com microssílica no Brasil. In: REUNIÃO ANUAL DO IBRACON, 30., Rio de Janeiro. Anais. v. 1, p. 81-93.

KECK, R.; CASEY, K. (1991). A tower of strength. Concrete International, v.13, n.3, p.23-25, Mar. 1991.

de LARRARD, F. (1991). Mechanical properties. In: High-strength concrete. Report of RILEM Committee TC 115-HSC.

de LARRARD, F.; ITHURRALDE, G.; ACKER, P.; CHAWEL, D. (1990). High performance concrete for a nuclear containement. In: INTERNATIONAL SUMPOSIUM ON UTILIZATION OF HIGH STRENGTH CONCRETE, 2. Berkeley, California. Proceedings. Detroit: American Concrete Institute, 1990. (ACI Special Publication, 121).

MANDER, J. B.; PRIESTLEY, M. J. N.; PARK, R. (1998). Observed Stress-Strain Model of Confined Concrete. ASCE Journal of Structural Engineering, vol 114, n. 8, p. 1827-1849, aug.

MEHTA, P. K.; MONTEIRO, P. J. M. (1994). Concreto: estrutura, propriedade e materiais. São Paulo, Pini, 573p. 
MEHTA, P.K.; AITCIN, P.C. (1990). Principles underlying production of highperformance concrete. Cement, Concrete and Aggregates, Philadelphia, v.12, n.2, p.70-78, Winter.

MORENO, J. (1990). 225 W. Wacker Driver - the state-of-the art of high strength concrete in Chicago. Concrete International, v.12, n.1, p.35-39, jan.

NILSON, A. H. (1985). Design implications of current research on high-strength concrete. High-Strength Concrete, SP-87, American Concrete Institute, p.85118.

NILSON, A. H. (1990). Concreto de alta resistência - desempenho como material e comportamento estrutural. In: $30^{\circ}$ REIBRAC, Rio de Janeiro, Brasil.

NILSON, A. H. (1994). Structural Members. High performace concrete: properties and applications, S. P. Shah and S.H. Ahmad, eds., McGraw-Hill Inc., New York, N.Y., p. 213-236.

OLIVEIRA, F. R. M. (1993). Comportamento estrutural de colunas utilizando concreto armado de alto desempenho In: JORNADAS SUDAMERICANAS DE INGENIERIA ESTRUCTURAL, 26., Montevideo, Uruguay, 15-19 nov. Memorias v.3, p. $489-500$.

PAGE, K.M. (1990). Pumping high strength concrete on world's tallest concrete building. Concrete International, v.12, n.1, p.26-28, jan.

RONNEBERG, H.; SANDVIK, M. (1990). High strength concrete for North Sea plataforms. Concrete International, v.12, n.1, p.29-34, jan.

RUSSEL, H. G. (1994). Structural Design considerations and applications. High performace concrete: properties and applications, S. P. Shah and S.H. Ahmad, eds., McGraw-Hill Inc., New York, N.Y., p. 313-340. 
SHEEHAN, T. (1991). High strength concrete - a review of U.S. expertise. Concrete, v.25, n.7, p.35-37, nov./dec.

TARTUCE, R. (1989). Dosagem experimental do concreto. São Paulo. Ibracon/pini. $115 p$. 